US Army Corps of Engineers ${ }_{\circledast}$ Engineer Research and Development Center

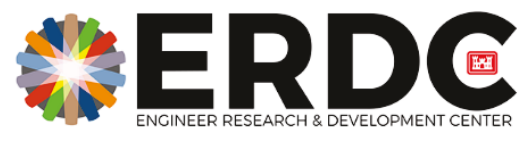

Numerical Model Study of the Flows around Pile Dikes and Conventional Rock Dikes in the Columbia River

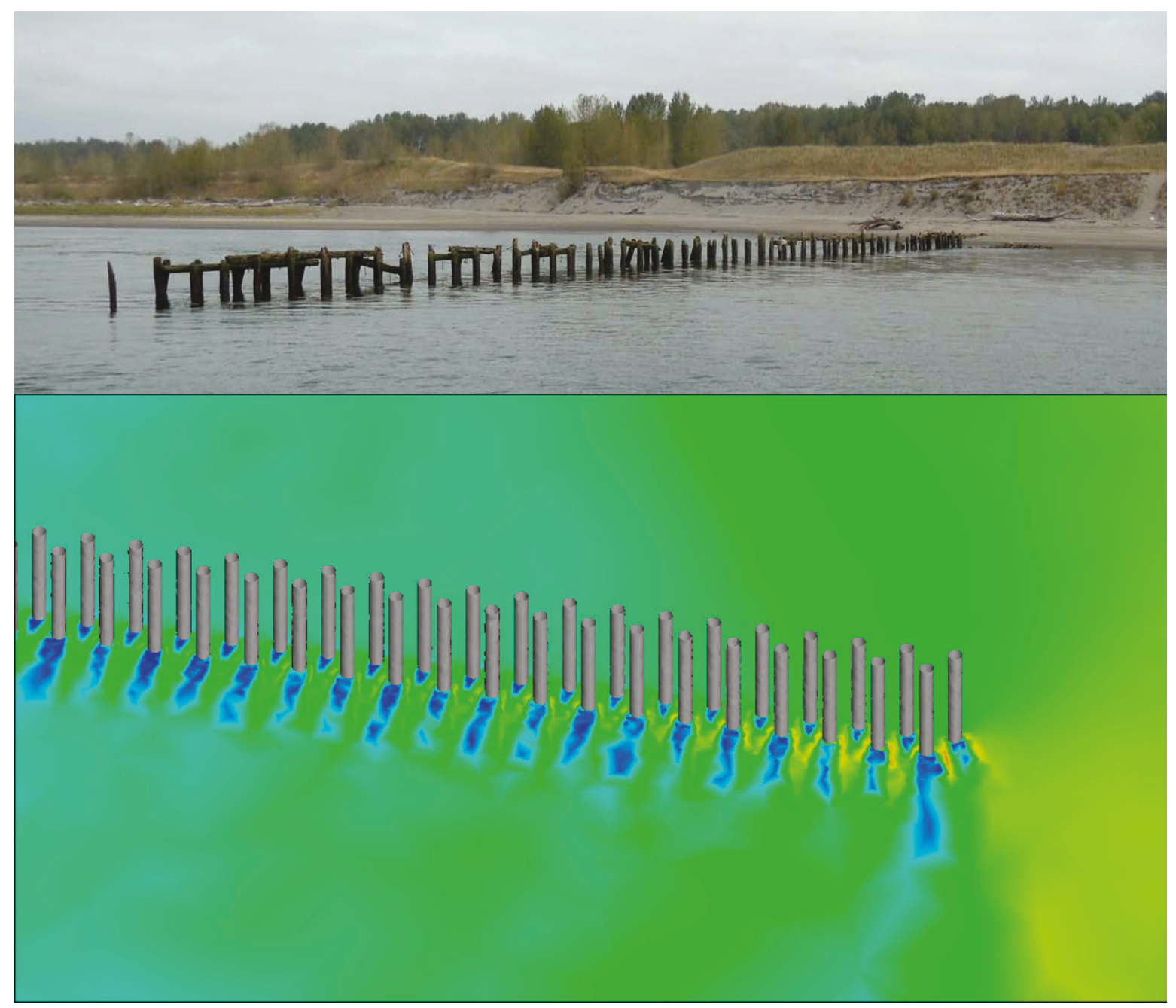

Photo credit: USACE NWP 2015 (top); ERDC (bottom)

Approved for public release; distribution is unlimited. 
The U.S. Army Engineer Research and Development Center (ERDC) solves the nation's toughest engineering and environmental challenges. ERDC develops innovative solutions in civil and military engineering, geospatial sciences, water resources, and environmental sciences for the Army, the Department of Defense, civilian agencies, and our nation's public good. Find out more at www.erdc.usace.army.mil.

To search for other technical reports published by ERDC, visit the ERDC online library at http://acwc.sdp.sirsi.net/client/default. 


\section{Numerical Model Study of the Flows around Pile Dikes and Conventional Rock Dikes in the Columbia River}

Allen Hammack, Morgan M. Johnston, and David S. Smith

Coastal and Hydraulics Laboratory

U.S. Army Engineer Research and Development Center

3909 Halls Ferry Road

Vicksburg, MS 39180-6199

Final report

Approved for public release; distribution is unlimited.

Prepared for U.S. Army Corps of Engineers, Portland District 333 SW 1st Ave.

Portland, OR 97204

Under Project 445535, “O\&M MCR COL R Pile Dikes MMR/DDR” 


\section{Abstract}

Pile dikes in the Columbia River are approaching the end of their expected service life. Two replacement options have been suggested: similarly shaped pile dikes and conventional rock dikes. A three-dimensional numerical model study has been conducted to provide flow information to support a decision between the two replacement options. This study focuses on the Cottonwood Island site on the Columbia River. The primary interest is determining the potential navigation impacts of changing from the pile dikes to the conventional rock dikes. The results of this model will also be used to study the secondary interests of effects to fish habitat and the possible operation concerns of scour potential and sediment deposition between the dikes. This report contains a discussion of the geometry and computational mesh development and flow solver used. The flow solutions are presented as contour plots in multiple areas of the flow domain. General trends among the flow solutions between the two types of dikes are evaluated and discussed.

DISCLAIMER: The contents of this report are not to be used for advertising, publication, or promotional purposes. Citation of trade names does not constitute an official endorsement or approval of the use of such commercial products. All product names and trademarks cited are the property of their respective owners. The findings of this report are not to be construed as an official Department of the Army position unless so designated by other authorized documents. 


\section{Contents}

Abstract.................................................................................................................................. if

Figures and Tables..............................................................................................................v

Preface ................................................................................................................ X

Unit Conversion Factors................................................................................................. xi

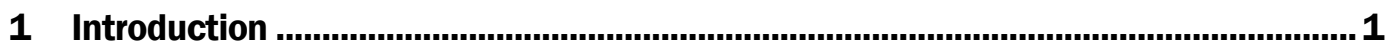

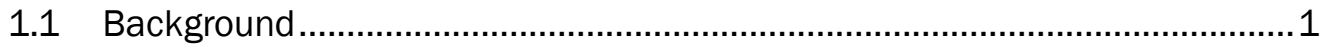

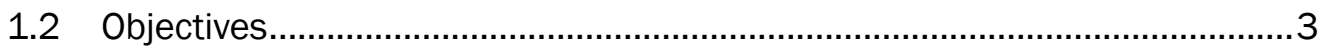

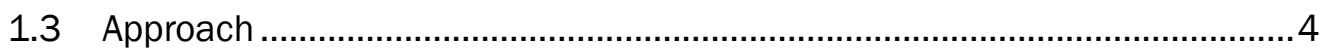

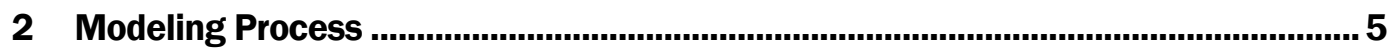

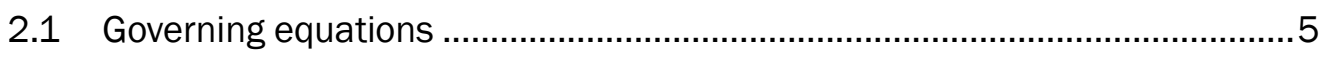

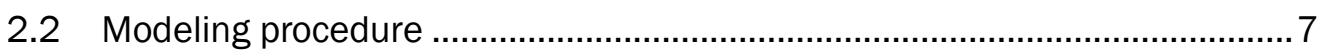

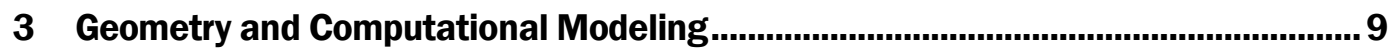

3.1 Flow domain ........................................................................................ 9

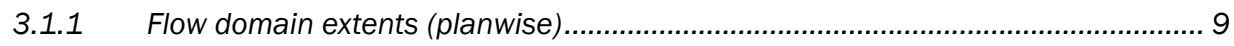

3.1.2 Flux boundaries........................................................................................ 12

3.1.3 Bathymetry and dike geometry ................................................................... 13

3.1.4 Water surface ............................................................................................... 18

3.1.5 Northern and southern boundaries ................................................................... 18

3.1.6 Total flow domain summary ..................................................................... 21

3.2 Computational meshing ................................................................. 25

3.2.1 General meshing challenges........................................................................... 25

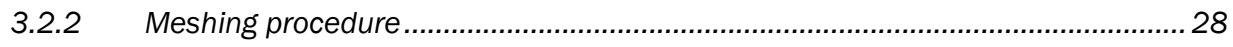

3.3 Sand Island meshing attempt...................................................... 36

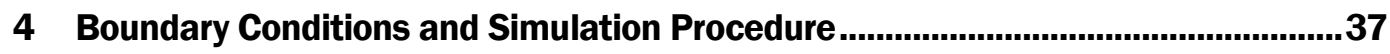

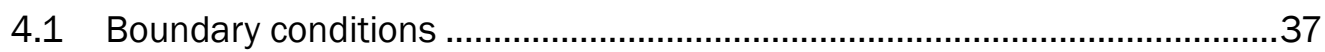

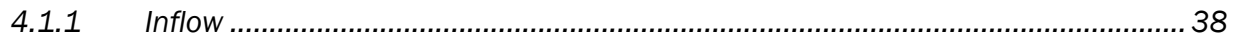

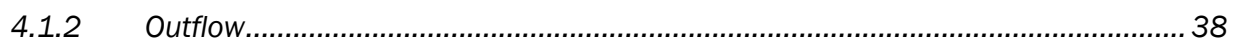

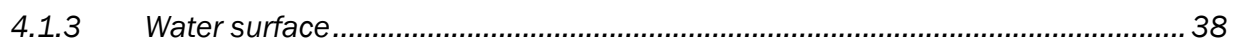

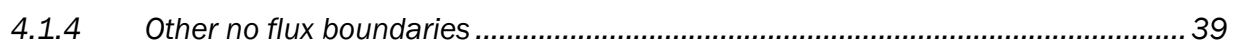

4.2 Simulation procedure summary ...................................................... 39

5 Numerical Model Results........................................................................................40

5.1 High discharge ............................................................................ 42

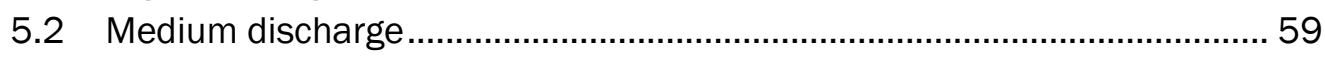

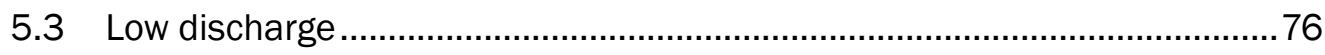

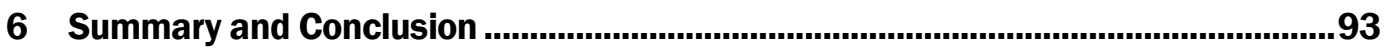




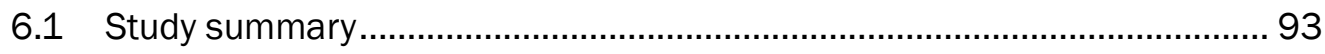

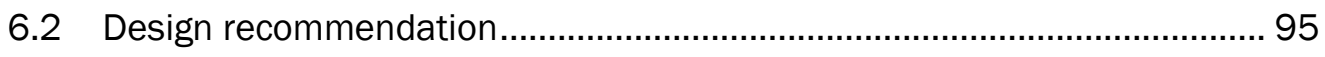

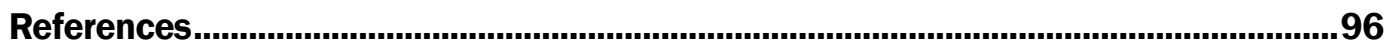

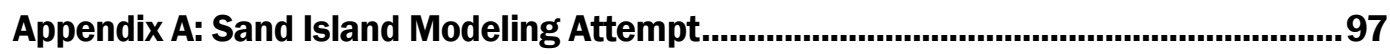

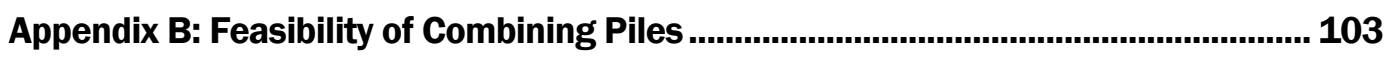

Appendix C: Free Surface vs. Fixed-Lid Water Surface Treatment ............................ 109

Appendix D: Additional Flow Solution Images ..................................................... 117

Report Documentation Page 


\section{Figures and Tables}

\section{Figures}

Figure 1. Basic construction of a pile dike on the Columbia River (USACE NWP,

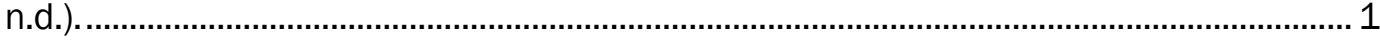

Figure 2. Deteriorated pile dike, Columbia River (USACE NWP, n.d.)................................... 2

Figure 3. Pile dike with a missing section, Columbia River (USACE NWP, n.d.).................... 2

Figure 4. Location of Cottonwood Island and Sand Island sites. .......................................... 3

Figure 5. Dikes located to the south of Cottonwood Island. ..............................................10

Figure 6. Figures of Cottonwood Island SW2-Adh flow solutions.....................................11

Figure 7. Cottonwood Island flow domain extents - SW2-AdH and RANS-AdH. .................12

Figure 8. Inflow and outflow boundaries of RANS-AdH simulations..................................13

Figure 9. Schematic used to create rock dike geometry (USACE NWP 2015)....................14

Figure 10. Dike 69.79 cross sections................................................................................

Figure 11. Locations of cross sections shown for Dike 69.79 base comparison................15

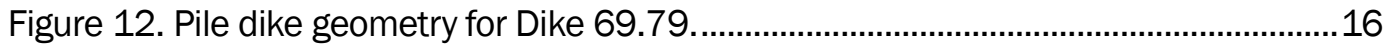

Figure 13. Rock dike geometry for Dike 69.79. ............................................................ 17

Figure 14. Main navigation channel for near Cottonwood Island. ......................................19

Figure 15. Northern and southern boundaries for 3D flow solution. ...................................21

Figure 16. Cottonwood Island flow domain surfaces.......................................................22

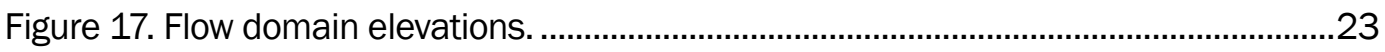

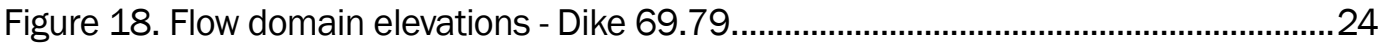

Figure 19. Cottonwood Island locations of vertical slices showing elevation......................26

Figure 20. Cottonwood Island vertical slice along Pile Dike 70.07 center..........................27

Figure 21. Cottonwood Island vertical slice between Pile Dike 70.07 and $69.79 \ldots \ldots \ldots . . . . .27$

Figure 22. Dike area material division used for meshing. ..................................................28

Figure 23. Pile dike surface mesh resolution. …...................................................................30

Figure 24. Rock dike surface mesh resolution. .................................................................... 31

Figure 25. Element count versus surface area for pile dike mesh......................................34

Figure 26. Element count versus surface area for rock dike mesh......................................35

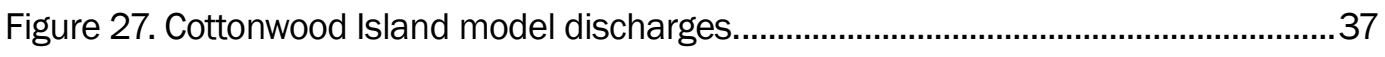

Figure 28. Cottonwood Island locations of vertical slices showing velocity magnitude.

Figure 29. High discharge full domain water surface velocity magnitude comparison.

Figure 30. High discharge upstream zoom water surface velocity magnitude comparison.

Figure 31. High discharge full domain $10 \mathrm{ft}$ depth velocity magnitude comparison. 
Figure 32. High discharge full domain $10 \mathrm{ft}$ depth velocity magnitude comparison.

Figure 33. High discharge full domain $10 \mathrm{ft}$ depth velocity magnitude comparison - isometric.

Figure 34. High-discharge velocity contours at $10 \mathrm{ft}$ depth around Dike 69.79.

Figure 35. Vertical slices of pile dike high discharge simulation.

Figure 36. Vertical slices of rock dike high discharge simulation.

Figure 37. High discharge Dike 70.07 bed velocity magnitude comparison isometric.

Figure 38. High discharge Dike 69.79 bed velocity magnitude comparison isometric.

Figure 39. High discharge extreme difference velocity magnitude comparison. ...............57

Figure 40. High discharge extreme difference velocity magnitude comparison.

Figure 41. Medium discharge full domain water surface velocity magnitude comparison.

Figure 42. Medium discharge upstream zoom water surface velocity magnitude comparison.

Figure 43. Medium discharge full domain $10 \mathrm{ft}$ depth velocity magnitude comparison.

Figure 44. Medium discharge upstream zoom $10 \mathrm{ft}$ depth velocity magnitude comparison.

Figure 45. Medium discharge full domain $10 \mathrm{ft}$ depth velocity magnitude comparison - isometric.

Figure 46. Medium discharge velocity contours at $10 \mathrm{ft}$ depth around Dike 69.79

- isometric. 66

Figure 47. Vertical slices of pile dike medium discharge simulation. 68

Figure 48. Vertical slices of rock dike medium discharge simulation.

Figure 49. Medium discharge Dike 70.07 bed velocity magnitude comparison isometric.

Figure 50. Medium discharge Dike 69.79 bed velocity magnitude comparison isometric.

Figure 51. Medium discharge extreme difference velocity magnitude comparison. ......... 74

Figure 52. Medium discharge extreme difference velocity magnitude comparison..........75

Figure 53. Low discharge full domain water surface velocity magnitude comparison.

Figure 54. Low discharge upstream zoom water surface velocity magnitude comparison.

Figure 55. Low discharge full domain $10 \mathrm{ft}$ depth velocity magnitude comparison. .........80

Figure 56. Low discharge upstream zoom $10 \mathrm{ft}$ depth velocity magnitude comparison.

Figure 57. Low discharge full domain $10 \mathrm{ft}$ depth velocity magnitude comparison

- isometric. 
Figure 58. Low discharge velocity contours at $10 \mathrm{ft}$ depth around Dike 69.79 -

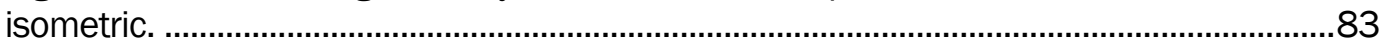

Figure 59. Vertical slices of pile dike low discharge simulation........................................85

Figure 60. Vertical slices of rock dike low discharge simulation........................................86

Figure 61. Low discharge Dike 70.07 bed velocity magnitude comparison isometric.

Figure 62. Low discharge Dike 69.79 bed velocity magnitude comparison isometric 89

Figure 63. Low discharge extreme difference velocity magnitude comparison. 91

Figure 64. Low discharge extreme difference velocity magnitude comparison. . .92

Figure 65. Sand Island flow domain extents - SW2-AdH and RANS-AdH. ..........................98

Figure 66. Sand Island model discharges.........................................................................98

Figure 67. Figures of Sand Island SW2-Adh flow solutions............................................. 100

Figure 68. Schematic of existing pile dike geometry (USACE NWP 1968)...................... 104

Figure 69. Water surface geometry of the different pile combinations. ........................... 104

Figure 70. Existing pile water surface velocity magnitudes.............................................. 106

Figure 71. 2-pile combination water surface velocity magnitudes. ................................. 107

Figure 72. 3-pile combination water surface velocity magnitudes................................... 108

Figure 73. Free-surface vs. fixed lid - pile dike full domain water surface velocity magnitudes.

Figure 74. Free-surface vs. fixed lid - pile dike zoom water surface velocity magnitudes

Figure 75. Free-surface vs. fixed lid - pile dike free-surface movement.

Figure 76. Free-surface vs. fixed lid - rock dike full domain water surface velocity magnitudes.

Figure 77. Free-surface vs. fixed lid - rock dike zoom water surface velocity magnitudes.

Figure 78. Free-surface vs. fixed lid - rock dike free-surface movement........................ 116

Figure 79. High discharge full domain $5 \mathrm{ft}$ depth velocity magnitude comparison.......... 118

Figure 80. High discharge full domain $5 \mathrm{ft}$ depth velocity magnitude comparison......... 119

Figure 81 . High discharge full domain $5 \mathrm{ft}$ depth velocity magnitude comparison

- isometric. 120

Figure 82. High discharge velocity contours at $5 \mathrm{ft}$ depth around Dike 69.79 isometric. 121

Figure 83. Eddies formed downstream of Dike 70.07 at $10 \mathrm{ft}$ depth for high discharge.

Figure 84. Eddies formed downstream of Dike 69.79 at $10 \mathrm{ft}$ depth for high discharge. 123

Figure 85. High discharge velocity magnitude difference comparison.

Figure 86. High discharge velocity magnitude difference comparison. 125

Figure 87. Medium discharge full domain $5 \mathrm{ft}$ depth velocity magnitude comparison. 
Figure 88. Medium discharge full domain $5 \mathrm{ft}$ depth velocity magnitude comparison.

Figure 89. Medium discharge full domain $5 \mathrm{ft}$ depth velocity magnitude comparison - isometric.

Figure 90. Medium discharge velocity contours at $5 \mathrm{ft}$ depth around Dike 69.79

- isometric.

Figure 91. Eddies formed downstream of Dike 70.07 at $10 \mathrm{ft}$ depth for medium discharge.

Figure 92. Eddies formed downstream of Dike 69.79 at $10 \mathrm{ft}$ depth for medium discharge.

Figure 93. Medium discharge velocity magnitude difference comparison.

Figure 94. Medium discharge velocity magnitude difference comparison. 133

Figure 95. Low discharge full domain $5 \mathrm{ft}$ depth velocity magnitude comparison........... 134

Figure 96. Low discharge full domain $5 \mathrm{ft}$ depth velocity magnitude comparison........... 135

Figure 97. Low discharge full domain $5 \mathrm{ft}$ depth velocity magnitude comparison isometric.

Figure 98. High discharge velocity contours at $5 \mathrm{ft}$ depth around Dike 69.79 isometric.

Figure 99. Eddies formed downstream of Dike 70.07 at $10 \mathrm{ft}$ depth

for low discharge.

Figure 100. Eddies formed downstream of Dike 69.79 at $10 \mathrm{ft}$ depth

for low discharge.

Figure 101. Low discharge velocity magnitude difference comparison

Figure 102. Low discharge velocity magnitude difference comparison.

Figure 103. Vertical slice locations for Pile Dike 70.07.

Figure 104. High discharge vertical velocity profile at slices across

Pile Dike 70.07.

Figure 105. Medium discharge vertical velocity profile at slices across Pile Dike 70.07 .

Figure 106. Low discharge vertical velocity profile at slices across

Pile Dike 70.07.

Figure 107. Vertical slice locations for Rock Dike 70.07.

Figure 108. High discharge vertical velocity profile at slices across

Rock Dike 70.07.

Figure 109. Medium discharge vertical velocity profile at slices across Rock Dike 70.07 .

Figure 110. Low discharge vertical velocity profile at slices across Rock Dike 70.07

Figure 111. Vertical slice locations for Pile Dike 69.79.

Figure 112. High discharge vertical velocity profile at slices across

Pile Dike 69.79.

Figure 113. Medium discharge vertical velocity profile at slices across Pile Dike 69.79. 
Figure 114. Low discharge vertical velocity profile at slices across

Pile Dike 69.79.

Figure 115. Vertical slice locations for Rock Dike 69.79.

Figure 116. High discharge vertical velocity profile at slices across

Rock Dike 69.79.

Figure 117. Medium discharge vertical velocity profile at slices across Rock Dike 69.79 156

Figure 118. Low discharge vertical velocity profile at slices across

Rock Dike 69.79. 157

\section{Tables}

Table 1. Element count versus area for pile dike mesh. .................................................33

Table 2. Element count versus area for rock dike mesh....................................................33

Table 3. Friction values used for each material................................................................39

Table 4. Element and node count of the different pile combinations............................... 105 


\section{Preface}

This study was conducted for the U.S. Army Corps of Engineers (USACE), Portland District (NWP), under Project 445535, "O\&M MCR COL R Pile Dikes MMR/DDR." Ms. Laurie Ebner served as the technical point of contact for NWP.

The work was completed by the U.S. Army Research and Development Center (ERDC) Coastal and Hydraulic Laboratory (CHL), Navigation Branch, Locks Group of the Navigation Division. At the time of the study, Mr. Tim Shelton was Chief, Navigation Branch (CEERD-HNN); Dr. Jacqueline Pettway was Chief, Navigation Division (CEERD-HN). Mr. Jeffrey R. Eckstein was the Acting Director of ERDC-CHL (CEERD-HZA), and Mr. John T. Tucker III was the Acting Deputy Director of ERDC-CHL (CEERD-HZB). Mr. W. Jeff Lillycrop (CHL) was the ERDC Technical Director for Civil Works, and Navigation Research, Development, and Technology Transfer portfolio (CEERD-HZT).

Special thanks are extended to Mrs. Amanda Hines of the ERDC Information Technology Laboratory for providing assistance with the computational meshing effort.

At the time of publication of this report, Mr. Jeffrey R. Eckstein was the Deputy Director of CHL (CEERD-HZB), and Dr. Ty V. Wamsley was the Director (CEERD-HZA).

COL Ivan P. Beckman was the Commander of ERDC (CEERD-ZC), and Dr. David W. Pittman was the Director of ERDC (CEERD-ZA). 


\section{Unit Conversion Factors}

\begin{tabular}{|l|c|l|}
\hline Multiply & By & To Obtain \\
\hline cubic feet & 0.02831685 & cubic meters \\
\hline cubic inches & 1.6387064 E-05 & cubic meters \\
\hline cubic yards & 0.7645549 & cubic meters \\
\hline degrees (angle) & 0.01745329 & radians \\
\hline feet & 0.3048 & meters \\
\hline miles (U.S. statute) & $1,609.347$ & meters \\
\hline miles per hour & 0.44704 & meters per second \\
\hline slugs & 14.59390 & kilograms \\
\hline
\end{tabular}




\section{Introduction}

\subsection{Background}

The U.S. Army Corps of Engineers (USACE), Portland District (NWP), is responsible for the operation and maintenance of a system of 233 pile dikes that extend from the mouth of the Columbia River to Bonneville Dam (AECOM 2011). The current pile dikes are constructed of timbers that are driven vertically into an enrockment base that keeps the piles in place. Figure 1 shows the basic construction of a pile dike on the Columbia River.

Figure 1. Basic construction of a pile dike on the Columbia River (USACE NWP, n.d.).

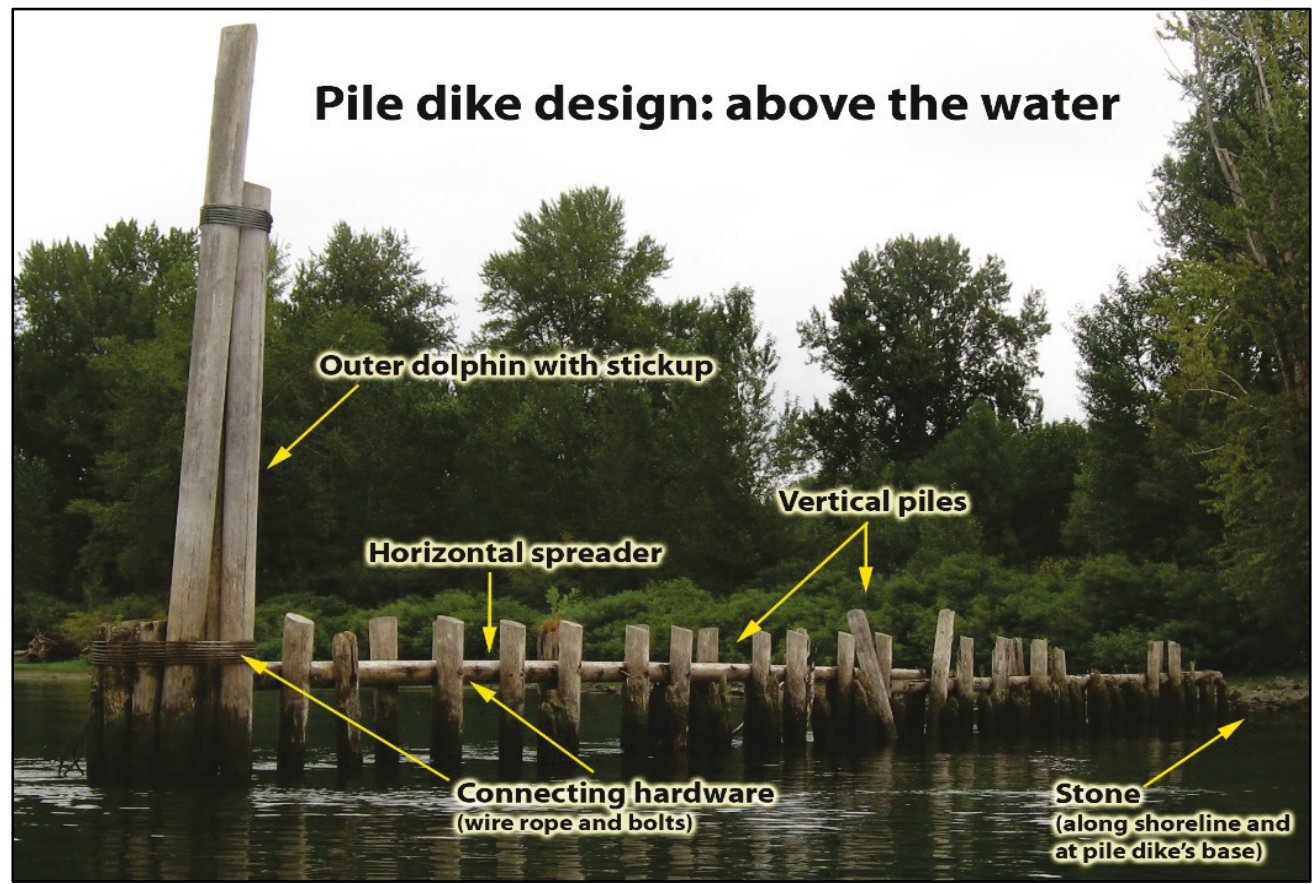

The pile dikes on the Columbia River were constructed between 1885 and 1969 (AECOM 2011). They have become deteriorated (Figure 2) and damaged (Figure 3). Questions have arisen concerning the best options for replacing the existing pile dikes. Two options have been proposed:

replacement with similarly shaped piles or replacement with conventional rock dikes. The similarly shaped pile dikes are expected to perform in the same manner as the existing piles, but the construction of the pile dikes would require significant fabrication and installation costs. The conventional rock dikes have unknown performance but have lower 
expected construction and installation costs, and the construction materials would be provided by sources close to the dike locations.

Figure 2. Deteriorated pile dike, Columbia River (USACE NWP, n.d.).

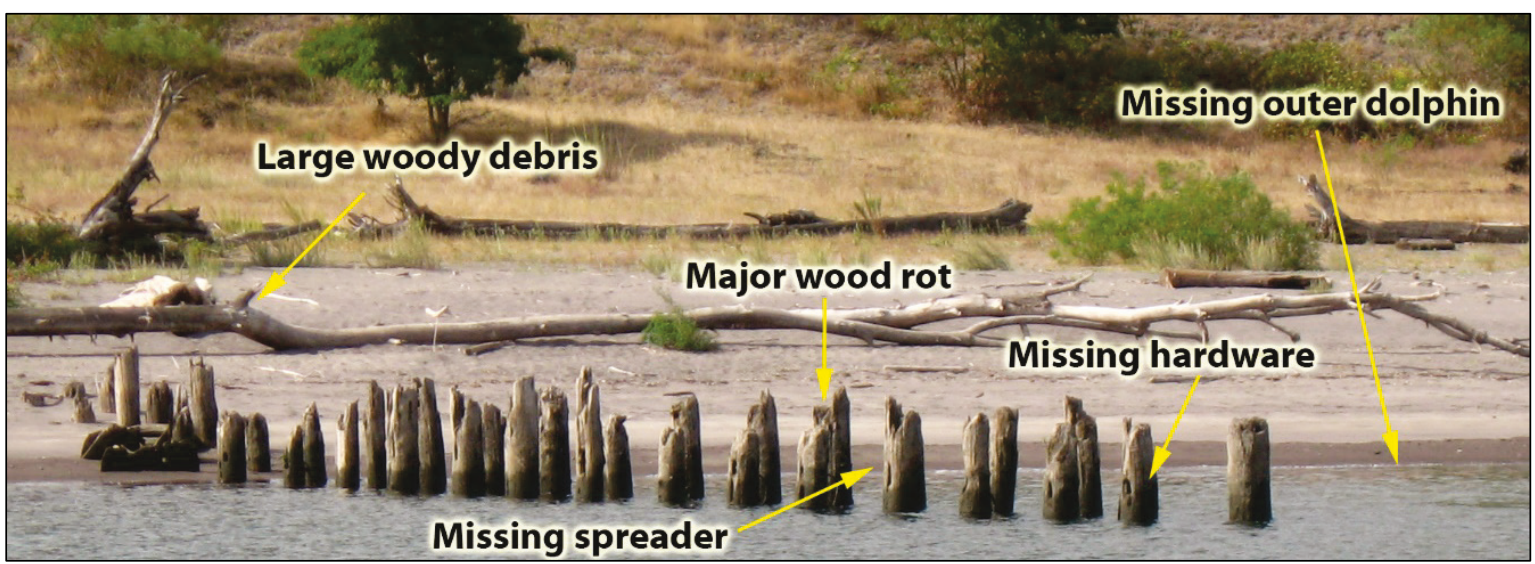

Figure 3. Pile dike with a missing section, Columbia River (USACE NWP, n.d.).

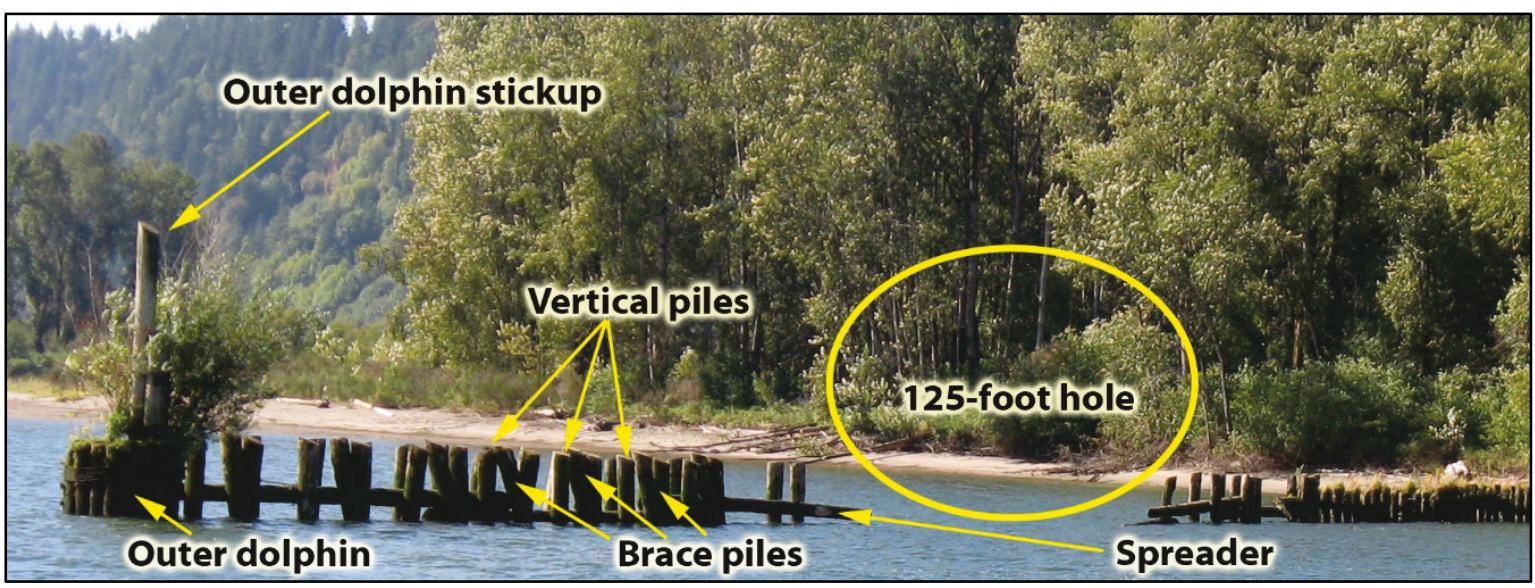

Two sites are included this study: Cottonwood Island and Sand Island. The location of these sites is shown in Figure 4. Cottonwood Island is an inland site that is subjected to riverine flows while Sand Island is a coastal site that is subjected to estuarine flows. (Additional details on these sites can be found in the major maintenance report [AECOM 2011]). 
Figure 4. Location of Cottonwood Island and Sand Island sites.

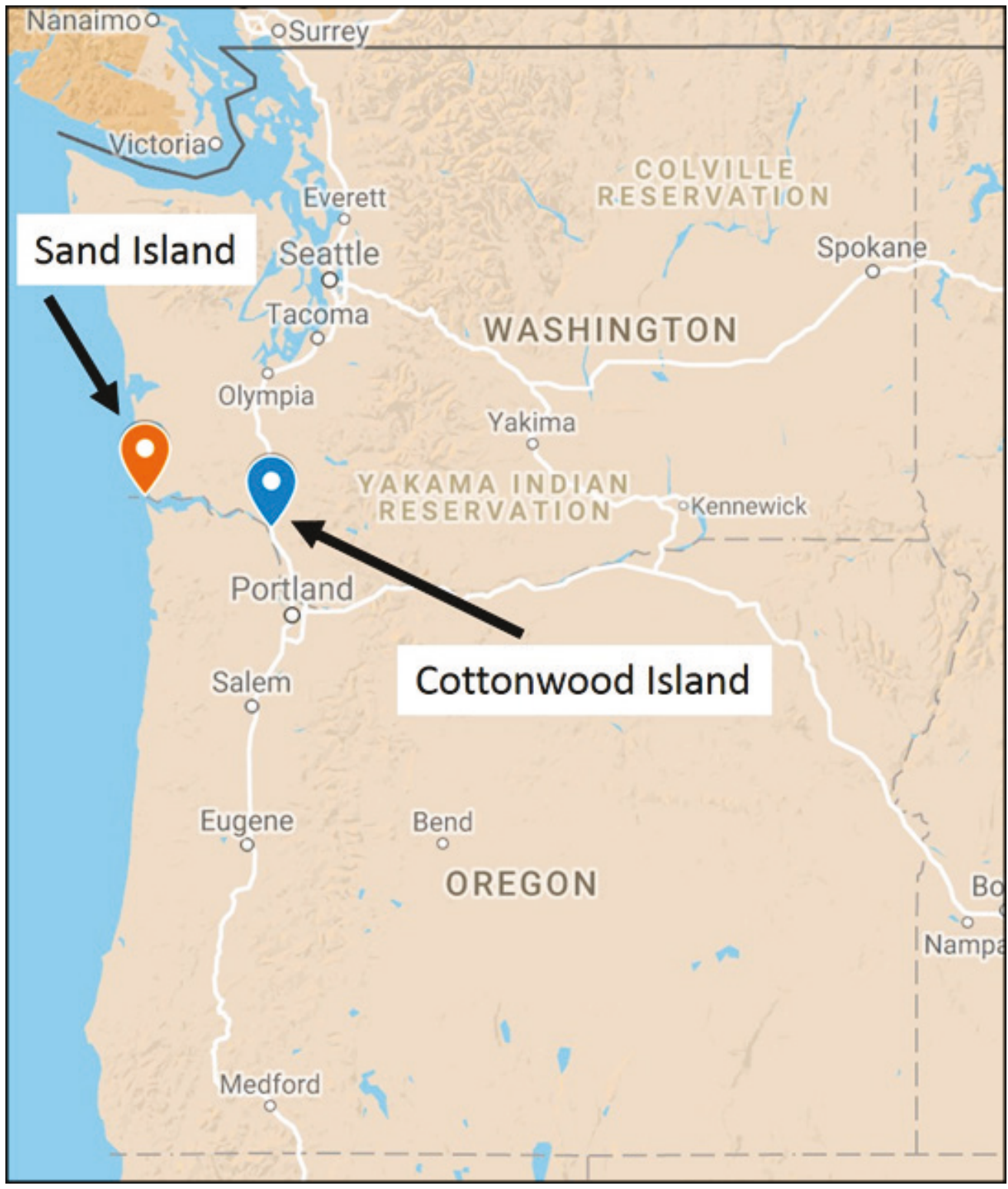

\subsection{Objectives}

The focus of this study is the effect that proposed rock dikes would have on the flows in the navigation channel. Areas between the dikes that are habitat for fish species and sediment deposition/scour would also be analyzed.

This project is a numerical model study associated with the hydraulic evaluation of the flow behavior for the pile and rock dike designs and the potential impacts to navigation of each type. The numerical modeling process includes the following: 
- development of the three-dimensional (3D) geometry for each type of dike and the corresponding flow conditions

- development of the computational meshes for each model and flow condition

- completion of the numerical simulations to produce the required flow solution

- post-processing the flow solutions to present the information necessary to determine which dike design (pile or rock dikes) deflects fluvial/tidal energy from the bank line to the navigation channel.

This report includes a thorough discussion of each aspect of the numerical modeling process and provides the necessary results to support a decision based on the hydraulic impacts of the proposed rock dikes. Information about the flow behavior caused by each dike type is included to aid in evaluation and comparison. The flow behavior does not necessarily affect the navigation but will provide insight into the scour potential near the dikes as well as the impacts to the habitat of aquatic species that are present near the dikes.

\subsection{Approach}

To address the question regarding the performance of the rock dikes, NWP contacted the U.S. Army Engineer Research and Development Center (ERDC) to conduct a 3D numerical model study of the hydraulic performance of the existing pile dikes and the proposed rock dike geometry. The pile dike models served as a baseline to which the rock dike simulations can be compared. The flow calculations will include the nonhydrostatic flow behavior near the dikes that has not been included in any previous model work of the dikes along the Columbia River. 


\section{Modeling Process}

Vertical acceleration of the flow can be significant very near dikes. Predicting flow near dikes requires a tool capable of accurately calculating the flow acceleration in all three spatial dimensions. A 3D Navier-Stokes (non-hydrostatic) numerical flow solver is an appropriate tool for predicting the flows in this study. The ERDC 3 D Reynolds-Averaged, Navier-Stokes module of the Adaptive Hydraulics (RANS-AdH) code has been used to model the complicated turbulent exchange near hydraulic structures whose near-field flows are similar to those of dikes. All modules of Adaptive Hydraulics (AdH) produce time-varying flow solutions. Steady-state solutions are obtained by simulating flow through time until the dynamic variation in the flow field ceases.

\subsection{Governing equations}

The Reynolds-Averaged Navier-Stokes (RANS) equations are employed to model the flow field approaching, interacting with, and passing by hydraulic structures. The RANS equations are $3 \mathrm{D}$ with 4 degrees of freedom: the pressure and the three components of fluid velocity. These equations make no assumptions about pressure distributions. Since many hydraulic flow models assume the flow is hydrostatic, RANS models are referred to as non-hydrostatic models.

The RANS equations are derived from the conservation of mass and conservation of momentum applied to fluid flow by decomposing the instantaneous flow velocity into a mean component, $\boldsymbol{U}$, and a fluctuating component, $\boldsymbol{u}$, and averaging these equations over time periods that are long when compared to the periods of the fluctuations. Mathematically, the conservation of mass for an incompressible fluid is described as

$$
\nabla \cdot \boldsymbol{U}=0
$$

and the conservation of momentum is given as

$$
\rho\left(\frac{\partial U}{\partial t}+\boldsymbol{U} \cdot \nabla \boldsymbol{U}\right)-\nabla \cdot \sigma+\nabla \cdot(\rho \boldsymbol{u} \boldsymbol{u})=0
$$

where:

$$
\begin{aligned}
t & =\text { time } \\
\rho & =\text { fluid density }
\end{aligned}
$$




$$
\begin{aligned}
\sigma & =\text { the total stress }(\sigma=-p \boldsymbol{I}+\tau) \\
\boldsymbol{I} & =\text { the identity matrix } \\
\tau & =\text { the stress tensor }(\tau=2 \mu \boldsymbol{\Gamma}) \\
\Gamma & =\text { the rate of strain tensor }\left(\boldsymbol{\Gamma}=\frac{\mathbf{1}}{\mathbf{2}}\left(\nabla \boldsymbol{u}+\nabla \boldsymbol{u}^{\boldsymbol{T}}\right)\right) \\
\mu & =\text { the fluid viscosity }
\end{aligned}
$$

The RANS equations are written in terms of the mean velocity, $\mathrm{U}(\mathrm{x}, \mathrm{t})$ and pressure $\mathrm{p}(\mathrm{x}, \mathrm{t})$ to reduce the modeling of turbulence to a set of quasisteady-state equations that incorporate terms to model the effects of turbulence on the main flow. In a RANS approach, the term $\nabla \cdot(\rho \boldsymbol{u u})$ is used to represent the effect of turbulence on the mean flow.

Following the suggestion of Boussinesq, an eddy viscosity is added to the molecular viscosity in the momentum equations to account for the effects of turbulence. A constant eddy viscosity model (throughout the flow domain) was used to replicate the turbulent effects. The eddy viscosity value was reduced until the velocity magnitudes no longer changed with decreasing values of the eddy viscosity. This threshold value of eddy viscosity was used for all simulations.

The flow resistance due to the boundaries of the flow domain is included in the flow domain through the skin roughness coefficient. The boundary layer is not modeled directly, but the wall effects are modeled using the law of the wall.

$$
u=\frac{u_{\tau}}{\kappa} \ln \frac{y}{y_{0}}
$$

where:

$$
\begin{aligned}
u & =\text { velocity parallel to the boundary } \\
u_{\tau} & =\text { friction velocity (also referred to as the shear velocity) } \\
\kappa & =\text { von Kármán constant } \\
y & =\text { distance normal to the boundary } \\
y_{o} & =\text { roughness height. }
\end{aligned}
$$

AdH uses an automatic mesh adaptation scheme to ensure that the flow solution is independent of the mesh. This mesh is controlled through two parameters: a mesh refinement tolerance and a maximum number of mesh refinement levels. During each flow calculation, AdH calculates a 
residual value that is used to estimate the error in the computational solution. This residual combines the flow information (pressure, velocity, etc.) into a single parameter, which reduces the amount of information that must be considered when determining the threshold values at which to adapt the mesh. A useful aspect of this mesh adaptation technique is the versatility of the parameters used to control adaptation, which are relevant for any flow situation. Appropriate choices for a refinement tolerance and the maximum number of levels of mesh refinement do not require extremely detailed insights into the flow situation.

The refinement tolerance, which the user specifies during the simulation setup process, is the value of this residual above which AdH will refine a mesh element. The mesh adaptation scheme used in RANS-AdH is the same adaptation technique used in the shallow-water modules of AdH (SW2-AdH and SW3-AdH-SW3). (More information on the mesh adaptation scheme used in RANS-AdH can be found at https://chl.erdc.dren.mil/chladh.)

\subsection{Modeling procedure}

Before the equations of motion can be applied, the domain must be discretized into numerical elements. This process includes the construction of a $3 \mathrm{D}$ computer aided drafting (CAD) representation of the flow boundaries including the geometric features of the hydraulic structure, the bathymetry of the river bed including the dikes, and the water surface. The CAD model is then used as input for a mesh generator. ICEM-CFD was selected as the mesh generator for this project.

A computational mesh is constructed to fill the volume enclosed by the CAD model surfaces. For any AdH simulation, the computational mesh must only sufficiently describe the boundaries of the flow domain because automatic mesh refinement that occurs during an AdH simulation ensures that the flow features interior to the domain are reproduced correctly. The mesh of the CAD volume is composed of many volume elements. The faces of these volume elements form the channel boundaries, the water surface boundary, and the flux (inflow and outflow) boundaries. These boundaries are based on the areas of interest in the study and the information available. Boundary conditions, such as velocity, discharge, and pressure information, are applied on element faces and their corresponding nodes, so a particular solution to the governing partial differential (RANS) equations can be calculated. 
The AdH modeling procedure of automatic mesh adaptation ensures a mesh-independent flow solution. The maximum number of refinement iterations should be high enough that the residual value after adaptation is below the refinement tolerance. This must occur before the maximum number of adaptation levels has been reached. Setting up mesh adaptation for a simulation requires the residual information from the initial/coarse mesh. Once a simulation has been completed on the initial mesh, the user must select a value of refinement tolerance, and the maximum number of refinement levels, to begin the mesh adaptation. During the adaptation simulation, AdH identifies elements with residual values that exceed the refinement tolerance. These elements will then be refined. Once refined, the flow solution and a new residual value is calculated. The new residual is compared to the refinement tolerance determining if a further level of adaptation is required. This process is repeated until either the residual value everywhere in the mesh is below the refinement tolerance or the maximum number of levels of refinement has been reached.

AdH simulations advance through time. The amount of simulated time needed depends upon flow behavior and information needed from the simulation. For this study, steady-state behavior of the flows near the dikes is needed to determine what effects the dikes have on navigation. Therefore, all simulations in this study were run to a steady-state solution. 


\section{Geometry and Computational Modeling}

Before modeling, a representation of the relevant geometry must be created. For a hydraulic model, the relevant geometry is the flow domain, and for the numerical model, the flow domain is some form of CAD file. Since this study is composed of $3 \mathrm{D}$ numerical simulations, a CAD file with surfaces that fully enclose the volume of the flow domain is required. Once that $\mathrm{CAD}$ representation has been developed, the volume of the flow domain must be discretized into a computational mesh for the simulations. This chapter is a discussion of the development of the flow domain geometry and the computational meshing effort.

\subsection{Flow domain}

The computational flow domain for each of the RANS-AdH simulations in this study includes the bathymetry, the flux boundaries, the dike geometry, the water surface, and the vertical northern and southern boundaries. NWP provided the mesh and flow solution files from a previously-completed two-dimensional (2D) Shallow Water Adaptive Hydraulics (SW2-AdH) study of an area that included the vicinity of Cottonwood Island (Alden 2016). Those files included information that was used to create the computation flow domain for the RANS-AdH simulations.

\subsubsection{Flow domain extents (planwise)}

The extents of the flow domain are based on three main criteria:

- which dikes are included for the results needed

- the direction of flow from the SW2-AdH solution

- constraints related to the size of the computational mesh created from the flow domain.

ERDC and NWP selected a four-dike section of the Columbia River for the RANS-AdH flow domain. This section, located immediately south of Cottonwood Island and includes Dikes 70.35, 70.07, 69.79, and 69.51, is shown in orange in Figure 5. 
Figure 5. Dikes located to the south of Cottonwood Island.

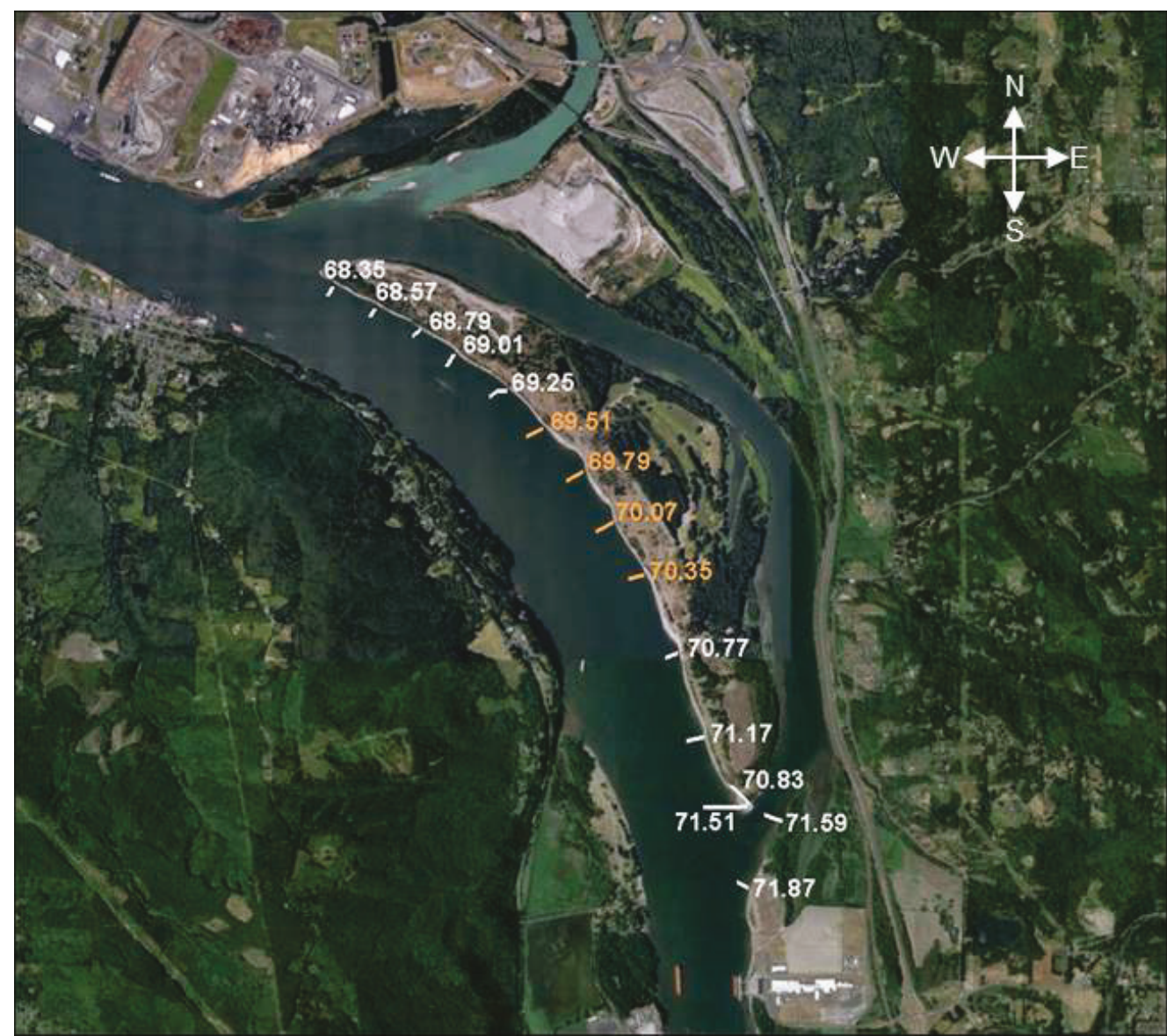

The Cottonwood Island site experiences riverine flows, and flow directions indicated by the SW2-AdH simulation (Figure 6) are very similar for the three discharges chosen for this study. Because all three flows are generally parallel to the channel direction, the flow domain boundary locations are appropriately located. 
Figure 6. Figures of Cottonwood Island SW2-Adh flow solutions.

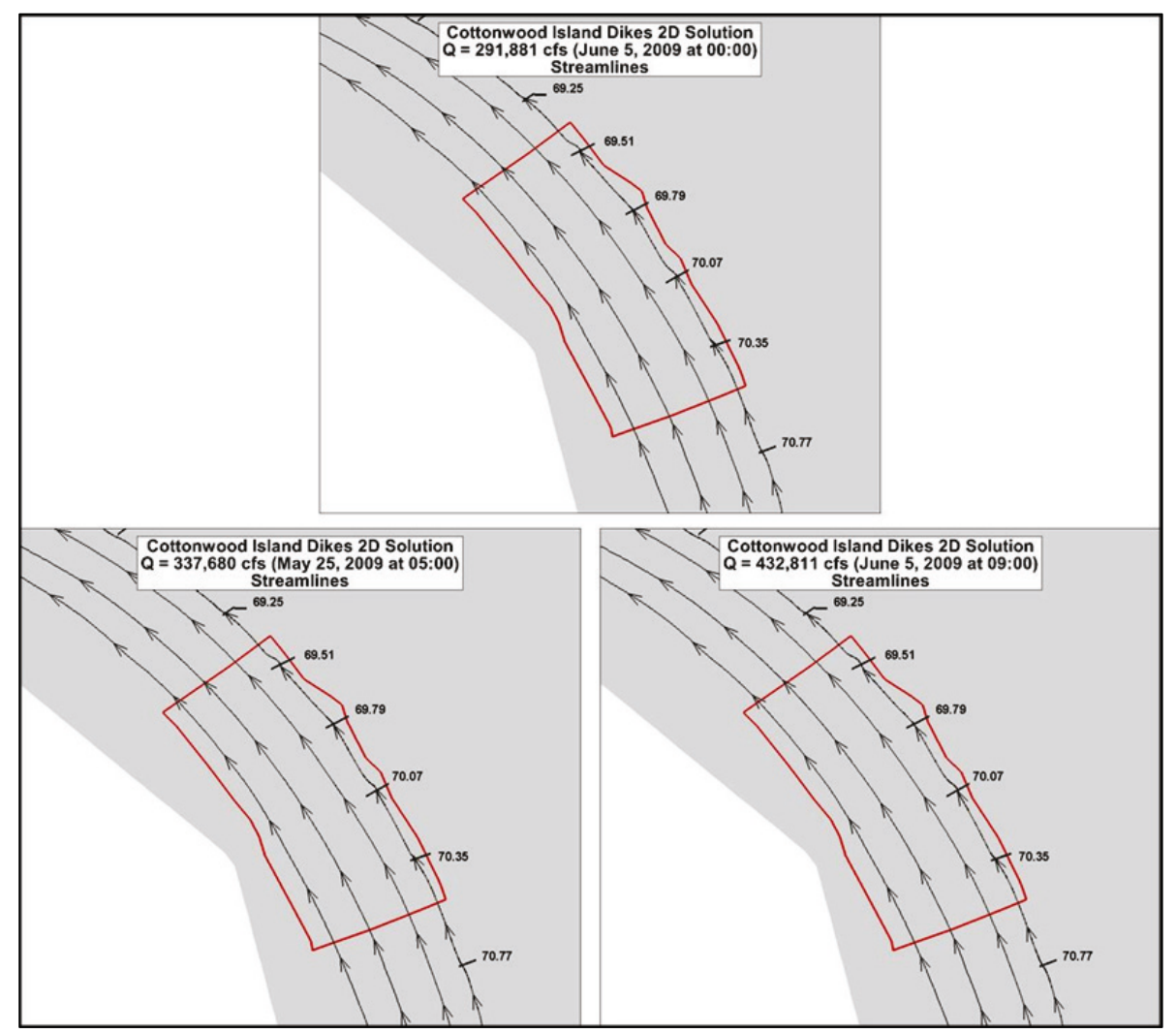

For a RANS-AdH simulation, the number of elements required to sufficiently refine the mesh is higher than with a SW2-AdH model. This relationship is generally true between a $2 \mathrm{D}$ shallow water model and a $3 \mathrm{D}$ RANS model. The 3D-RANS models are employed to provide more detailed flow information than the 2D models. This increased mesh size is due to having to mesh in the vertical and because of the level of detail of the geometric features (typically hydraulic structures) in the flow domain. To ensure computationally viable meshes, the area covered by the RANSAdH models for this study has a much smaller footprint than that used for the SW2-AdH study.

The RANS-AdH and SW2-AdH flow domain extents are shown in Figure 7 to highlight the relative difference in the areas included in each model. Along the Columbia River, the SW2-AdH model extends approximately 37,000 feet ( $\mathrm{ft}$ ) from inflow to outflow boundary. The RANS-AdH model extends 6,000 ft from inflow to outflow and approximately 2,500 ft across the Columbia River. 
Figure 7. Cottonwood Island flow domain extents SW2-AdH and RANS-AdH.

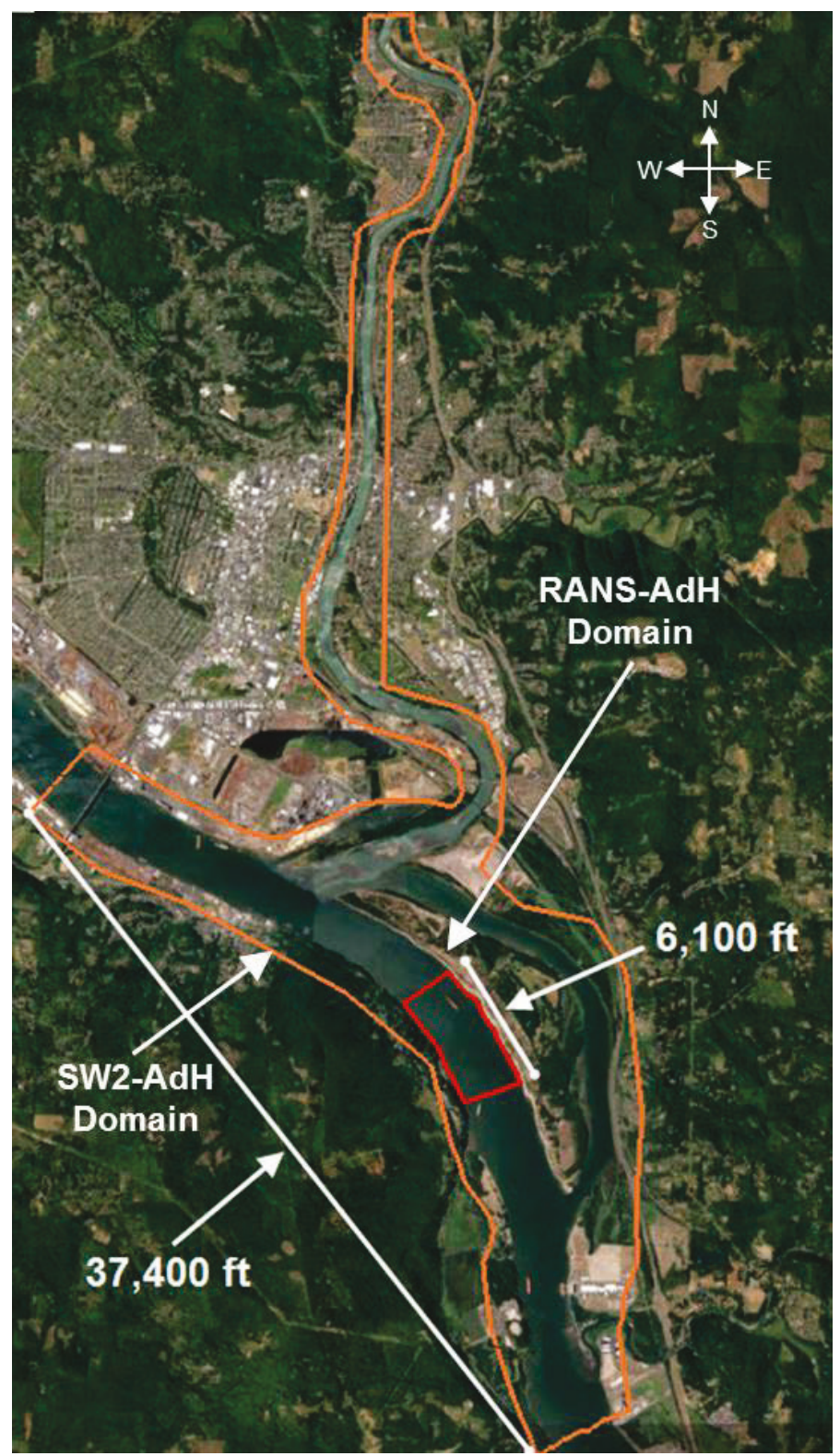

\subsubsection{Flux boundaries}

The RANS-AdH simulation flow domain consists of two flux boundaries: an upstream inflow and a downstream outflow boundary. The inflow boundary is located on the upstream end of the flow domain approximately halfway between Dikes 70.35 and 70.77. The outflow boundary is placed halfway between Dikes 69.51 and 69.25. These boundaries are positioned normal to the flow direction calculated in the SW2-AdH study, and each boundary extends vertically through the water column. The inflow and outflow boundaries are shown in Figure 8. 
Figure 8. Inflow and outflow boundaries of RANS-AdH simulations.

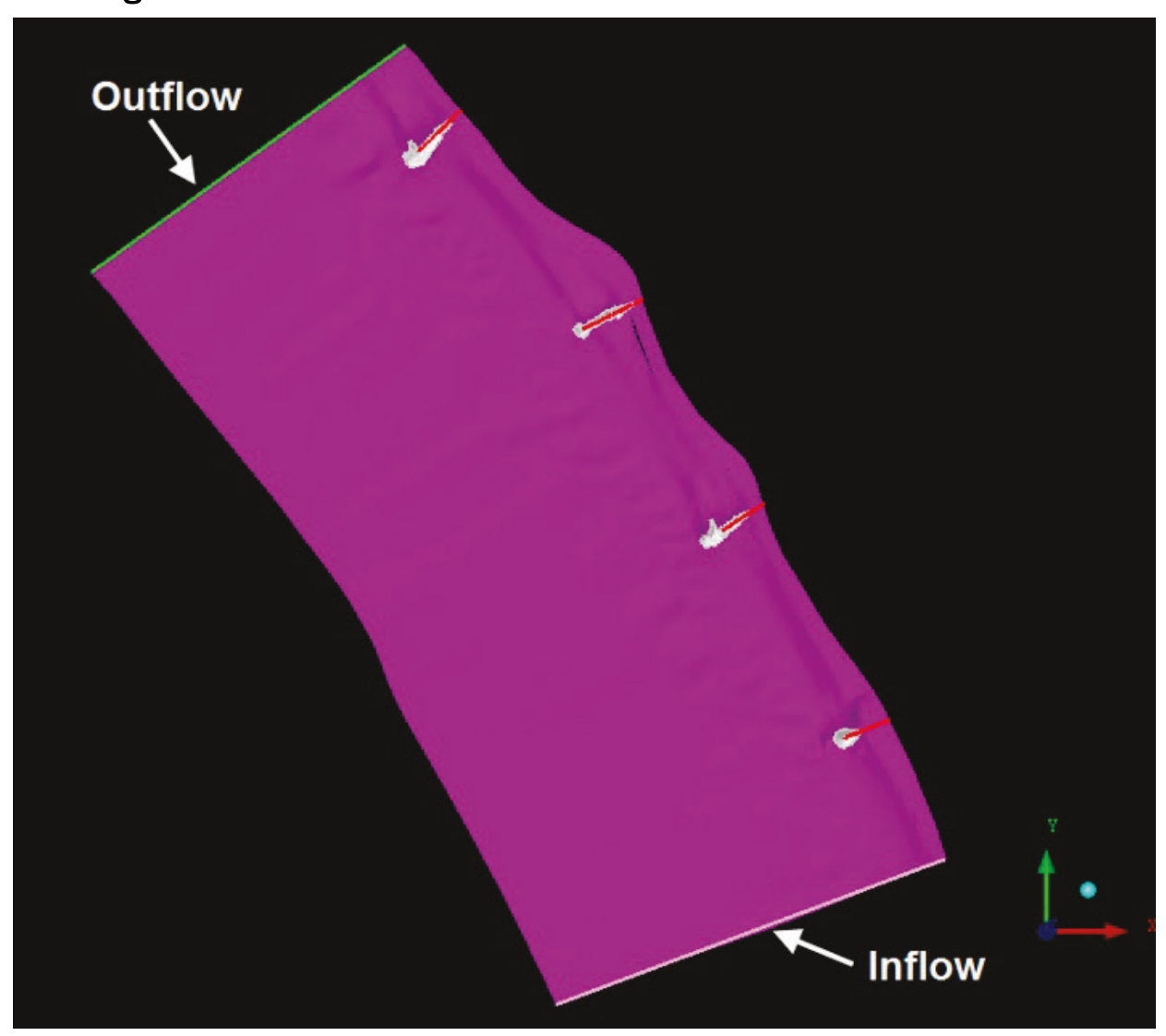

\subsubsection{Bathymetry and dike geometry}

The mesh from the SW2-AdH simulation constitutes the bathymetry (excluding the dikes) for each of the RANS-AdH simulations. Since SW2$\mathrm{AdH}$ simulations do not include the pile or rock dike geometries, each of these geometries had to be created for the RANS-AdH mesh. Information on the dike geometries was limited to elevation drawings and schematics of the pile and rock dike cross sections. Figure 9 shows the schematic used to build the pile and rock dike geometry. The rock dike base is taller and broader than the pile dike base. Also, the sides of the rock dike base have a lower grade than the pile dike bases. 
Figure 9. Schematic used to create rock dike geometry (USACE NWP 2015).

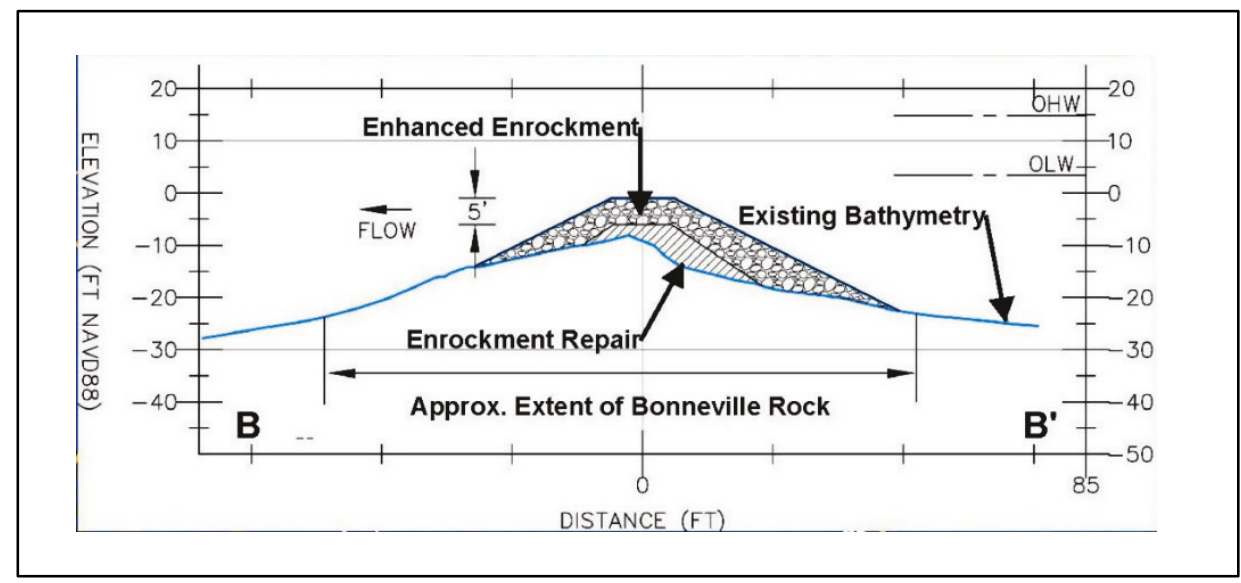

$\mathrm{CAD}$ surfaces were generated from the information provided and incorporated into the bathymetric surfaces created from the SW2-AdH meshes. Cross sections of Dike 69.79 (both across and along the dike), for both dike types were created from the provided dike geometry information, are shown in Figure 10. (Note that the elevations shown in Figure 9 are not for the Cottonwood Island site. The Cottonwood Island elevations will not match those shown in Figure 10.) The location of each cross section is shown in Figure 11. Each pile dike contains two rows of $1.5 \mathrm{ft}$ diameter piles at a $2.5 \mathrm{ft}$ spacing (center-to-center). The mesh geometry for pile Dike 69.79 and for rock Dike 69.79 is shown in Figure 12 and Figure 13, respectively.

Figure 10. Dike 69.79 cross sections.

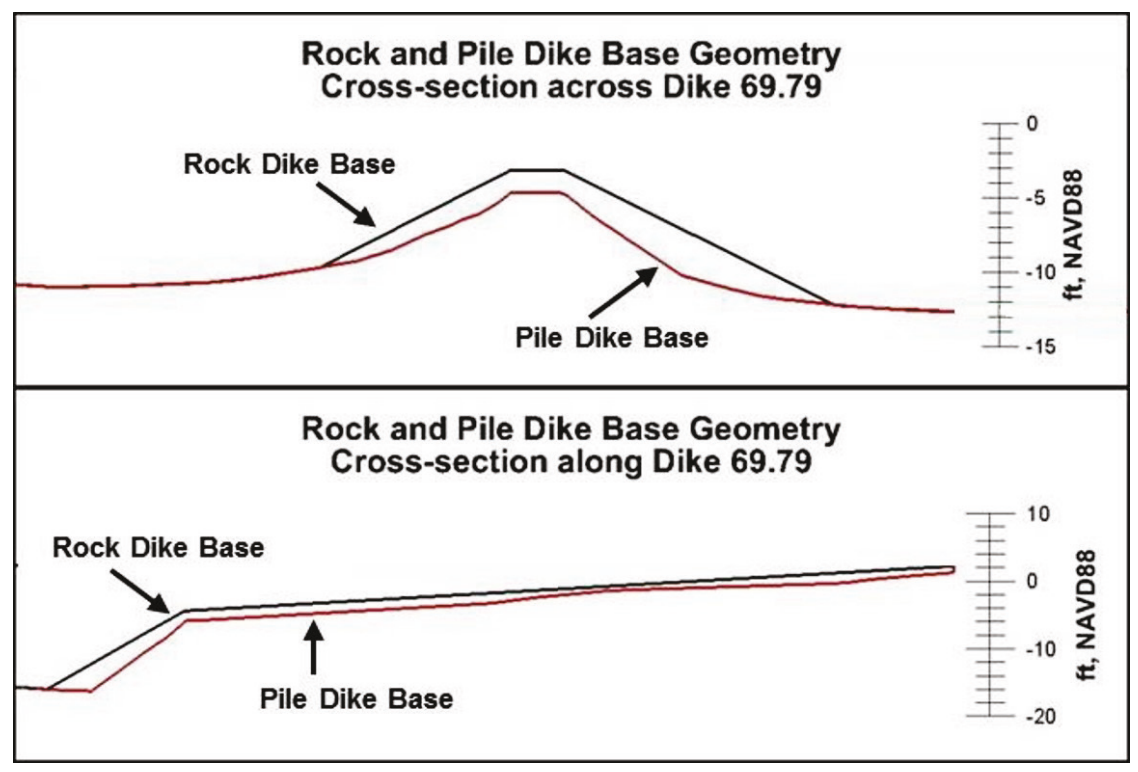


Figure 11. Locations of cross sections shown for Dike 69.79 base comparison.

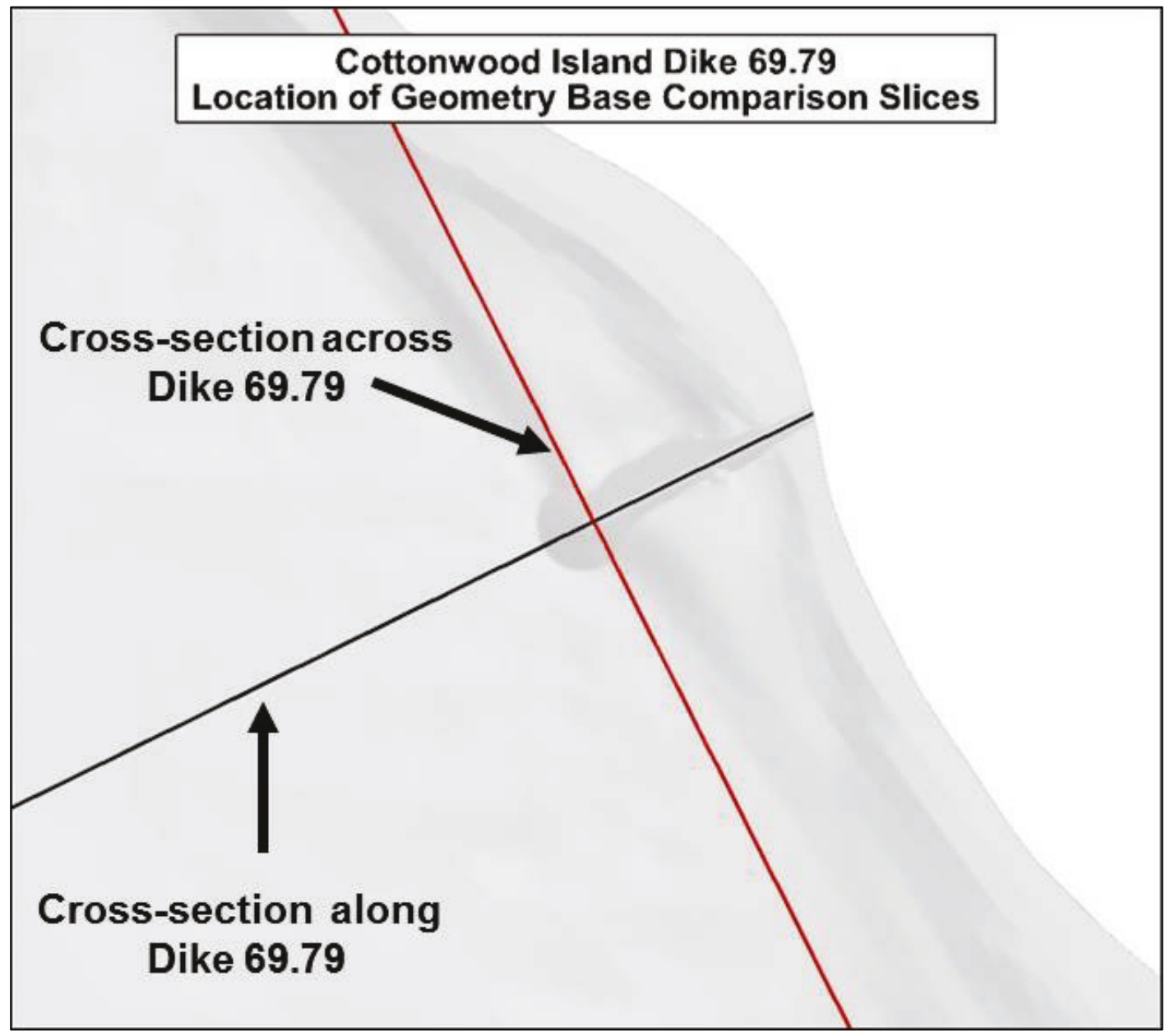


Figure 12. Pile dike geometry for Dike 69.79.

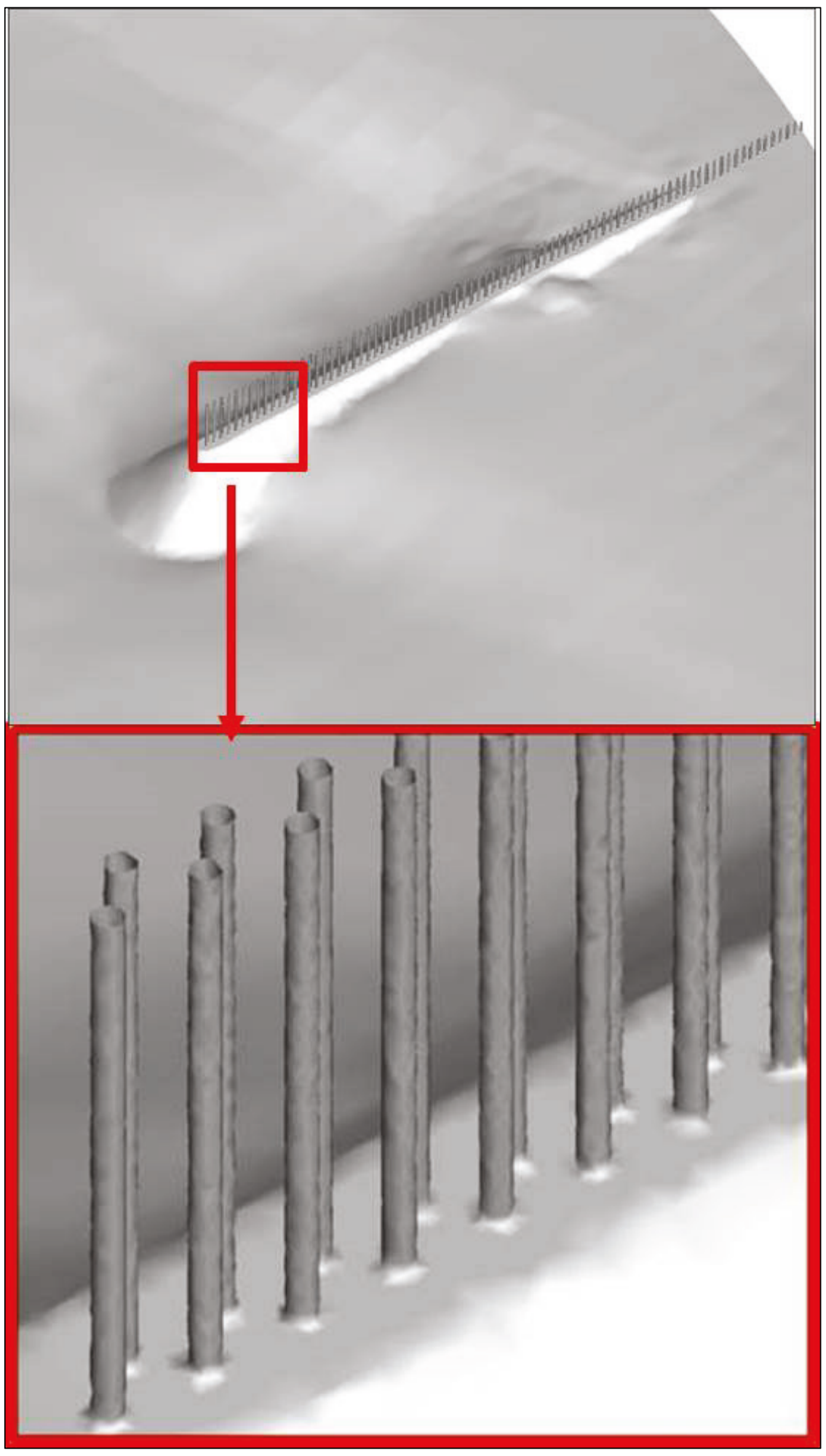


Figure 13. Rock dike geometry for Dike 69.79.

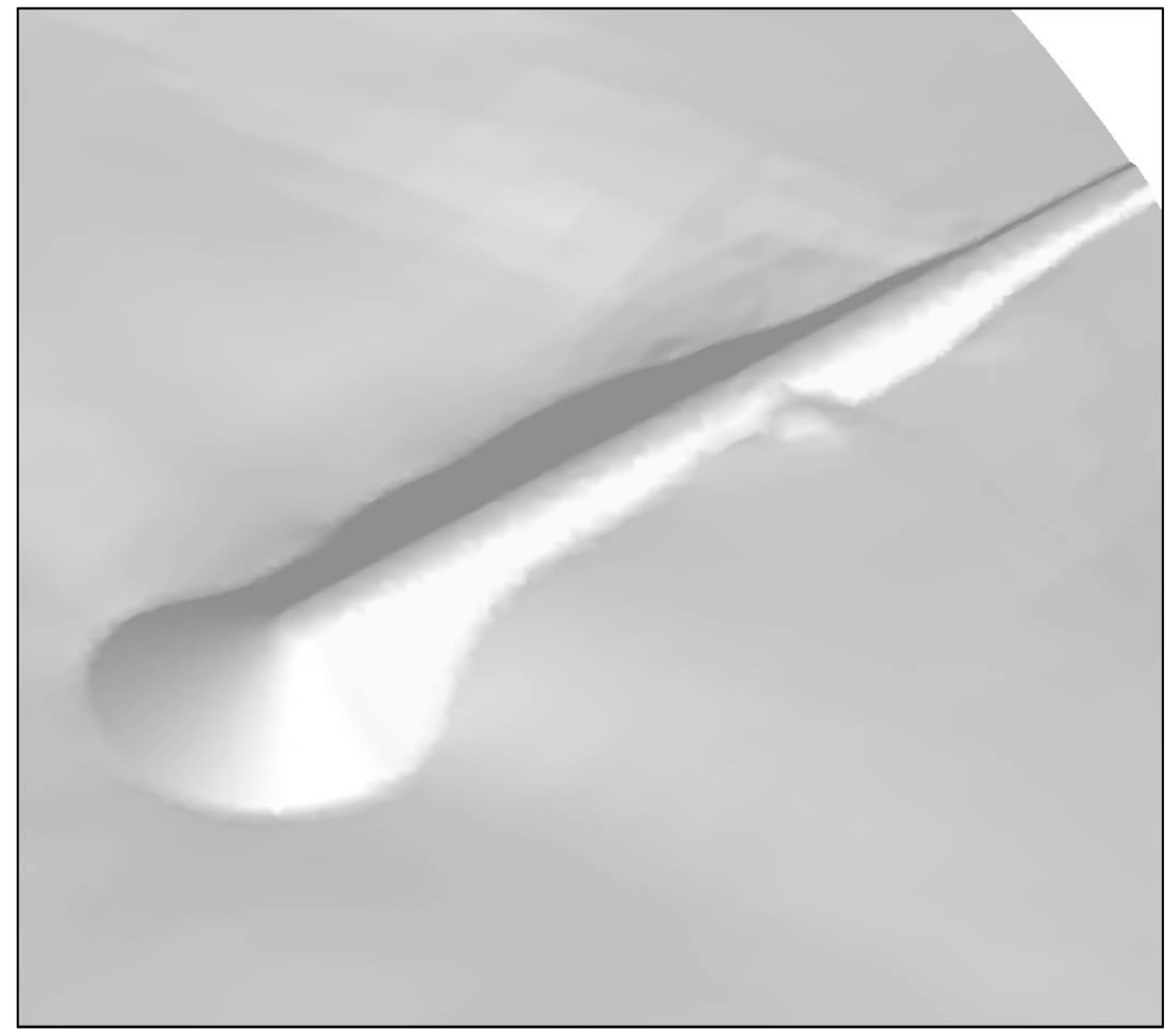

Although the total surface area that the piles account for in the pile dike surface area is less than $1 \%$ of the entire surface mesh area, the percentage of the surface mesh elements that the piles account for is much larger ( $37 \%$ of the mesh). Adequately resolving the surfaces of the piles requires relatively small elements, which significantly (perhaps prohibitively) increases the number of nodes and elements in each pile dike mesh. Prior to the completion of the pile dike meshes, a small study was conducted to determine if the piles could be combined into a simpler representation without changing the flow behavior in areas of interest. Combining the piles reduces the total number of nodes and elements required to reproduce the pile surfaces, which in turn reduces the computational resources required to generate the flow solution. This effort showed that combining the piles in the manner chosen significantly affects the flow field in the area of interest, so individual pile geometries were used for all the simulations. Further details of the dike combination effort are discussed in in Appendix B: Feasibility of Combining Piles. 


\subsubsection{Water surface}

For each flow domain, the top surface is comprised of the same node coordinates and connectivity as the mesh in the SW2-AdH study with one modification. At each node in the flow domain, the SW2-AdH flow depth has been added to the bathymetric elevation to provide the water surface elevation. The surfaces for each of the RANS-AdH discharges have been created using this method.

\subsubsection{Northern and southern boundaries}

SW2-AdH can perform simulations where the bank line location is not static because it has element wetting-and-drying calculation capabilities that allow for three types of elements: always submerged, always dry, and those that can be either wet or dry depending on the flow conditions. RANS-AdH does not have wetting-and-drying capabilities, so the flow domain is restricted to only areas that will remain submerged throughout the simulation. For this reason, the flow domain does not extend to the actual bank line, and artificial sides extending vertically from the water surface to the bathymetric surface fully enclose the flow domain for RANSAdH on the northern and southern sides of the flow domain. These sides are referred to as the northern and southern model boundaries. These boundaries are treated as frictionless boundaries in the simulations. The friction losses of the shallow regions beyond the northern and southern boundaries have been taken into account by using the flow velocities of the inflow boundary from the SW2-AdH flow domain that includes those shallow region friction effects up to the bank line.

The northern and southern boundaries of the RANS-AdH model coincide with streamlines of the SW2-AdH flow solution. This boundary location is appropriate because there is no flow though the side boundaries of the RANS-AdH flow domain, and by definition, there is no flow across a streamline. Placing boundaries along streamlines ensures that the location of the flow domain northern and southern boundaries has an insignificant effect on the flow solution. The location of the northern and southern boundaries is chosen by considering two different aspects of the model study and modeling process: the information that is sought from the flow solution and how much the element and node count of the mesh is increased by the placement of these boundaries. 
The primary focus of this modeling effort is to determine the effects that replacing the pile dikes with conventional rock dikes will have on navigation near the Cottonwood Island. The navigation channel of the Columbia River near Cottonwood Island (Figure 14) is located close to the northern shore (the dike side) just off the river-side end of the dikes. Since the primary area of interest of the model study is far from the channel-end of the dikes, the location of the northern and southern boundaries will not have a strong impact on the flow solution. A secondary interest for these models is flow behavior between the dikes for potential fish habitat. For the fish habitat concern, the northern and southern boundaries are located in shallow areas ( $5 \mathrm{ft}$ depth) near the bank line. Otherwise placement in these areas would not be necessary.

Figure 14. Main navigation channel for near Cottonwood Island.

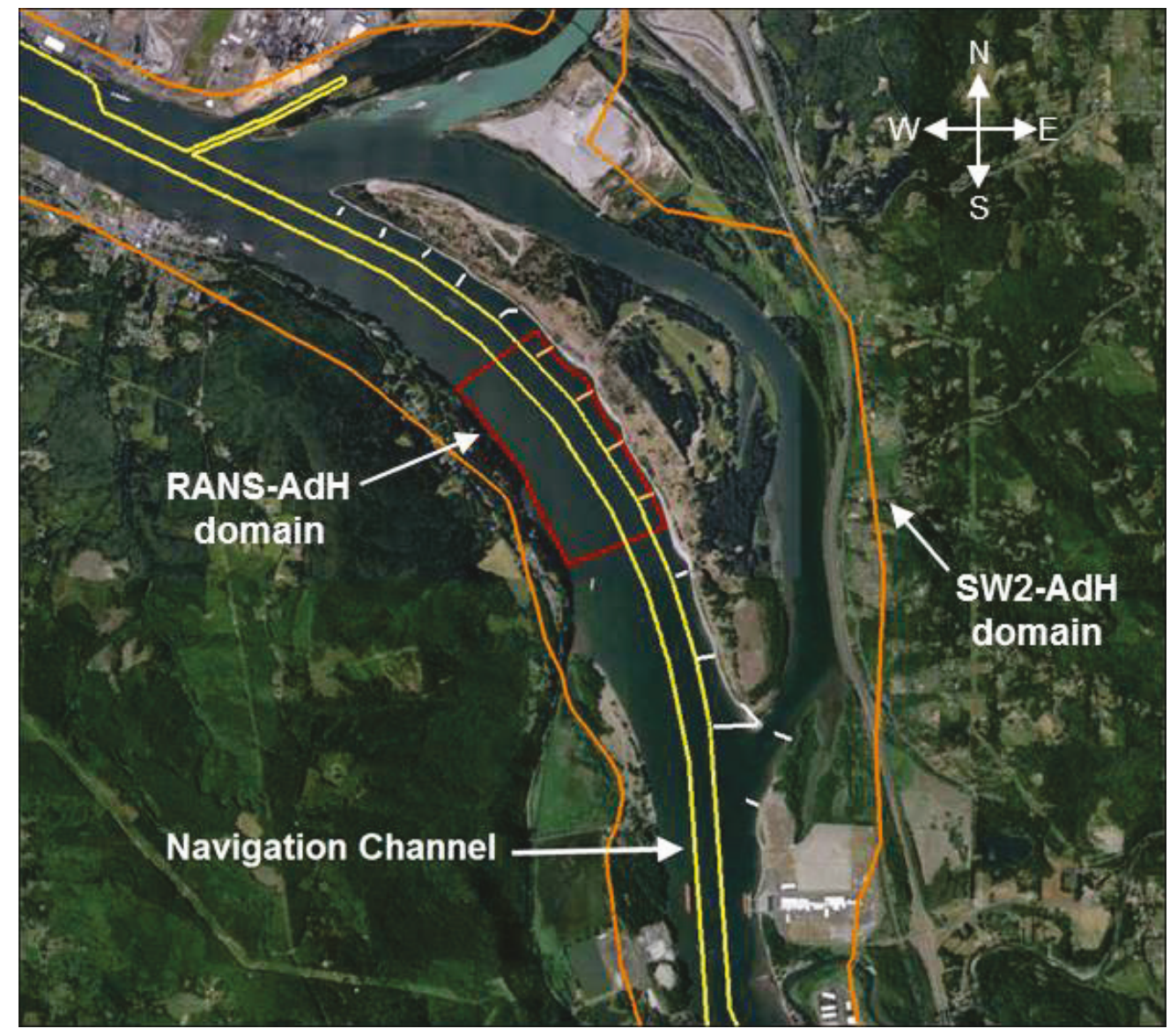

The second consideration when choosing the location of the northern and southern boundaries is how efficiently the domain can be meshed. For any numerical model, the quality of the mesh determines how quickly the solver can perform the required calculations to get the solution. The 
quality of the mesh depends on the shape of the elements. For an efficient model all of these factors must be considered when deciding upon the flow domain.

The element quality is quantified by several different techniques; one is the aspect ratio of the elements. For RANS-AdH simulations, all elements are tetrahedra, and the aspect ratio can be thought of as the cube root of the volume of the element. Elements with an aspect ratio close to 1 produce the best flow solutions. Ensuring that the elements in shallow areas have sufficiently low aspect ratios requires smaller mesh elements much smaller than is required to for the deep areas. Such resolution increases the total mesh size dramatically, so limiting the amount of shallow areas in the flow domain is critical to maintaining computationally viable mesh size and quality.

After discussing considerations for the flow domain near the northern and southern shores of the Columbia River, ERDC and NWP agreed to place the northern and southern boundaries of the flow domain at the $5 \mathrm{ft}$ depth on the northern boundary for each RANS-AdH simulation. These boundaries are located along the streamline in the SW2-AdH flow solution (for each flow situation) passing through the $5 \mathrm{ft}$ depth point near the north bank line of the Columbia River at the inflow boundary location.

For all meshes used in this study, the southern boundary location corresponds to a streamline that begins at the inflow boundary at a location near the left bank line with a depth-averaged velocity of 2.5 feet per second ( $\mathrm{ft} / \mathrm{s})$. Using the velocities and depths at multiple locations along the inflow boundary and the streamlines beginning at those locations, the discharge and the size of the shallow area being removed along the southern boundary was calculated. This location only reduces the discharge through the flow domain by $5 \%$ but significantly reduces the number of nodes and elements required by eliminating much of the shallow areas around the southern boundary. Since the flow behavior is different for each condition and the north and south boundaries are shaped by streamlines, the north and south boundaries are unique for each of the three RANS-AdH flow conditions.

The northern and southern boundaries of the Cottonwood Island flow domain for one discharge are shown in Figure 15. The northern boundary aligned with the $5 \mathrm{ft}$ depth streamline is shown in blue, and the $2.5 \mathrm{ft} / \mathrm{s}$ velocity boundary is shown in yellow. 
Figure 15. Northern and southern boundaries for 3D flow solution.

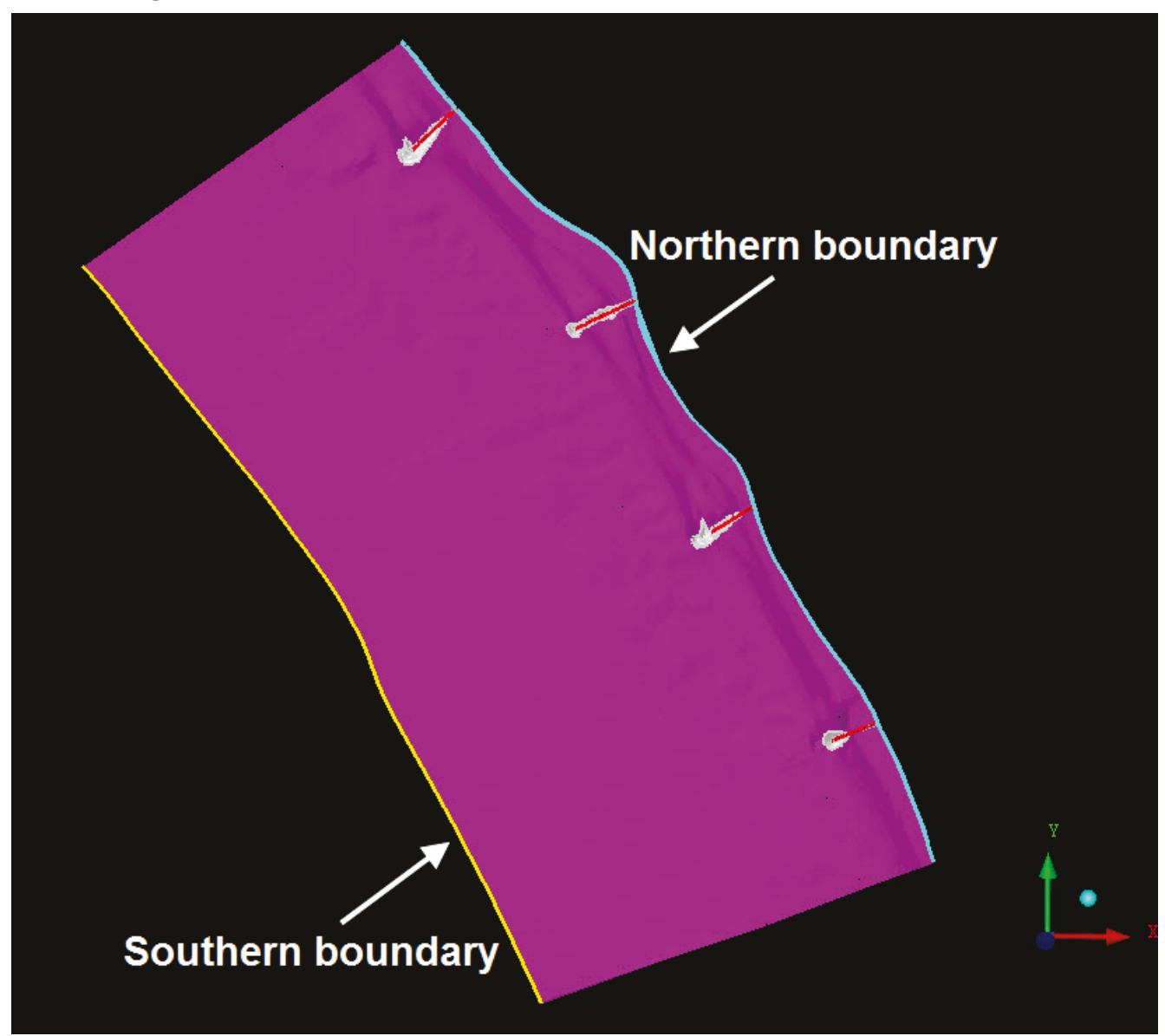

\subsubsection{Total flow domain summary}

Previous sections include a detailed description of each part of Cottonwood Island's flow domain. It consists of a bottom (the bathymetry and the dike geometries), two flux boundaries (the upstream inflow boundary and the downstream outflow boundary), and two side boundaries (one along the northern bank line of the Columbia River and one along the southern bank line). The surfaces of the flow domain are shown in Figure 16. In the top image, the water surface has been removed to reveal the bathymetry and dike surfaces. In the bottom image, the water surface has been included. The elevations are in North American Vertical Datum of 1988 (NAVD88) for the entire domain and around Dike 69.79 are shown in Figure 17 and Figure 18, respectively. 
Figure 16. Cottonwood Island flow domain surfaces.
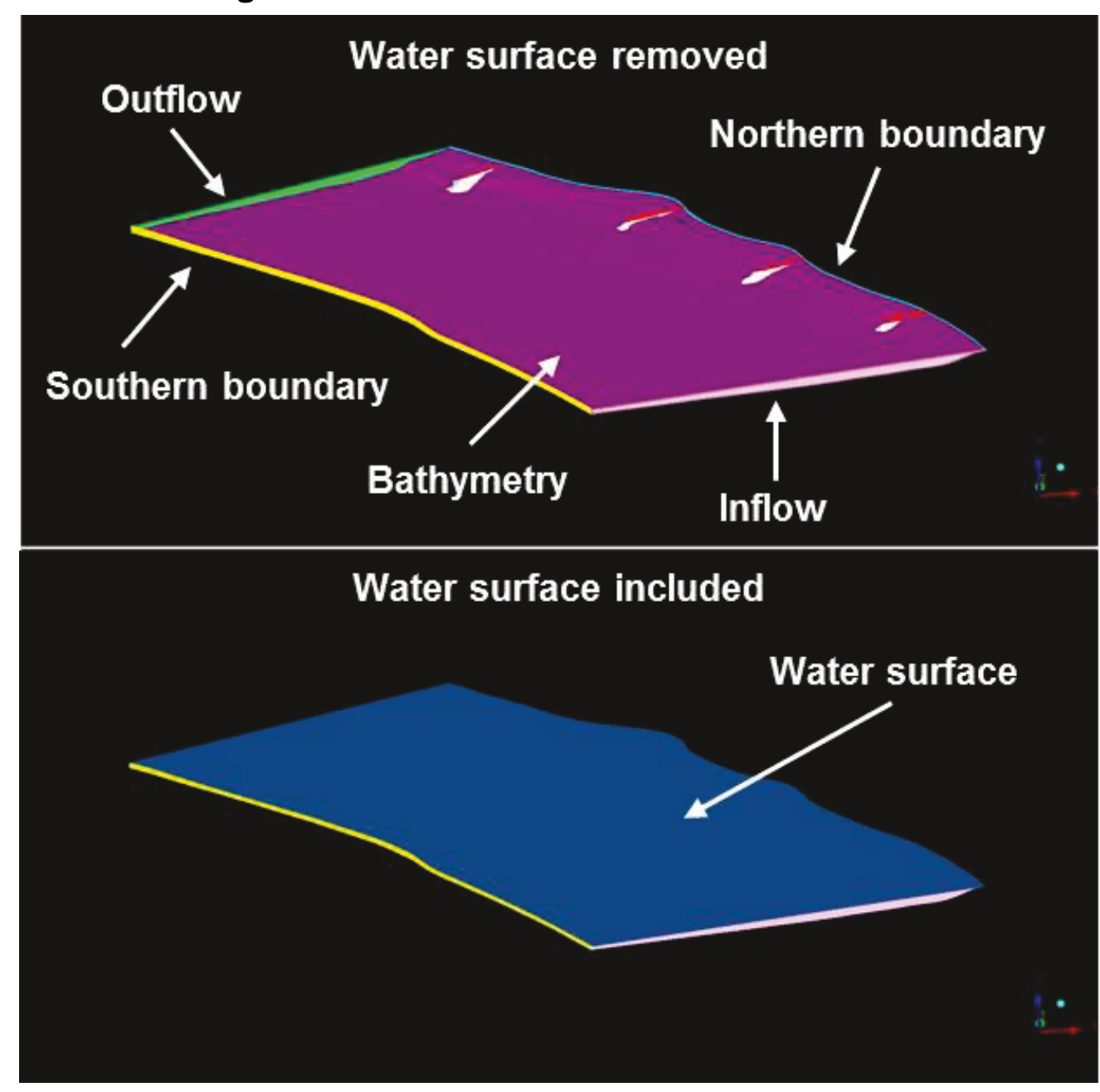
Figure 17. Flow domain elevations.

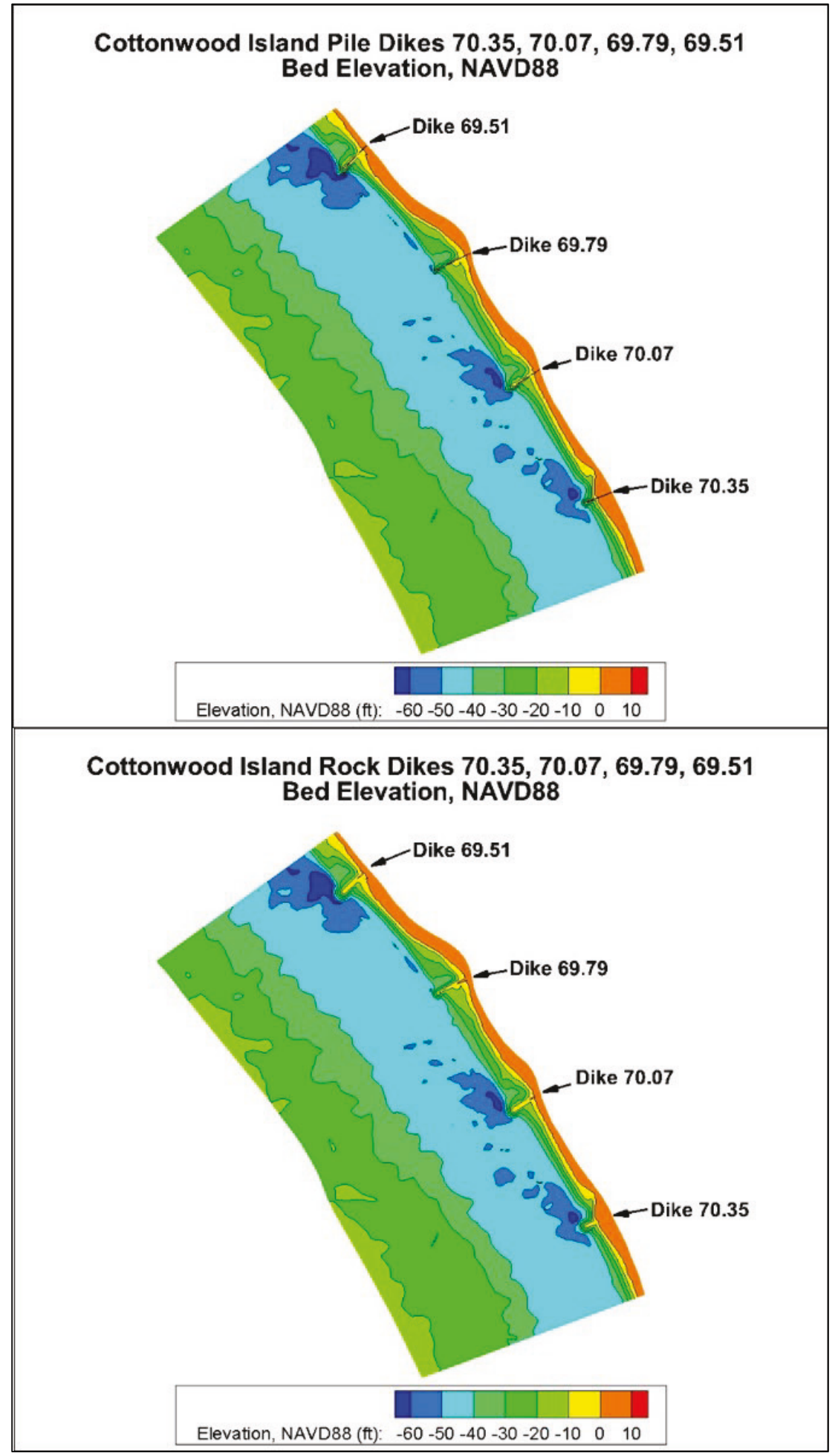


Figure 18. Flow domain elevations - Dike 69.79.

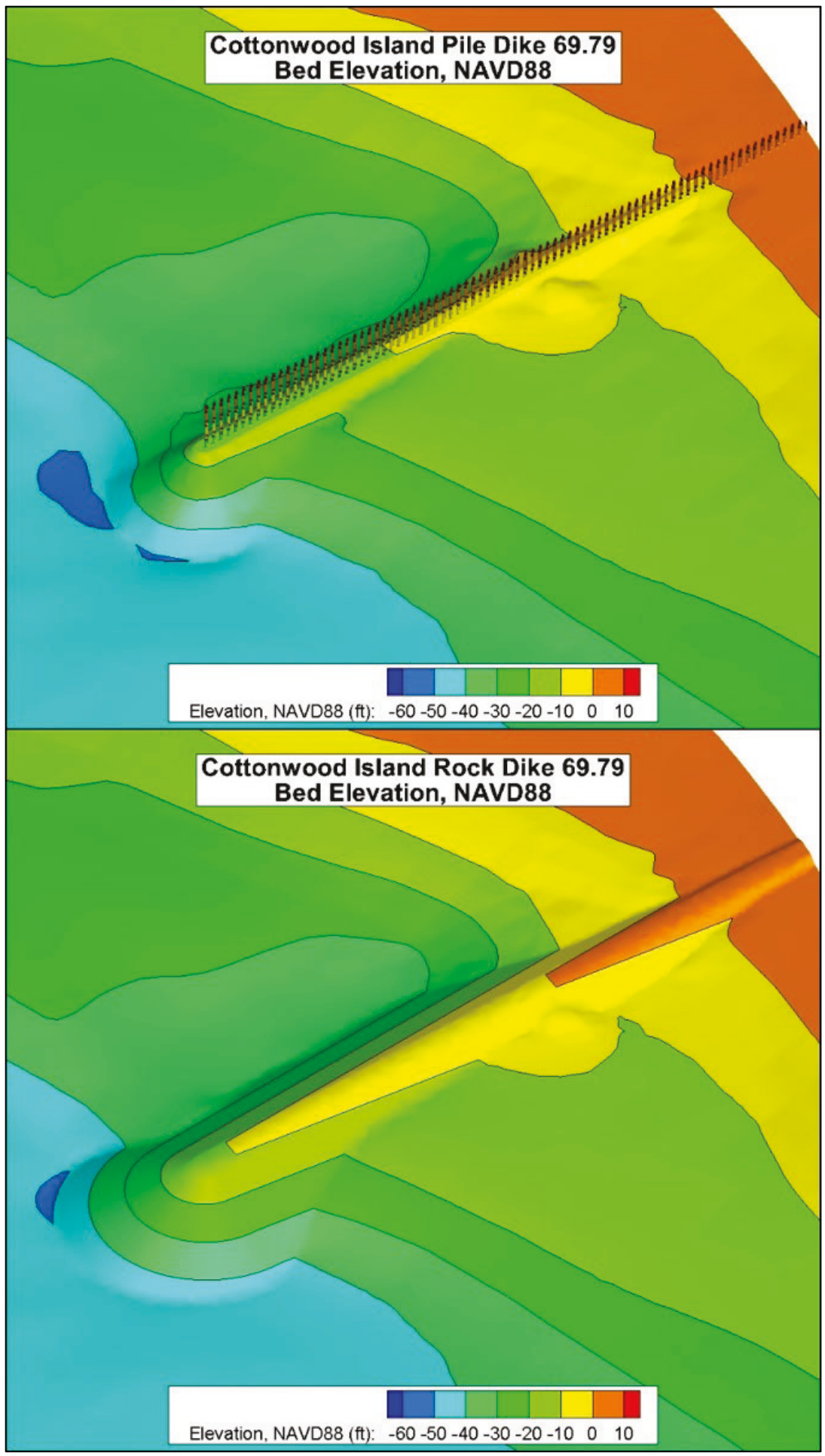




\subsection{Computational meshing}

During mesh creation for a RANS-AdH simulation, the intent is to model the geometry of the boundary faces and have a sufficient amount of resolution to get a reasonable flow solution. A mesh that meets these criteria is sufficient because the automatic-adaptation of RANS-AdH refines the mesh to more accurately calculate the details of the flow throughout the simulation. Resolving the initial mesh any further to ensure accurate hydraulic calculations is unnecessary.

\subsubsection{General meshing challenges}

A challenge of this study was creating meshes that captured the geometric detail in the flow domain without it being prohibitively large. Currently, RANS-AdH simulations require tetrahedral element meshes. As stated earlier, tetrahedral elements must have a low aspect-ratio to ensure that their quality is high enough to produce accurate flow solutions. Balancing those two requirements was key to the completion of this study.

The Cottonwood Island flow domains are large compared to those of most RANS-AdH model studies. The degree to which the elevation varied throughout the flow domain in this model is also more than most other models. The flow domain varies from approximately $80 \mathrm{ft}$ deep; elevation (el.) -60, NAVD88, to $5 \mathrm{ft}$ deep; el. 10, NAVD88, near the dikes. The area of the flow domain that is considered shallow (10 ft deep or less) is very large. This depth variation is shown in Figure 17 through Figure 21. The bed elevation contours are shown in Figure 17 and Figure 18. Figure 19 shows the location of two cross-sectional slices through the Cottonwood Island flow domain - one slice along Dike 70.07, the other between Dikes 70.07 and Dike 69.79. The cross sections for these slices are shown in Figure 20 and Figure 21. These two cross sections show the extent of shallow areas in the flow domain.

A sufficient number of elements must be used to define the flow domain properly. Small elements are used in areas less than $10 \mathrm{ft}$ deep; however, larger elements are used in areas deeper than $10 \mathrm{ft}$. This element sizing reduces the number of elements in the mesh as a whole while the flow domain details are fully represented. This sizing also makes the mesh more computationally efficient. 
The pile dike geometries present a further challenge because the piles are very small compared to the flow domain as a whole. The small pile diameters require small elements be used to reproduce the geometry in these areas; the number of piles significantly increase the mesh size.

Figure 19. Cottonwood Island locations of vertical slices showing elevation.

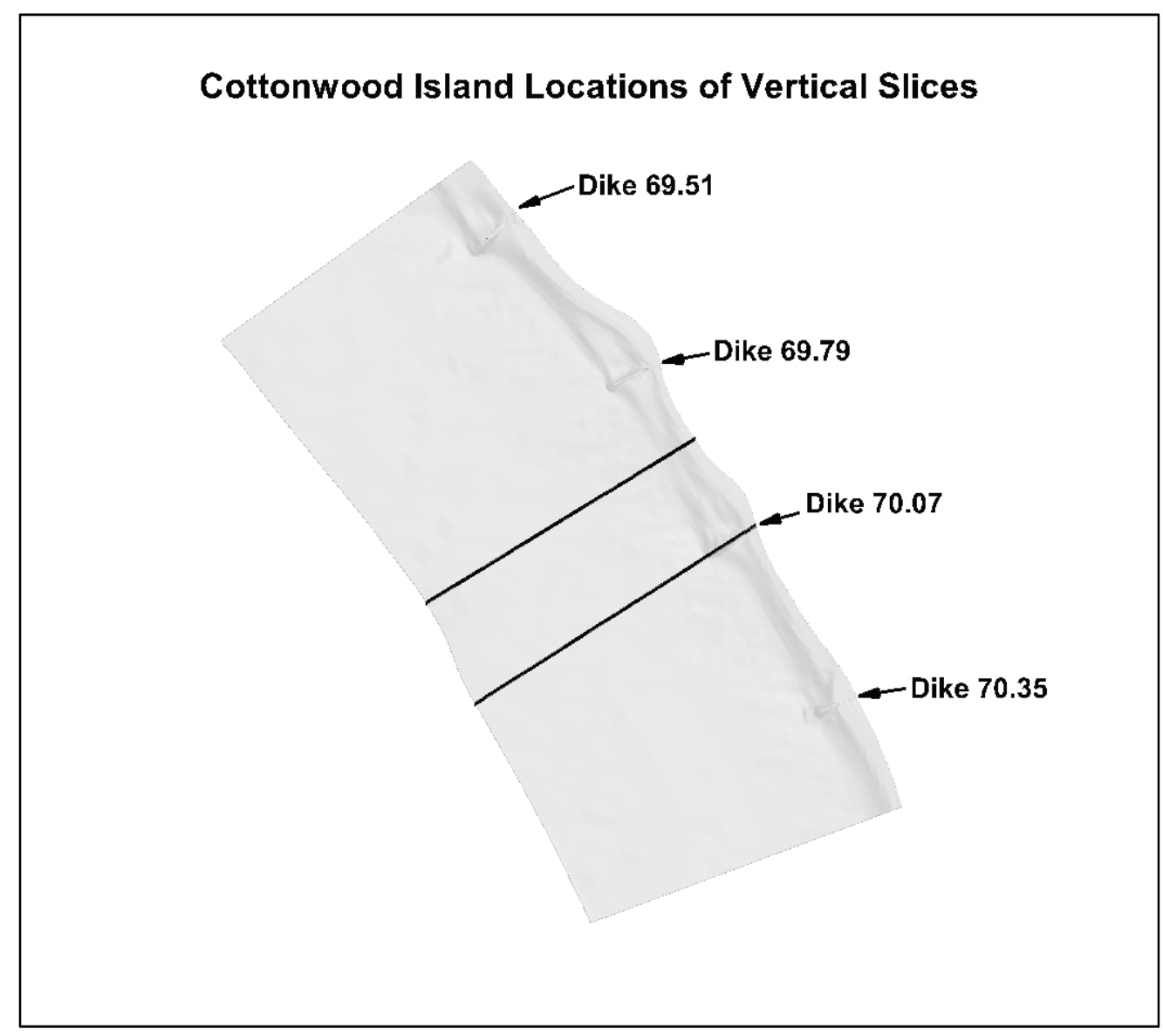


Figure 20. Cottonwood Island vertical slice along Pile Dike 70.07 center.

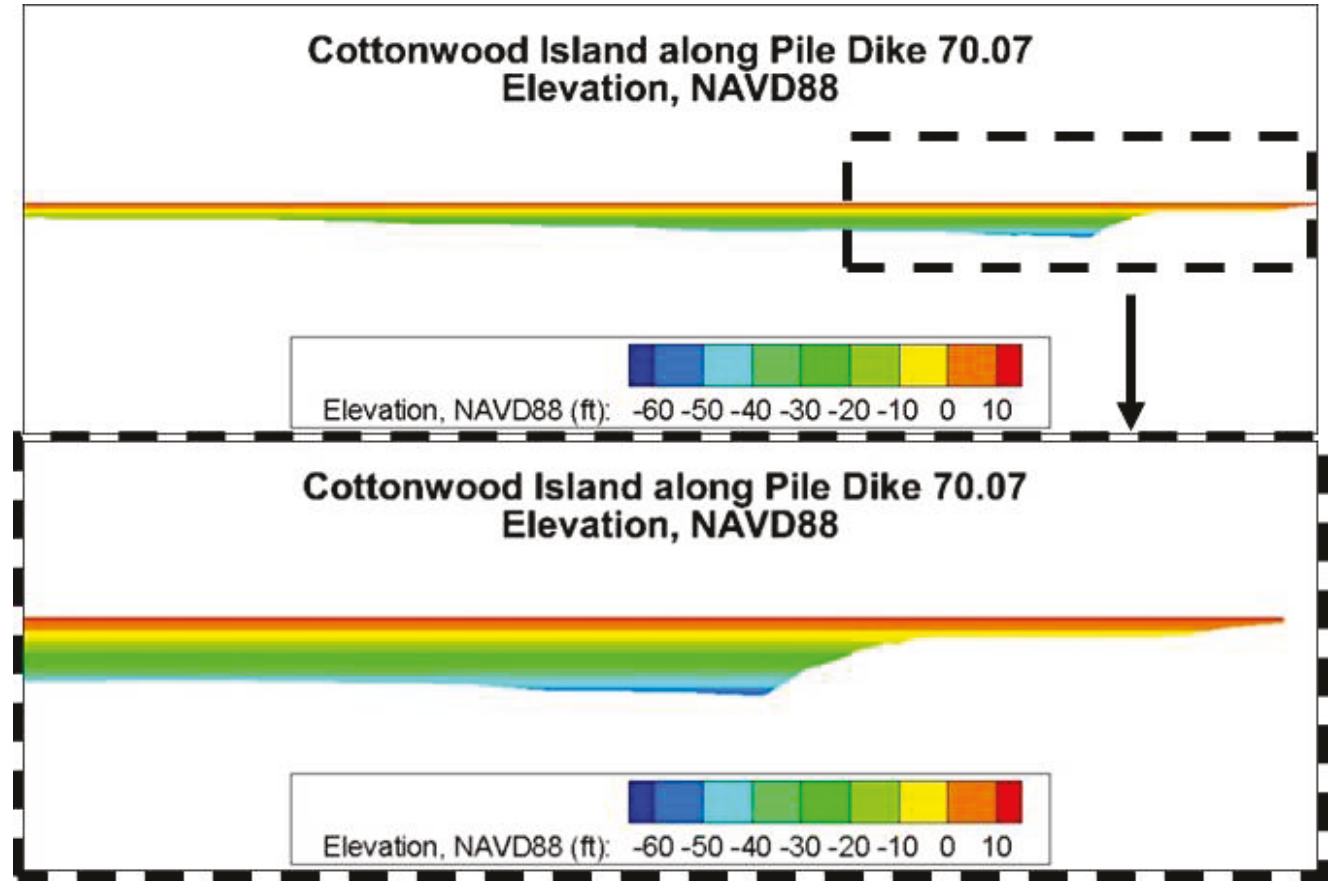

Figure 21. Cottonwood Island vertical slice between Pile Dike 70.07 and 69.79.

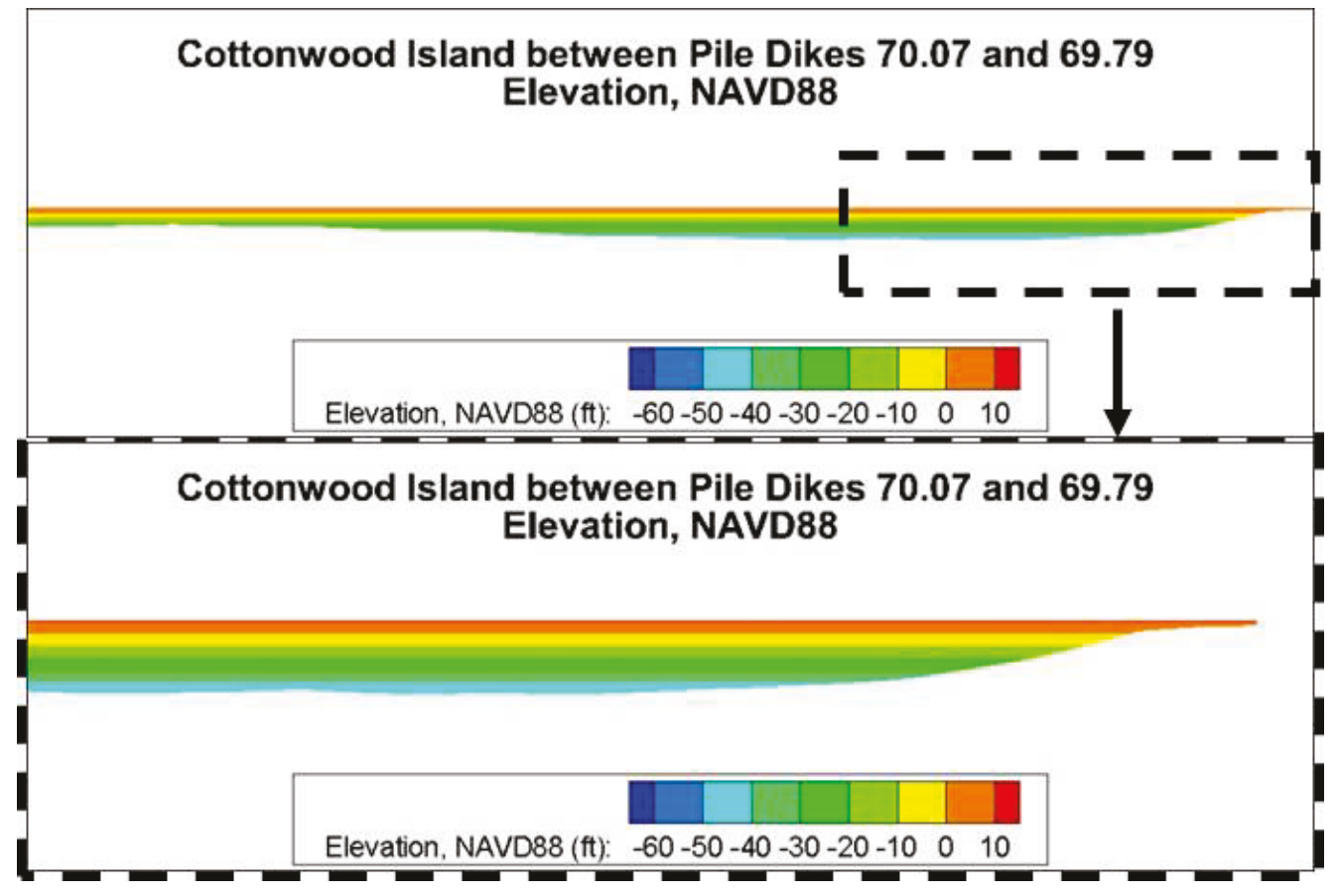




\subsubsection{Meshing procedure}

To address the depth varying significantly laterally across the channel coupled with the large shallow areas, the bathymetry is divided into three sections based on flow depth. These divisions allow for the use of element size controls in the deep, intermediate, and shallow areas of the flow domain. These divisions correspond to the deep navigation channel area, the shallow areas along the northern bank line, and the intermediate regions that fall between the deep and shallow areas. Separating these sections allows for smaller elements in the shallow regions near the northern boundary of the flow domain and larger elements in the navigation channel helping to optimize the mesh. These sections are shown in Figure 22. The navigation channel (deep) area, the shallow area and the intermediate regions are shown in red, blue, and yellow, respectively.

Figure 22. Dike area material division used for meshing.

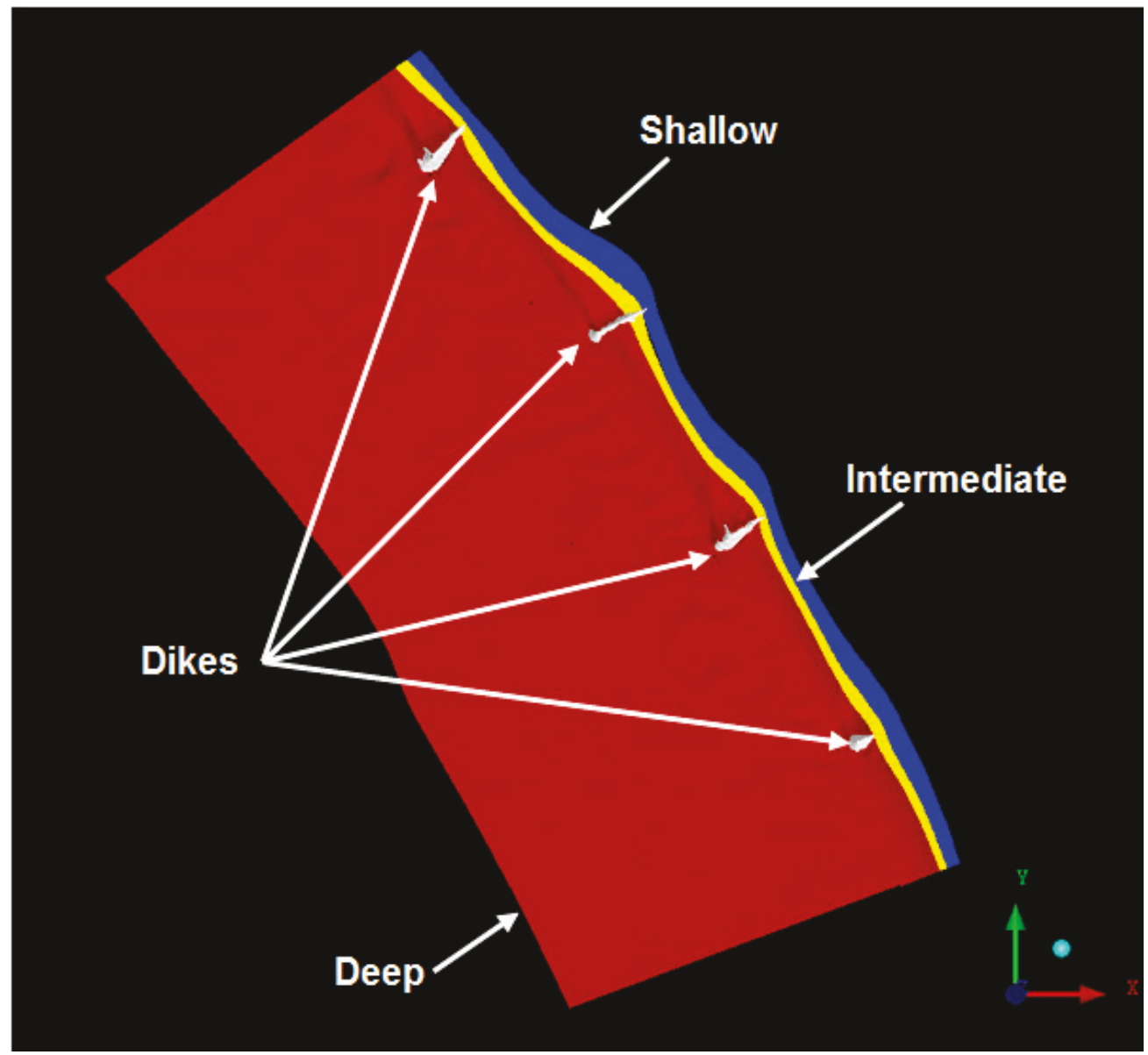


The surface meshes for one of the pile dike simulations and for one of the rock dike simulations are shown in Figure 23 and Figure 24. In each of these figures, the left column of images shows the bottom surface geometry for different areas of the mesh, and the right column of images shows the corresponding surface mesh resolution. Starting with the top left and moving down the left column, each image shows a closer view of the geometry. Directly across from each geometry picture is an image of the corresponding surface mesh. Surface elements in the navigation channel have sides that are approximately $20 \mathrm{ft}$ long. In the shallow areas, away from the dikes, the element side lengths are approximately $2 \mathrm{ft}$ long. Between the navigation channel and shallow sections, the element side lengths transition from $1.5 \mathrm{ft}$ to $5 \mathrm{ft}$ long. For pile dike simulations, the elements on the piles have sides that are $4 \mathrm{in}$. long, and the top of the dike foundation has element sides that are $8 \mathrm{in.} \mathrm{long.} \mathrm{The}$ sides of the pile dike foundations have elements with sides that transition from $8 \mathrm{in}$. long at the top to $3.25 \mathrm{ft}$ long at the bottom. On the rock dike simulations, the sides of the dike foundations have elements with sides that are approximately $3.25 \mathrm{ft}$ long. 
Figure 23. Pile dike surface mesh resolution.

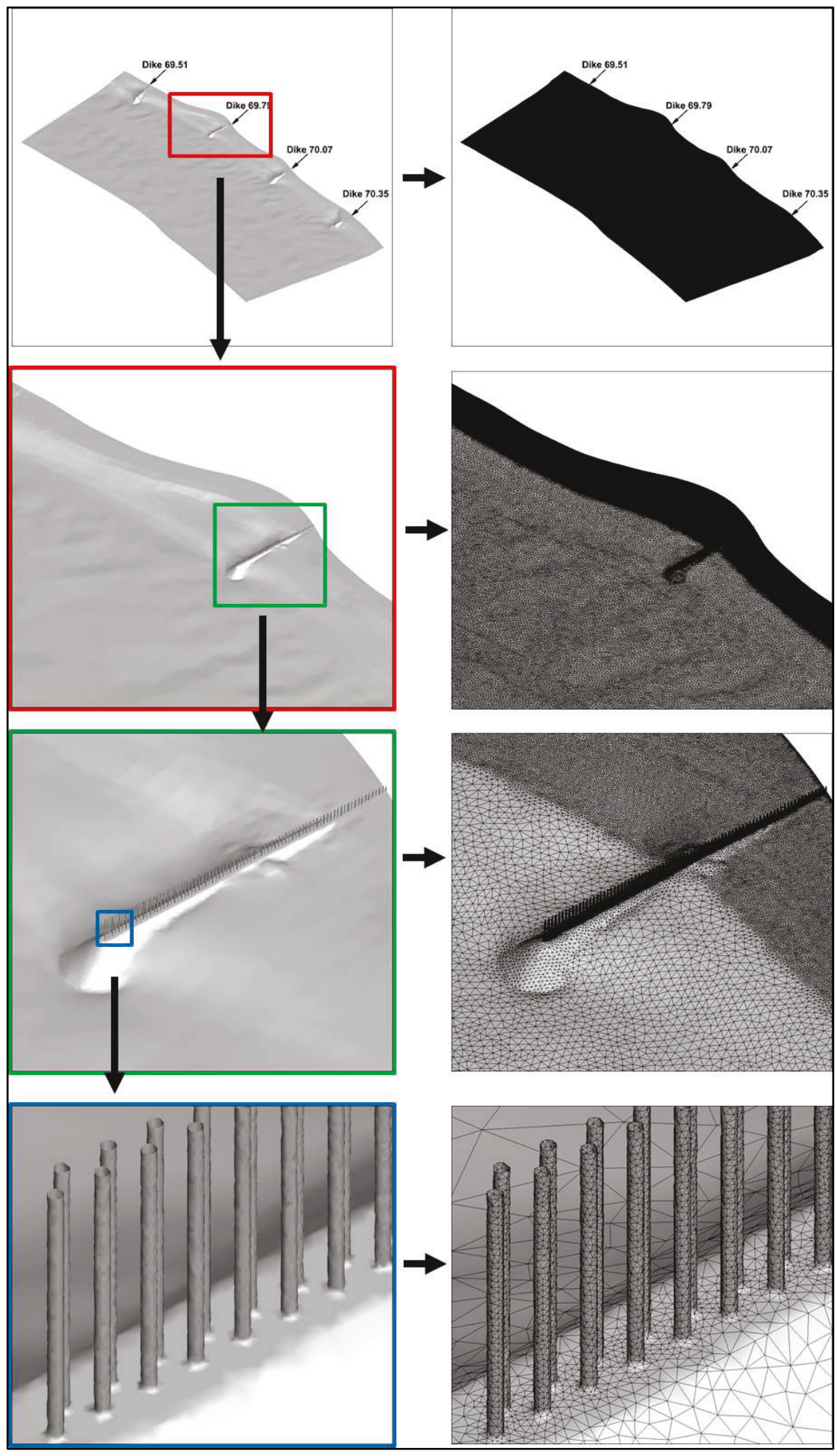


Figure 24. Rock dike surface mesh resolution.

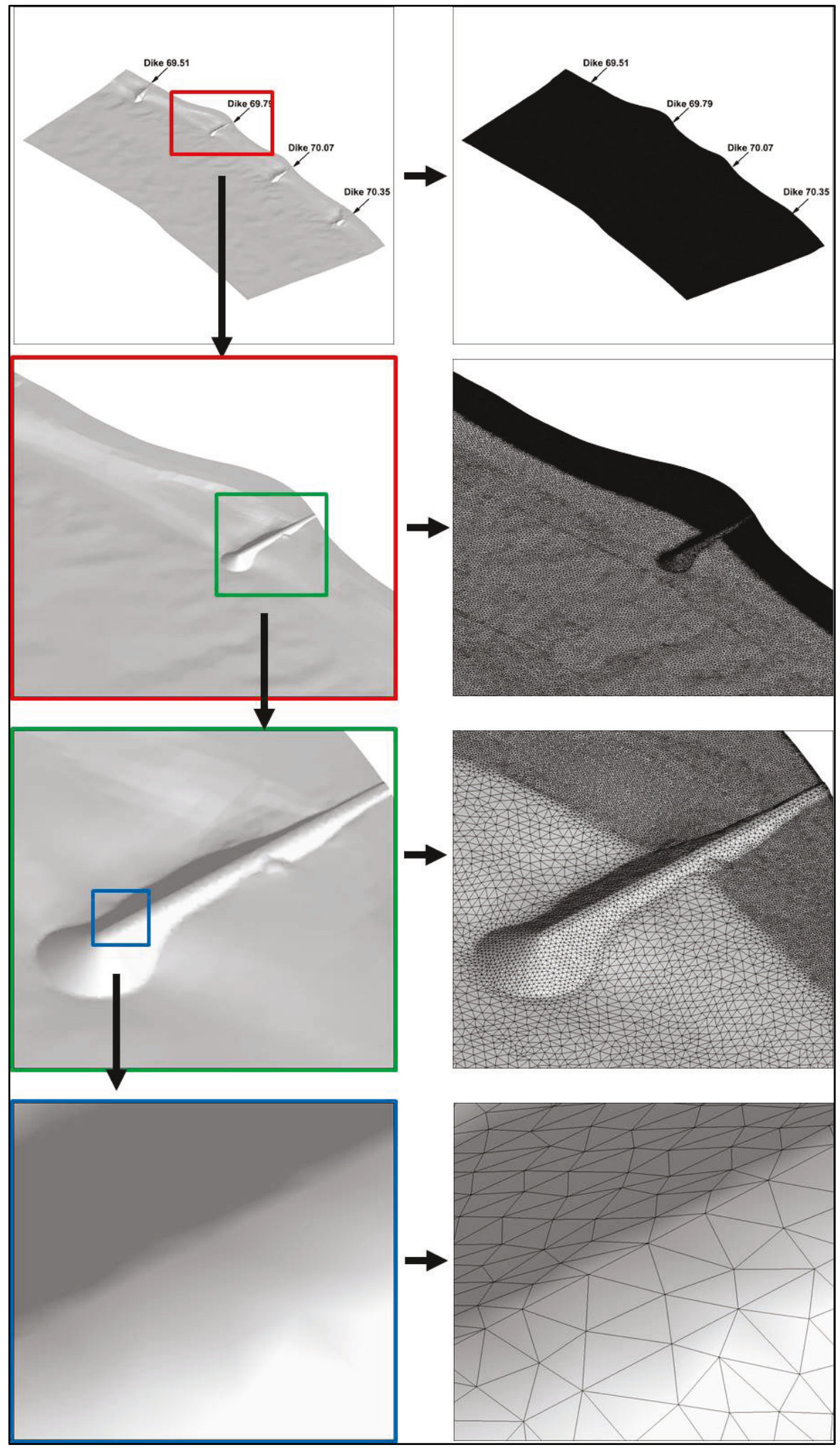


With this type of resolution for the elements, the meshes are quite large, but they remain computationally viable and calculate steady-state flow solutions within a reasonable amount of time ( $\sim 1$ day of computational time). The pile dike meshes have approximately 10.5 million tetrahedral volume elements and 2 million nodes. The rock dike meshes have approximately 5 million elements and 1 million nodes. The node and surface element breakdown for the four-dike model, pile dike domain high discharge mesh is listed in Table 1 . The total surface area of the flow domain bathymetry and dikes is approximately 11 million $\mathrm{ft}^{2}$ and is divided into six sub-domains (Figure 25). The piles comprise less than $1 \%$ of the dike/bathymetry surface area but make up $37 \%$ of the dike/bathymetry surface element count. Similarly, the shallow northern bank line area is just $4 \%$ of the dike/bathymetry surface area but forms $35 \%$ of the dike/bathymetry surface element count. Together these two areas comprise $72 \%$ of the element count while forming less than $5 \%$ of the dike/bathymetry surface area in the flow domain.

The node and surface element breakdown for the four-dike model, rock dike domain high-discharge mesh is listed in Table 2. The surface area/surface element count relationship for the rock dike meshes (Figure 26) is similar to that of the pile dike meshes. The navigation channel and other deep bathymetry comprise $25 \%$ and $68 \%$, respectively, of the dike/bathymetry surface area but only comprise $11 \%$ and $31 \%$, respectively, of the dike/bathymetry surface element count. The shallow northern bank line and intermediate northern shore areas form $4 \%$ and $3 \%$ of the dike/ bathymetry surface area but comprise $27 \%$ and $21 \%$ of the dike/bathymetry surface element count. Together these two areas comprise $48 \%$ of the element count while forming only $7 \%$ of the dike/bathymetry surface area in the flow domain.

Note that the element count for the rock dikes is approximately half that of the pile dikes even though the surface areas are approximately the same. This indicates how much resolution the piles added to the entire mesh. 
Table 1. Element count versus area for pile dike mesh.

\begin{tabular}{|l|l|l|l|l|}
\hline & & Surface Element & $\begin{array}{l}\text { Amount of Total } \\
\text { Mesh Surface } \\
\text { Area (\%) }\end{array}$ & $\begin{array}{l}\text { Amount of Total } \\
\text { Mesh Surface } \\
\text { Element Count (\%) }\end{array}$ \\
\hline Piles & Surface Area (ft $\left.{ }^{2}\right)$ & 297,588 & $<1$ & 37 \\
\hline Pile Dike Base & 91,650 & 50,731 & $<1$ & 6 \\
\hline $\begin{array}{l}\text { Shallow Northern } \\
\text { Shore Area }\end{array}$ & 598,662 & 278,439 & 4 & 35 \\
\hline $\begin{array}{l}\text { Intermediate Northern } \\
\text { Shore Area }\end{array}$ & 408,412 & 63,748 & 3 & 8 \\
\hline Navigation Channel & $4,118,200$ & 27,762 & 25 & 3 \\
\hline $\begin{array}{l}\text { Non-Navigation } \\
\text { Channel Deep } \\
\text { Bathymetry }\end{array}$ & $11,021,358$ & 87,108 & 68 & 11 \\
\hline Total Dike/bathymetry & $16,288,895$ & 805,376 & 100 & 100 \\
\hline
\end{tabular}

Table 2. Element count versus area for rock dike mesh.

\begin{tabular}{|l|l|l|l|l|}
\hline & Surface Area $\left(\mathrm{ft}^{2}\right)$ & $\begin{array}{l}\text { Surface Element } \\
\text { Count for Section }\end{array}$ & $\begin{array}{l}\text { Amount of Total } \\
\text { Mesh Surface } \\
\text { Area (\%) }\end{array}$ & $\begin{array}{l}\text { Amount of Total } \\
\text { Mesh Surface } \\
\text { Element Count (\%) }\end{array}$ \\
\hline Rock Dike Base & 168,224 & 51,054 & 1 & 10 \\
\hline $\begin{array}{l}\text { Shallow Northern } \\
\text { Shore Area }\end{array}$ & 598,662 & 135,602 & 4 & 27 \\
\hline $\begin{array}{l}\text { Intermediate Northern } \\
\text { Shore Area }\end{array}$ & 403,302 & 104,053 & 3 & 21 \\
\hline $\begin{array}{l}\text { Navigation Channel } \\
\text { Non-Navigation } \\
\text { Channel Deep } \\
\text { Bathymetry }\end{array}$ & $4,118,200$ & 54,485 & 25 & 11 \\
\hline Total Dike/bathymetry & $16,244,194$ & 498,830 & 100 & 31 \\
\hline
\end{tabular}


Figure 25. Element count versus surface area for pile dike mesh.

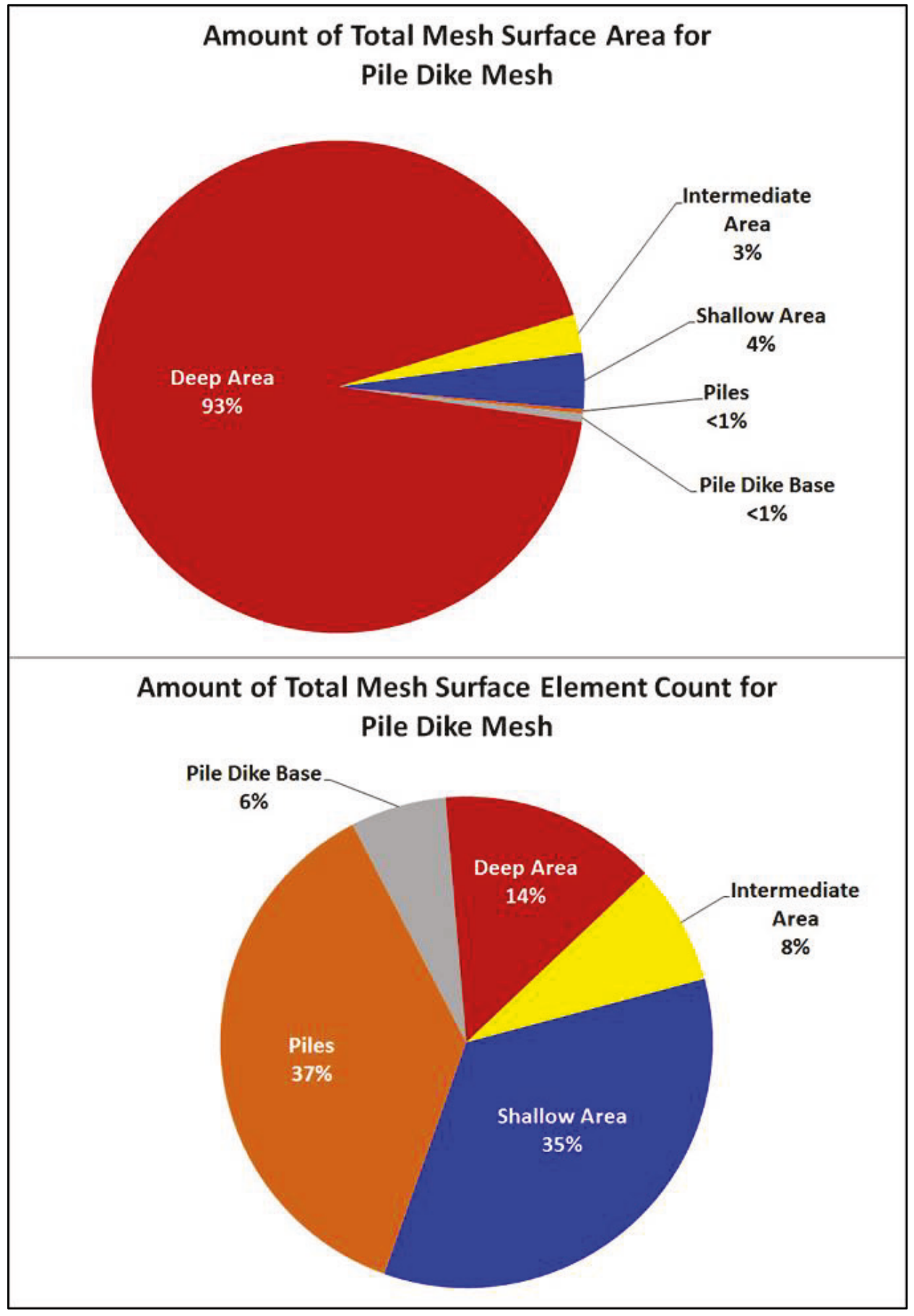


Figure 26. Element count versus surface area for rock dike mesh.

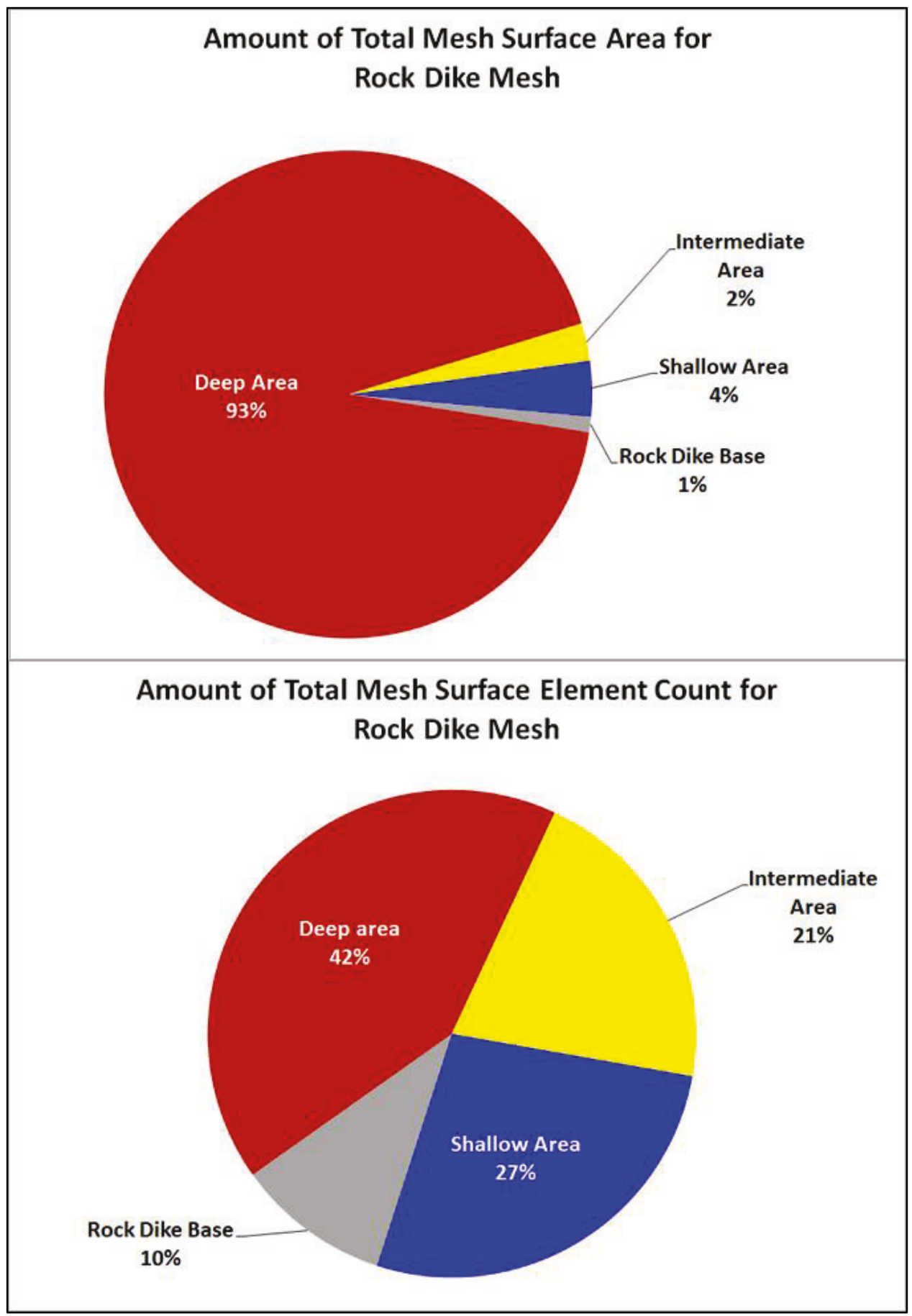




\subsection{Sand Island meshing attempt}

The Sand Island site presents similar but more extensive meshing challenges than the Cottonwood Island Site. The parameters and procedures from the Cottonwood Island meshing effort produce meshes for the Sand Island site that are orders of magnitude larger in both size and element/node count than those of the Cottonwood Island site meshes. Such meshes are time prohibitive with the computing power available. Differences in the size and shape of the flow area at the Sand Island site as well as the resulting flow behavior as indicated by the SW2-AdH simulation results (Savant and McAlpin 2014) mean that creating a flow domain and computational mesh for a RANS-AdH simulation of the Sand Island site is unfeasible. CHL and NWP agree that limitations in the available technology preclude any efforts to numerically model the flow behavior at the Sand Island site. A thorough discussion of the attempt at creating an appropriate flow domain and computational mesh is included in Appendix A: Sand Island Modeling. 


\section{Boundary Conditions and Simulation Procedure}

In this chapter, the boundary conditions, including the river discharges and wall friction values, are discussed. The flow domain for each simulation contains two flux boundaries - one inflow and one outflow. In addition, each flow domain consists of several non-flux boundaries that require wall friction values. General simulation setup and how automatic mesh adaptation was employed are also discussed.

\subsection{Boundary conditions}

This study is comprised of three pairs of simulations with different discharges. As determined by NWP, the three discharges are a high discharge $(432,811$ cubic feet per second [cfs]), a medium discharge $(337,680 \mathrm{cfs})$, and a low discharge (291,881 cfs). Columbia River discharges measured over a 2-month period include the three discharges chosen for the RANS-AdH simulations are shown in Figure 27. The flow conditions for each of these discharges have been extracted from the SW2AdH flow solution to create the boundary conditions for the RANS-AdH simulations (ALDEN 2016).

Figure 27. Cottonwood Island model discharges.

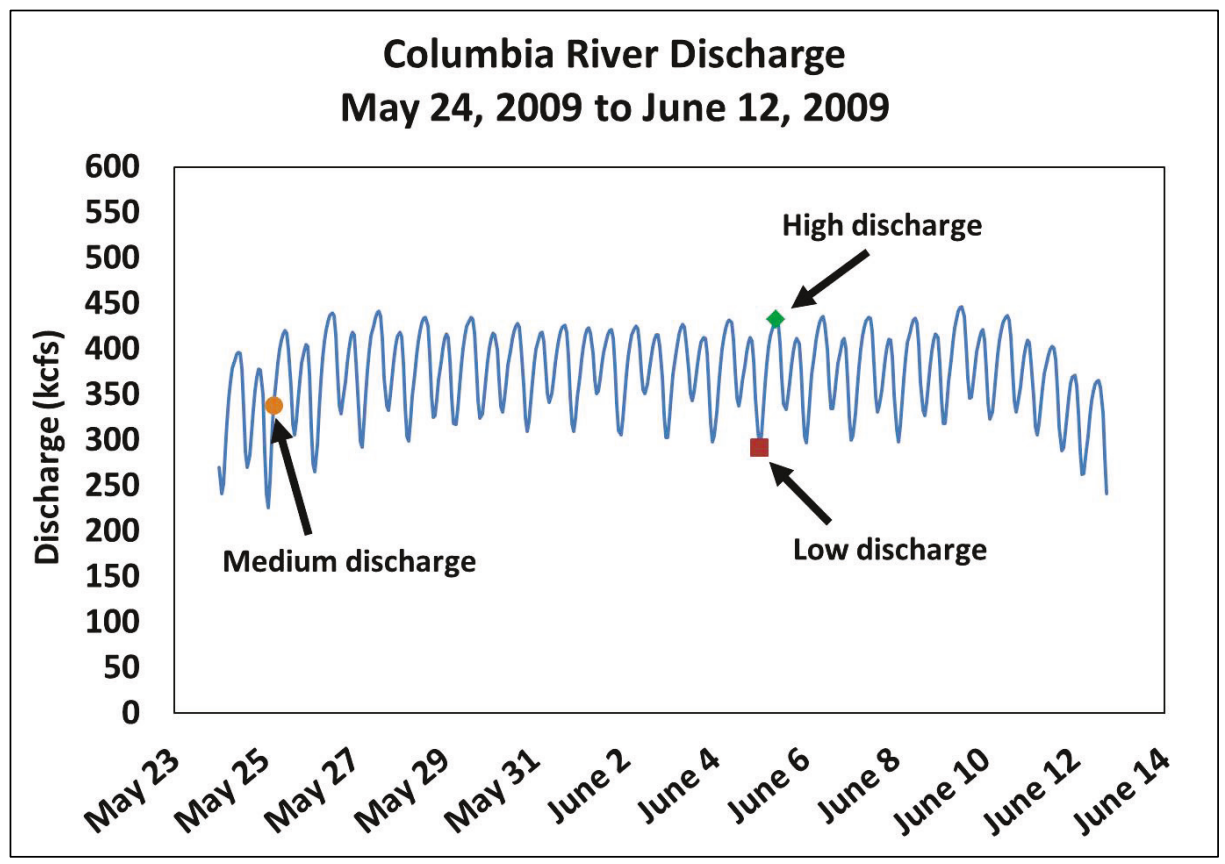




\subsubsection{Inflow}

A velocity is assigned directly to each node on the inflow boundary. Velocities for the nodes on the inflow boundary of the RANS-AdH mesh have been interpolated from the SW2-AdH flow solution using the $\mathrm{x}$ - and $y$-coordinate of each node. Assigning these velocities at the inflow ensures that the appropriate total discharge is used for each simulation.

\subsubsection{Outflow}

A hydrostatic pressure boundary condition is applied to the nodes located on the outflow boundary. This assigns a pressure, according to the elevation, corresponding to a previously determined water surface location. The water surface elevation along the outflow boundary for these simulations is taken from the water surface of the SW2-AdH simulation results. The water surface location is set before the simulations. The nodes along the top of the outflow boundary are assigned with a zero gauge pressure, and the remaining nodes on the outflow boundary are assigned the corresponding hydrostatic pressures. Near the outflow boundary the flow field is predominately hydrostatic, but near the dikes the flow is nonhydrostatic. To ensure that the assigned hydrostatic boundary condition at the outflow boundary does not unduly affect the flow near the dikes, the outflow boundary is located far from the dikes of interest.

\subsubsection{Water surface}

The water surface boundary is treated as a frictionless wall. This treatment is commonly referred to as fixed-lid. While the water surface is a freesurface, using a free-surface simulation for a $3 \mathrm{D}$ RANS-AdH simulation is difficult and time and cost prohibitive. Comparisons were made of simulations for a single-dike domain (for both the pile and rock dikes) to determine the difference in the flow solution based on the different boundary condition treatments of the water surface (free-surface and fixed-lid). The maximum difference in the water surface elevation between the free-surface and fixed-lid simulations is approximately $0.3 \mathrm{ft}$. The velocities of the free-surface and fixed-lid simulations are very similar. Using the results of this comparison of the flow solutions, the fixed-lid water surface treatment was selected to complete the study. Thus, all fourdike section simulations included in this report use fixed-lid simulations. A more-detailed description of the free-surface simulations with the 
single-dike simulation modeling process and results is included in Appendix C: Free Surface vs. Fixed-Lid Water Surface Treatment.

\subsubsection{Other no flux boundaries}

The remaining surfaces bounding the flow domain are the bathymetry, the dike bases, the piles (pile dike simulations only), and the northern and southern boundaries. The northern and southern boundaries are treated as frictionless walls since they are not rough (they are boundaries through the water) and there is no flow through them. For these boundaries, wall boundary conditions with skin friction coefficients are assigned values corresponding to the Manning's $n$ values used in the SW2-AdH simulations. Since the piles are not directly included in the SW2-AdH simulations, a skin friction coefficient corresponding to the wood they are built from is used. The friction values used in all simulations are listed in Table 3.

Table 3. Friction values used for each material.

\begin{tabular}{|l|l|}
\hline Material & Manning's $n$ \\
\hline Dike base & 0.045 \\
\hline Piles & 0.012 \\
\hline Sides & 0 \\
\hline Channel bathymetry & 0.025 \\
\hline
\end{tabular}

\subsection{Simulation procedure summary}

The simulation procedure for all six four-dike simulations (three different discharges tested on both pile and rock dikes) follows the process described in Chapter 2. An eddy viscosity of $0.00001 \mathrm{ft}^{2} / \mathrm{s}$ is used for the simulation results in this report. For all simulations, a refinement tolerance level between 0.04 and 0.05 and one level of adaptation are used. Because of the mesh size and the time required to reach a steadystate condition, the results reported are steady-state behavior after mesh adaptation had been employed.

The simulations for each discharge/dike type combination use 648 processors located on the ERDC Department of Defense Supercomputing Resource Center machine Topaz. A total of 150 hours of computational time and 97,000 processor-hours computational power is needed to reach a final result for each simulation. 


\section{Numerical Model Results}

This chapter is divided into three separate subsections: the high discharge results, the medium discharge results, and the low discharge results. The figures in each of these sections are presented in the same order. The following section briefly describes what is shown in each of the presented figures. Further discussion for each different discharge can be found at the beginning of each subsection. Each set of simulation results is presented via multiple contour plots at different depths in the flow domain.

The focus of the model results presented in this chapter is the velocity magnitude, $V$, which is defined as

$$
V=\sqrt{u^{2}+v^{2}+w^{2}}
$$

where:

$$
\begin{aligned}
u & =\mathrm{x} \text {-component of flow velocity } \\
v & =\mathrm{y} \text {-component of flow velocity } \\
w & =\mathrm{z} \text {-component of flow velocity. }
\end{aligned}
$$

Contour plots of the velocity magnitude with vectors indicating the flow direction are provided. Plots are also provided to show the difference between near-dike flow behavior for both pile dikes and rock dikes. Plots representative of the flow solutions are included and discussed in this chapter. Additional plots are included with a brief discussion in Appendix D: Additional Flow Solution Images.

The flow solutions include the area from Dike 70.35 through Dike 69.51. Flow velocities upstream of the Dike 70.35 are disregarded because the inflow velocities were specified from the SW2-AdH study's depth-averaged values, and the $3 \mathrm{D}$ flow behavior is not fully developed upstream of that dike. The flow solution near the inflow boundary is not representative of what would appear in the prototype, so flow velocities in the model upstream of Dike 70.35 are ignored. Similarly, the simulation cannot model flow obstructions that lie downstream of the outflow boundary, so the effects of those obstructions are not included. Therefore, the flow velocities in the model downstream of Dike 69.51 are also ignored. 
The figures of the flow results presented in the following sections are representative of the entire flow solution and give insights into the flow behavior caused by each type of dike to help determine if rock dikes can be used as an alternative to the pile dikes. A flow arrow is included in each figure to indicate the direction of the flow. For all figures except the last two figures in each subsection, the top image shows the pile dike results, and the bottom image has the rock dike results.

The last two images in each subsection show the differences in velocity magnitudes between the pile and rock dike flow solutions. For these plots, the velocity magnitude at specific locations for the pile dike simulation has been subtracted from corresponding velocity magnitude for the rock dike simulation. Positive velocity magnitude differences indicate that the rock dikes yield higher velocity magnitudes at that location whereas negative velocity magnitude differences indicate that the pile dikes yield higher velocity magnitudes. To further highlight the differences in the velocity magnitudes between the pile and rock dikes, the areas where velocity magnitude differences are less than $0.5 \mathrm{ft} / \mathrm{s}$ are excluded from the plot. Therefore, the areas that remain colored are the areas that are most affected by the change from pile to rock dikes. In the discussion of each flow solution, the figures that have these small differences in velocity magnitudes removed are referred to as the extreme velocity magnitude difference plots. In those figures, the top image shows the velocity magnitude differences at the water surface while the bottom image shows the velocity magnitude differences at the bed.

Figures showing how the flow varies in the planwise dimensions of the flow domain and figures that show the vertical variation of flow are included in each subsection. These vertical variations are indicated by showing flow velocities along five slices through the flow domain. These slices, which are located both along and between dikes, are shown in Figure 28. Supplemental figures of each flow simulation are available in Appendix D: Additional Flow Solution Images. 
Figure 28. Cottonwood Island locations of vertical slices showing velocity magnitude.

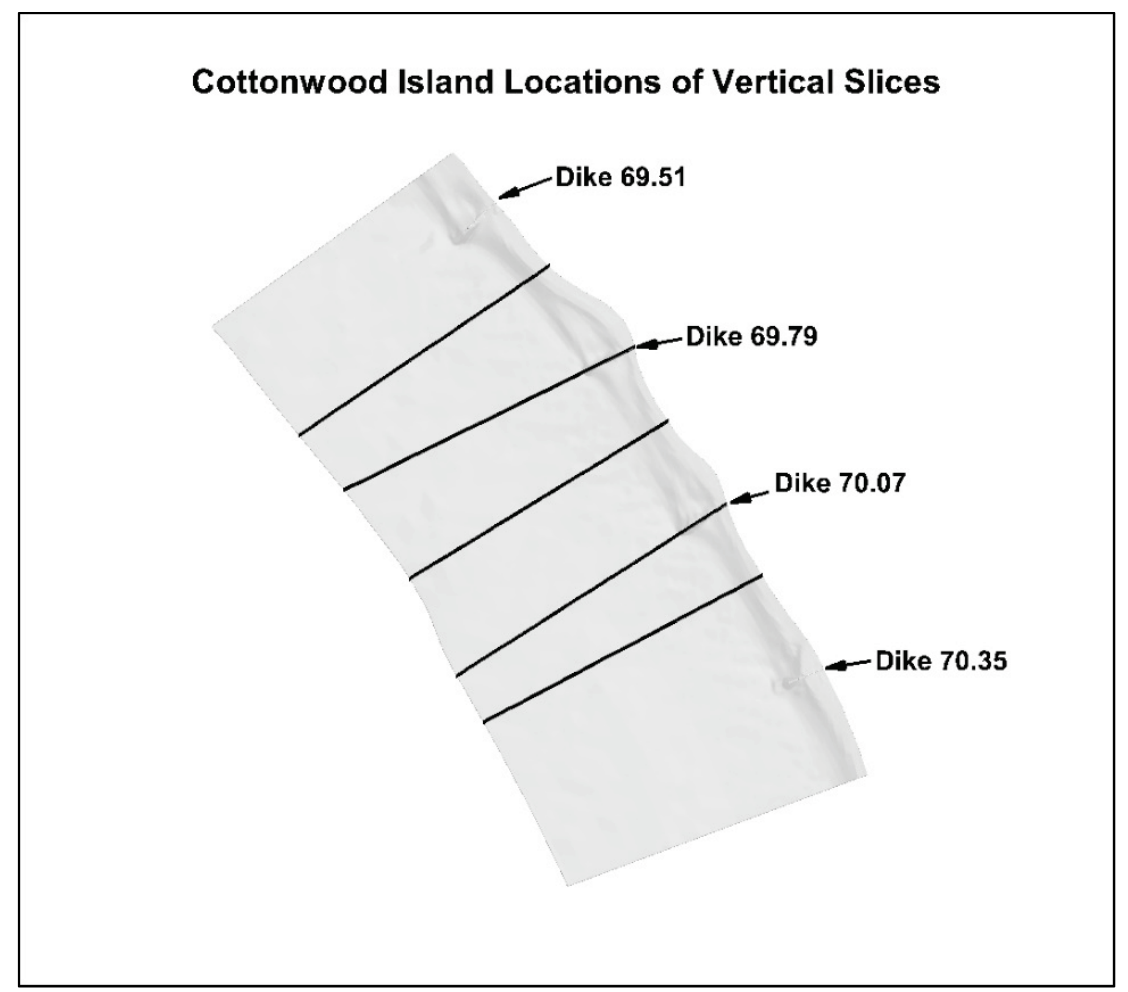

\subsection{High discharge}

The results for the high-discharge $(432,811 \mathrm{cfs})$ model are shown in Figure 29 through Figure 40. The velocity magnitudes at the water surface for both the pile dike and rock dike simulations are shown in Figure 29 and Figure 30. Figure 29 includes the entire flow domain while Figure 30 focuses on the area downstream of Dikes 70.35 and 70.07. The velocity magnitudes at the water surface in the deep parts of the flow domain downstream of Dike 70.35 are above $4.5 \mathrm{ft} / \mathrm{s}$ for the pile dikes and rock dikes. The most significant difference in the flow behavior at the water surface between the two types of dikes is between consecutive dikes. The pile dikes produce lower velocity magnitudes $\left(0.5^{-1.5} \mathrm{ft} / \mathrm{s}\right)$ near the shore (along the northern boundary of the flow domain) than the rock dikes, which produce velocities up to $4.0 \mathrm{ft} / \mathrm{s}$. These two flow behaviors are expected given the geometry of each dike. The piles for the pile dikes extend to the water surface itself, which means that a flow obstruction is present at the water surface. However, the rock dikes are completely submerged, allowing the water at the surface to flow more quickly. 
Figure 29. High discharge full domain water surface velocity magnitude comparison.

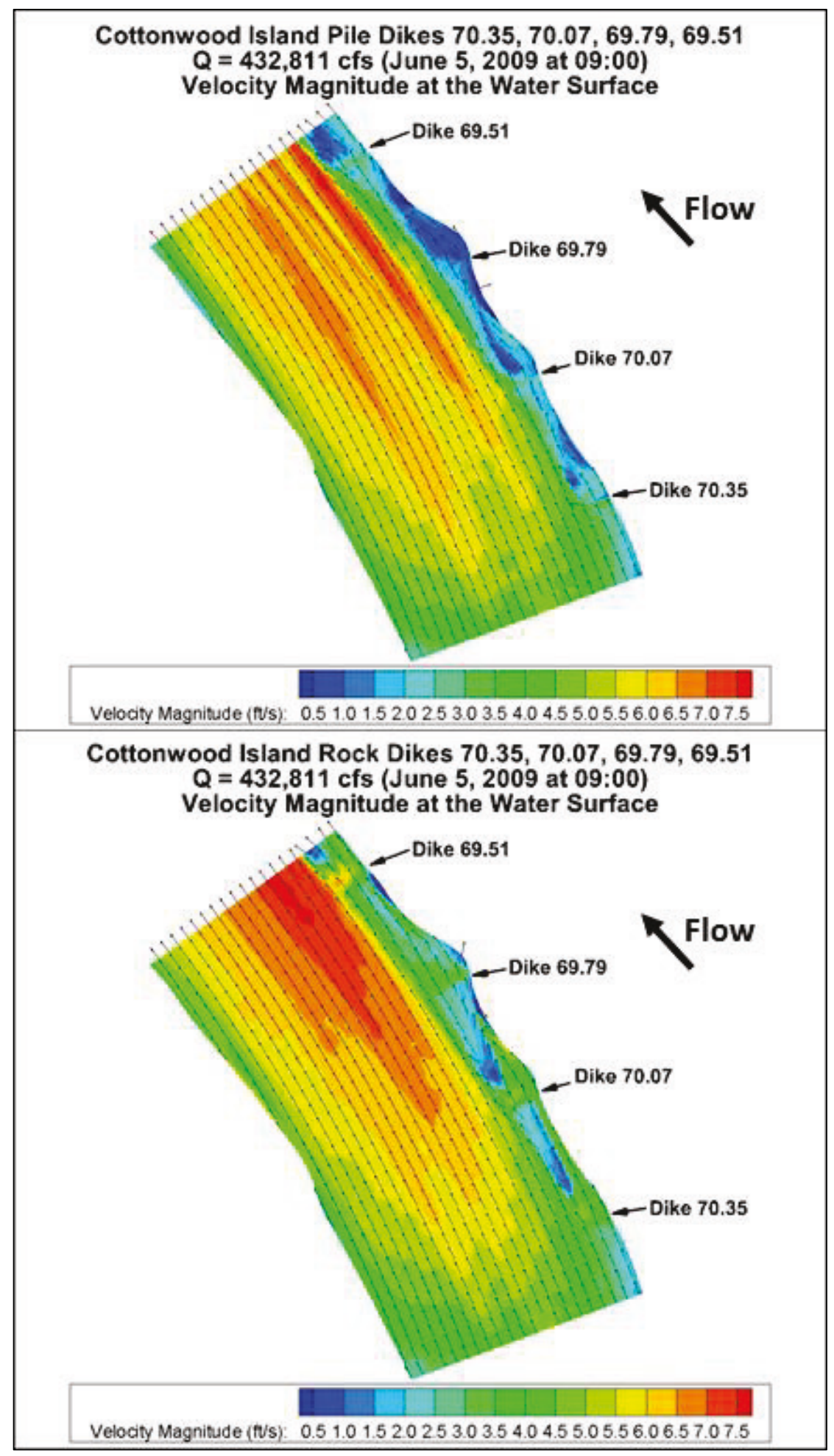


Figure 30. High discharge upstream zoom water surface velocity magnitude comparison.

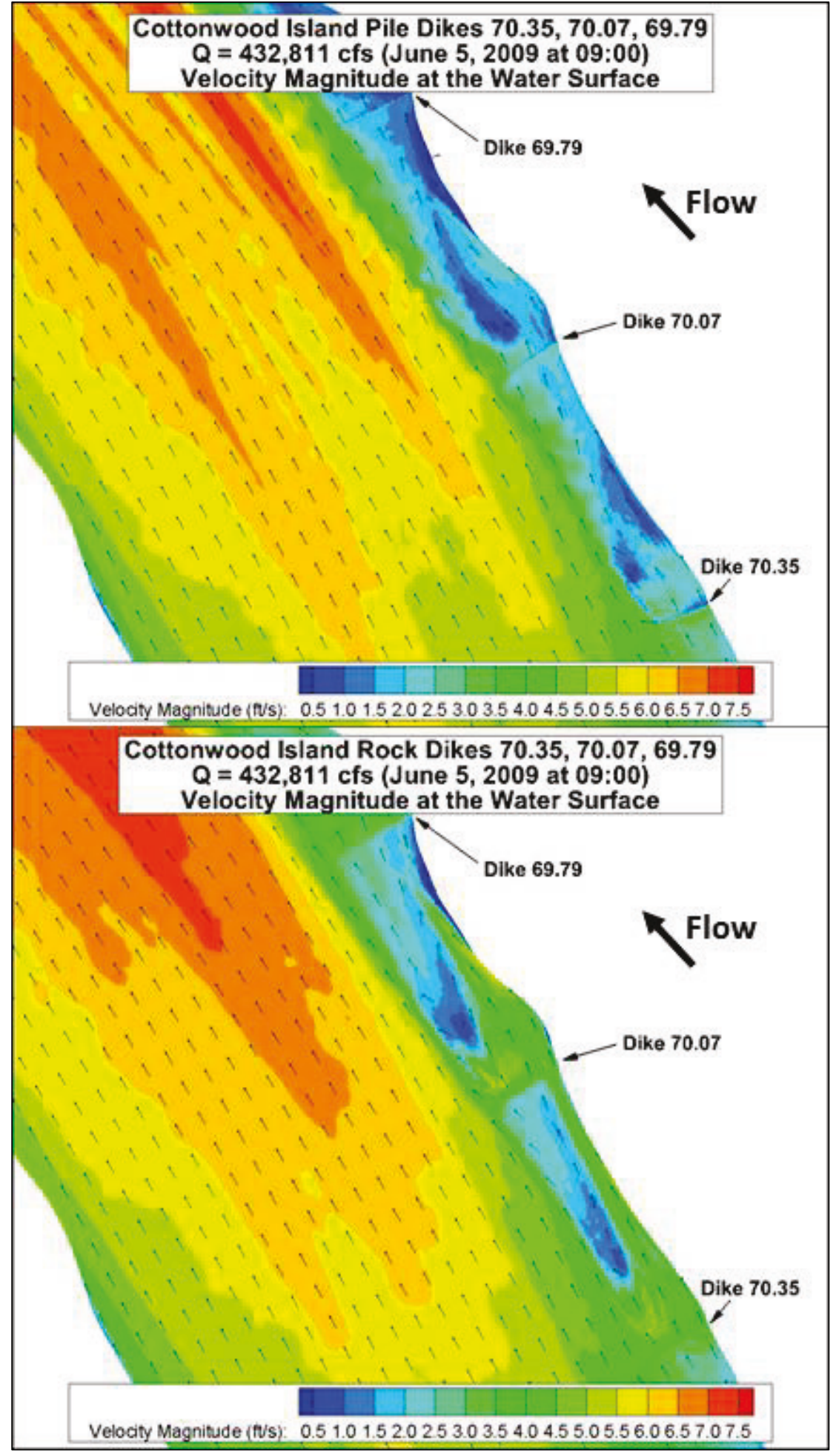


Figure 31 through Figure 34 show the flow velocity magnitudes at a $10 \mathrm{ft}$ depth in the flow domain. At this depth, the flow behaviors produced by the pile dikes and by the rock dikes are very similar. The navigation channel and deeper areas have flow velocities between 5.0 and $7.5 \mathrm{ft} / \mathrm{s}$ downstream of Dike 70.07. Immediately downstream of each dike, velocity magnitudes of 0.5 to $1.0 \mathrm{ft} / \mathrm{s}$ are common. The rock dikes produce higher flow velocity magnitudes near the shore than the pile dikes. The flow direction is not significantly different between the pile dikes and the rock dikes. For both dike types, eddies are present immediately downstream of each dike. These eddies extend along the length of the dikes and approximately one-fourth of the distance between each dike. Figure 33 and Figure 34 are isometric views of the velocity magnitude contours at the $10 \mathrm{ft}$ depth including the bathymetry, which is shown in gray. These figures provide some insight into how flow is influenced by the dikes. The $10 \mathrm{ft}$ depth is below the dike base at the bank line end of the dike, so the velocity magnitudes at that depth are strongly affected by the dike base geometry. The top image of Figure 34 indicates where the highest-velocity flows are located relative to the end of the dikes. The navigation channel lies between the channel end of the dike and these highest-velocity areas. 
Figure 31. High discharge full domain $10 \mathrm{ft}$ depth velocity magnitude comparison.

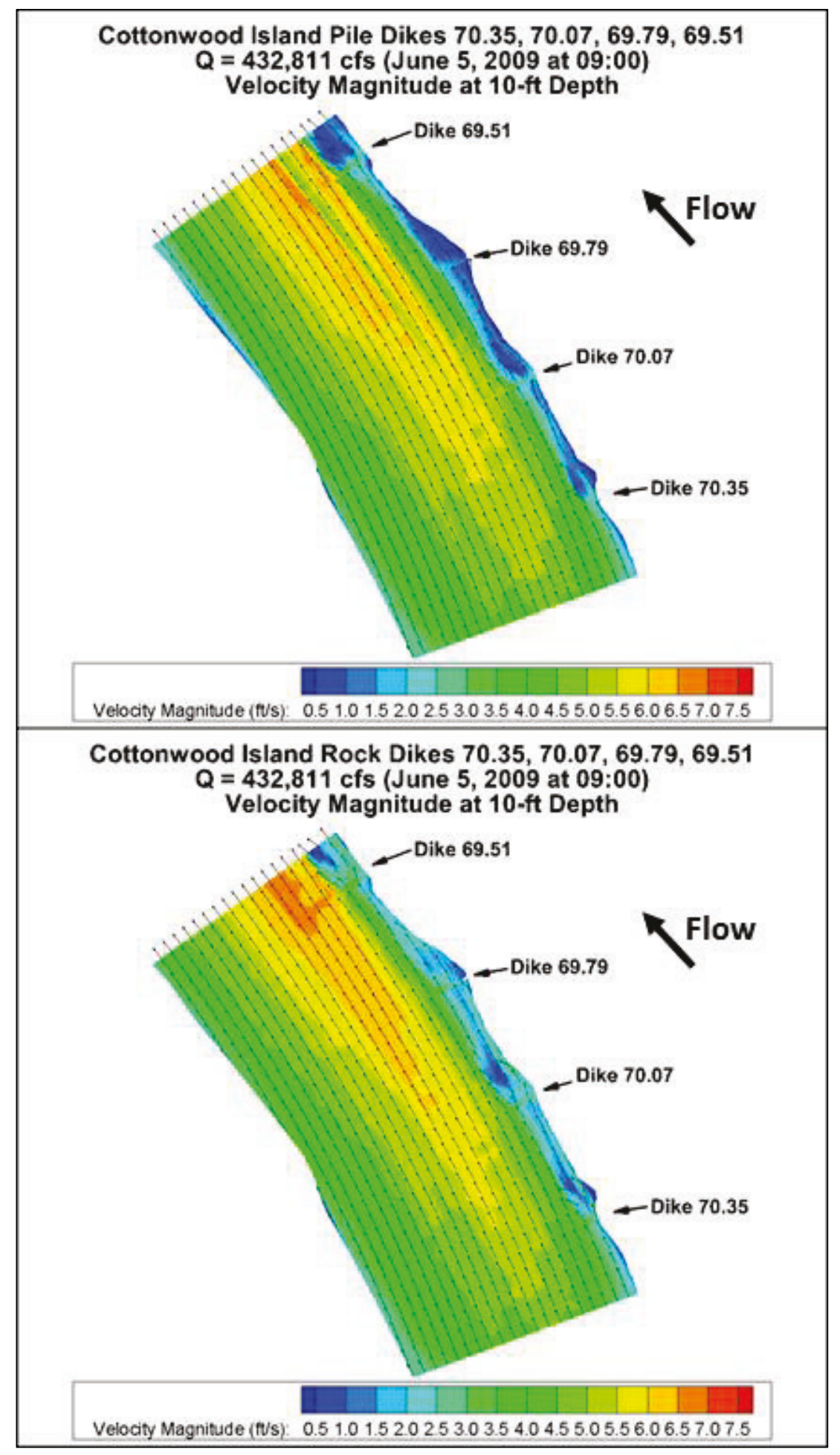


Figure 32. High discharge full domain $10 \mathrm{ft}$ depth velocity magnitude comparison.

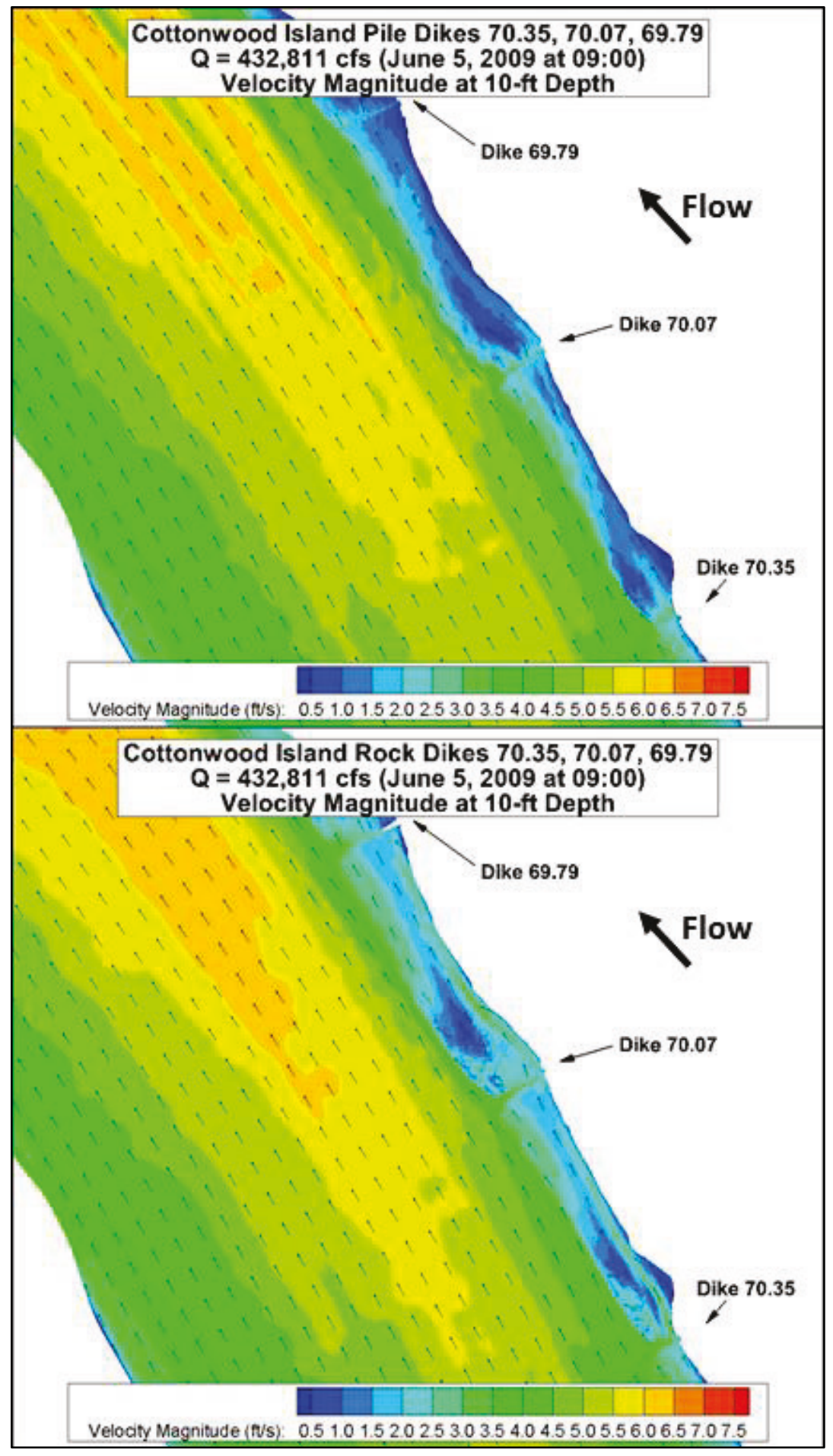


Figure 33. High discharge full domain $10 \mathrm{ft}$ depth velocity magnitude comparison - isometric.

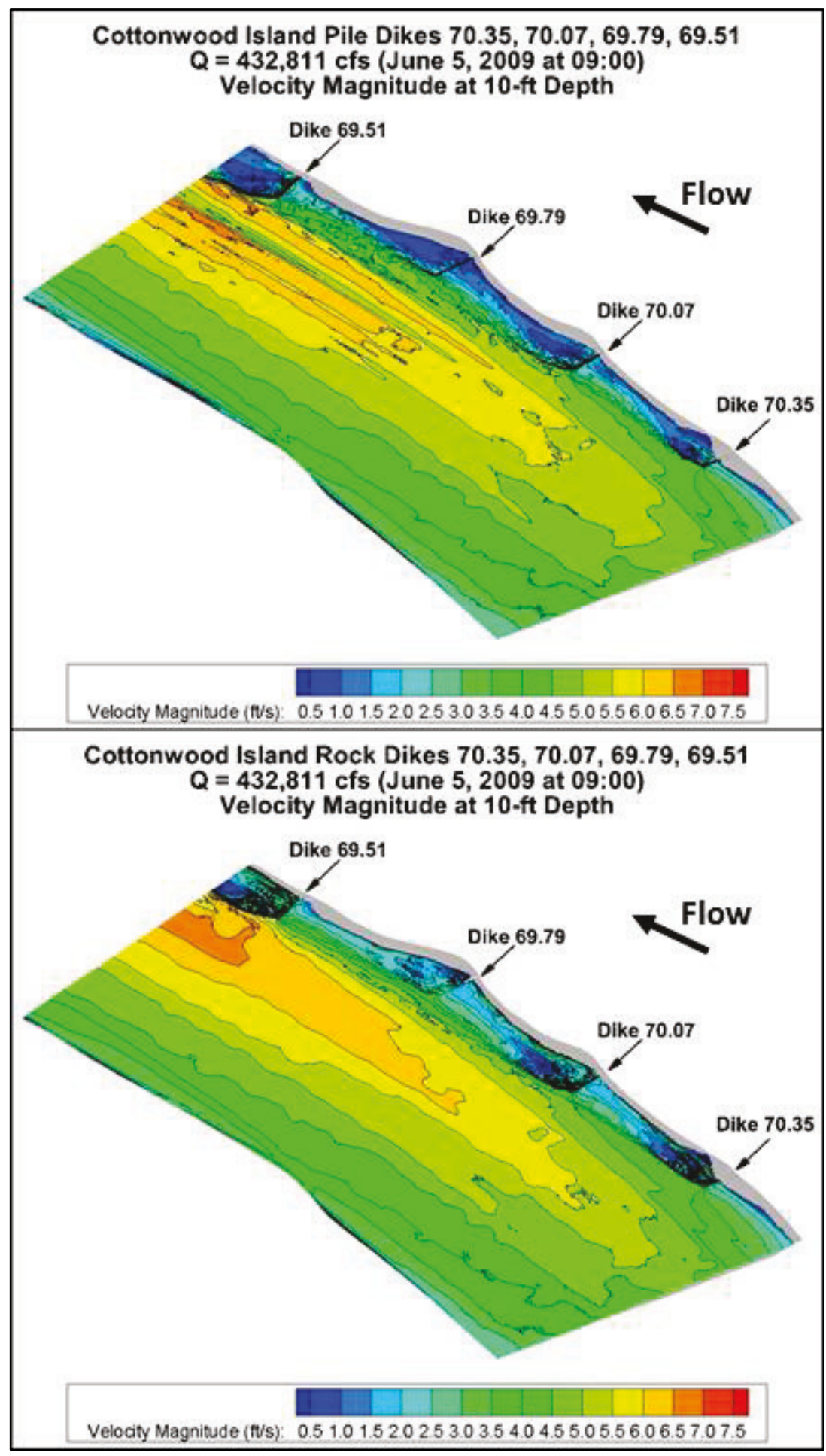


Figure 34. High-discharge velocity contours at $10 \mathrm{ft}$ depth around Dike 69.79.

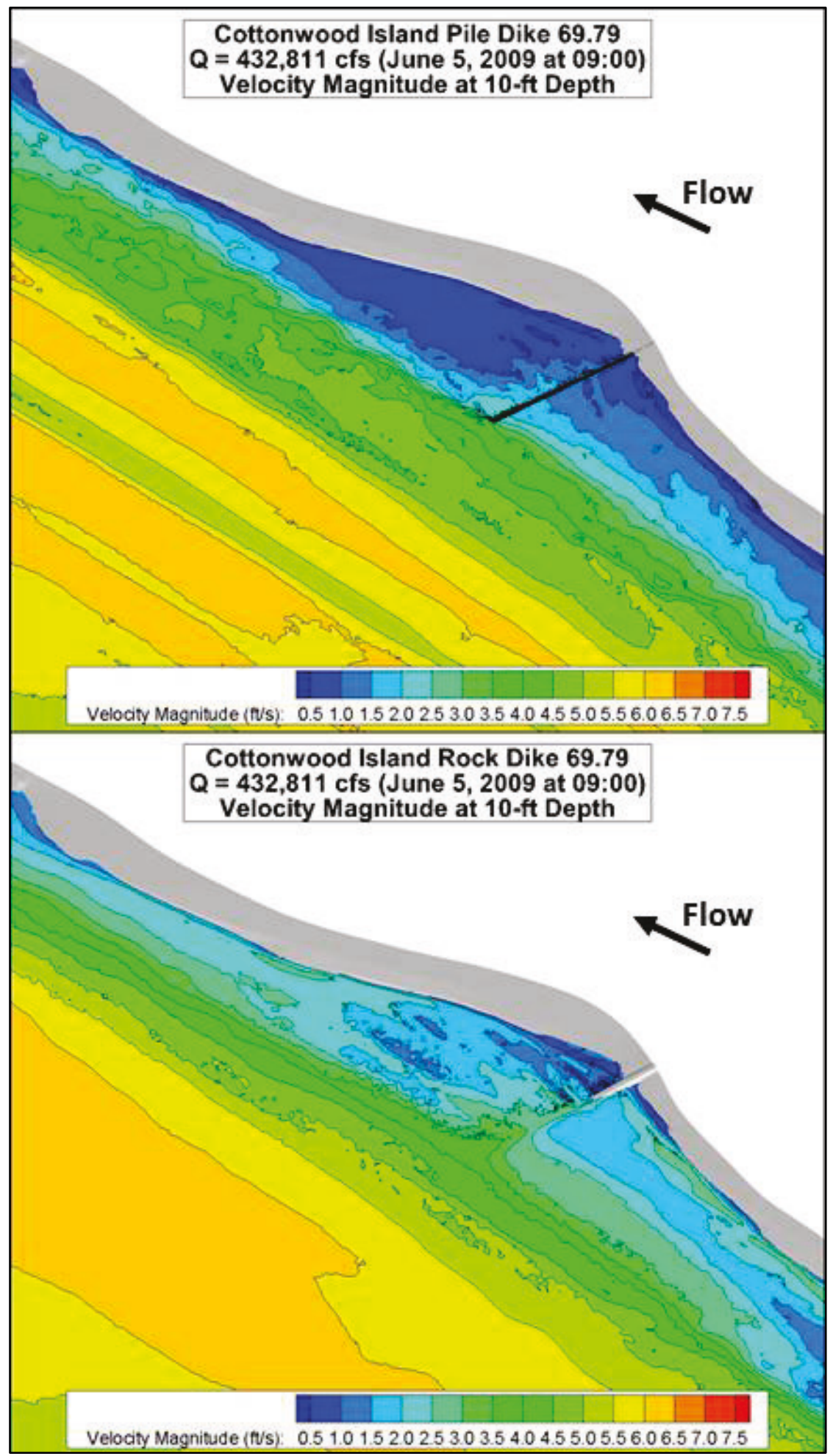


Flow magnitudes at five vertical locations within the pile and rock dike flow domains are shown in Figure 35 and Figure 36, respectively. The vertical direction is distorted by a factor of 5 to more clearly show the vertical variation in the shallow regions. In each figure, the northern bank line (where the dikes are located) is on the right side of the image. The pile dikes produce a more pronounced vertical variation in the flow velocities than the rock dikes. The pile dikes also produce lower velocities than the rock dikes very close to the dikes. With both dike types, the highest velocities are on the water surface, but the pile dikes produce slightly higher velocities (approximately 1.0-1.5 ft/s higher) in the navigation channel than the rock dikes. In the shallow areas along the northern bank line, the pile dikes show much less vertical variation with the velocity magnitudes than the rock dikes. 
Figure 35. Vertical slices of pile dike high discharge simulation.

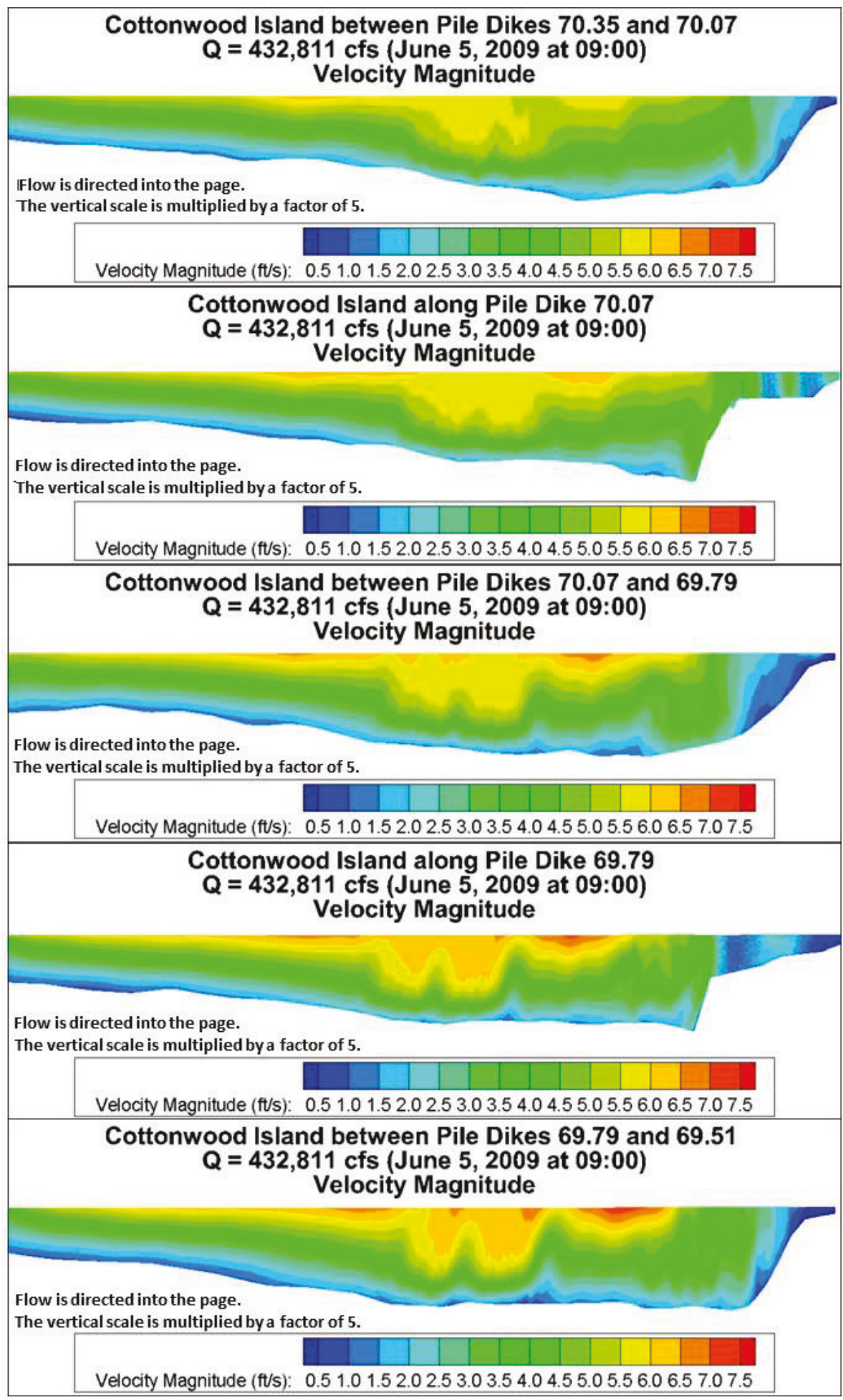


Figure 36. Vertical slices of rock dike high discharge simulation.

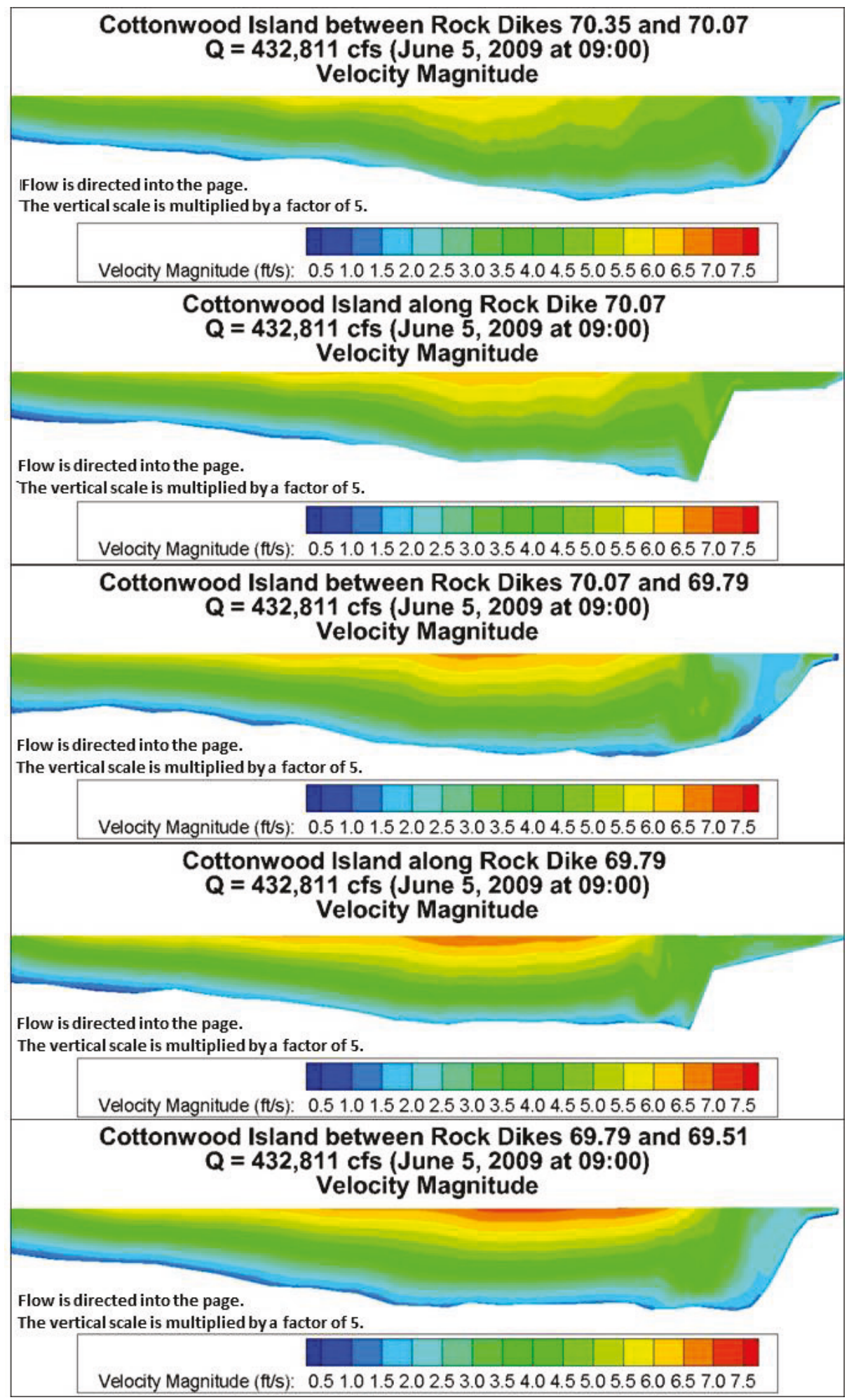


The velocity magnitude contours along the river bed at Dikes 69.79 and 70.07 are shown in Figure 37 and Figure 38, respectively. These are included to provide information relating to potential scour/deposition near the dikes. The velocity magnitudes near the bed immediately downstream of each dike are smaller than in the deeper areas of the flow domain - except downstream of the channel-end of each dike, which extends into the main channel area. At Dike 70.07, each dike type produces near-bed velocities up to $4.5 \mathrm{ft} / \mathrm{s}$ immediately downstream of the dike tip for approximately two-thirds of the distance to the next dike. The behavior is present with Dike 69.79 but is much less pronounced. The pile dikes tend to direct flow around its channel-end toward the main channel whereas the rock dikes direct some flow around the shore-end of the dike as well. The rock dikes induce more flow in the shallow areas between the dikes than do the pile dikes. Immediately downstream of the dike (for both types of dikes) and in the very shallow areas ( $\sim 5-7 \mathrm{ft}$ deep) near the northern bank line, the flow velocity near the bed is less than $0.5 \mathrm{ft} / \mathrm{s}$, making these shallow areas the most susceptible to sediment deposition that might occur in the flow domain. 
Figure 37 . High discharge Dike 70.07 bed velocity magnitude comparison - isometric.

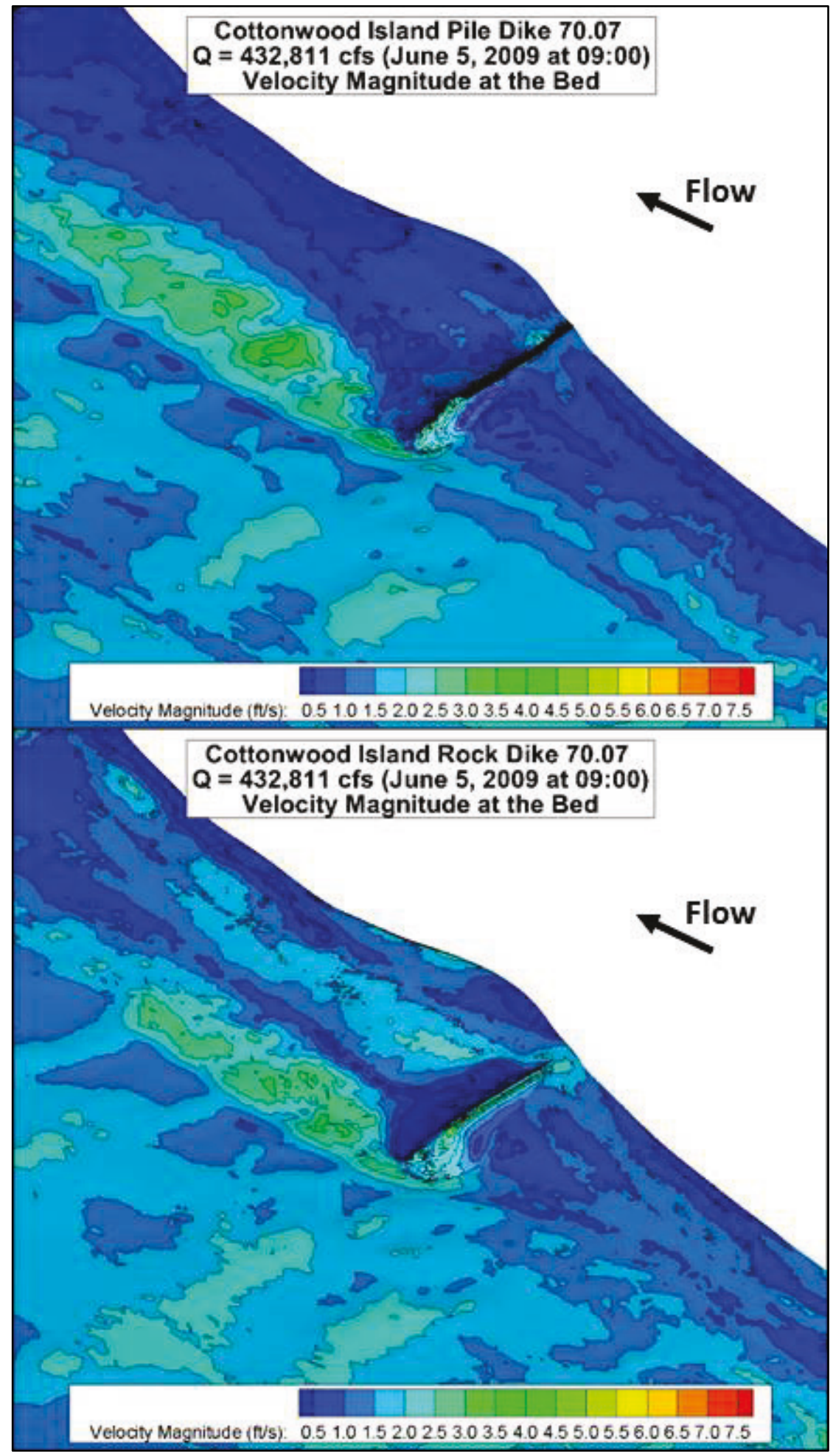


Figure 38. High discharge Dike 69.79 bed velocity magnitude comparison - isometric.

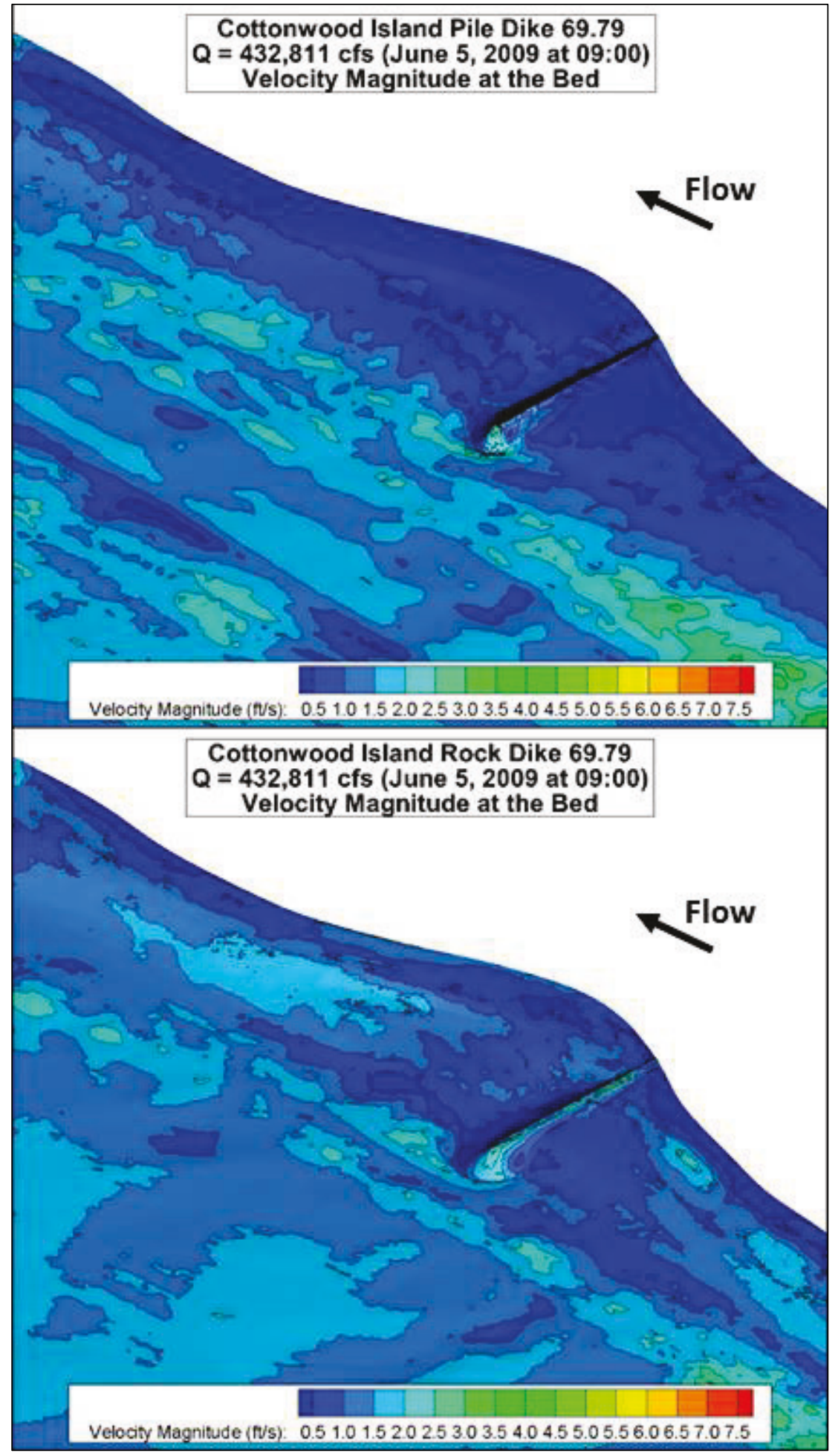


The velocity differences between the pile and rock dikes are shown in Figure 39 and Figure 40. The velocity magnitude differences range from 2 to $5 \mathrm{ft} / \mathrm{s}$. The differences between the pile dike and rock dike are much more significant at the water surface (top image) than at the bed (bottom image). The rock dikes have higher velocity magnitudes (approximately $2.0 \mathrm{ft} / \mathrm{s}$ higher) between the dikes at both the water surface and the bed. The pile dikes produce velocity magnitudes near the center of the main channel that are 1.0-1.5 ft/s higher than the rock dikes. These trends are caused by the pile dike piles extending up to the water surface whereas the rock dikes are fully submerged. The smaller velocity magnitude differences at the bed are expected because the pile and rock dikes are similarly shaped at the base. 
Figure 39. High discharge extreme difference velocity magnitude comparison.

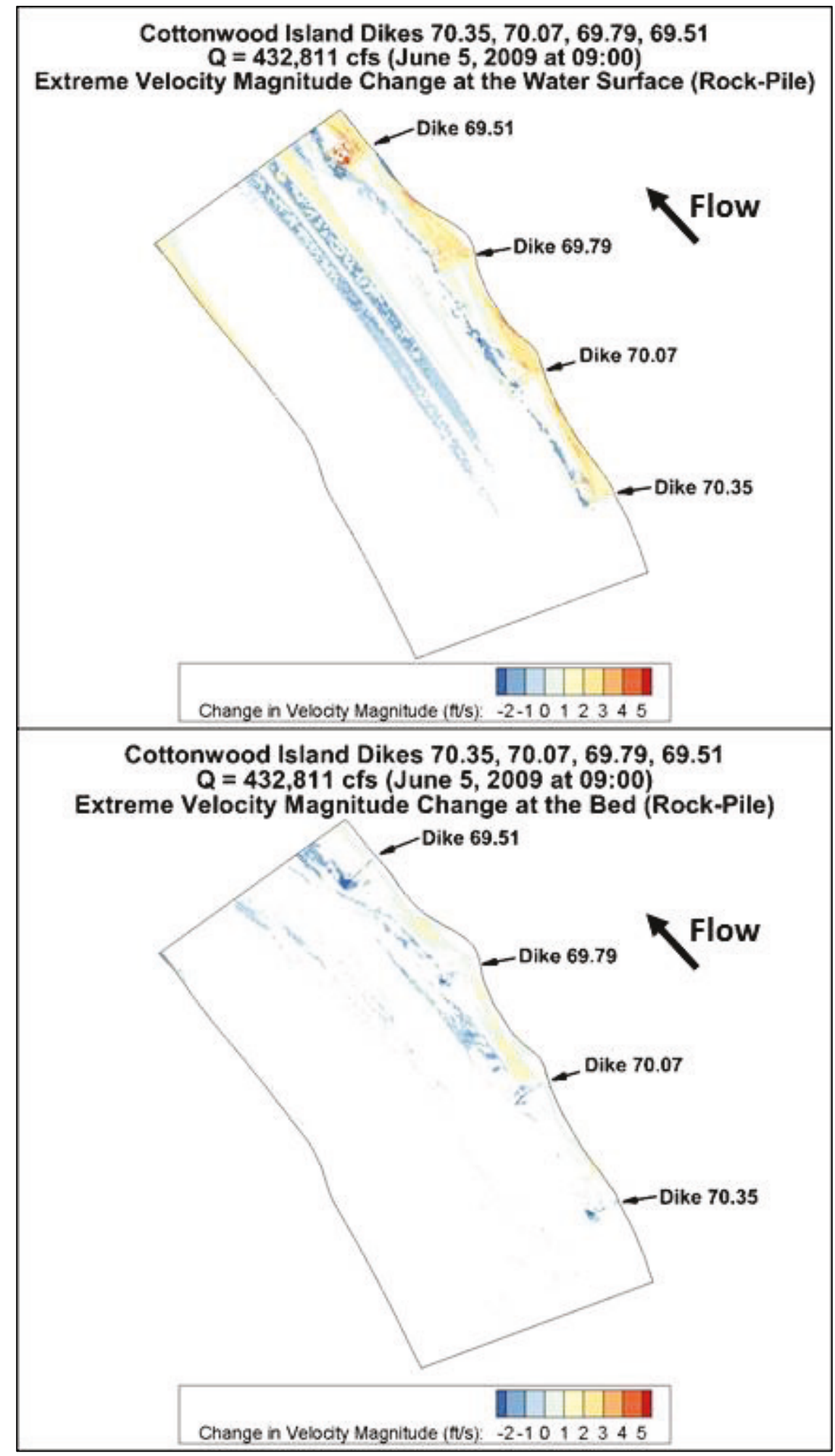


Figure 40. High discharge extreme difference velocity magnitude comparison.

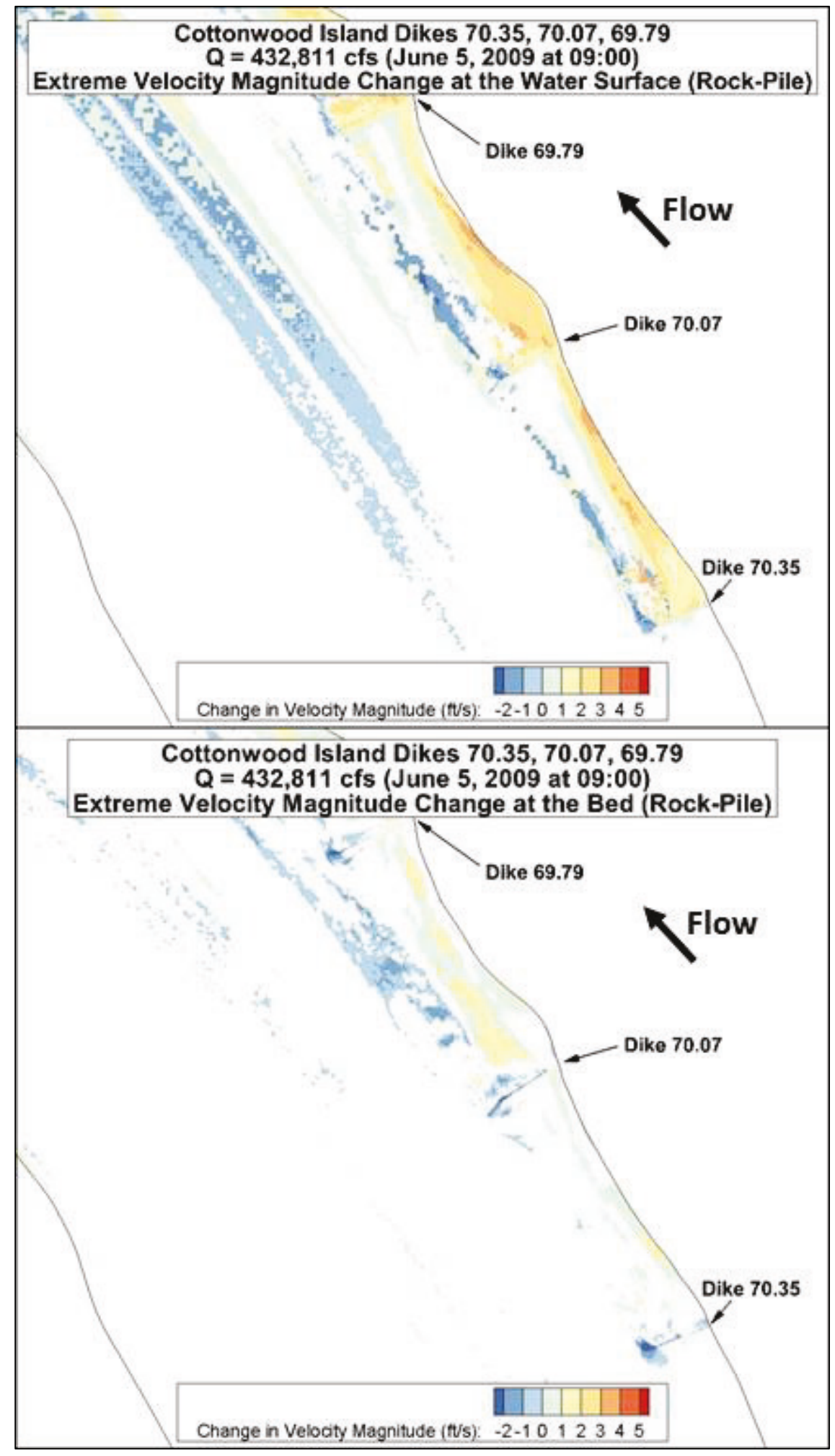




\subsection{Medium discharge}

The results for the medium-discharge (337,680 cfs) model are shown in Figure 41 through Figure 52 . The velocity magnitudes at the water surface for both the pile dike and rock dike simulations are shown in Figure 41. Figure 42 shows a magnified view of the area downstream of Dikes 70.35 and 70.07. The navigation channel and deeper areas downstream of Dike 70.07 have flow velocities above $3.5 \mathrm{ft} / \mathrm{s}$ for both the pile dikes and the rock dikes. The most significant differences between the pile dike and rock dike velocities occur at and between the dikes at the water surface. The pile dikes produce a lower flow velocity magnitude $\left(0.5^{-1.5} \mathrm{ft} / \mathrm{s}\right)$ near the northern boundary than the rock dikes (up to $4.0 \mathrm{ft} / \mathrm{s}$ ). The different geometries of the rock dikes and the pile dikes account for these differences in magnitude. The pile dike piles extend to the water surface, which causes a flow obstruction and slow the flow. The rock dikes are completely submerged and do not impede flow along the water surface. 
Figure 41. Medium discharge full domain water surface velocity magnitude comparison.

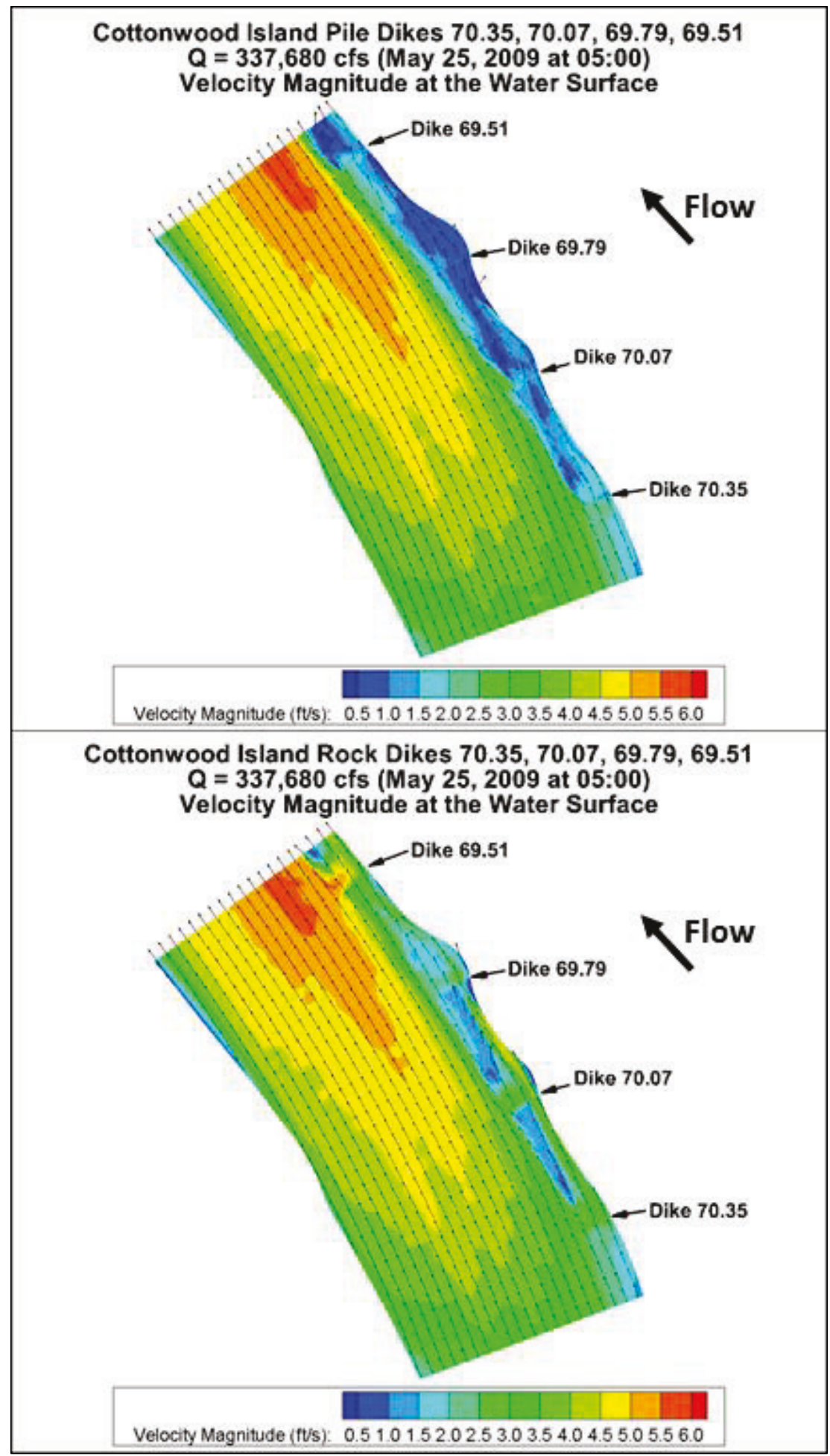


Figure 42. Medium discharge upstream zoom water surface velocity magnitude comparison.

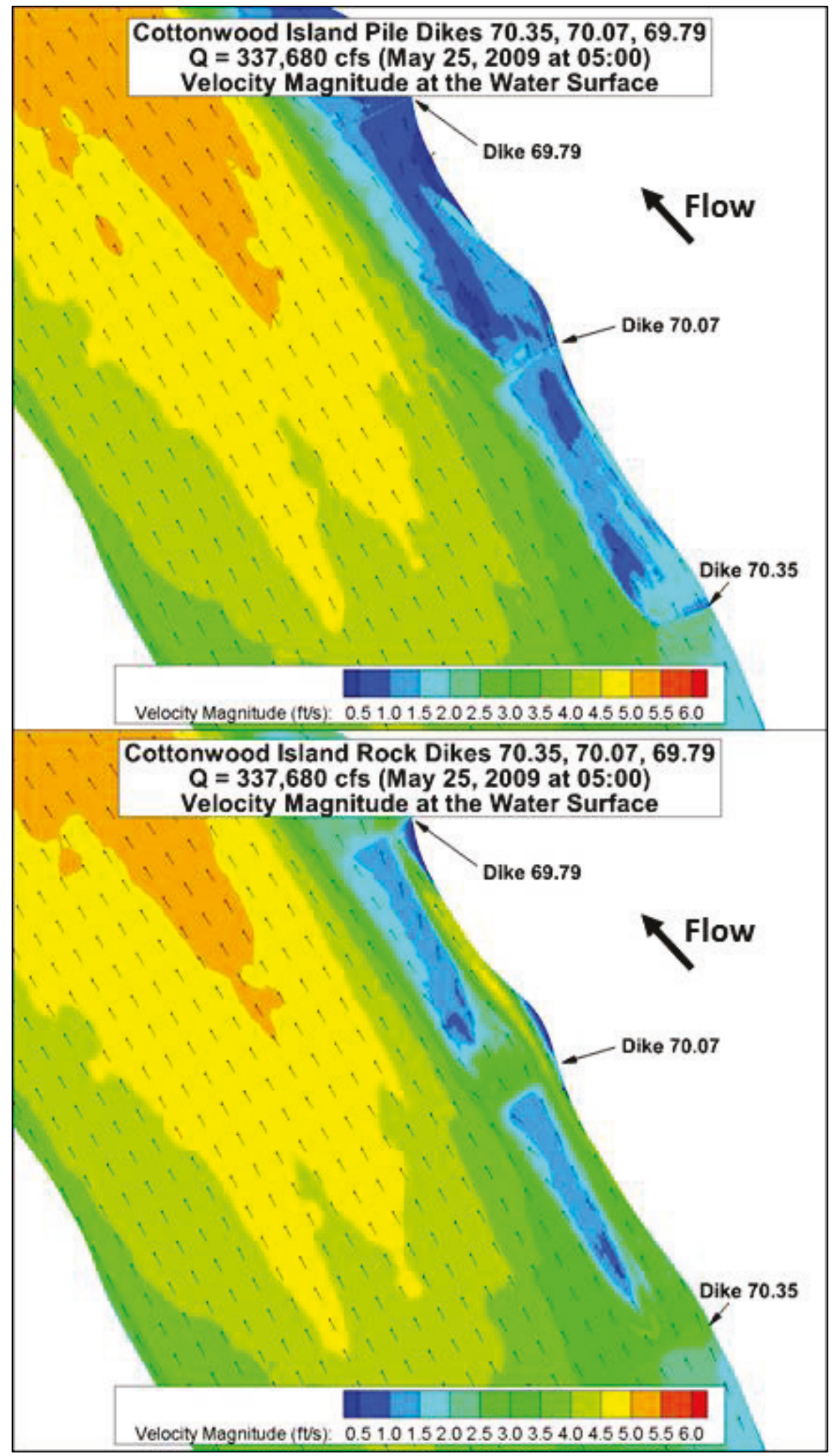


Flow velocity magnitudes at $10 \mathrm{ft}$ depth for the pile dike and rock dike simulations are shown in Figure 43 through Figure 46 . At $10 \mathrm{ft}$ depth, the flow behavior of the rock dikes and the pile dikes is similar. The velocity magnitudes at the water surface in the navigation channel and other deep parts of the flow domain downstream of Dike 70.35 are between 3.0 and $5.0 \mathrm{ft} / \mathrm{s}$ for both dike types. Velocity magnitudes are 0.5 to $1.0 \mathrm{ft} / \mathrm{s}$ immediately downstream of the dikes. Rock dikes produce higher velocity magnitudes near shore than the pile dikes. This flow variation can be expected with the differences in water surface obstruction caused by the piles. Overall, the flow direction is similar for both types of dikes. Pile dikes and rock dikes also show eddies immediately downstream of each dike. These eddies extend about a quarter of the distance between each dike and approximately the entire length of the dikes. Isometric views of velocity magnitude contours at $10 \mathrm{ft}$ depth can be seen in Figure 45 and Figure 46 . The bathymetry is shown in gray. These figures provide insight into how the flow is influenced by dikes. The $10 \mathrm{ft}$ depth falls below the dike base near the shore, so the velocity magnitudes show variance due to the different geometries. The top image of Figure 46 indicates how far the highest-velocity flows are located relative to the end of the dikes. The navigation channel lies between the channel end of the dike and these highest-velocity areas. 
Figure 43. Medium discharge full domain $10 \mathrm{ft}$ depth velocity magnitude comparison.

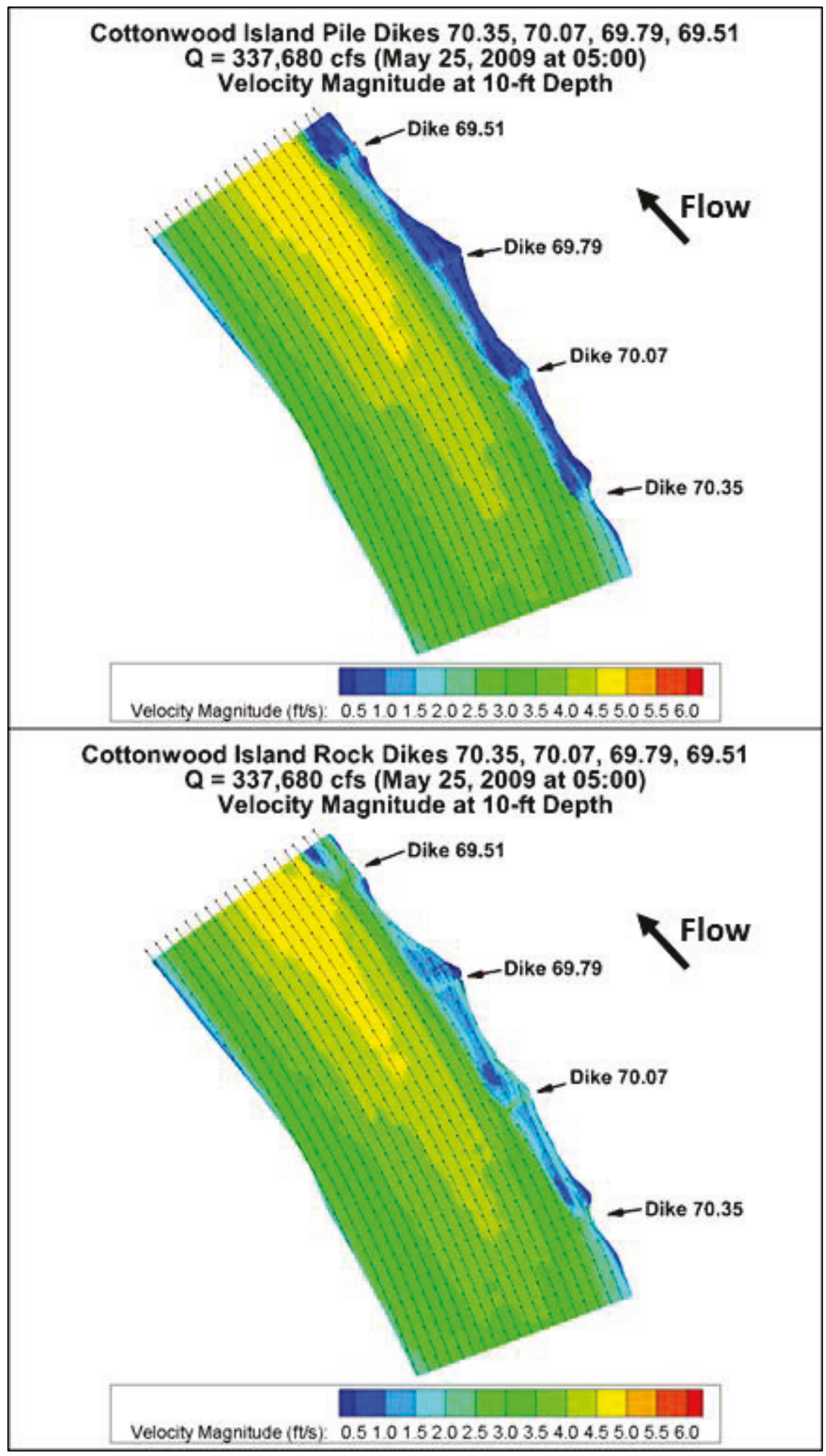


Figure 44. Medium discharge upstream zoom $10 \mathrm{ft}$ depth velocity magnitude comparison.

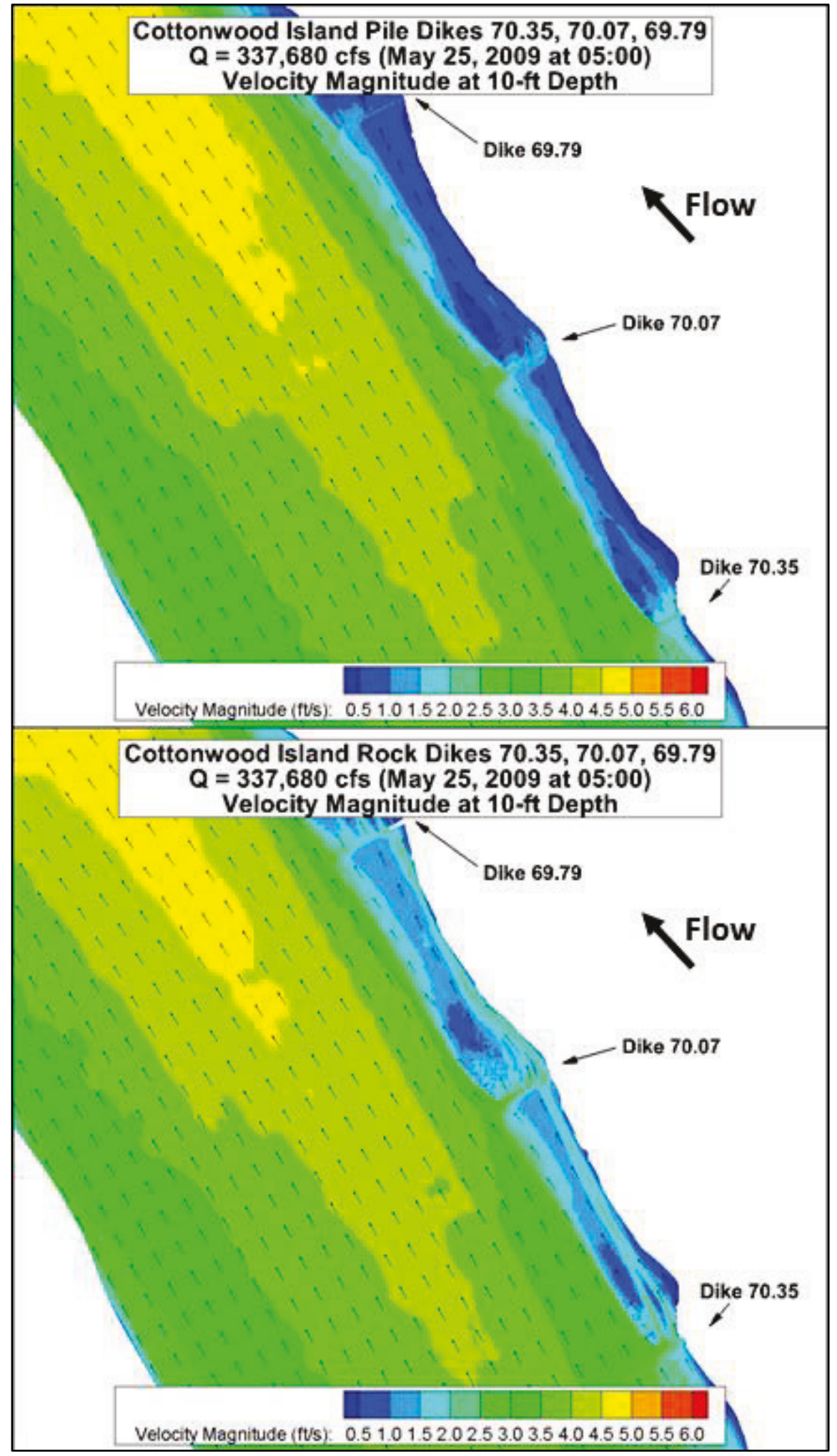


Figure 45. Medium discharge full domain $10 \mathrm{ft}$ depth velocity magnitude comparison - isometric.

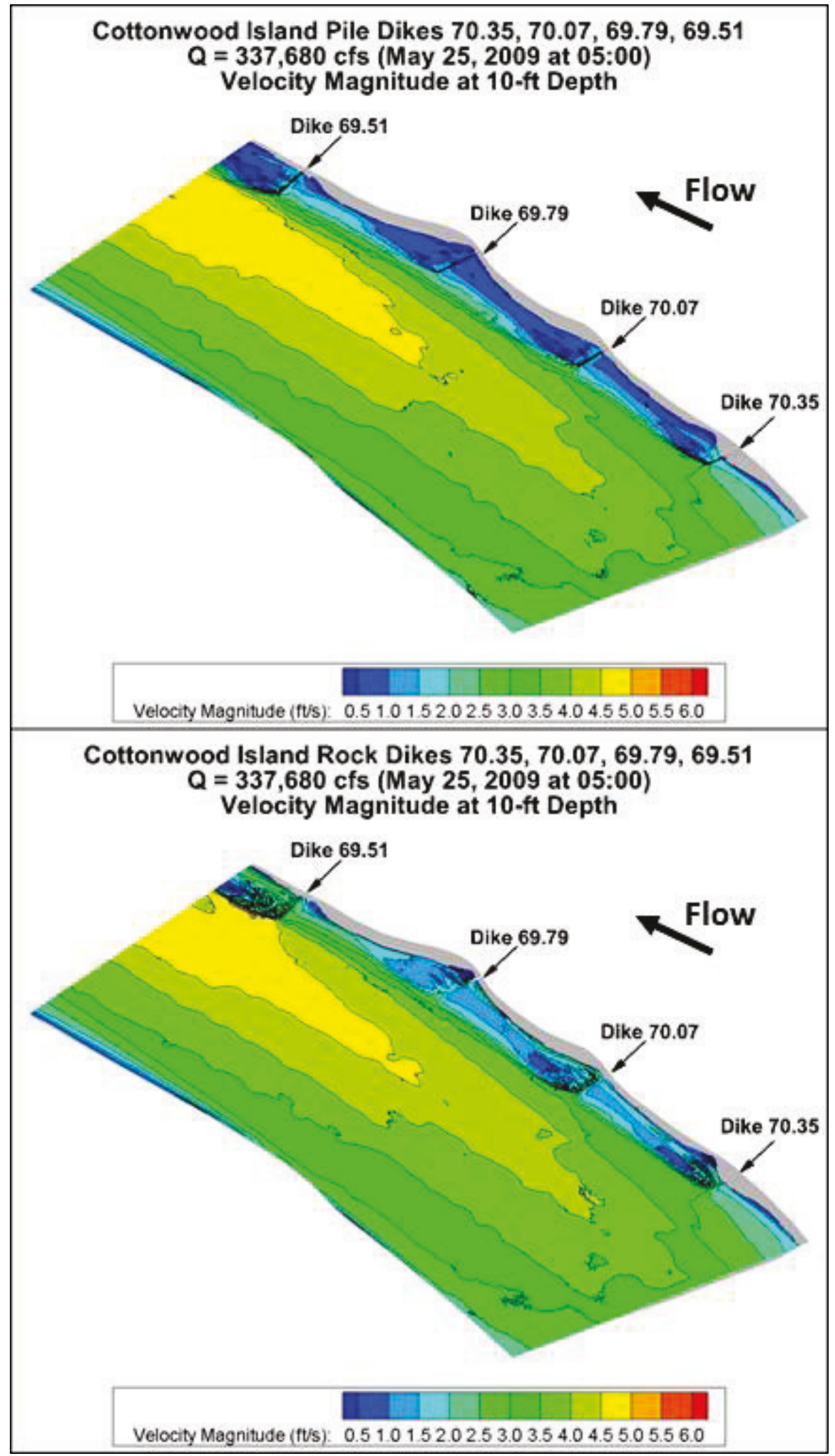


Figure 46. Medium discharge velocity contours at $10 \mathrm{ft}$ depth around Dike 69.79 - isometric.

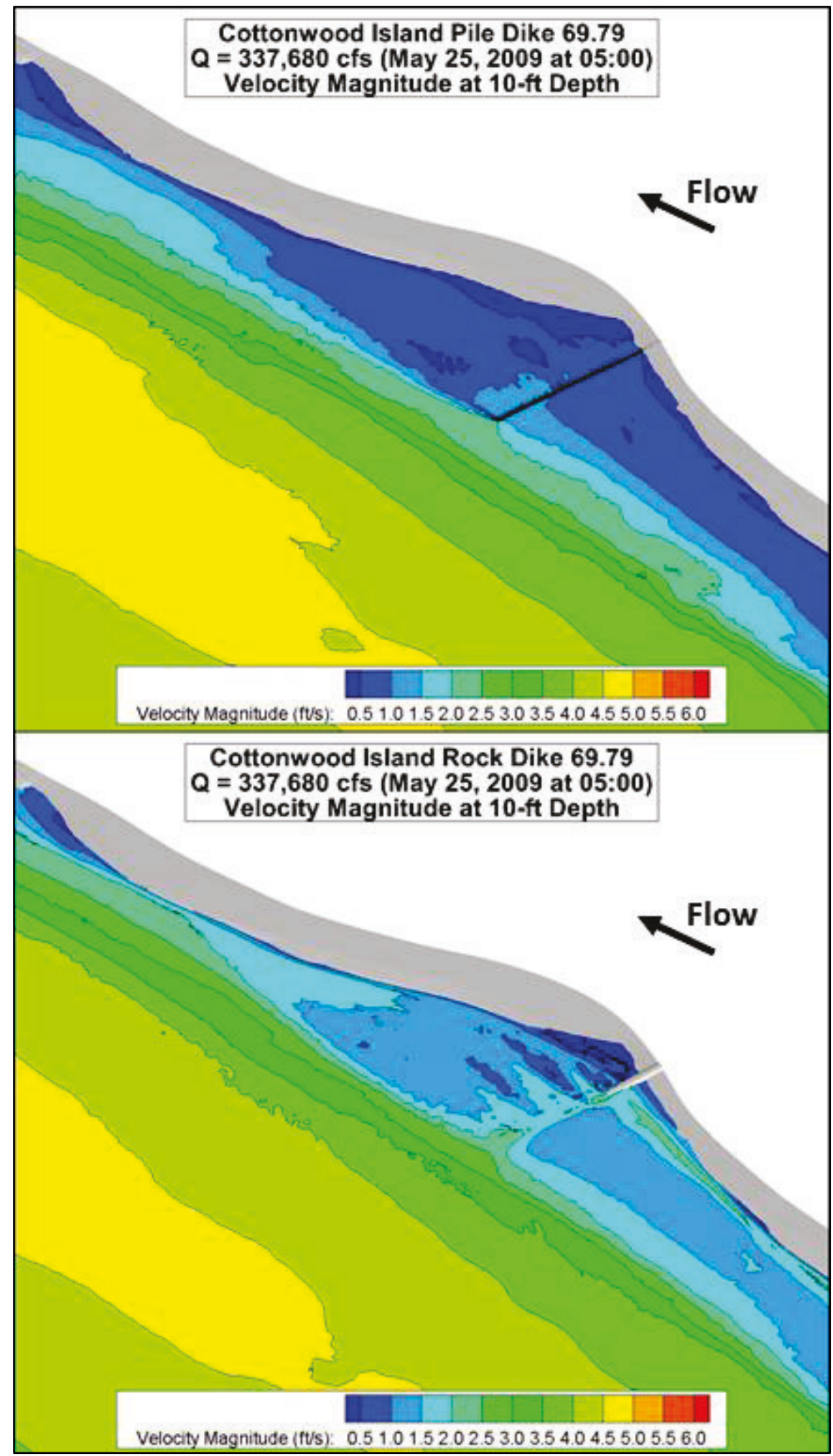


The flow magnitudes at five vertical locations within the pile and rock dike flow domains are shown in Figure 47 and Figure 48, respectively. The vertical direction has been distorted by a factor of 5 to more clearly show the vertical variation in the shallow regions. In each figure, the northern bank line (where the dikes are located) is on the right side of the images. The pile dikes produce a more pronounced vertical variation in the flow velocities than the rock dikes. The pile dikes also produce lower velocities close to the dikes. With both dike types, the highest velocities are at the water surface, and the dike types produce very similar flow velocities in the navigation channel. In the shallow areas along the northern bank line, the pile dikes show much less vertical variation with the velocity magnitudes than the rock dikes. 
Figure 47. Vertical slices of pile dike medium discharge simulation.

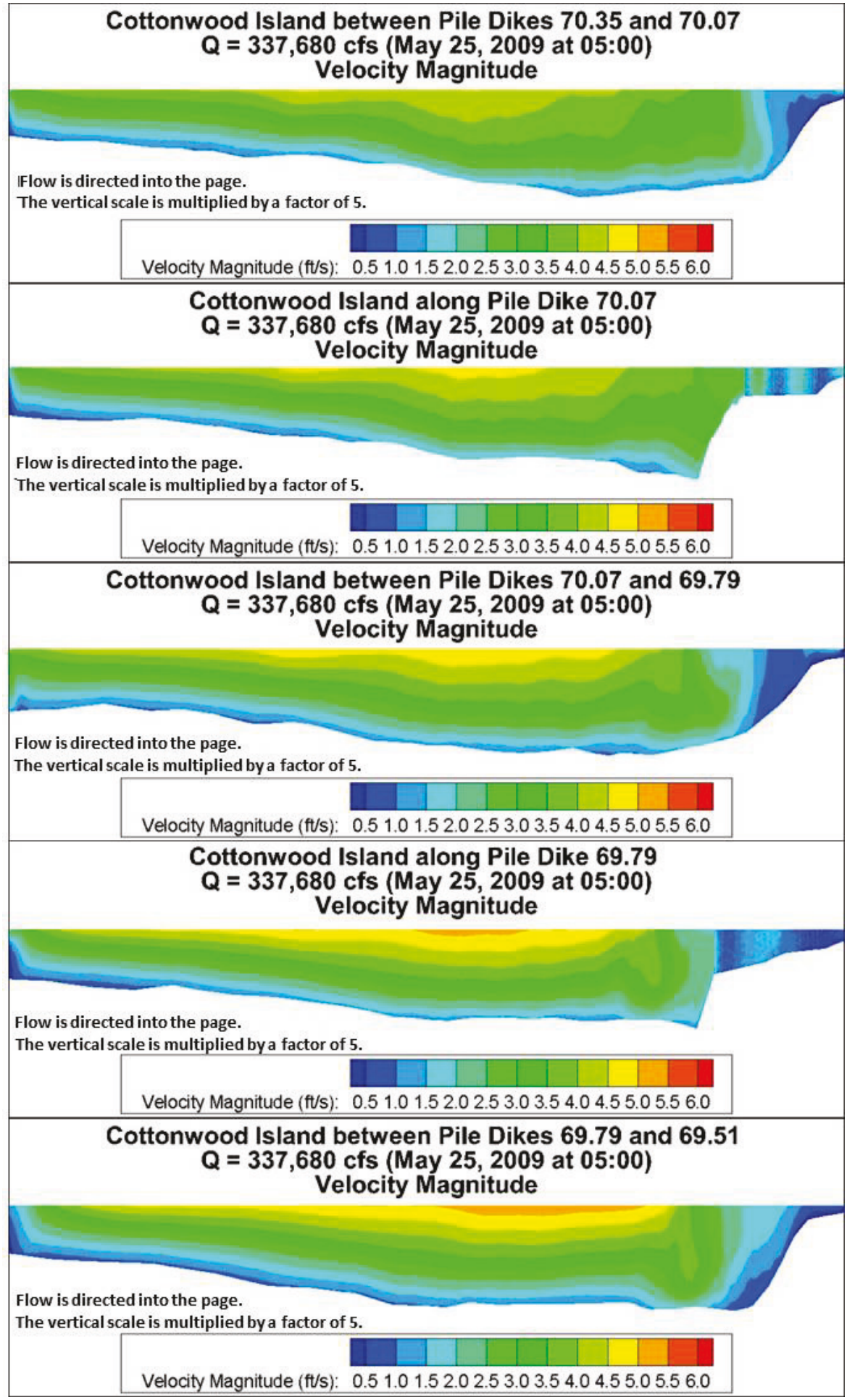


Figure 48. Vertical slices of rock dike medium discharge simulation.

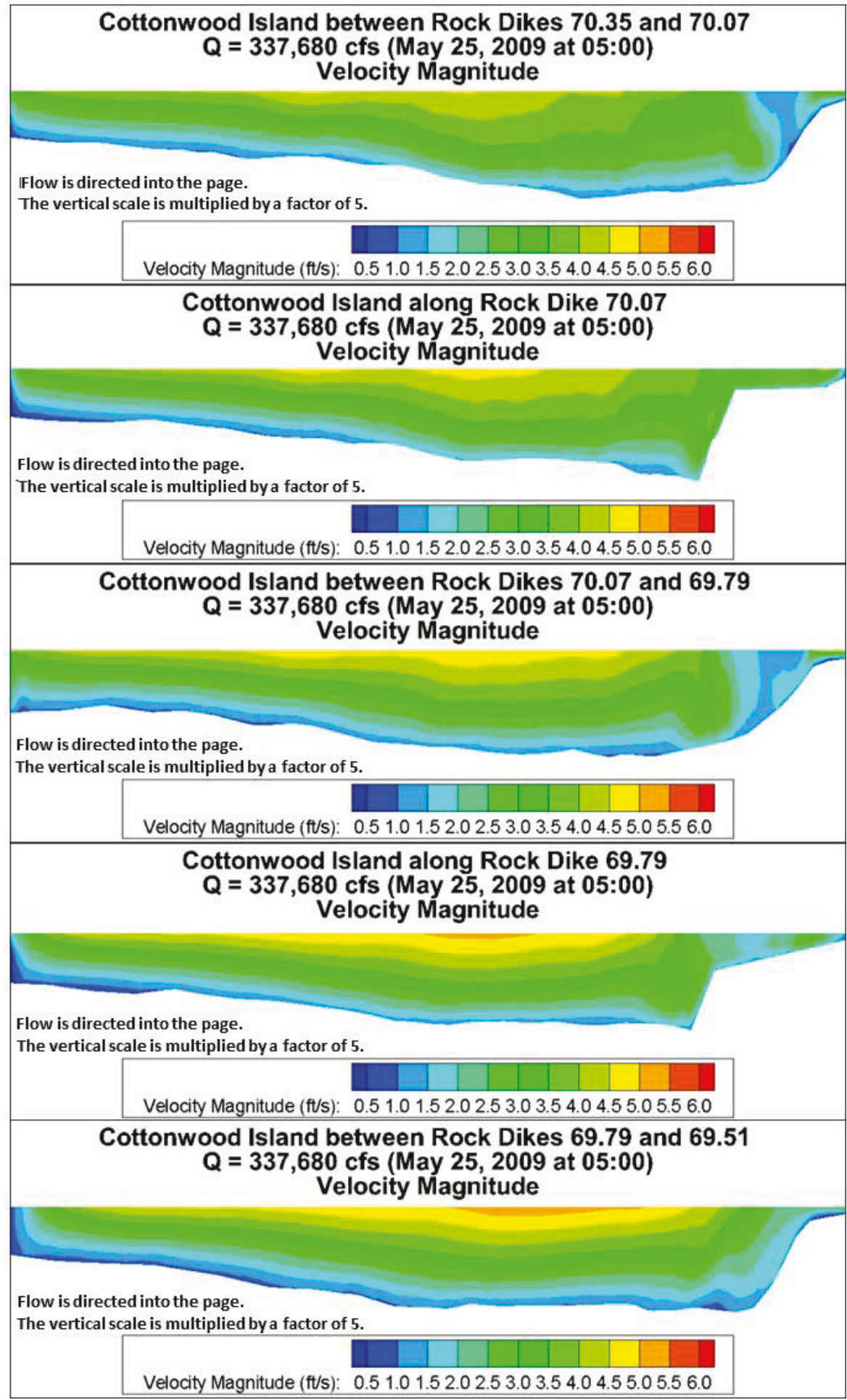


Figure 49 and Figure 50 show the velocity magnitude contours along the river bed near Dikes 69.79 and 70.07, respectively. The velocity magnitude contours at the bed provide insight about potential scouring near the dikes. The velocity magnitudes near the bed immediately downstream of the dikes are small except downstream of the channel-end tip of each dike. Both dike types produce relatively high near bed velocities (up to $2.3 \mathrm{ft} / \mathrm{s}$ ) immediately downstream of the channel-end tip of Dike 70.07 for about two-thirds of the distance to the next dike. At Dike 69.79, this behavior is also evident but is less pronounced. The rock dikes seem to direct some flow around the shoreend of the dike while the pile dikes tend to direct more of the flow around the channel-end of the dike. The rock dikes allow for noticeably more flow in the shallow areas between the dikes than the pile dikes. Sediment deposition is more likely to occur immediately downstream of both dike types and in the very shallow areas ( $\sim 5-7 \mathrm{ft}$ deep) near the northern bank line since the flow velocity near the bed is less than $0.5 \mathrm{ft} / \mathrm{s}$. 
Figure 49. Medium discharge Dike 70.07 bed velocity magnitude comparison - isometric.

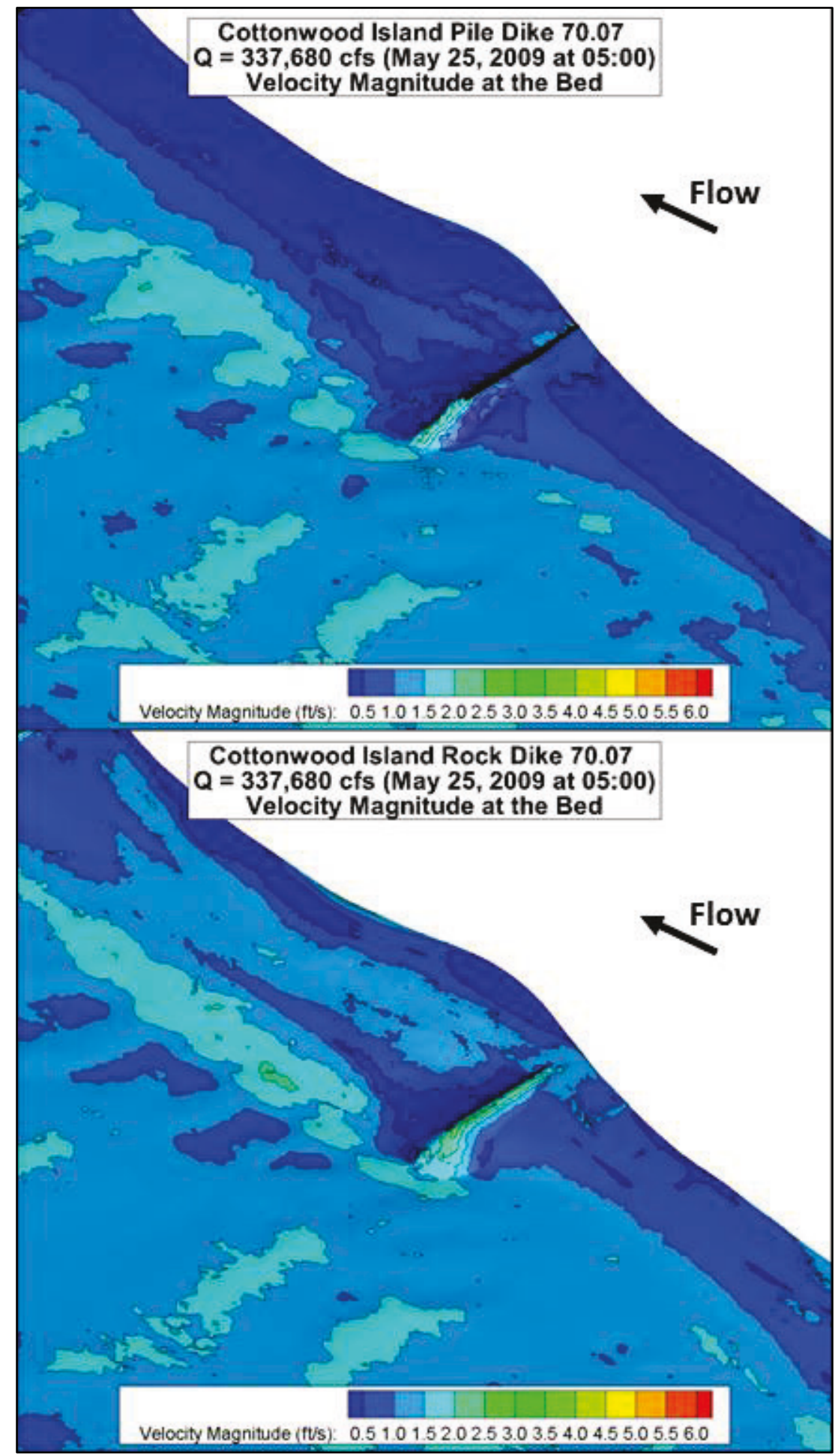


Figure 50. Medium discharge Dike 69.79 bed velocity magnitude comparison - isometric.

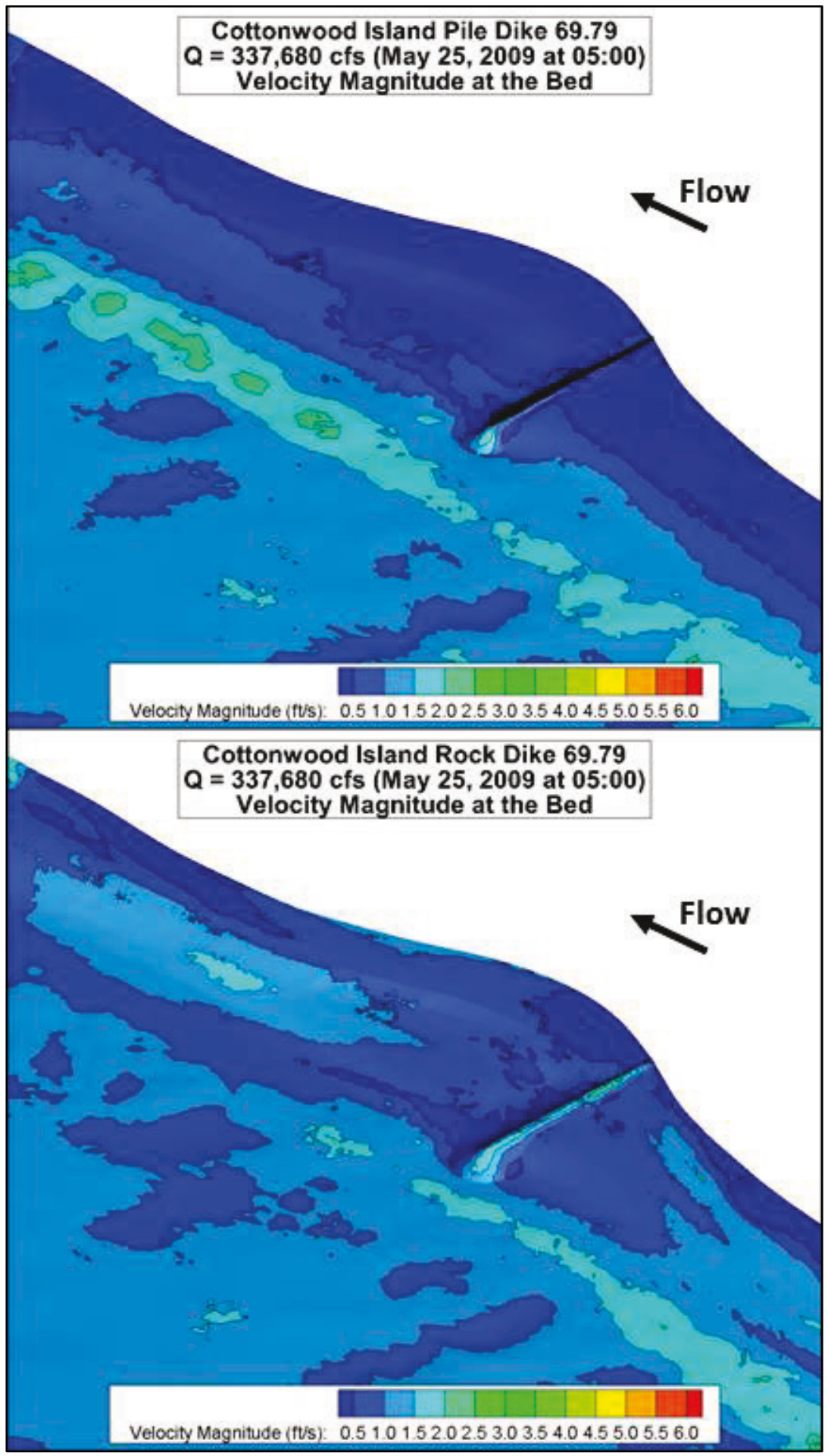


Figure 51 and Figure 52 show extreme velocity differences between the pile and rock dikes. The velocity magnitude differences range from -2 to $5 \mathrm{ft} / \mathrm{s}$. More significant differences between the pile dike and rock dike are present at the water surface (top image) than at the bed (bottom image). Rock dikes produce higher velocity magnitudes (approximately $2.0 \mathrm{ft} / \mathrm{s}$ more) between dikes at the bed as well as at the water surface. Velocity magnitudes are approximately the same for both dike types near the center of the main channel. 
Figure 51. Medium discharge extreme difference velocity magnitude comparison.

Cottonwood Island Dikes 70.35, 70.07, 69.79, 69.51 $\mathrm{Q}=337,680$ cfs (May 25, 2009 at 05:00)

Extreme Velocity Magnitude Change at the Water Surface (Rock-Pile)

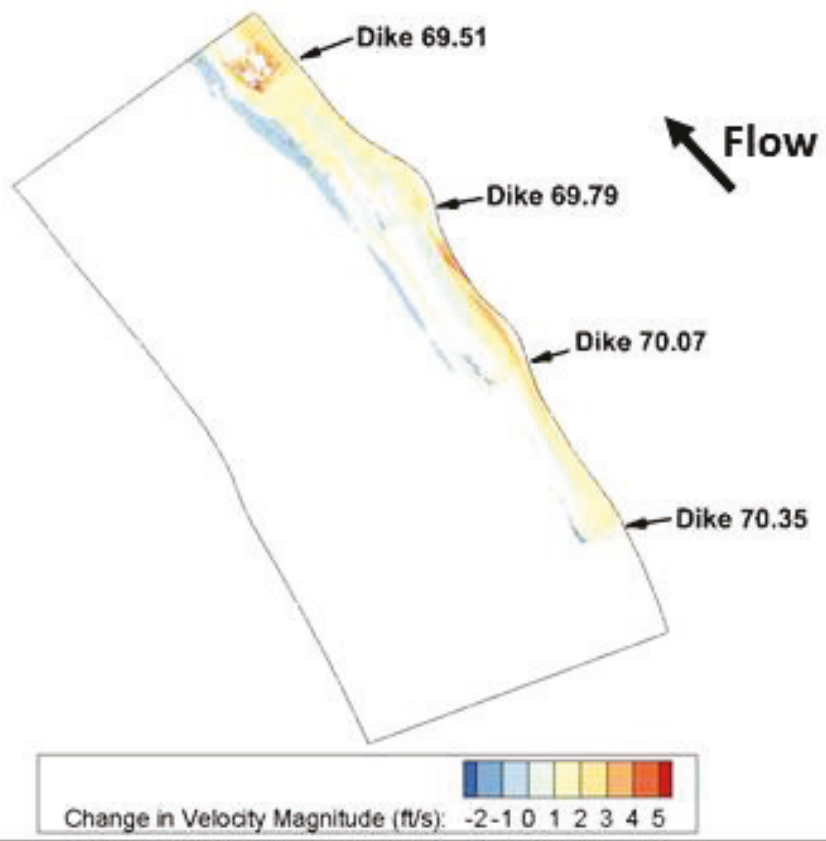

Cottonwood Island Dikes $70.35,70.07,69.79,69.51$ $\mathrm{Q}=337,680 \mathrm{cfs}$ (May 25, 2009 at 05:00)

Extreme Velocity Magnitude Change at the Bed (Rock-Pile)

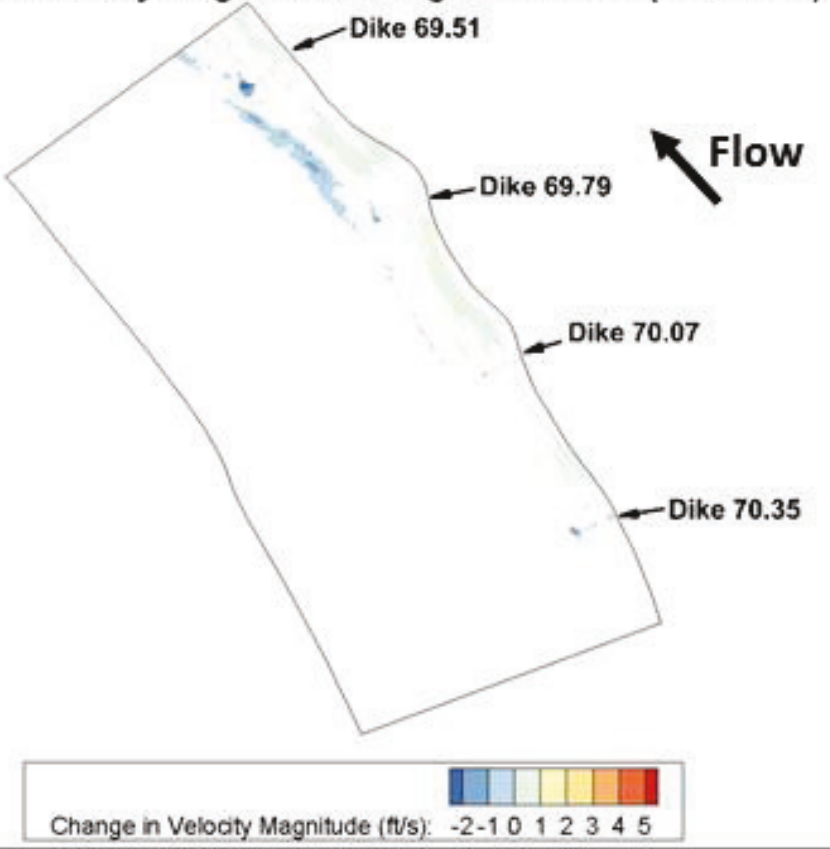


Figure 52. Medium discharge extreme difference velocity magnitude comparison.

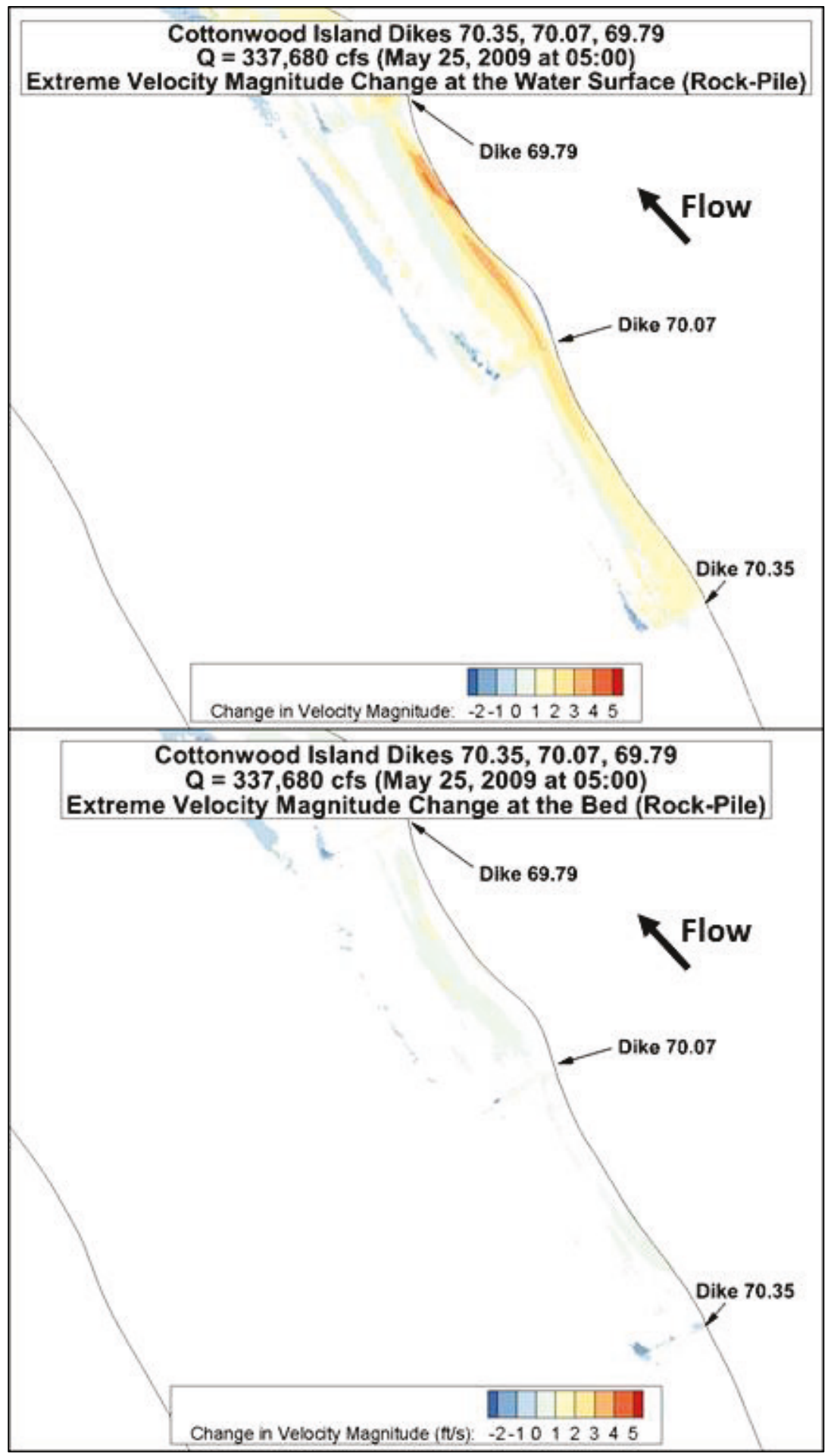




\subsection{Low discharge}

The results for the low-discharge (291,881 cfs) model are shown in Figure 53 through Figure 64. Figure 53 and Figure 54 show the velocity magnitude results at the water surface for the pile dike and rock dikes, respectively. Figure 53 shows the entire flow domain while Figure 54 focuses on the areas downstream of Dikes 70.35 and 70.07. At the water surface in the deep parts of the flow domain downstream of Dike 70.35, the velocity magnitudes are above $3.0 \mathrm{ft} / \mathrm{s}$ for both the pile dikes and the rock dikes. The most significant difference in the flow behavior of each dike type at the water surface is in areas extending from the northern boundary between the dikes. The pile dikes create lower flow velocity magnitudes $\left(0.5^{-1.5} \mathrm{ft} / \mathrm{s}\right)$ near the northern bank line than the rock dikes, which produce flow velocities up to 3.0 $\mathrm{ft} / \mathrm{s}$. Such differences in the two flow behaviors are not surprising given the geometry of each type of dike near the water surface. The pile dike piles extend to the water surface, obstructing the flow at the top of the water column. However, the rock dikes are completely submerged, so the flow has no obstruction at the water surface. 
Figure 53. Low discharge full domain water surface velocity magnitude comparison.

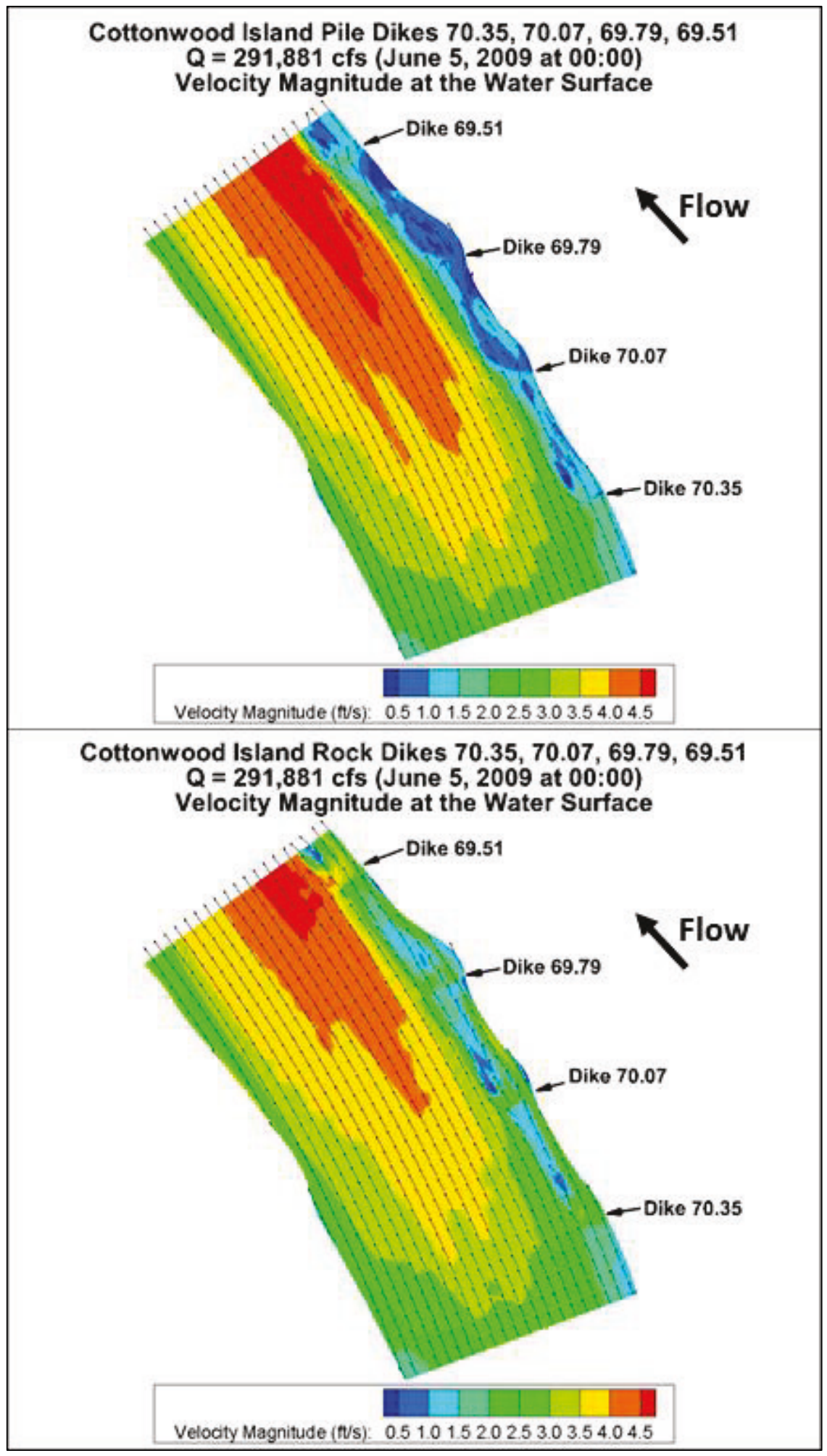


Figure 54. Low discharge upstream zoom water surface velocity magnitude comparison.

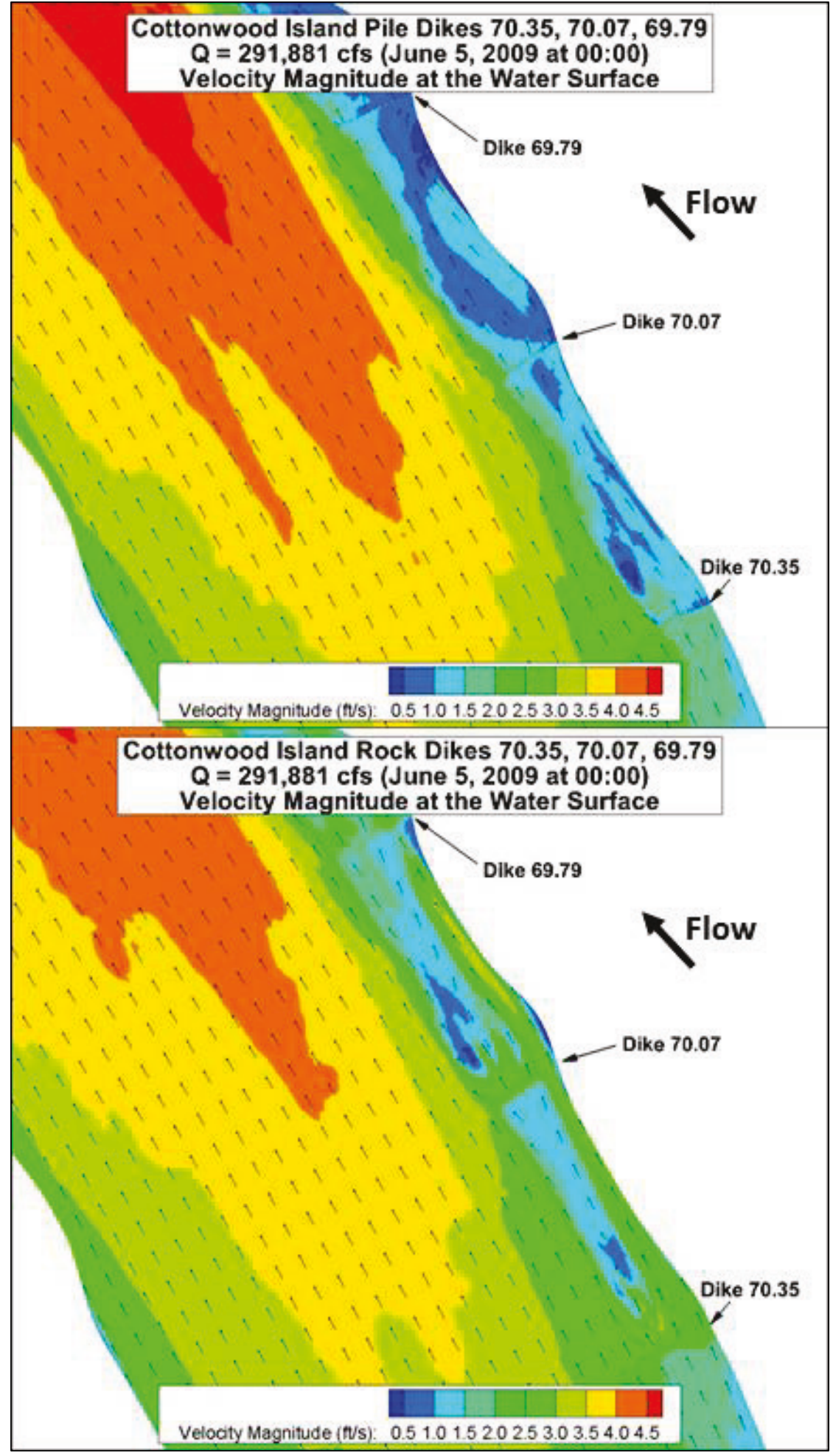


The flow velocity magnitudes at a $10 \mathrm{ft}$ depth in the flow domain are shown in Figure 55 through Figure 58. At this depth, the pile dikes and rock dikes produce similar flow behaviors. Downstream of Dike 70.07, the deep areas of the flow domain have flow velocities between 2.5 and $5.0 \mathrm{ft} / \mathrm{s}$. Velocity magnitudes of 0.5 to $1.0 \mathrm{ft} / \mathrm{s}$ are common immediately downstream of each dike. The rock dikes produce higher flow velocity magnitudes near the shore than those produced by the pile dikes. There is no significant change in the flow direction between the pile dikes and the rock dikes. Eddies are present immediately downstream of each dike for each dike type. These eddies extend approximately the entire length of the dikes and approximately one-fourth of the distance between each dike. Isometric views of the velocity magnitude contours at the $10 \mathrm{ft}$ depth including the bathymetry are shown in Figure 57 and Figure 58 . The bathymetric surface is shown in gray. These figures provide insight into how flow is influenced by the dikes. Note that the dike bases extend through the $10 \mathrm{ft}$ depth contour, so the dikes significantly alter the flow behavior in those areas. The top image of Figure 58 shows how the piles affect how far the highestvelocity flows extend from the end of the dikes. The navigation channel lies between the channel end of the dike and these highest-velocity areas. 
Figure 55. Low discharge full domain $10 \mathrm{ft}$ depth velocity magnitude comparison.

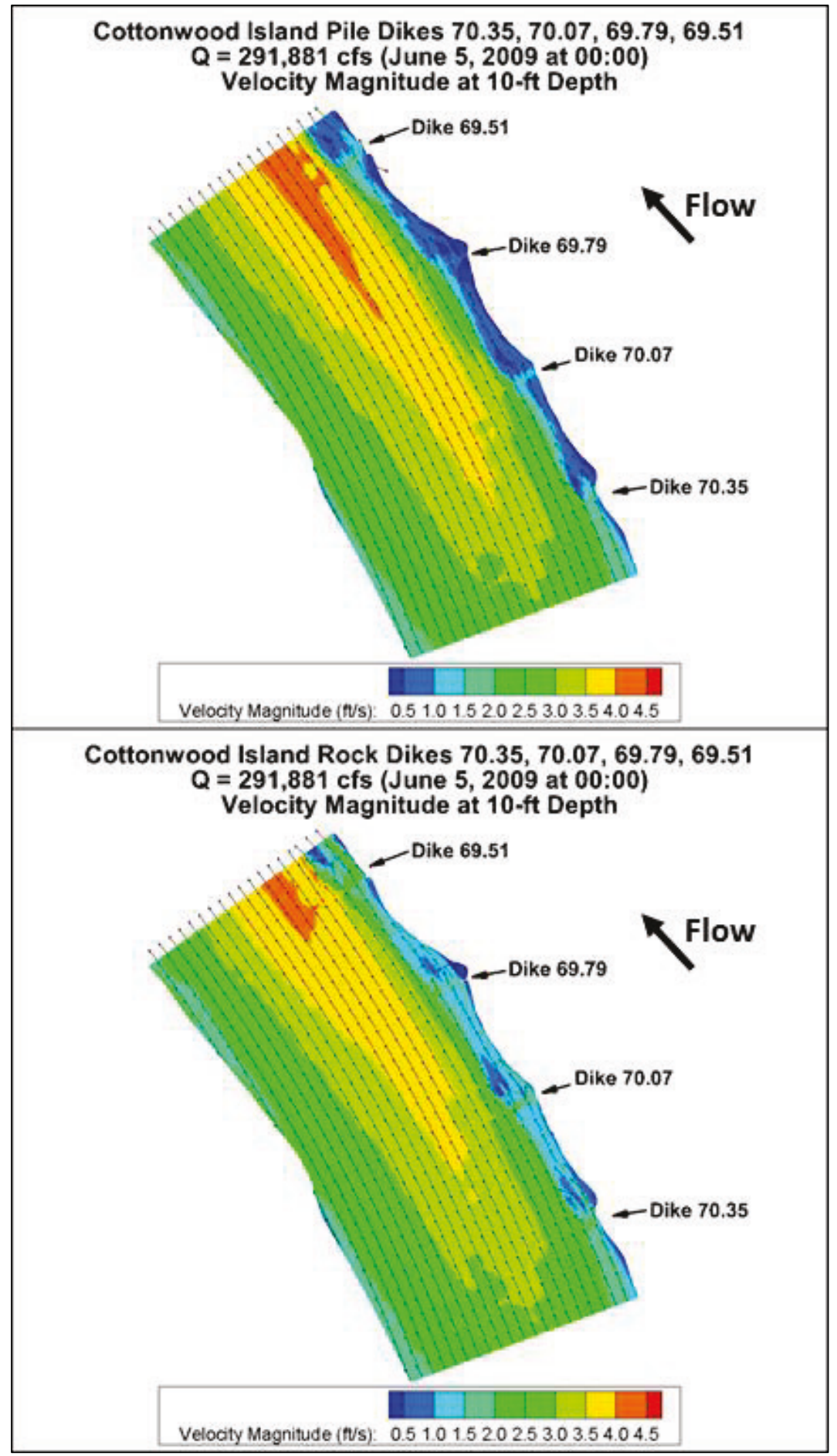


Figure 56. Low discharge upstream zoom $10 \mathrm{ft}$ depth velocity magnitude comparison.

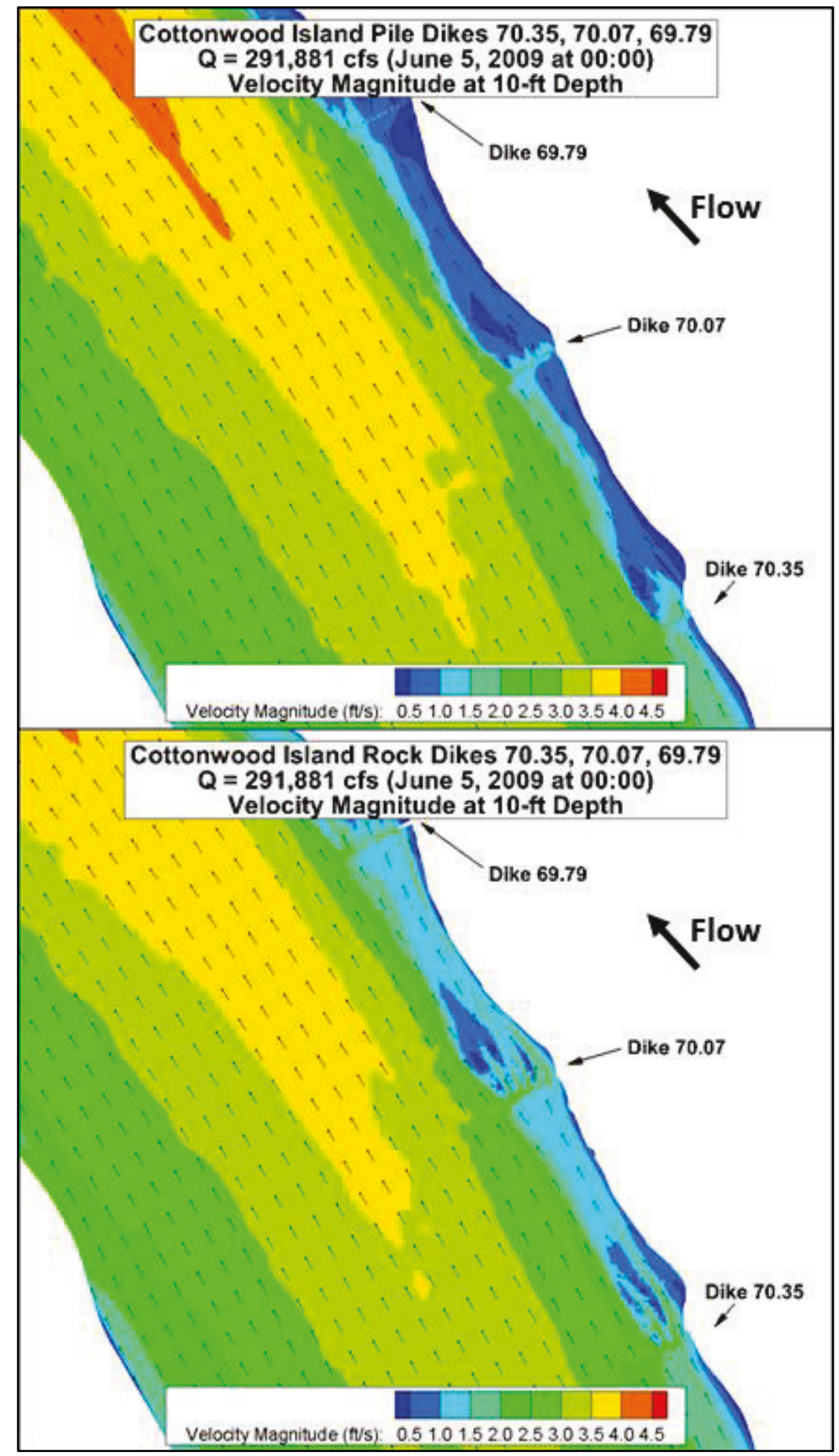


Figure 57. Low discharge full domain $10 \mathrm{ft}$ depth velocity magnitude comparison - isometric.

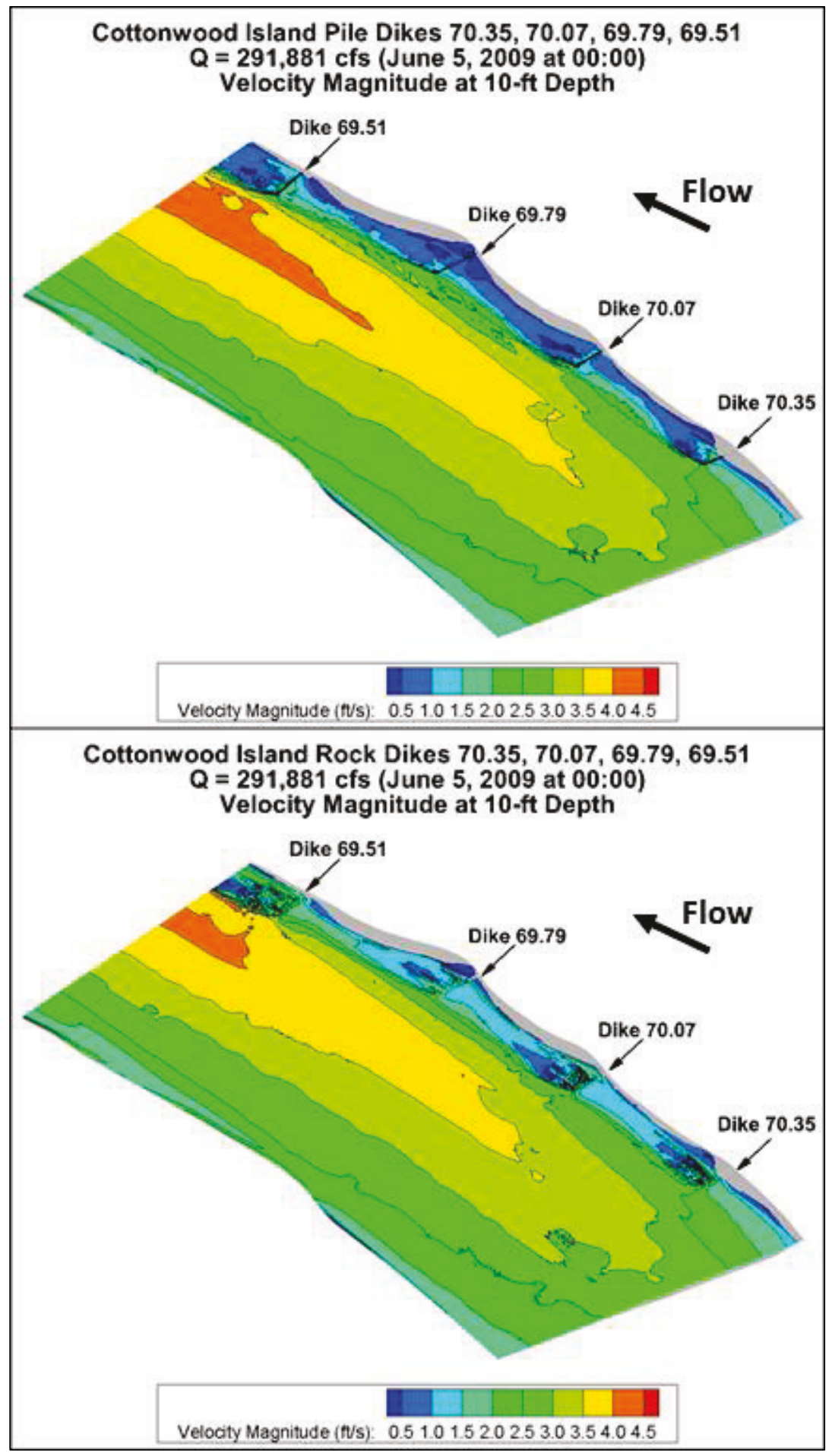


Figure 58. Low discharge velocity contours at $10 \mathrm{ft}$ depth around Dike 69.79 - isometric.

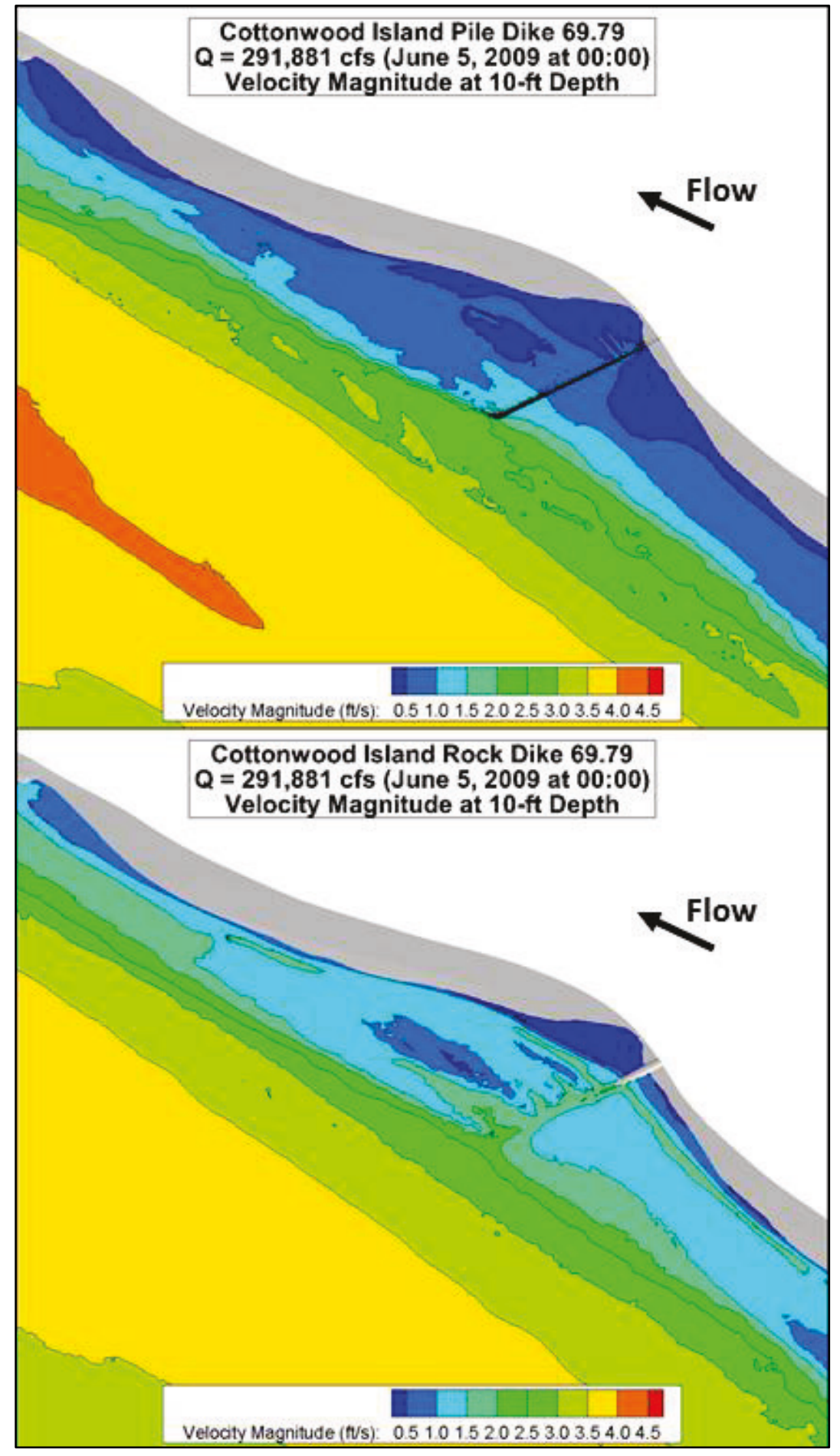


The flow magnitudes at five vertical locations within the pile and rock dike flow domains are shown in Figure 59 and Figure 60, respectively. The vertical direction has been stretched by a factor of 5 to show the vertical variation in the shallow regions more clearly. In each figure, the northern bank line (where the dikes are located) is on the right side of each image. The pile dikes produce a much more pronounced vertical variation in the flow velocities than the rock dikes. The pile dikes also produce much lower velocities very close to the dikes. With both dike types, the highest velocities are at the water surface, but the pile dikes produce slightly higher velocities (approximately 1.0-1.5 ft/s higher) than the pile dikes in the navigation channel. In the shallow areas along the northern bank line, the pile dikes show much less vertical variation with the velocity magnitudes than the rock dikes. 
Figure 59. Vertical slices of pile dike low discharge simulation.

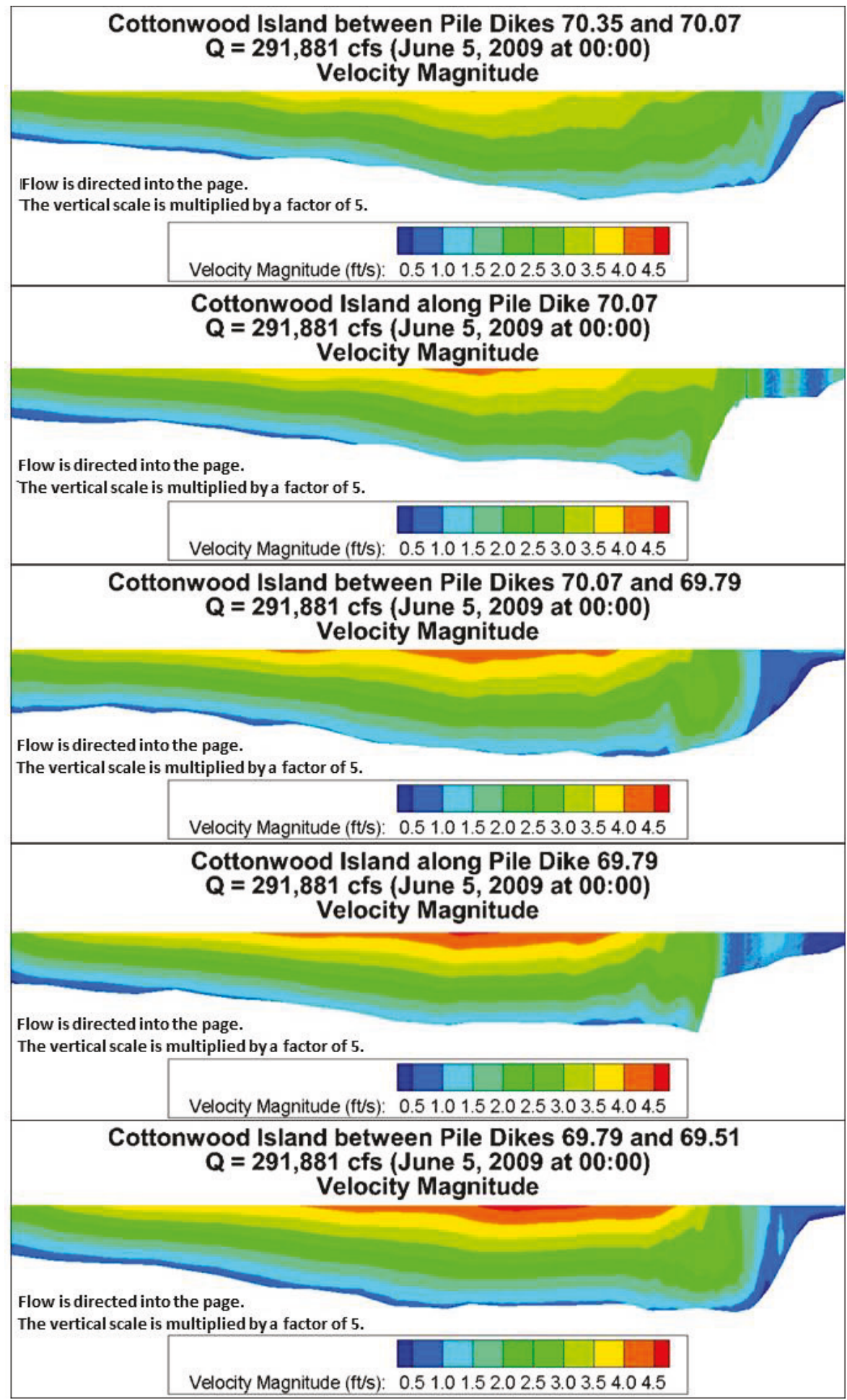


Figure 61 and Figure 62 show the velocity magnitude contours near the bed at Dikes 69.79 and 70.07, respectively. These images are included to provide information related to potential scour near the dikes. Except for the downstream area of the channel-end tip of each dike, which extends into the main channel flow, the velocity magnitudes near the bed immediately downstream of the dike are smaller than in in the deeper areas of the channel. At Dike 70.07, each dike type produces near-bed velocities up to $2.0 \mathrm{ft} / \mathrm{s}$ immediately downstream of the dike tip for approximately two-thirds of the distance to the next dike. Similar but much less pronounced behavior is present at Dike 69.79. With the pile dikes, much more of the flow is directed around the channel-end toward the main channel whereas the rock dikes direct some flow around the shore-end of the dike. More higher-velocity flow is present in the shallow areas between the rock dikes than the pile dikes. For both types of dikes, the flow velocity near the immediate downstream side of the dike (for both

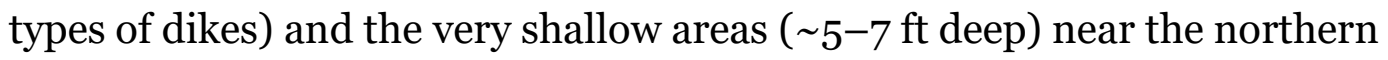
bank line bed is less than $0.5 \mathrm{ft} / \mathrm{s}$, making these areas of the flow domain susceptible to possible sediment deposition. 
Figure 61. Low discharge Dike 70.07 bed velocity magnitude comparison - isometric.

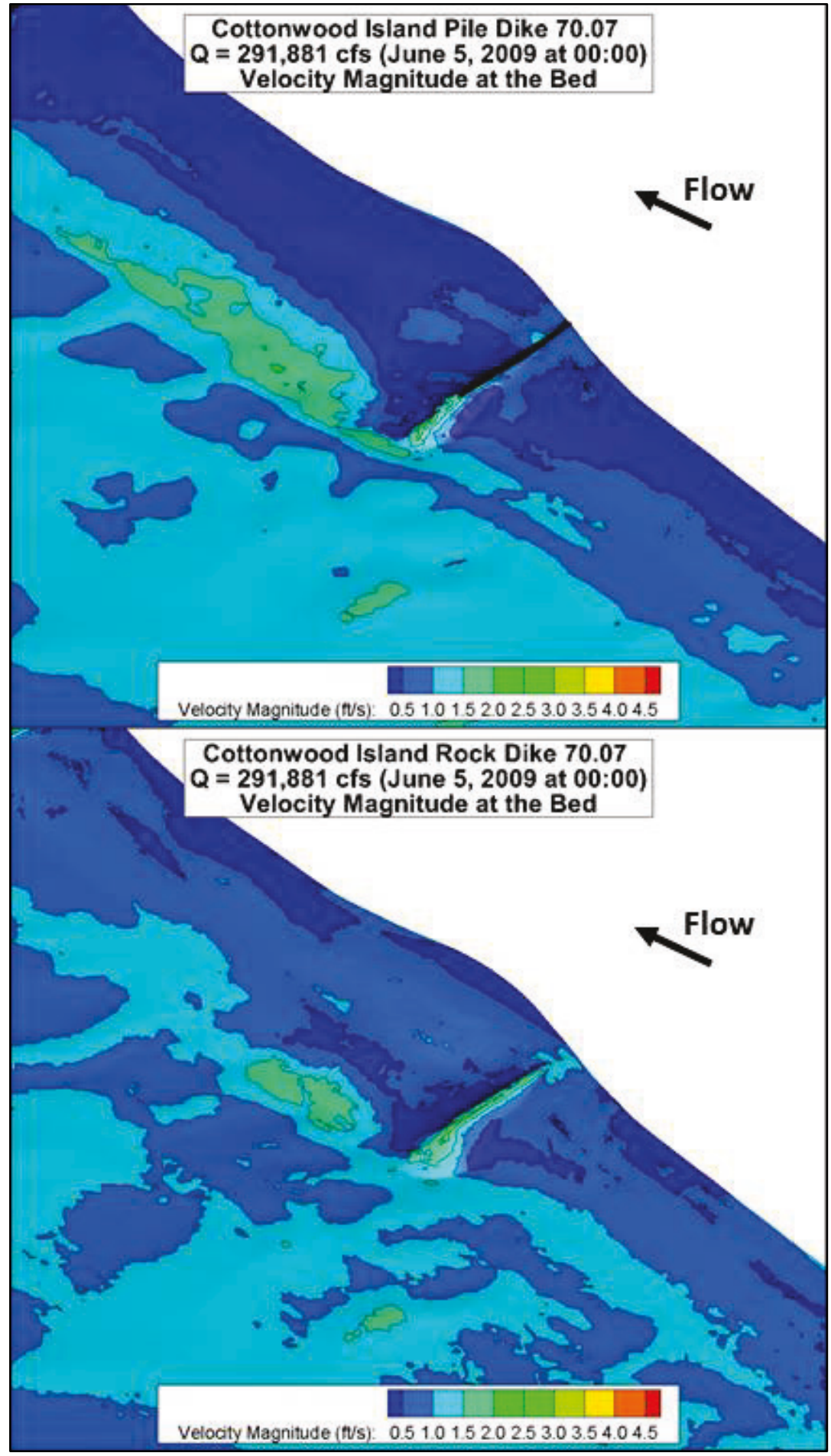


Figure 62. Low discharge Dike 69.79 bed velocity magnitude comparison - isometric.

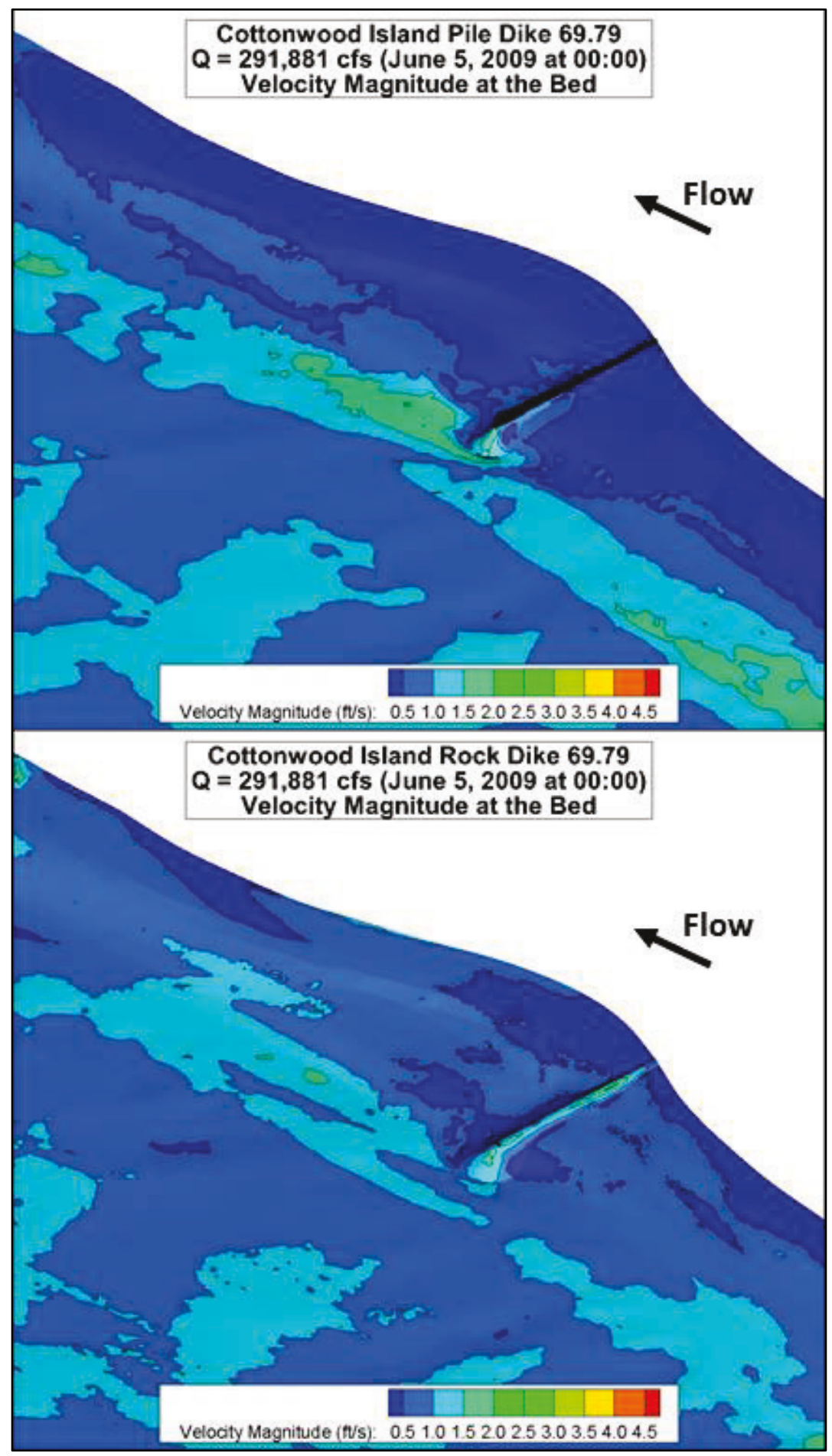


Figure 63 and Figure 64 show velocity differences between the pile and rock dikes. The change in velocity magnitude ranges from -2 to $5 \mathrm{ft} / \mathrm{s}$. Between the pile dikes and rock dikes, the velocity magnitude differences at the water surface (top image) are greater than those at the bed (bottom image). The rock dikes produce approximately $2 \mathrm{ft} / \mathrm{s}$ higher velocity magnitudes at the water surface along the northern bank line. The differences at the water surface are caused by the pile dike piles extending to the water surface whereas the rock dikes are fully-submerged. Near the center of the main channel, the velocity magnitudes produces by the pile dikes and rock dikes are approximately the same. The similarity in flow behavior between the dike types at the bed is expected because the pile and rock dikes are similarly shaped at the base. 
Figure 63. Low discharge extreme difference velocity magnitude comparison.

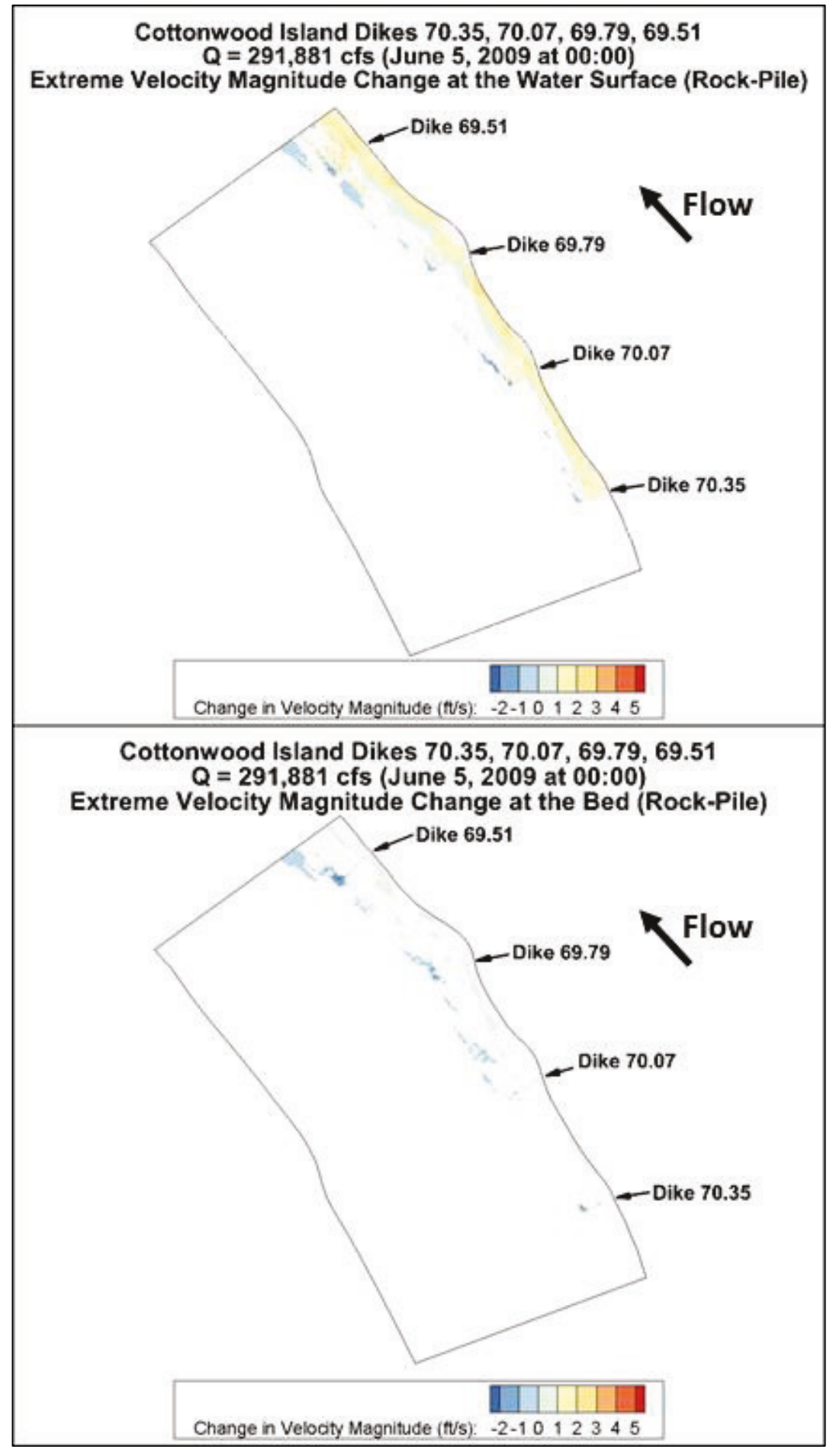


Figure 64. Low discharge extreme difference velocity magnitude comparison.

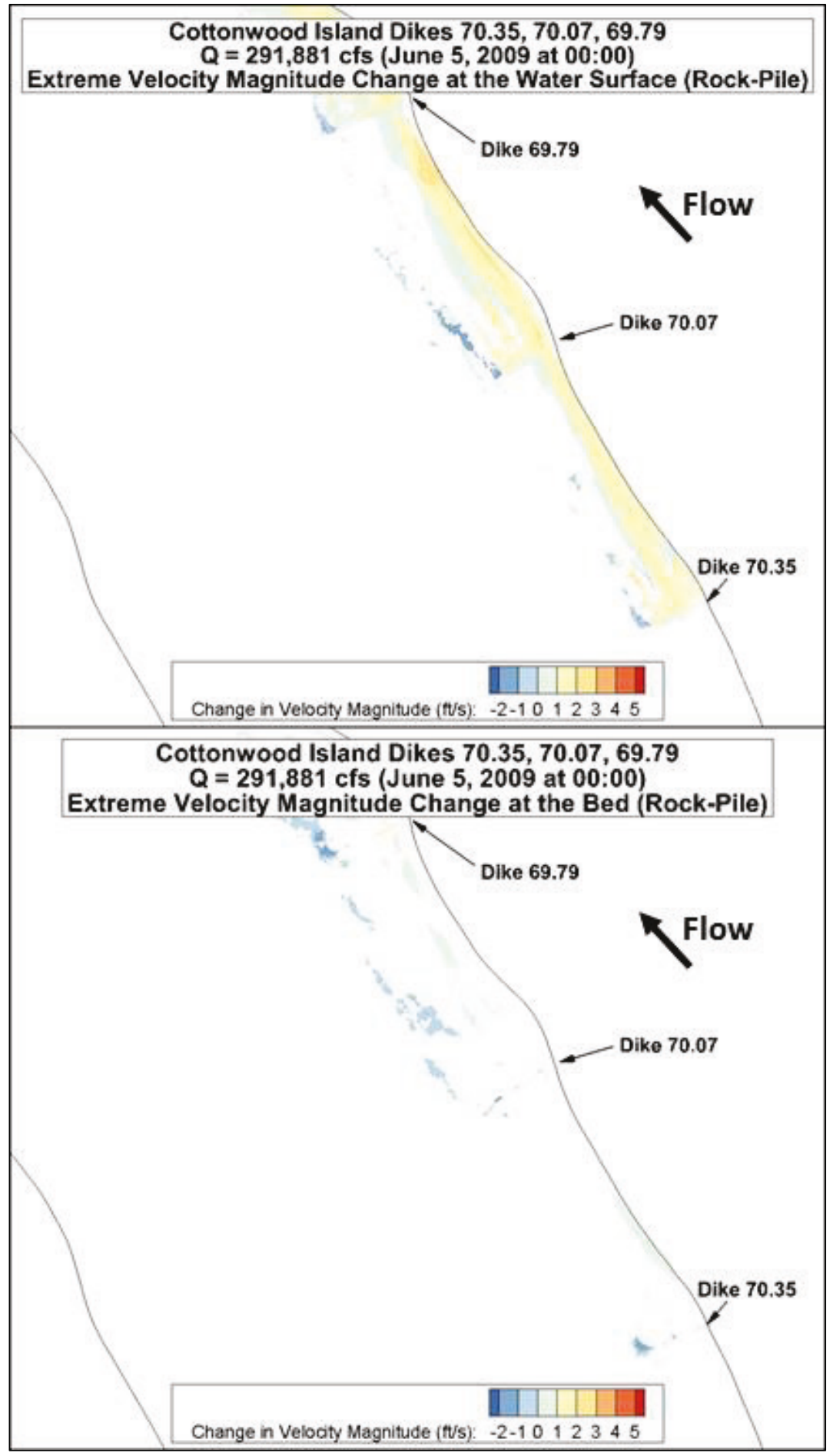




\section{Summary and Conclusion}

\subsection{Study summary}

Replacement options are being evaluated for a system of pile dikes that have begun to deteriorate. Two dike designs are proposed - a pile dike design similar to the existing dikes and a conventional rock dike. The potential effects to navigation caused by the rock dikes are a concern to NWP and the shipping industry. A secondary interest of the pile dike replacement is the impact the rock dikes would have on fish habitat near the dikes and possible environmental concerns with rock dikes such as scour/sediment deposition.

The flows near the dikes are $3 \mathrm{D}$, so a computational flow solver capable of non-hydrostatic, $3 \mathrm{D}$, open-channel flow calculations is required. The ERDC-developed computational code RANS-AdH has these capabilities and is used for all simulations in this study. The flow domain and boundary condition information have been derived from the results of a previously-conducted SW2-AdH model study of the Lower Columbia River.

The RANS-AdH study of the currents near Cottonwood Island is employed to determine the potential effects a proposed rock dike geometry might also have on navigability in the river. The models are of two different geometries: the existing pile dikes and the proposed rock dikes. The flow domains for the Cottonwood site consist of four dikes (Dikes 70.35, 70.07, 69.79, and 69.51). The results from simulations of a high discharge $(432,811 \mathrm{cfs})$, a medium discharge (337,680 cfs), and a low discharge $(291,881 \mathrm{cfs})$ are included in this study for each dike type. A total of six simulations are discussed.

The simulation results for each discharge/dike type combination are presented as a series of contour plots of the flow velocity magnitudes, flow direction, and flow velocity magnitude differences at different locations within the flow domain. The differences in the flow velocity between the existing pile dikes and the proposed rock dikes at the water surface and at the river bed are shown directly for each of the three discharges.

The flow domain comprises only a portion of the dike field along Cottonwood Island, so the inflow and outflow boundaries are located 
between dikes. Some portions of the flow domain are therefore affected by the upstream and downstream boundaries and are not representative of the behavior in the full Columbia River. The flow solution in these areas is ignored. Any analysis of the flows behavior using the results presented in this report should focus on the areas of flow domain downstream of Dike 70.35 and upstream of Dike 69.51.

The figures of the flow domain solution included in Chapter 5 show how the pile and rock dikes affect the flows in the navigation channel and what the flow behavior between the dikes is in relation to fish habitat and sediment scour/deposition potential. These plots are presented such that the flow behavior from the proposed rock dikes can be compared directly to the flow behavior from the existing pile dikes.

Overall, the proposed rock dikes produce similar velocity magnitudes in the navigation channel as those produced by the existing pile dikes. The velocity magnitudes in the navigation channel vary at most approximately $0.5 \mathrm{ft} / \mathrm{s}$, but the flow direction is almost identical in the navigation channel for the pile and rock dikes. Between the dikes, the rock dikes yield higher flow velocities farther up the water column than the pile dikes. This is likely due to the piles extending to the water surface whereas the rock dikes are completely submerged. The pile and rock dikes perform more similarly farther down the water column as their respective geometries become more similar. The rock dikes yield higher velocities near the northern bank line. The rock dikes produce noticeably lower velocities downstream of the dike tips because they allow more flow over the top of the dike as opposed to the piles dikes that extend to the water surface. Both dikes produce eddies that extend approximately one-fourth of the distance between the dikes. All contour plot figures are presented in either Chapter 5 or Appendix D: Additional Flow Solution Images.

A RANS-AdH model of the flows near Sand Island's dike field yields technical challenges from the expansive shallow areas near Sand Island and the flow behavior from the SW2-AdH simulation results. These challenges are cost and time prohibitive, given the current level of technology. Abandoning the Sand Island numerical modeling effort, CHL and NWP jointly note the difficulties and are proposing solutions so similar sites and flow situations can be numerically modeled to evaluate the $3 \mathrm{D}$ flows near hydraulic structures (dikes, etc.) in the future. 


\subsection{Design recommendation}

While the flow behavior caused by the pile dikes and rock dikes do have differences, these are contained in areas that are outside the navigation channel. Flow velocity magnitudes and flow directions in the navigation channel are nearly identical between the two dike types. Therefore, when only navigation effects are considered, the conventional rock dikes offer no significant impacts.

Other information obtained during this study, such as the near-bed velocities and the flow velocities at each dike and between dikes, offers insight into how the different dike types affect aspects of the environment near the dikes. 


\section{References}

AECOM. 2011. Structural and Hydraulic Analysis of the Columbia River Pile Dikes Final Report. Submitted to U.S. Army Corps of Engineers - Portland District. Los Angeles, CA: AECOM. https://cdm16021.contentdm.oclc.org/digital/collection/p266001coll1/id/2343

ALDEN Research Laboratory, Inc. 2016. Columbia River Pile Dikes Major Maintenance Reports for Sand Island and Cottonwood Island Systems: Numerical Modeling Report for Cottonwood Island Pile Dike System. W9127N-10-D-0002, Task Order No. 49. Prepared for U.S. Army Corps of Engineers, Portland District. Redmond, WA: ALDEN Research Laboratory, Inc.

ALDEN Research Laboratory, Inc. 2015. Columbia River Pile Dikes Major Maintenance Reports for Sand Island and Cottonwood Island Systems: Numerical Modeling Report for Sand Island Pile Dike System. W9127N-10-D-0002, Task Order No. 49. Prepared for U.S. Army Corps of Engineers, Portland District. Redmond, WA: ALDEN Research Laboratory, Inc.

Maynord, S. T. 2000. Physical Forces near Commercial Tows. ENV Report 19. Vicksburg, MS: U.S. Army Engineer Research and Development Center.

U.S. Army Corps of Engineers (USACE), Portland District (NWP). 1968. Columbia and Lower Willamette Rivers below Vancouver, Washington, and Portland, Oregon 35- and 40-foot Channel Modifications. Design Memorandum No. 10. Portland, OR: U.S. Army Corps of Engineers, Portland District.

USACE NWP. 2015. Columbia River Pile Dikes Major Maintenance Report and Environmental Assessment for Cottonwood Island Pile Dike System. Portland, OR: U.S. Army Corps of Engineers, Portland District.

USACE NWP. n.d. Accessed 12 December 2018. https://www.nwp.usace.army.mil/Missions/Navigation/Pile-dikes/ 


\section{Appendix A: Sand Island Modeling Attempt}

The flow behavior and subsequent effects on navigation of the dikes near Sand Island are studied in addition to those at the Cottonwood Island site. The numerical modeling techniques discussed in Chapter 3 were applied to this site. Since Sand Island is within the tidal influence of the Pacific Ocean, the tides have a strong effect on the flow behavior in the area. The general process for choosing, refining, and creating computational meshes for the Sand Island flow domain are the same as those used for Cottonwood Island.

\section{Flow domain}

The three main considerations for determining the extents of the flow domain are determined from three main criteria:

- which dikes to include that will produce useful results

- the direction of flow from the SW2-AdH solution

- constraints related to the size of the computational mesh of the area.

Using those guidelines, CHL and NWP agree that Dikes 4.01, 4.47, and 5.15 must be included the flow domain. Once the dikes selection was made, the extents of the flow domain must be chosen using the SW2-AdH flow solution. The SW2-AdH Sand Island flow domain (shown in Figure 65) is much more expansive (37,400 ft inflow to outflow length and 9,800 ft channel width at bay inlet) than the Cottonwood Island flow domain $(37,400$ inflow to outflow length and $1,300 \mathrm{ft}$ channel width), so careful consideration concerning the size of the flow domain is necessary. An acceptable flow domain is one that would yield a computational mesh that allows simulations to be completed in a reasonable time frame while still accurately depicting the flow boundaries and not interfering with the flow solution in the areas of interest. Discharges for the Sand Island site RANSAdH simulations come from the Columbia River discharges (Figure 66) from the SW2-AdH study (ALDEN 2015). 
Figure 65. Sand Island flow domain extents - SW2-AdH and RANS-AdH.

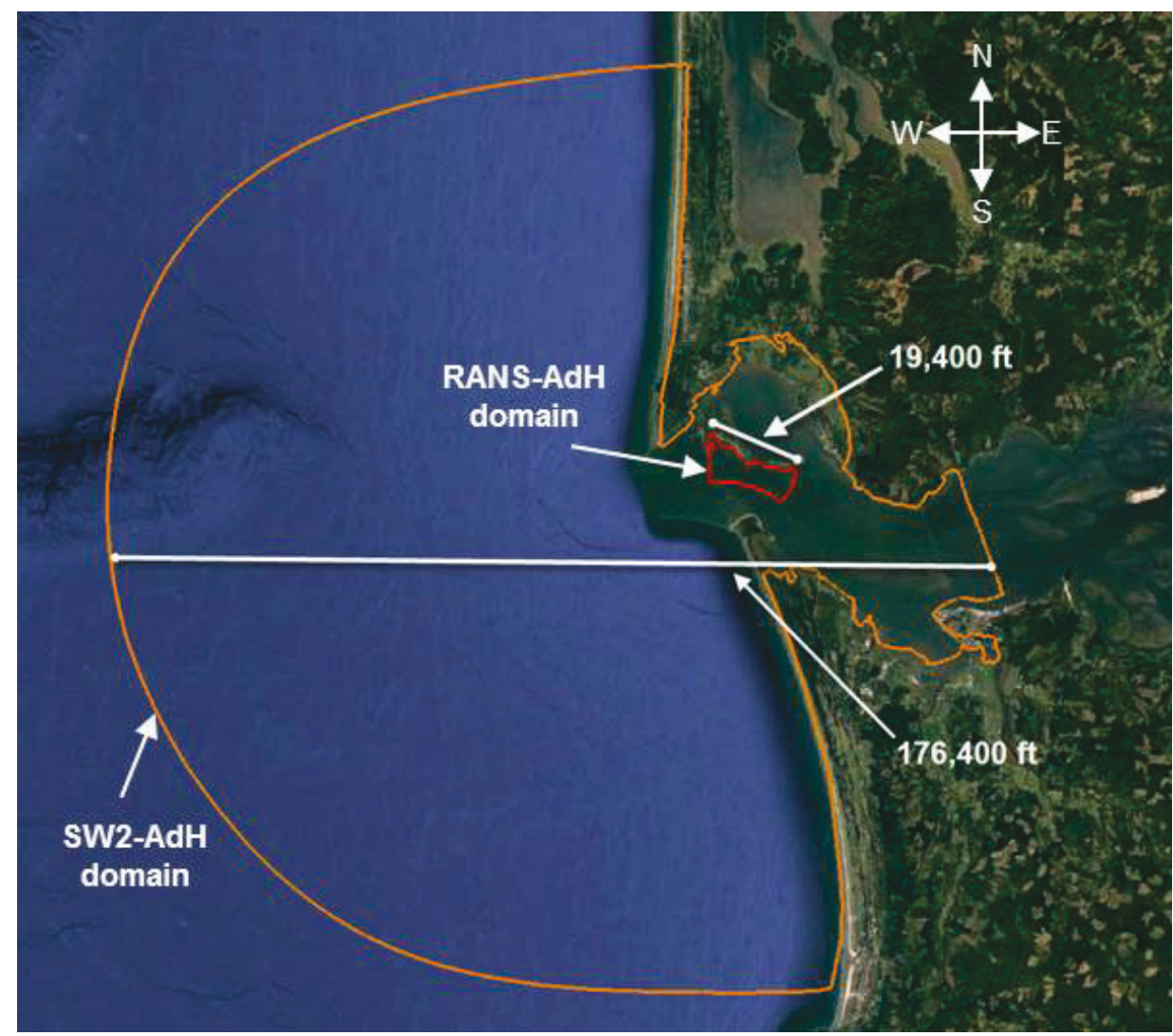

Figure 66. Sand Island model discharges.

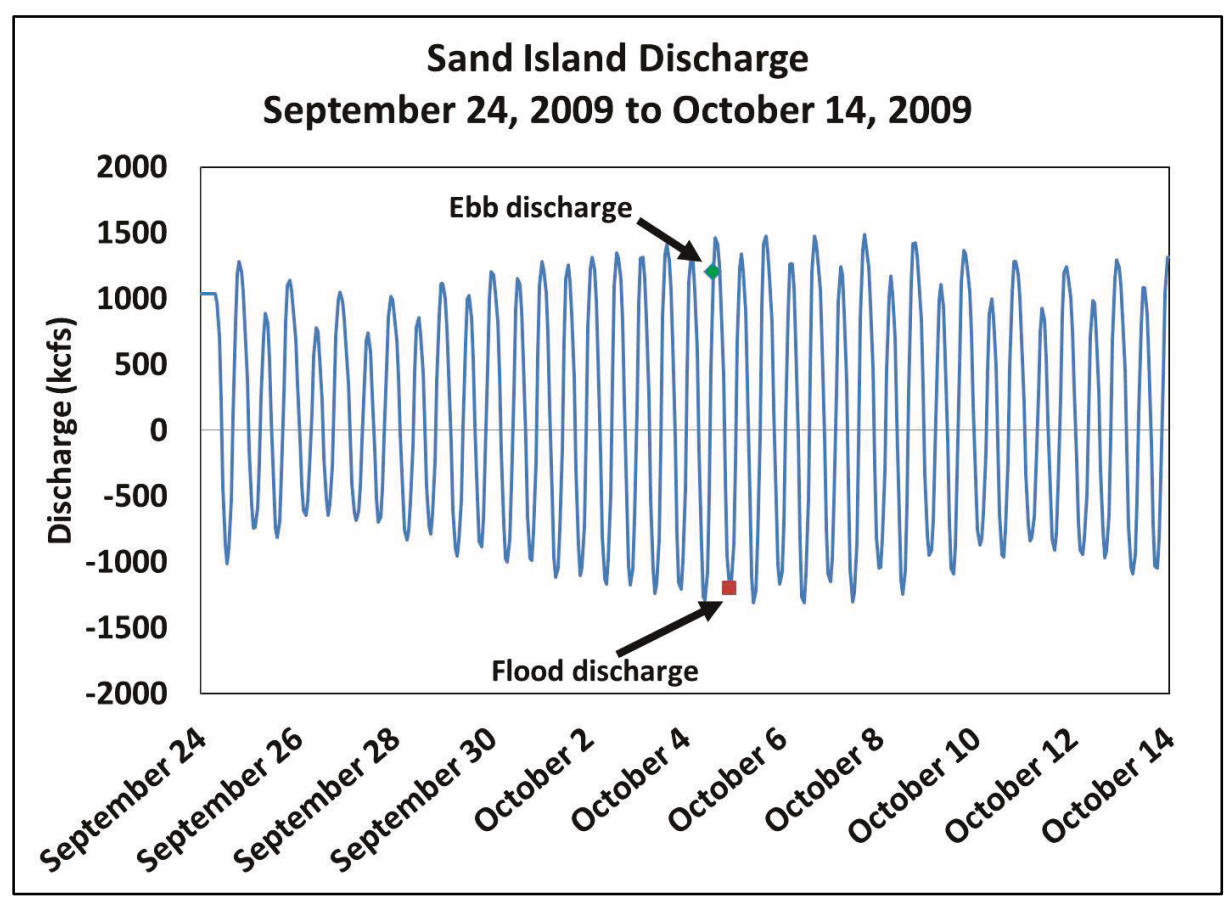


The SW2-AdH flow streamlines for both of the discharges chosen are shown in Figure 67. Since the flow domain area is so expansive in the vicinity of Sand Island, the computational mesh size considerations require that a boundary must be placed south of the chosen Sand Island dikes. The streamlines from the flow solution are generally perpendicular to the line of dikes, so placing a flow domain boundary south of the dikes does not pose a problem. The shallow areas of the flow domain near the dikes are much larger than the shallow areas near the Cottonwood Island dikes. Further, there is flow coming from north of the dikes that goes between the dikes, so these shallow areas cannot be completely excluded from the flow domain. The discharges chosen for the Sand Island simulations include ebb and flood tides. These produce eddies near the potential western boundary of the flow domain. To ensure that the boundary conditions imposed on the model accurately recreate the flows conditions generated by the SW2-AdH model, the boundaries of the flow domain must not intersect these eddies. These eddies are close enough to Dike 4.01 that excluding them negatively influences the applicability of the resulting RANS-AdH simulation results. Therefore, the flow domain chosen for the Sand Island flow simulations includes these eddies. 
Figure 67. Figures of Sand Island SW2-Adh flow solutions.

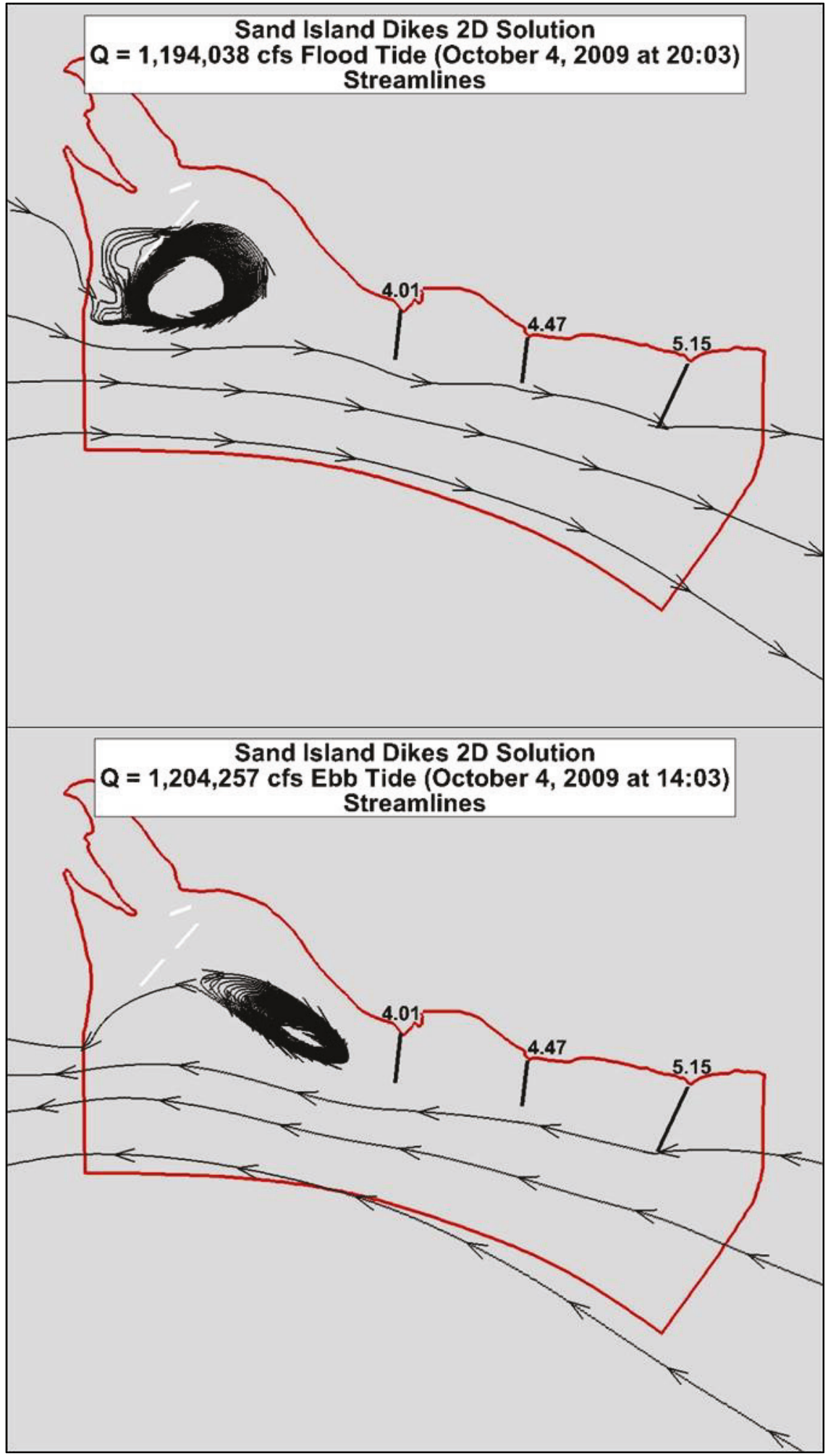




\section{Computational meshing}

Computational meshing efforts focus on a portion of the flow domain that includes only Dike 5.15 and extend from the proposed northern and southern boundaries (the top and bottom of the red outlines in Figure 67) of the full flow domain. The shallow areas of the mesh near the dikes and north of the dikes are so expansive that the computational meshes for even the one-dike domain are not computationally viable for the resources available for simulations. The meshing difficulties encountered guide NWP and CHL to abandon the Sand Island numerical modeling effort.

Discussions of the Sand Island meshing effort lead to the identification of aspects of the meshing process and RANS-AdH that must be addressed before a similar area and flow situation can be simulated. The shallow areas of the flow domain are so expansive that well-shaped tetrahedral elements produce meshes that are either too large for efficient flow simulation calculations to be made or too dense to generate a mesh at all. The aspect-ratio requirements of tetrahedral elements restrict the size of the elements in those shallow areas, which means the shallow areas require many more elements for a high-enough quality mesh for simulations.

To address these problems, different elements types of meshing are necessary. For any meshing software in use, the tetrahedral-only meshes are very large compared to meshes composed of other element shapes such as hexahedra or prisms. Tetrahedra-shaped elements are well suited for areas of flow domains that have complex shapes. However, in areas that lack such complex shapes, tetrahedra-shaped elements produce higher element counts relative to what those other element shapes produce. Further, other mesh shapes can have high aspect ratios (well suited for shallow areas) without degrading the quality of the computational solution. The advantages of these elements are used in flow simulations over airplane wings, through turbines, and around ship/submarine hulls where accurately defining the boundary layer is important. For regions near the surfaces in these types of flow simulations, the mesh resolution in one direction (normal to the surface) must be significantly higher than in the other directions (parallel to the surface).

Meshing techniques for flow domains with large, relatively shallow areas are being developed but are not in use to produce flow solutions on any USACE project at the time of this report. These meshing techniques need 
to be applied to projects that involve these types of flow domains and situations. With its automatic mesh refinement techniques, RANS-AdH stands to be a highly sought after tool for open-channel flow situations commonly of interest to USACE. To improve the applicability of RANSAdH, it must include the ability to work with new element-type meshes. Extending RANS-AdH to work with these types of meshes (particularly hexahedra-only and hybrid hexahedra-tetrahedra meshes) allows for problems involving large, shallow areas with intricate geometries and complex, 3D flows to be simulated numerically. 


\section{Appendix B: Feasibility of Combining Piles}

Each pile dike consists of a few hundred piles that are very close together relative to the size of the entire flow domain. Given the number of piles, their proximity, and their shape, the piles themselves significantly increase the size of the computational mesh required to sufficiently recreate the surface geometry of the flow domain. For meshes with such high element and node counts, the computing power required to complete the flow simulations is in the range of hundreds of processor hours. Different ideas are evaluated for reducing the mesh size. One suggestion is combining the piles, as long as the subsequent flow solution is not significantly different from the solution with the existing pile geometry. A comparison study of different pile combination techniques is conducted on a defined flow domain containing one dike (Dike 70.35). These comparison simulations use one flow discharge, $432,811 \mathrm{cfs}$. The one-dike flow domain extends from just downstream of the flow bifurcation immediately east of Cottonwood Island to approximately halfway between Dike 70.35 and Dike 70.77 starting at the southern bank of the Columbia River to the $5 \mathrm{ft}$ depth contour on the northern bank.

Two-pile and three-pile combinations are evaluated. No guidelines are available in the literature to combine separate piles in a way that ensures the solution is representative of that of the separated pile geometry. Further, no guidance on how to define the Reynolds number for this flow situation is available. When determining the size and spacing of the combined piles, consideration is given to ensure that the combined pile geometry flow patterns are comparable to the existing pile geometry flow patterns. The only information that is similar to this case for determining the Reynolds number is work done by Maynord (2000). It involves the blockage area of ships in navigation channels to determine wave affects in shallow areas. Using this information as a guide, a combined pile configuration is developed.

The configuration of the existing piles is shown in Figure 68. In each row, the piles have a $2.5 \mathrm{ft}$ spacing (center to center). The rows have a $-1 \mathrm{ft}$ gap (edge of pile to edge of pile). The combination pile structure is applied to each dike, and the pile size and spacing are the same between the existing pile geometry and the combination geometry. 
The two-pile combination has piles that are twice the diameter of the existing piles with a spacing that is twice as wide. Similarly, the three-pile combination piles are three times larger than the existing piles with a spacing that is three times as wide. Each pile combination flow domain is meshed according to the procedure described in Section 3.2.2 of the main report. The pile geometry of the water surface at the end of Dike 70.35 for each dike configuration is shown in Figure 69.

Figure 68. Schematic of existing pile dike geometry (USACE NWP 1968).

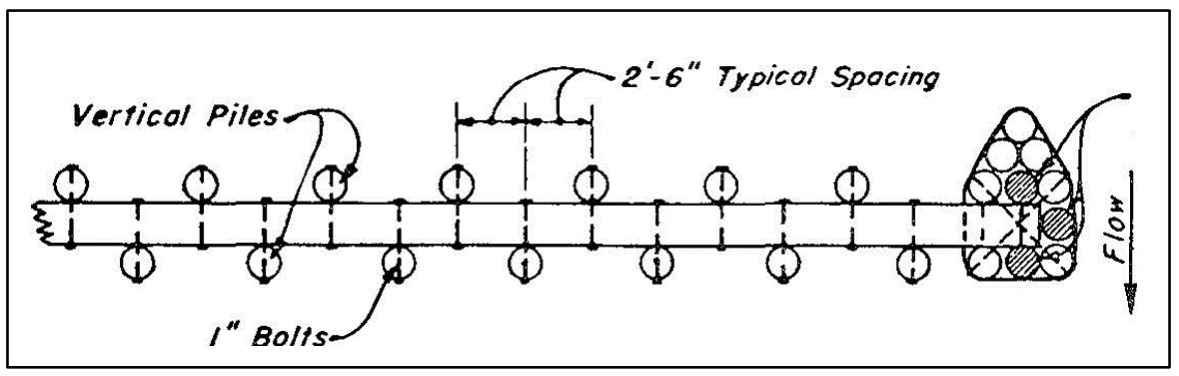

Figure 69. Water surface geometry of the different pile combinations.

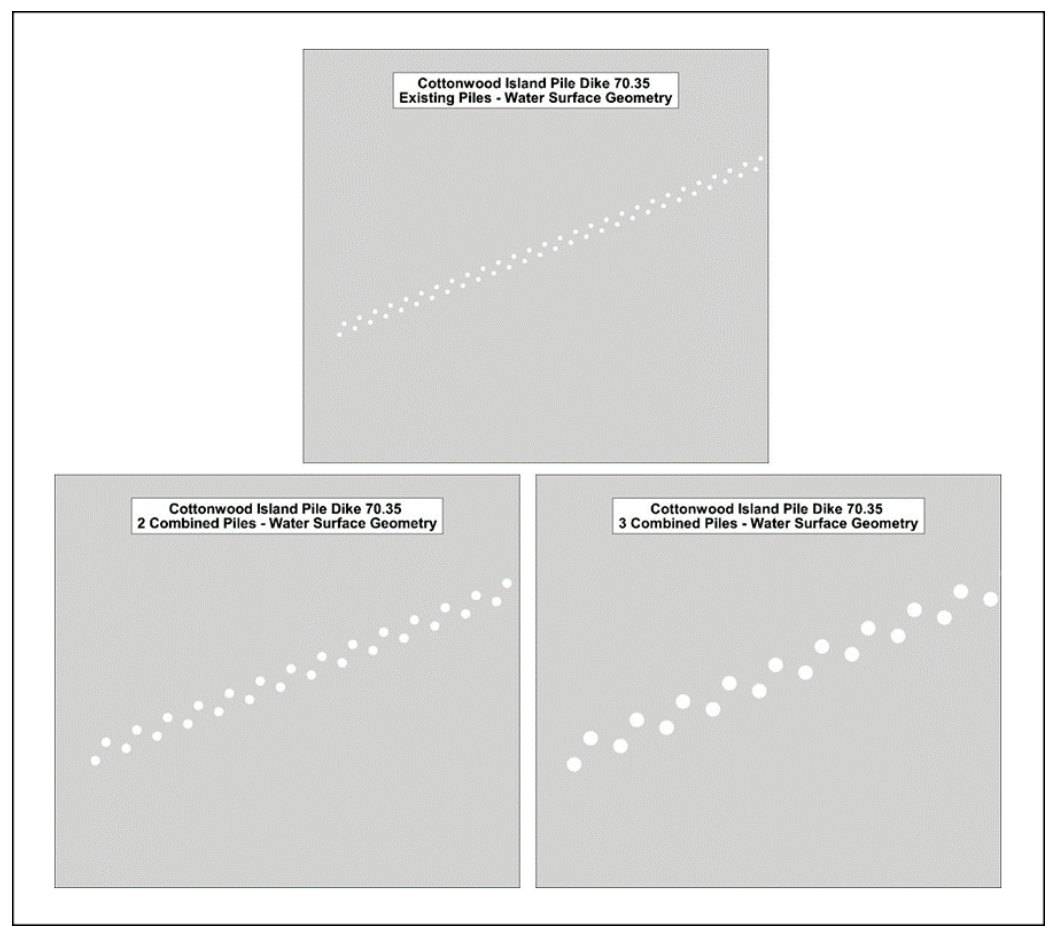

Table 4 lists the surface element count of the three different pile combination meshes. This information is provided to demonstrate the effect each pile combination structure has on the total mesh size. The twopile combination reduces the total mesh node count from the existing pile 
mesh by $25 \%$. Using the three-pile combination reduces the total mesh node count by essentially the same amount. This indicates that combinations of more than two piles will not provide additional reduction in the computational burden of the simulations.

Table 4. Element and node count of the different pile combinations.

\begin{tabular}{|l|l|l|l|}
\hline Pile Combination & $\begin{array}{l}\text { Pile Surface Element } \\
\text { Count for Area }\end{array}$ & $\begin{array}{l}\text { Total Mesh Node } \\
\text { Count }\end{array}$ & $\begin{array}{l}\text { Total Mesh Volume } \\
\text { Element Count }\end{array}$ \\
\hline Existing & 74,805 & 627,860 & $3,558,834$ \\
\hline Two-Pile & 19,498 & 471,800 & $2,661,084$ \\
\hline Three-Pile & 19,918 & 465,550 & $2,622,189$ \\
\hline
\end{tabular}

Boundary conditions for the pile combination comparison simulations are set up using the procedure described in Section 4.1 of the main report. The fixed-lid water surface treatment is used for each pile combination simulation. Contour plots of the velocity magnitudes on the water surface for each pile combination simulation are shown in Figure 70 through Figure 72. In each figure, the top image shows the entire flow domain and the bottom image is an enlarged area focusing on the region downstream of Dike 70.35. The contour range of each plot is identical, making direct comparison between the flow solutions possible. Each pile combination produces similar flow behavior in the navigation channel and deeper areas of the flow domain. There are almost no discernable differences in the velocity magnitudes at the water surface in those areas. However, the different pile dike configurations produce flow velocities between 0.5 and $4.0 \mathrm{ft} / \mathrm{s}$ in similar areas directly downstream of the dike. A particularly stark difference in the water surface velocity magnitudes occurs immediately downstream of the channel side of the dike. Because of the interest NWP has in the flow behavior downstream of the dikes, and the differences in the flow behavior in the area of each pile combination, CHL and NWP agree that the pile combination tests are not sufficient and the existing piles geometry must be included in the four-dike simulations. 
Figure 70 . Existing pile water surface velocity magnitudes.

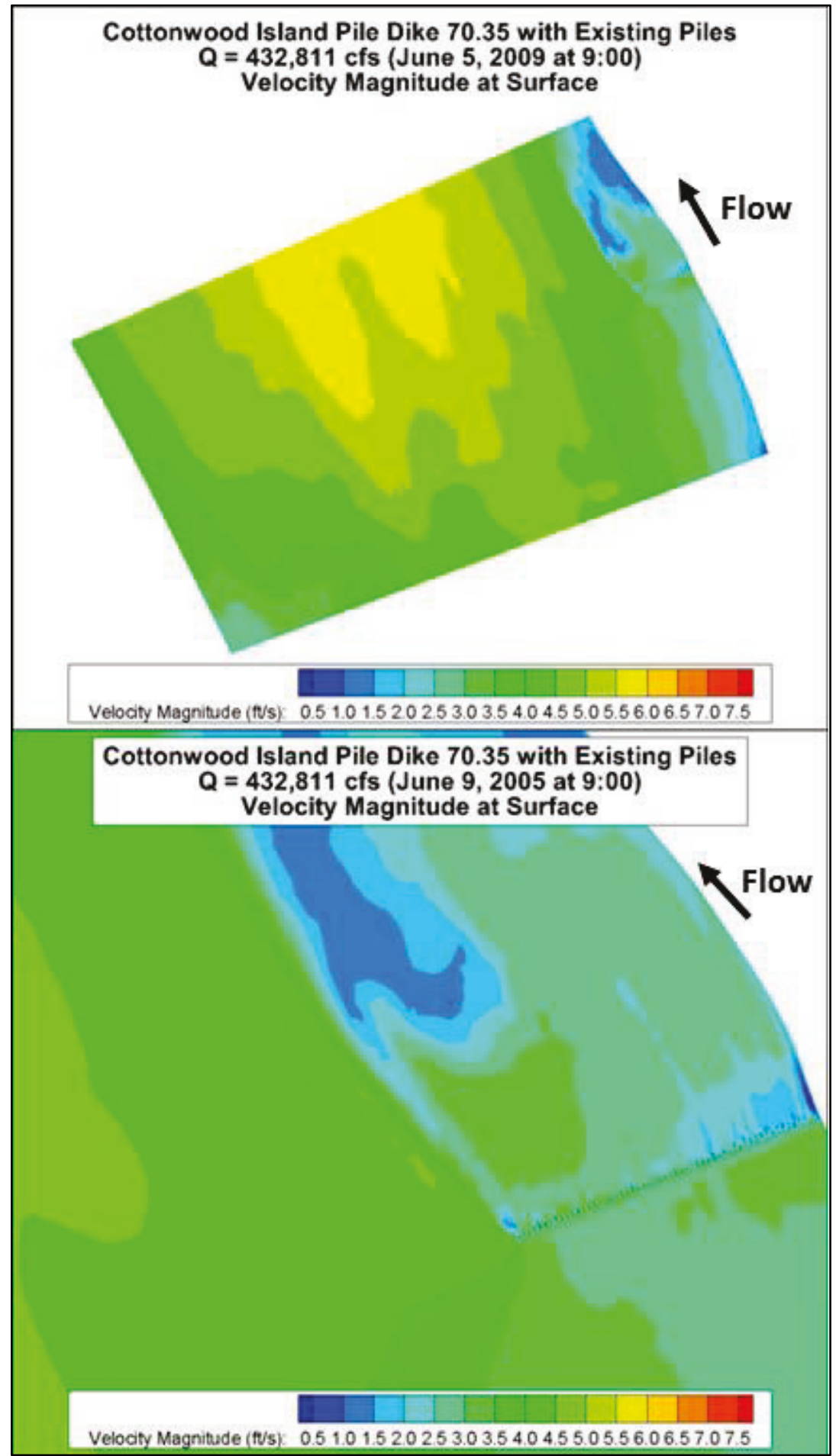


Figure 71. 2-pile combination water surface velocity magnitudes.

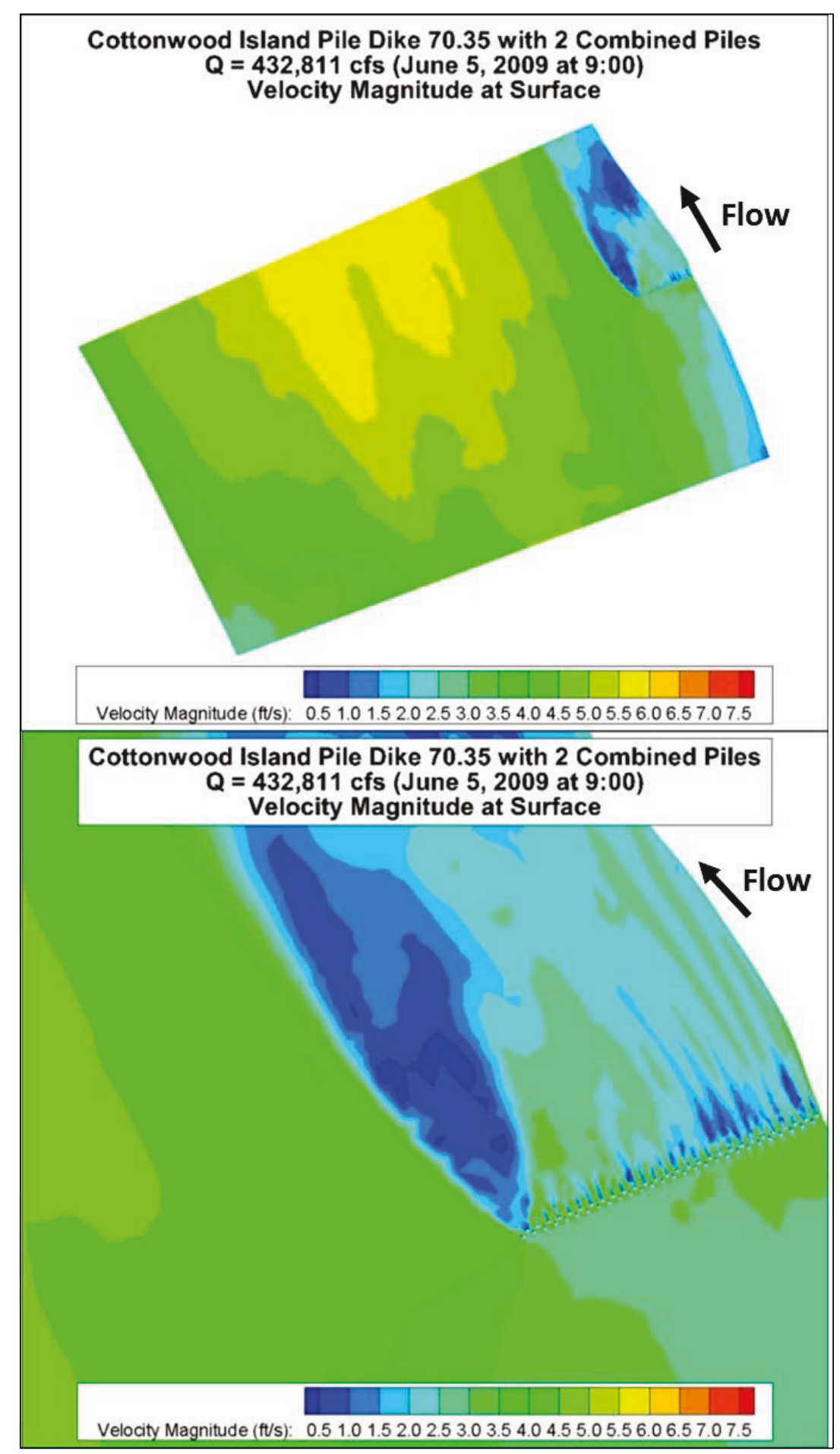


Figure 72. 3-pile combination water surface velocity magnitudes.

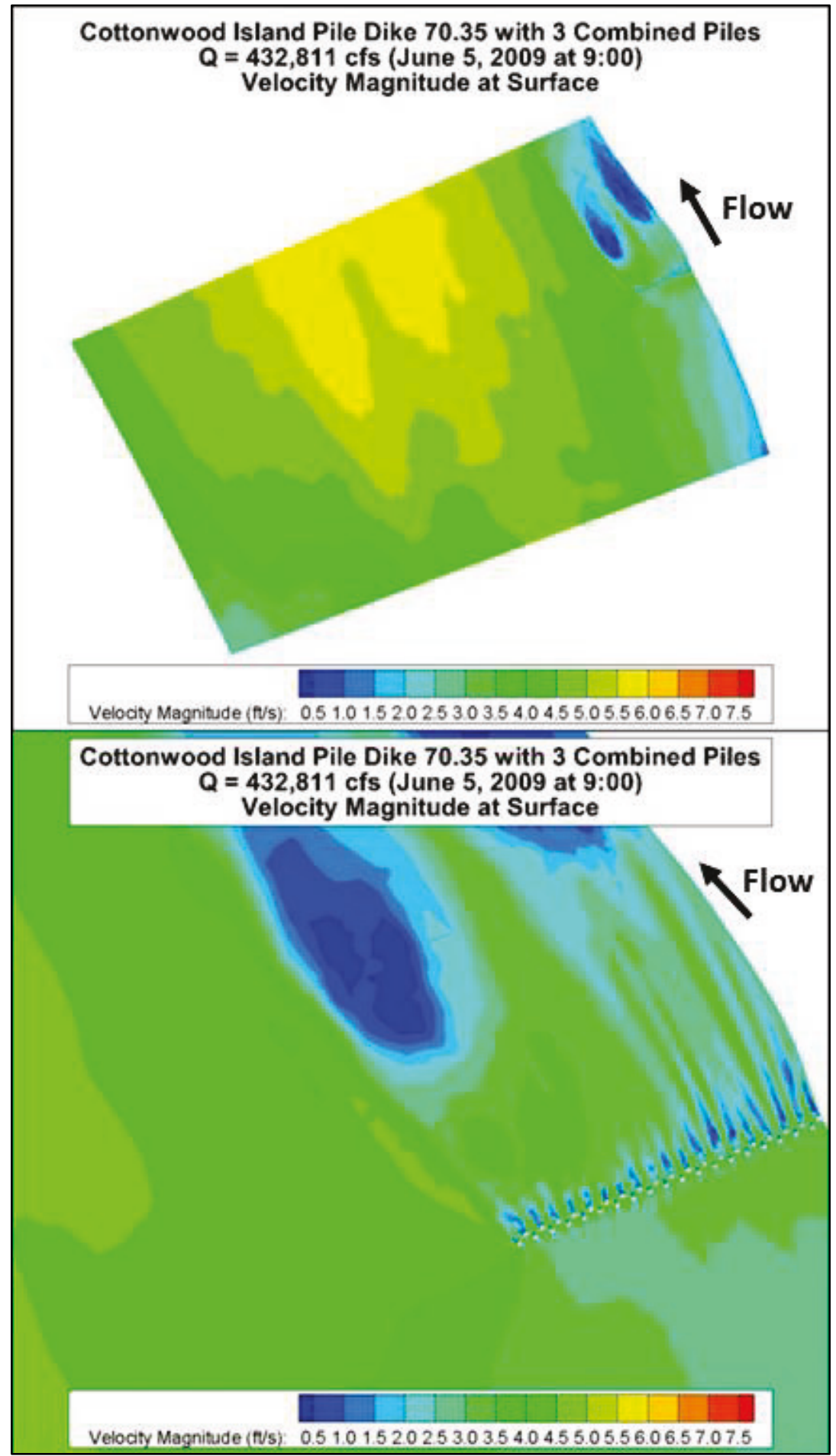




\section{Appendix C: Free Surface vs. Fixed-Lid Water Surface Treatment}

Water's free surface moves when there is flow. Although RANS-AdH can reproduce this water surface motion, the calculations required in the simulation are computationally intensive and require more simulation/processor time to complete than a fixed water surface (fixedlid) simulation. For many open-channel flow situations such as rivers, $3 \mathrm{D}$ flow solutions that are adequate for addressing the engineering questions of interest can be obtained using this fixed-lid method. Simulations using this method are referred to as a fixed-lid simulations. Since the meshes for this study have very high element and node count and the computational requirements are rigorous, ways to reduce the computational complexity of the simulations are sought. Determining if a fixed-lid simulation can produce a sufficiently accurate solution for the flows near the dikes in this study is one way to reduce the computational demand. A comparison study has been performed on a flow domain consisting of one dike (Dike 70.35) using one of the model discharges $(432,811 \mathrm{cfs})$ chosen for the main study.

The first phase of the study consists of free-surface and fixed-lid simulations for the pile dike and rock dike. The one-dike flow domain extends from just downstream of the flow bifurcation immediately east of Cottonwood Island to approximately halfway between Dike 70.35 and Dike 70.77 and includes the entire width of the channel up to the $5 \mathrm{ft}$ depth contour along the northern bank of the Columbia River. A mesh was created for the pile dike flow domain, and steady-state flow solutions were obtained for the single discharge both for the free-surface treatment and the fixed-lid treatment. The only difference between the simulations for each type of dike is the water surface method. The modeling procedure for these simulations is the same as those outlined in Section 3.1.2 of the main report. The decision on whether the fixed-lid simulation choice is sufficient for the four-dike simulations is based on the difference of the water surface elevation and the velocity magnitudes between the two methods.

The flow solutions for the all water-surface treatment simulations are shown in Figure 73 though Figure 78. The velocity magnitudes for each method at the water surface for the pile dikes are shown. The entire flow domain is in Figure 73, and an enlarged view of the dike is in Figure 74. In 
each figure the top image shows the moving free-surface solution, and the bottom image shows in the fixed-lid solution. The only significant differences in the velocity magnitudes between the free-surface treatment and fixed-lid treatment are at the water surface. Qualitatively, the flow solutions are essentially identical. The displacement of the water surface for the pile dike free-surface simulation is shown in Figure 75. In this figure the contour scale ranges from -0.3 to $0.3 \mathrm{ft}$ with a negative value indicating downward movement (a drop) of the water surface and a positive value indicating upward movement (a rise) of the water surface. Even with such a small contour range, the movement of the water surface appears to be negligible for the pile dikes. The largest surface movement is in the immediate vicinity of the piles.

For the rock dikes, the water surface velocity magnitudes are shown in Figure 76 (full domain) and Figure 77 (near the dike). The displacement of the water surface for the rock dike free-surface simulation is shown in Figure 78 . The contour scale ranges from -0.3 to $0.3 \mathrm{ft}$ with a negative value indicating downward movement (a drop) of the water surface and a positive value indicating upward movement (a rise) of the water surface. As with the pile dike, the water surface velocity differences between the free-surface and fixed-lid simulations are negligible. Qualitatively, the solutions are essentially identical with only small differences in the water surface velocity magnitudes. The displacement of the water surface with the rock dike is even smaller than that of the pile dikes.

Overall, the differences in velocity magnitude are slight with the largest variation very near the piles. Based on these flow results, the CHL/NWP team concur that the added computational complexity from the freesurface simulations is unnecessary. Therefore, the fixed-lid surface treatment is used for the water surface for all four-dike simulations. 
Figure 73. Free-surface vs. fixed lid - pile dike full domain water surface velocity magnitudes.

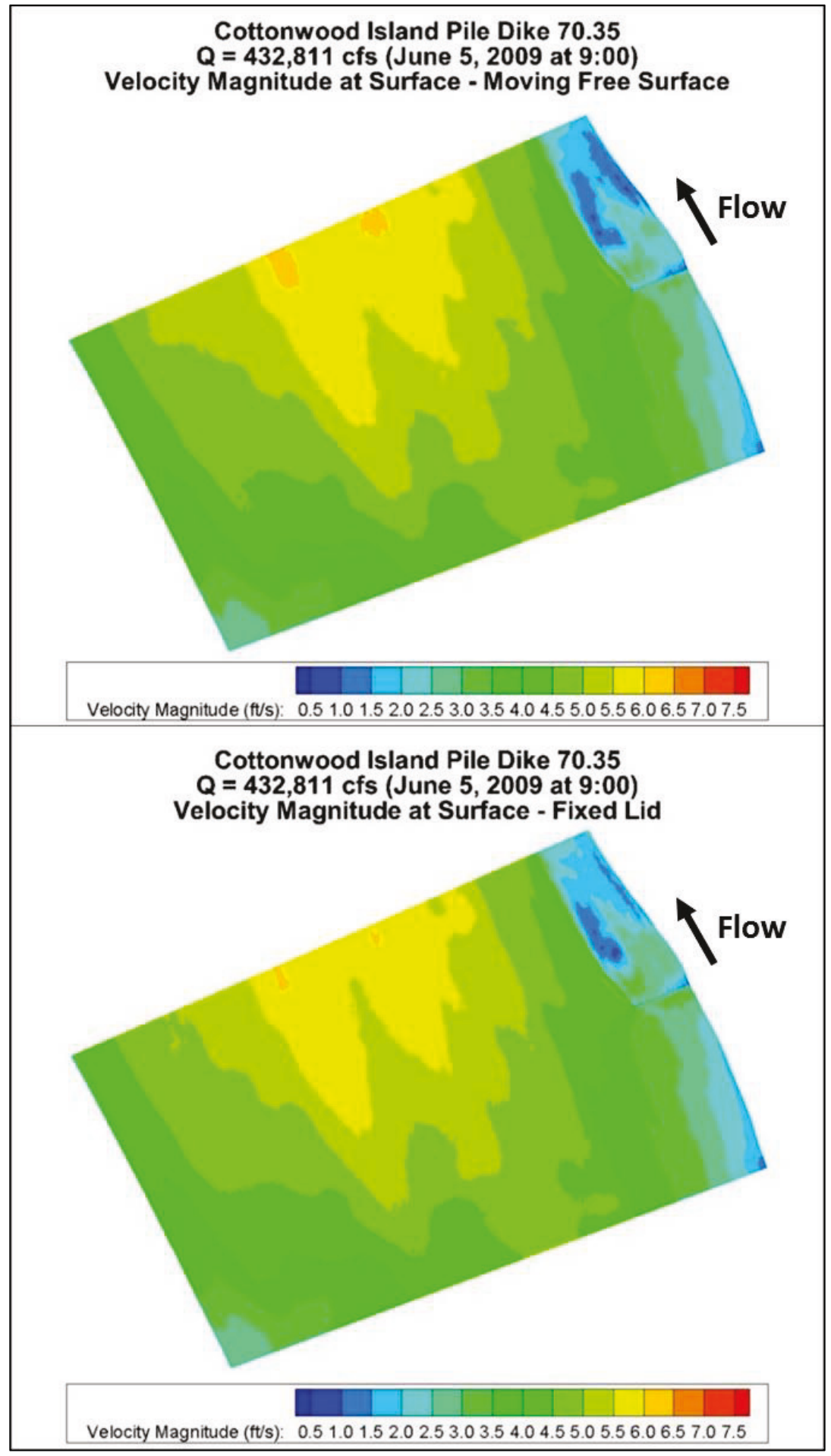


Figure 74. Free-surface vs. fixed lid - pile dike zoom water surface velocity magnitudes

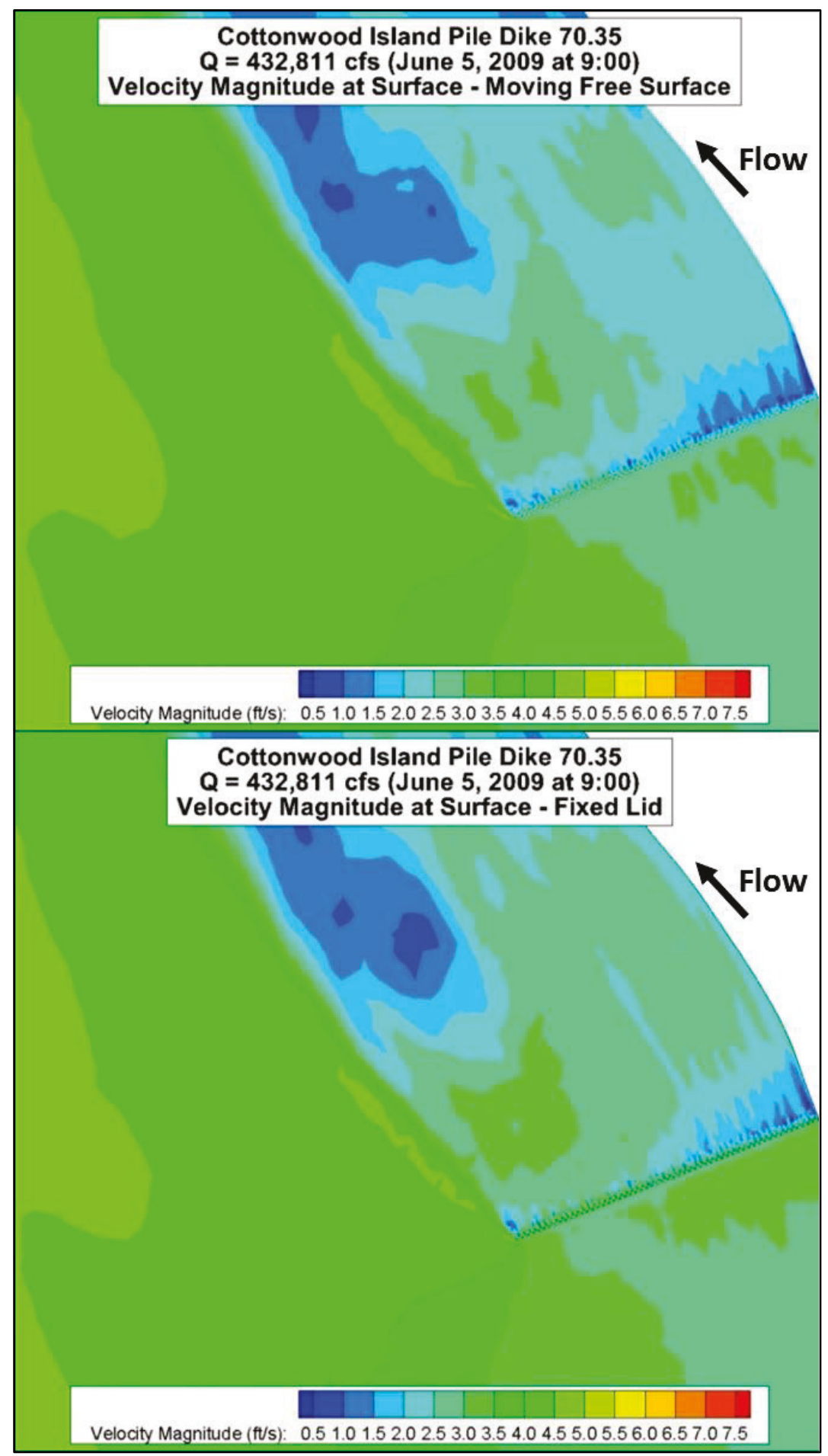


Figure 75. Free-surface vs. fixed lid - pile dike free-surface movement.

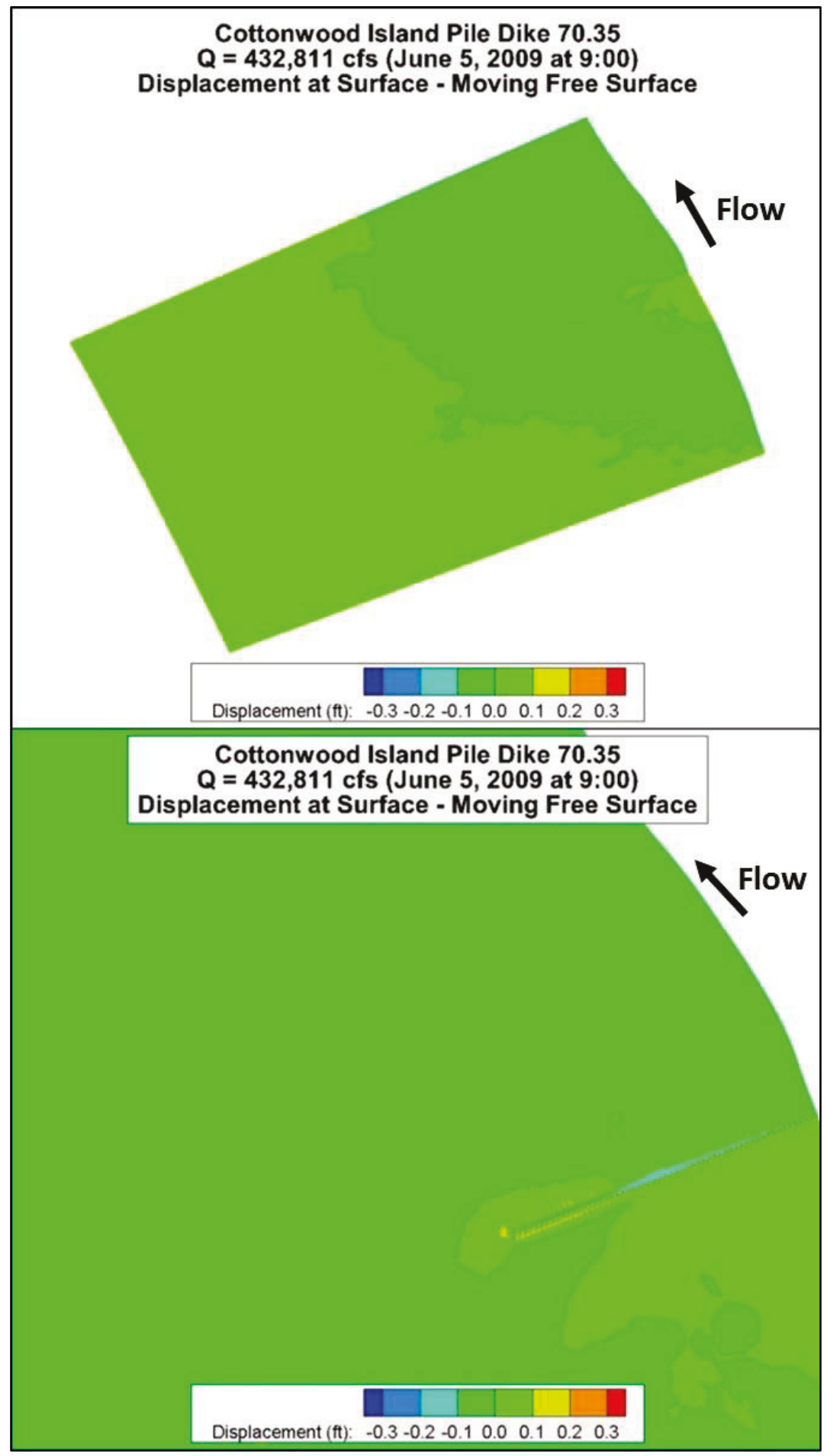


Figure 76. Free-surface vs. fixed lid - rock dike full domain water surface velocity magnitudes.

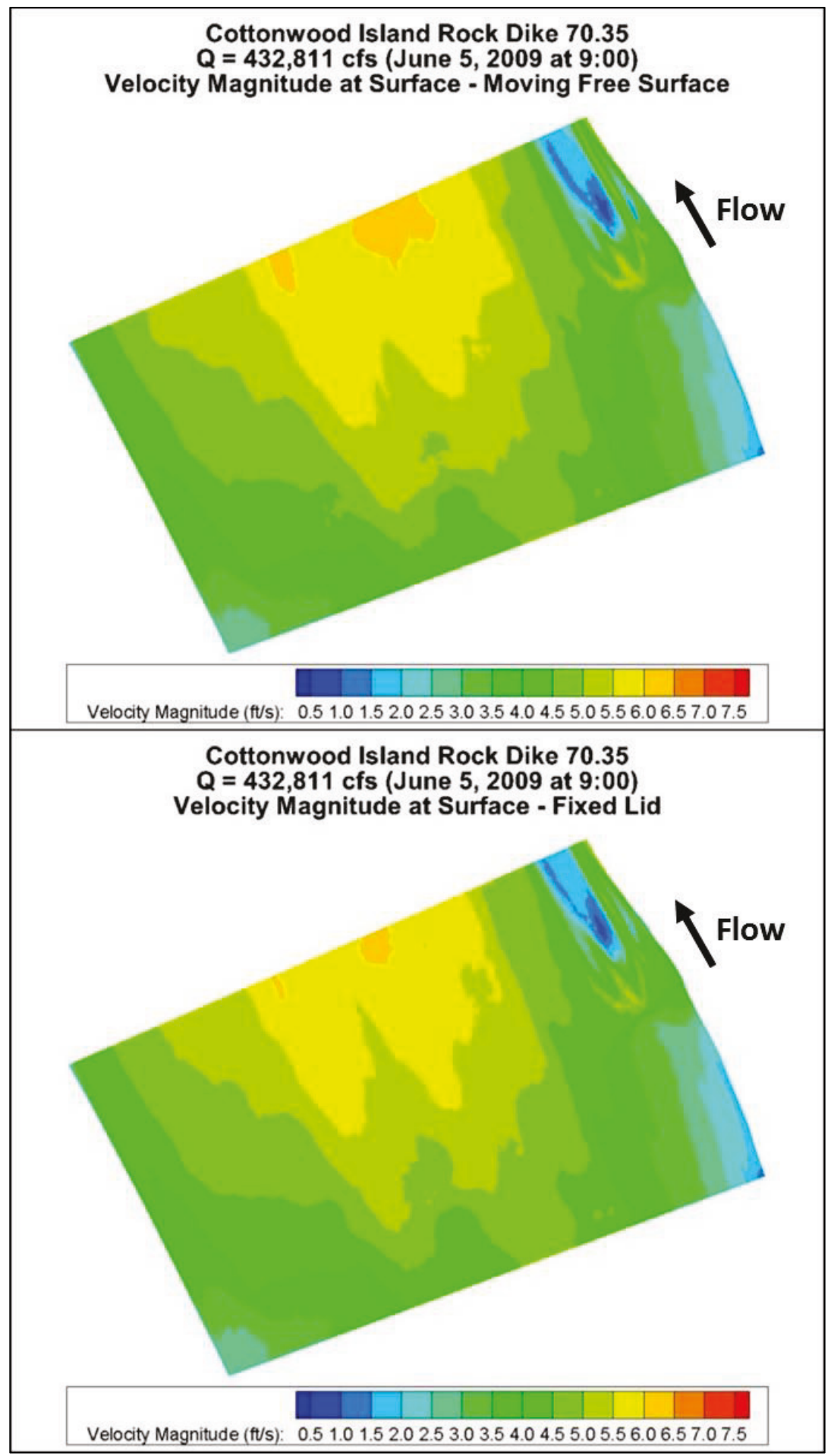


Figure 77. Free-surface vs. fixed lid - rock dike zoom water surface velocity magnitudes.

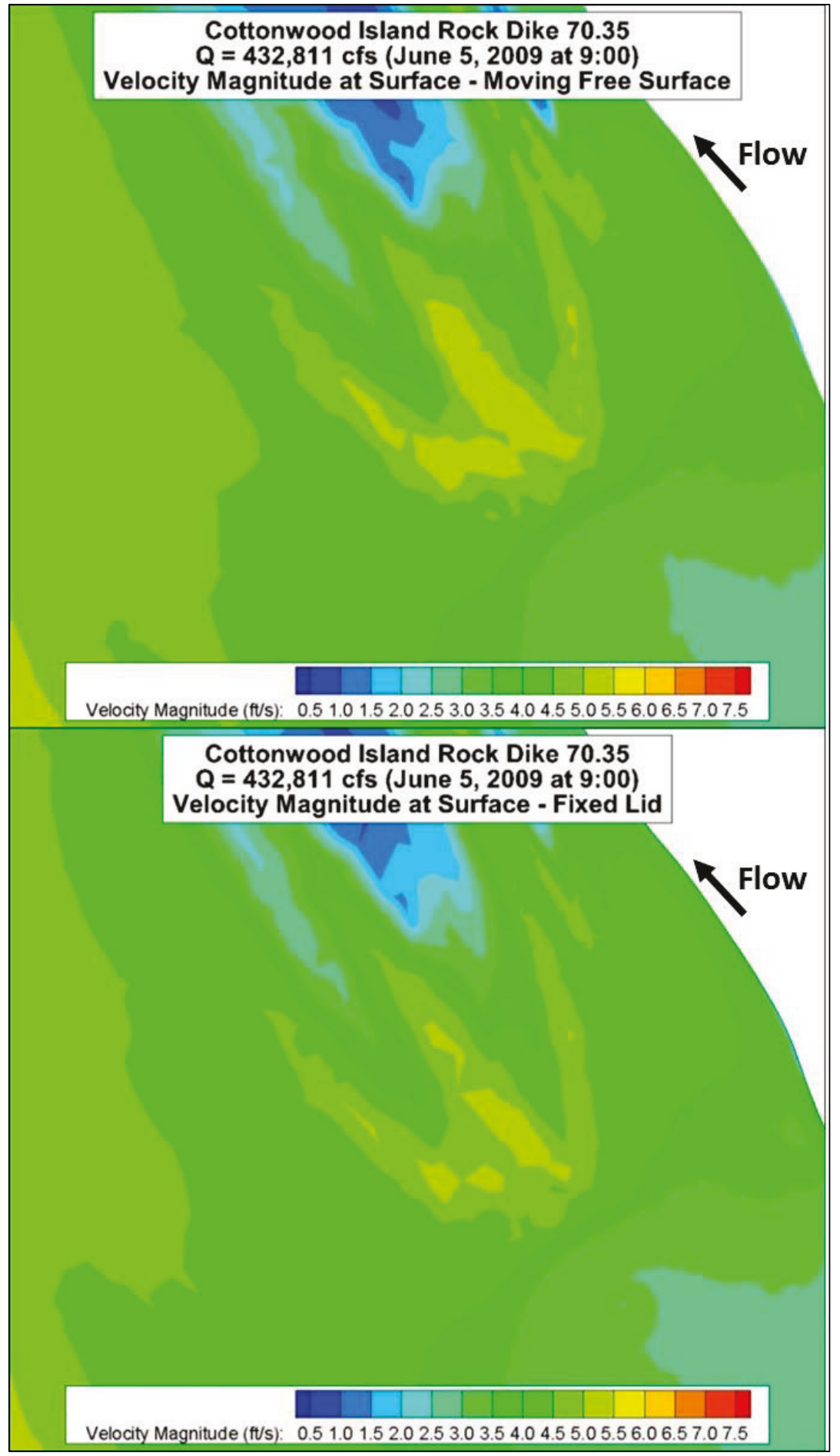


Figure 78. Free-surface vs. fixed lid - rock dike free-surface movement.

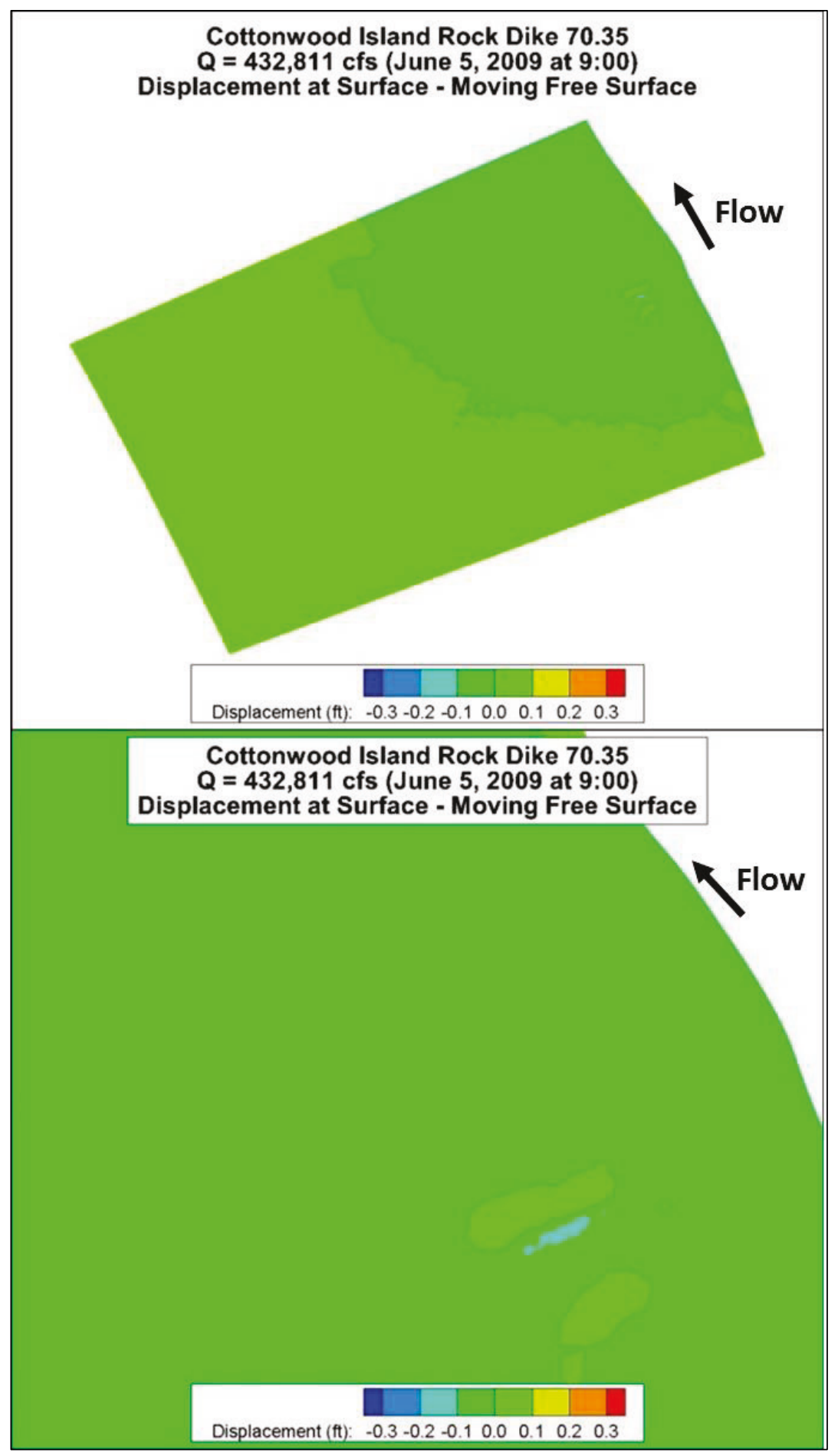




\section{Appendix D: Additional Flow Solution Images}

Additional figures of the flow solution for each discharge used in this numerical model study are included in this appendix. These figures are additional contour plots of the flow solutions at different locations within each flow domain and are intended to supplement the figures and discussion included in Chapter 5 of the main report.

Additional flow solution images for high discharge are presented in Figure 79 through Figure 86, for medium discharge are presented in Figure 87 through Figure 94, and for low discharge are presented in Figure 95 through Figure 102, respectively.

Vertical slice locations for Pile Dike 70.07 are shown in Figure 103. High, medium, and low discharge vertical velocity profiles for Pile Dike 70.07 are shown in Figure 104 through Figure 106, respectively.

Vertical slice locations for Rock Dike 70.07 are shown in Figure 107. High, medium, and low discharge vertical velocity profiles for Rock Dike 70.07 are shown in Figure 108 through Figure 110, respectively.

Vertical slice locations for Pile Dike 69.79 are shown in Figure 111. High, medium, and low discharge vertical velocity profiles for Pile Dike 69.79 are shown in Figure 112 through Figure 114, respectively.

Vertical slice locations for Rock Dike 69.79 are shown in Figure 115. High, medium, and low discharge vertical velocity profiles for Rock Dike 69.79 are shown in Figure 116 through Figure 118, respectively. 


\section{High discharge}

Figure 79. High discharge full domain $5 \mathrm{ft}$ depth velocity magnitude comparison.

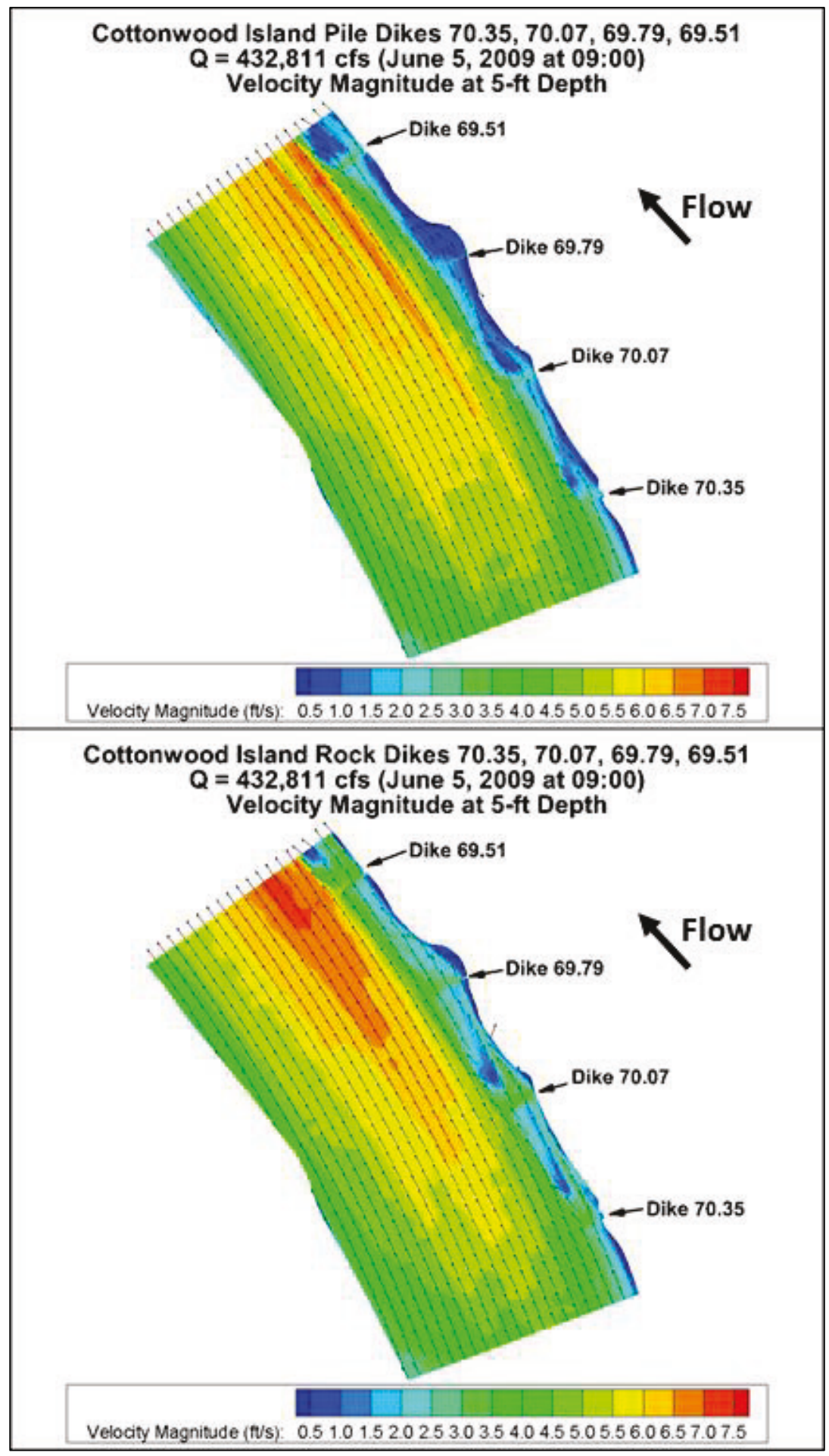


Figure 80. High discharge full domain $5 \mathrm{ft}$ depth velocity magnitude comparison.

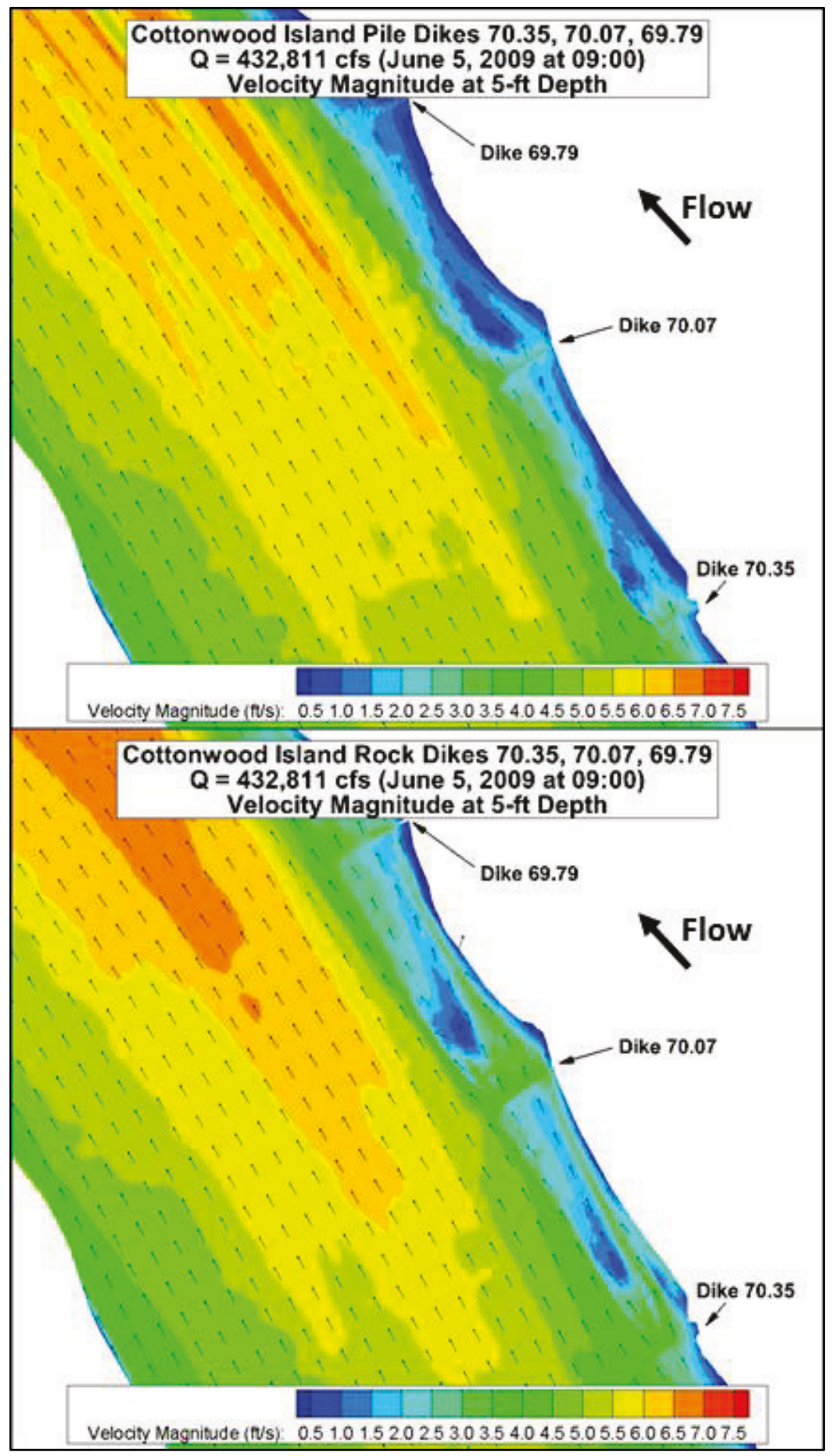


Figure 81. High discharge full domain $5 \mathrm{ft}$ depth velocity magnitude comparison - isometric.

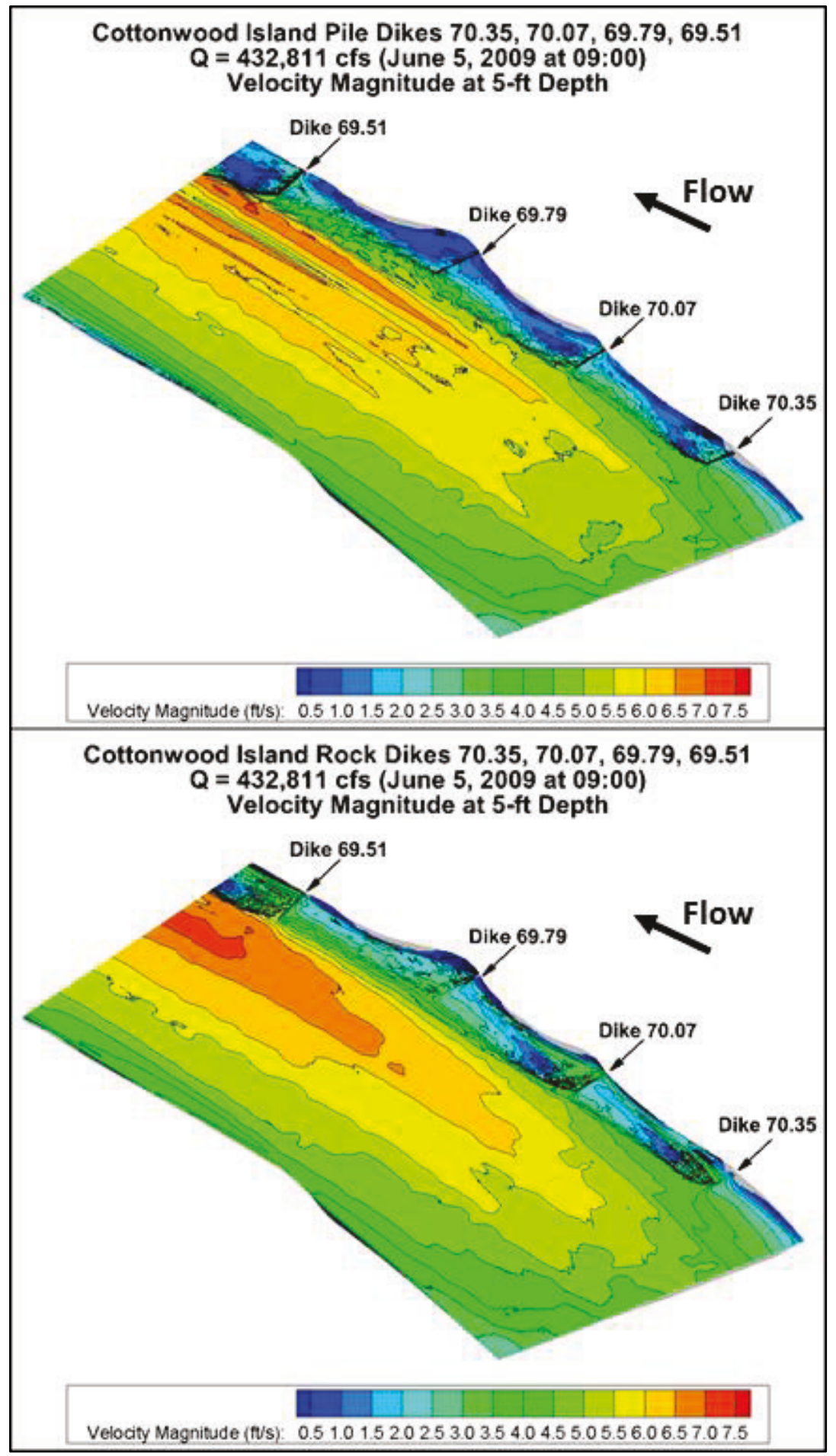


Figure 82. High discharge velocity contours at $5 \mathrm{ft}$ depth around Dike 69.79 - isometric.

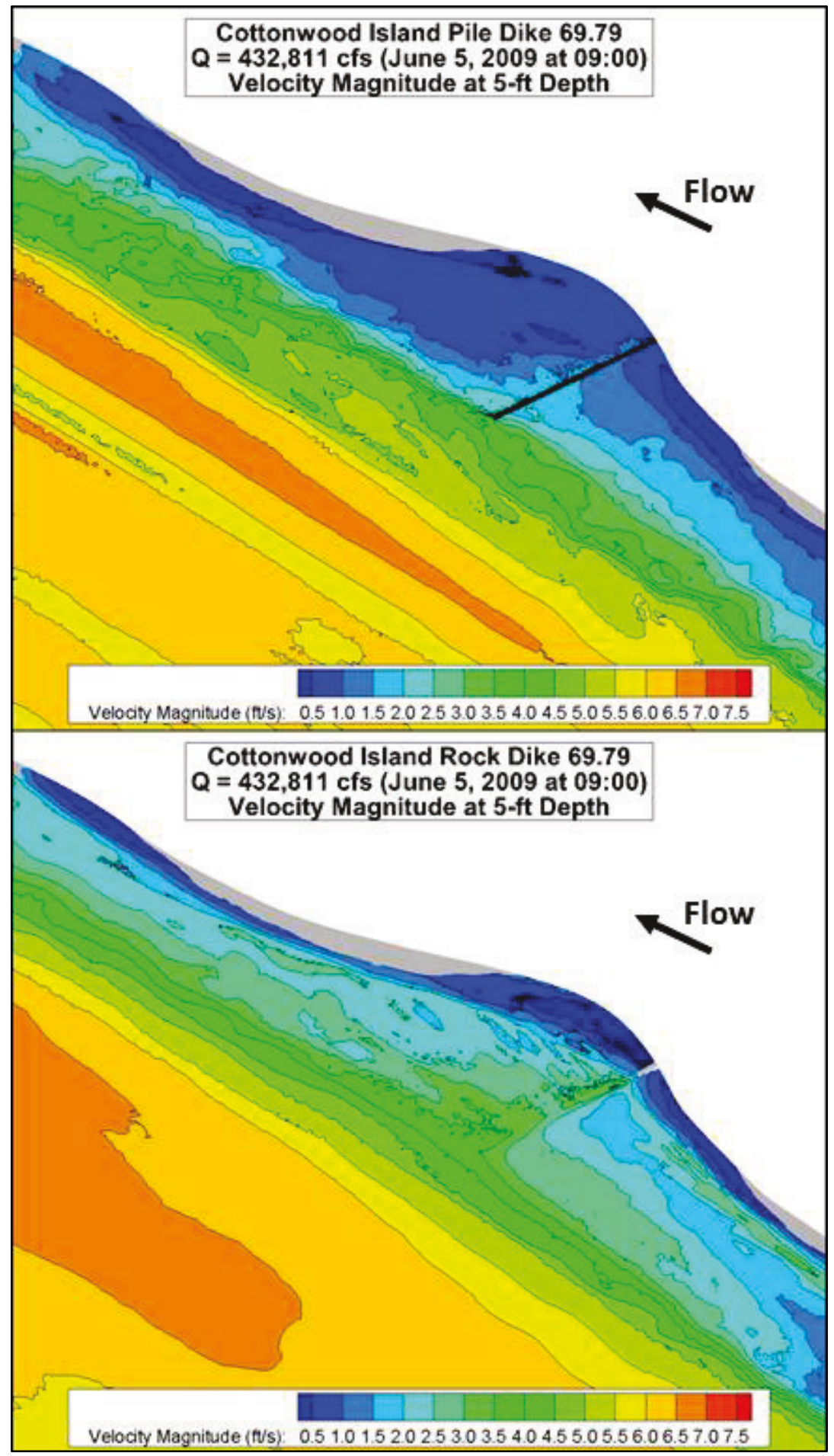


Figure 83. Eddies formed downstream of Dike 70.07 at $10 \mathrm{ft}$ depth for high discharge.

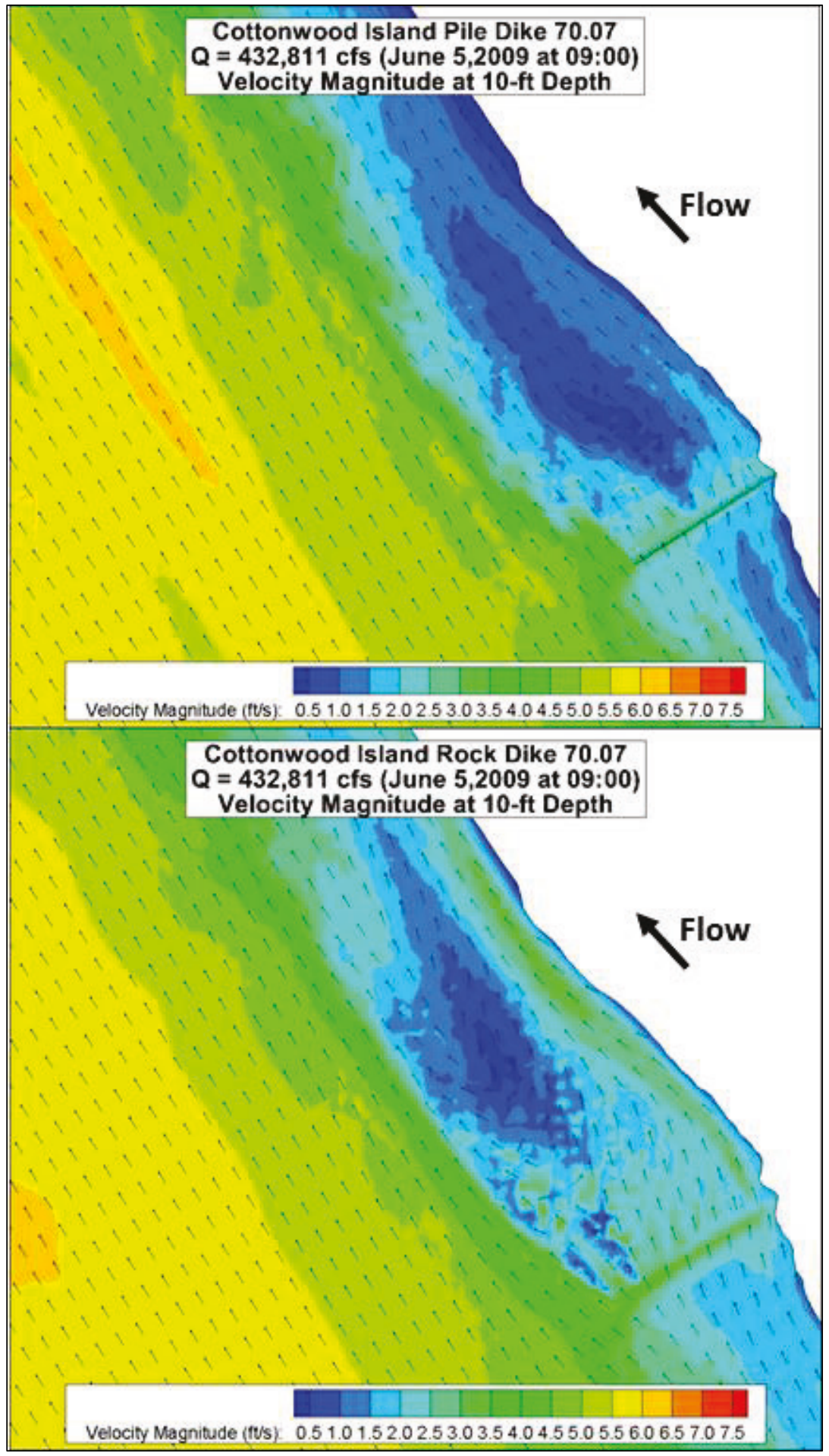


Figure 84. Eddies formed downstream of Dike 69.79 at $10 \mathrm{ft}$ depth for high discharge.

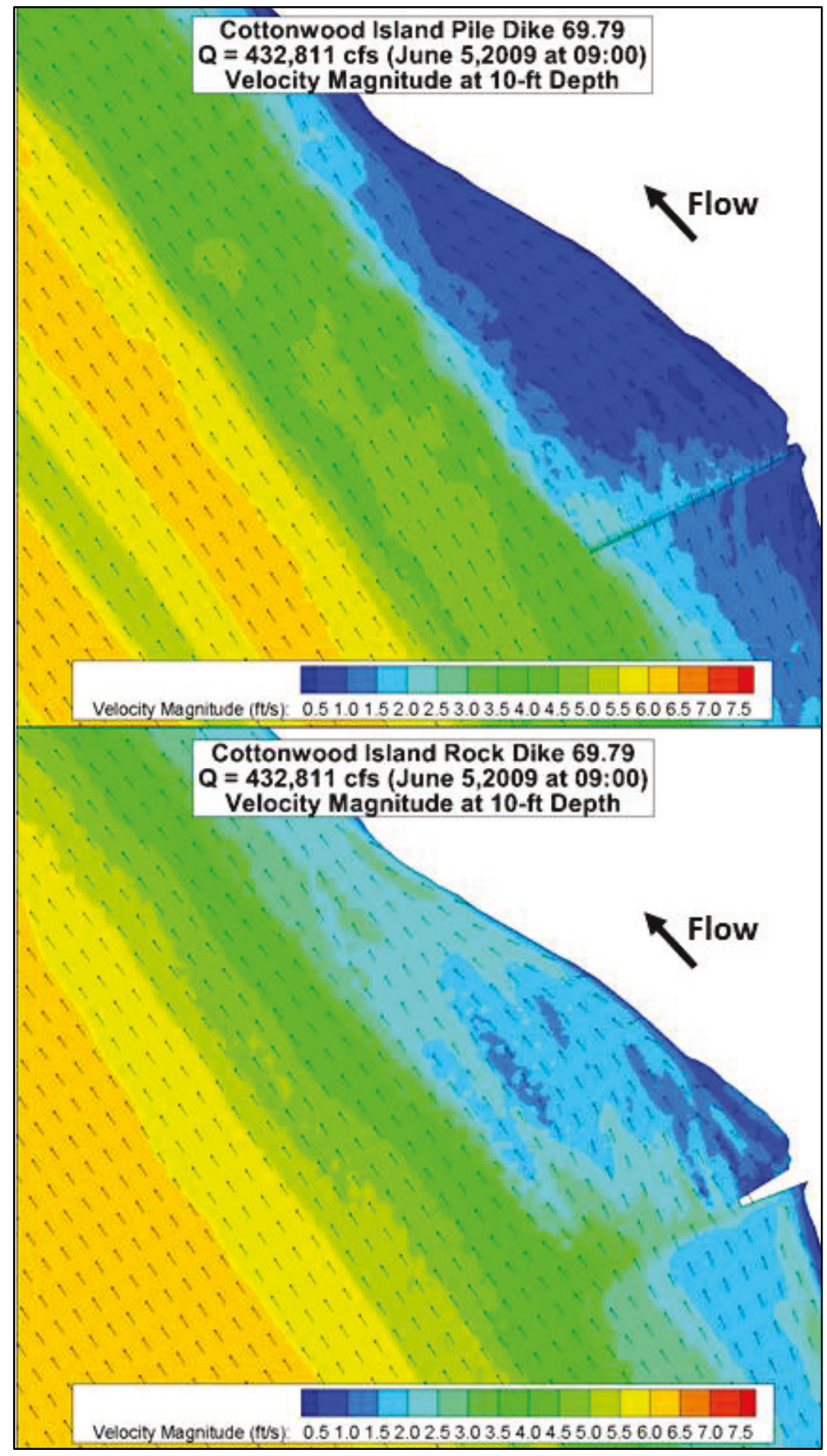


Figure 85. High discharge velocity magnitude difference comparison.

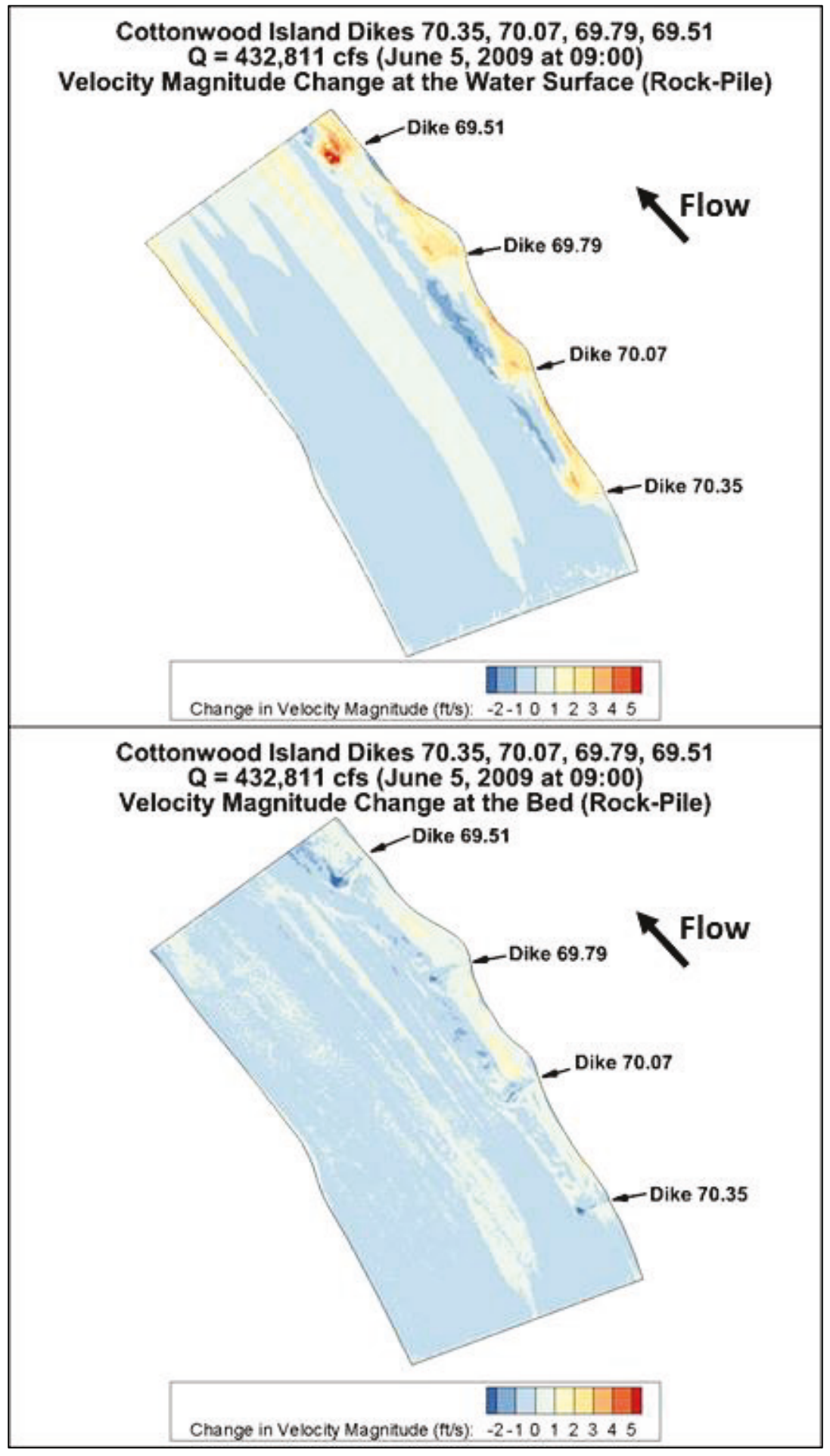


Figure 86. High discharge velocity magnitude difference comparison.

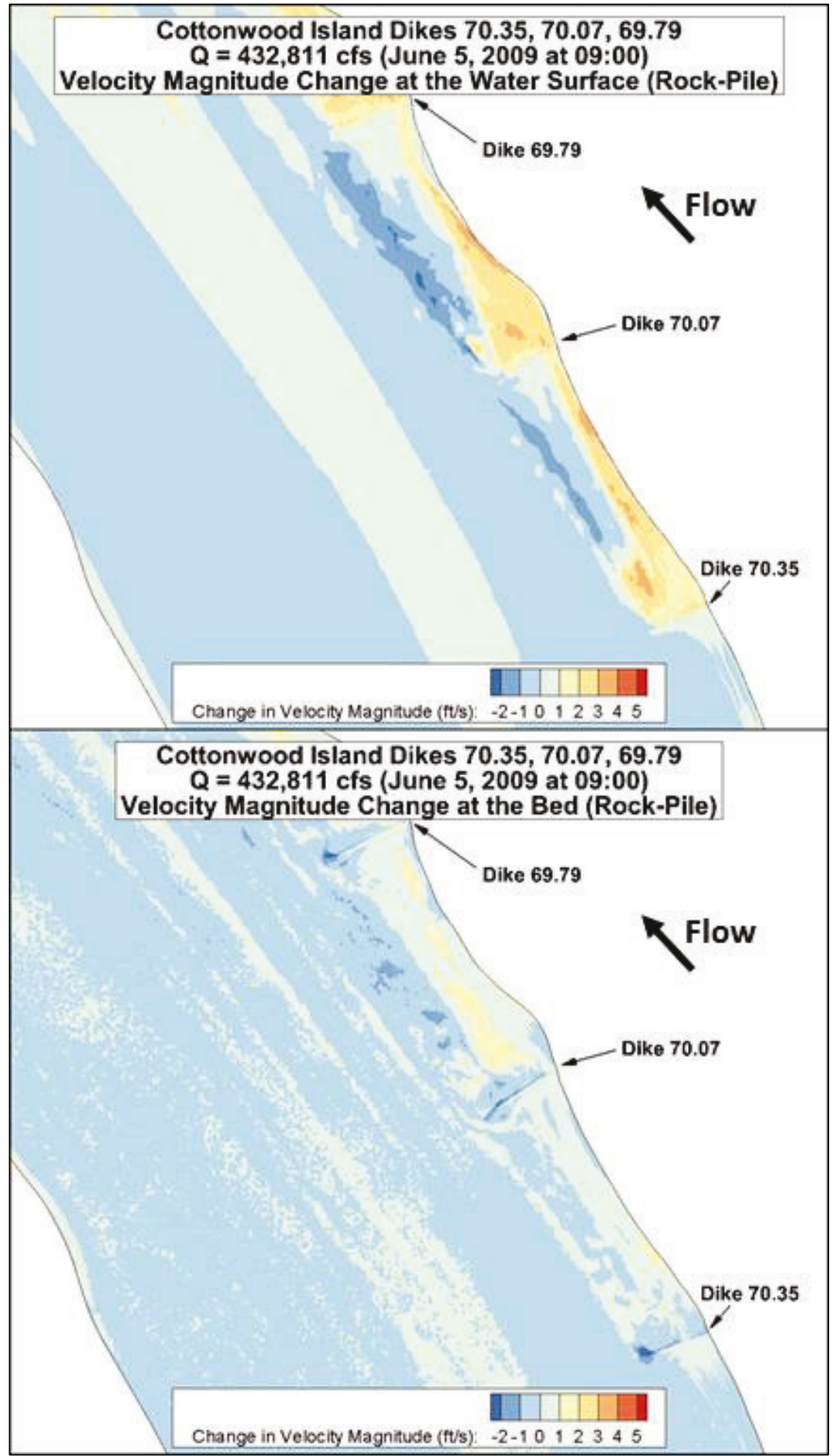




\section{Medium discharge}

Figure 87. Medium discharge full domain $5 \mathrm{ft}$ depth velocity magnitude comparison.

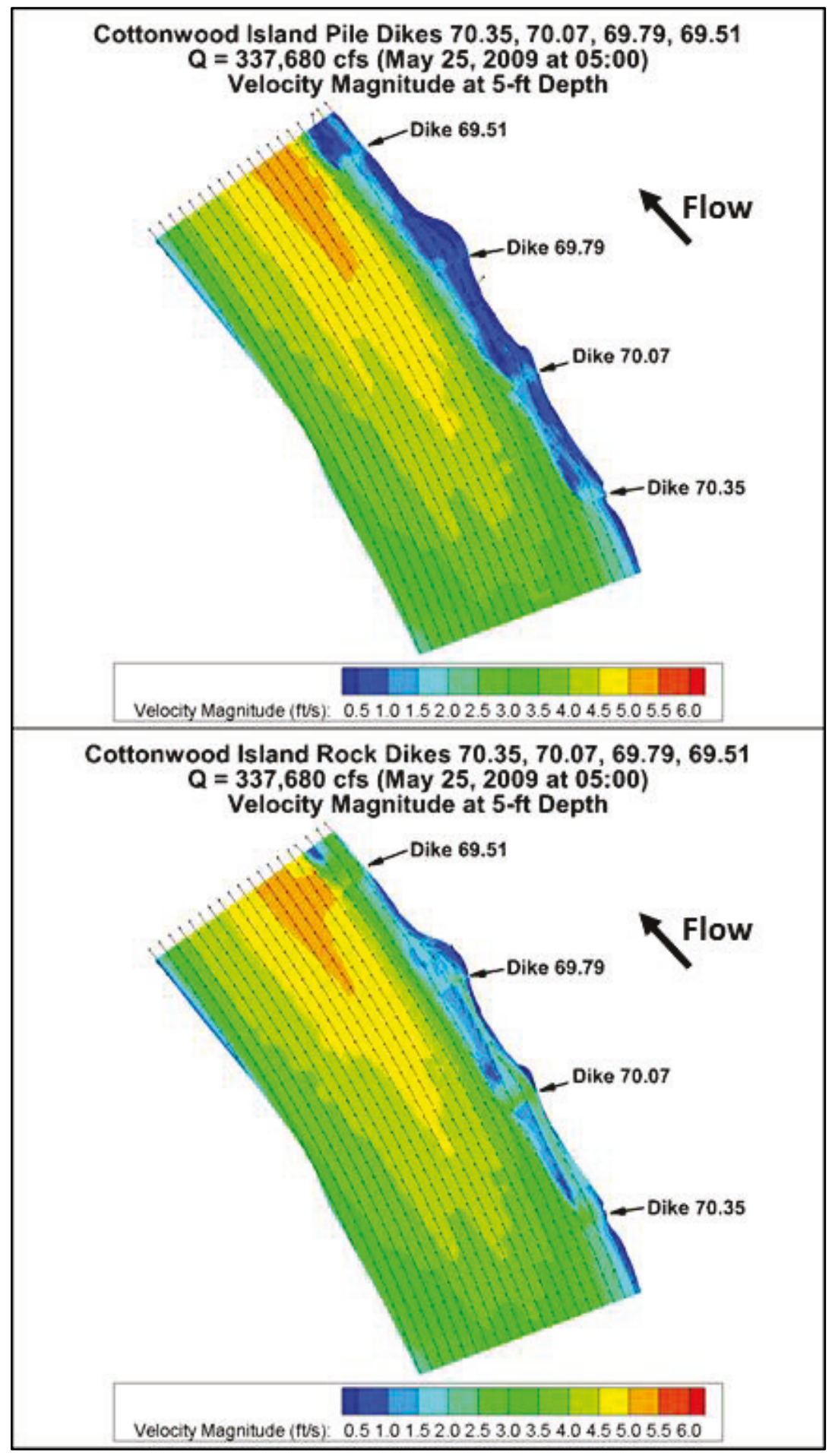


Figure 88. Medium discharge full domain $5 \mathrm{ft}$ depth velocity magnitude comparison.

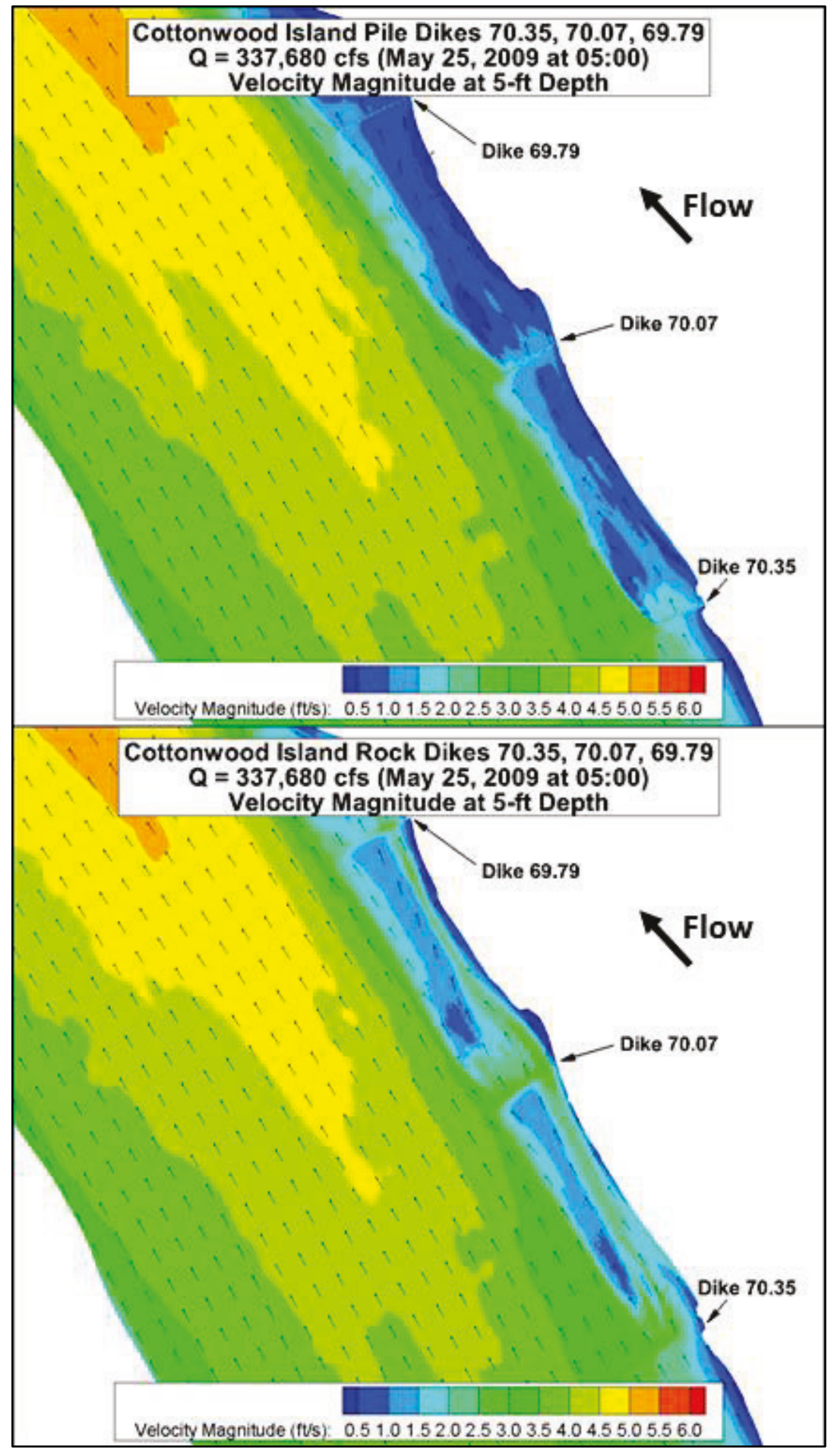


Figure 89. Medium discharge full domain $5 \mathrm{ft}$ depth velocity magnitude comparison - isometric.

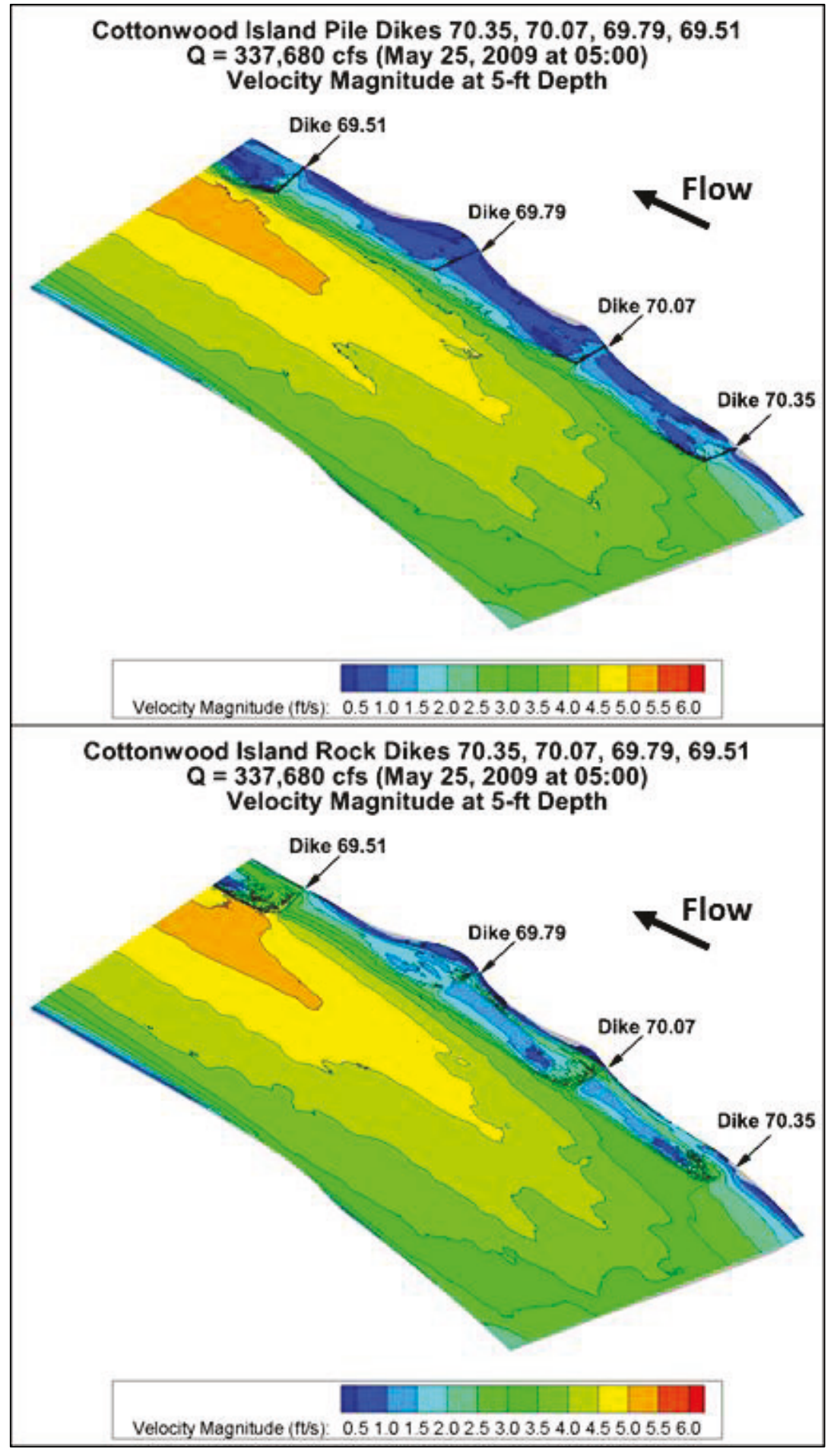


Figure 90 . Medium discharge velocity contours at $5 \mathrm{ft}$ depth around Dike 69.79 - isometric.

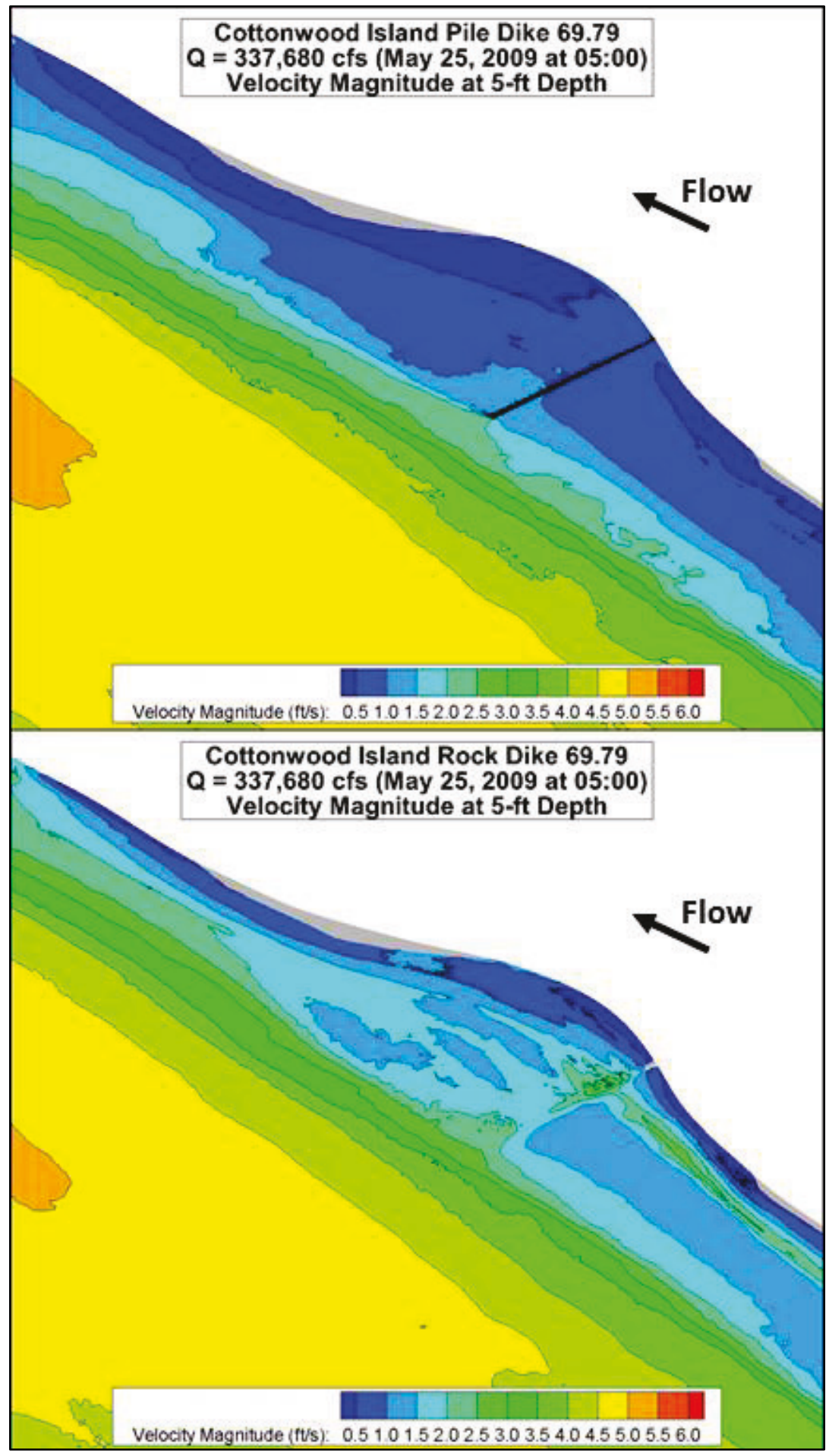


Figure 91. Eddies formed downstream of Dike 70.07 at $10 \mathrm{ft}$ depth for medium discharge.

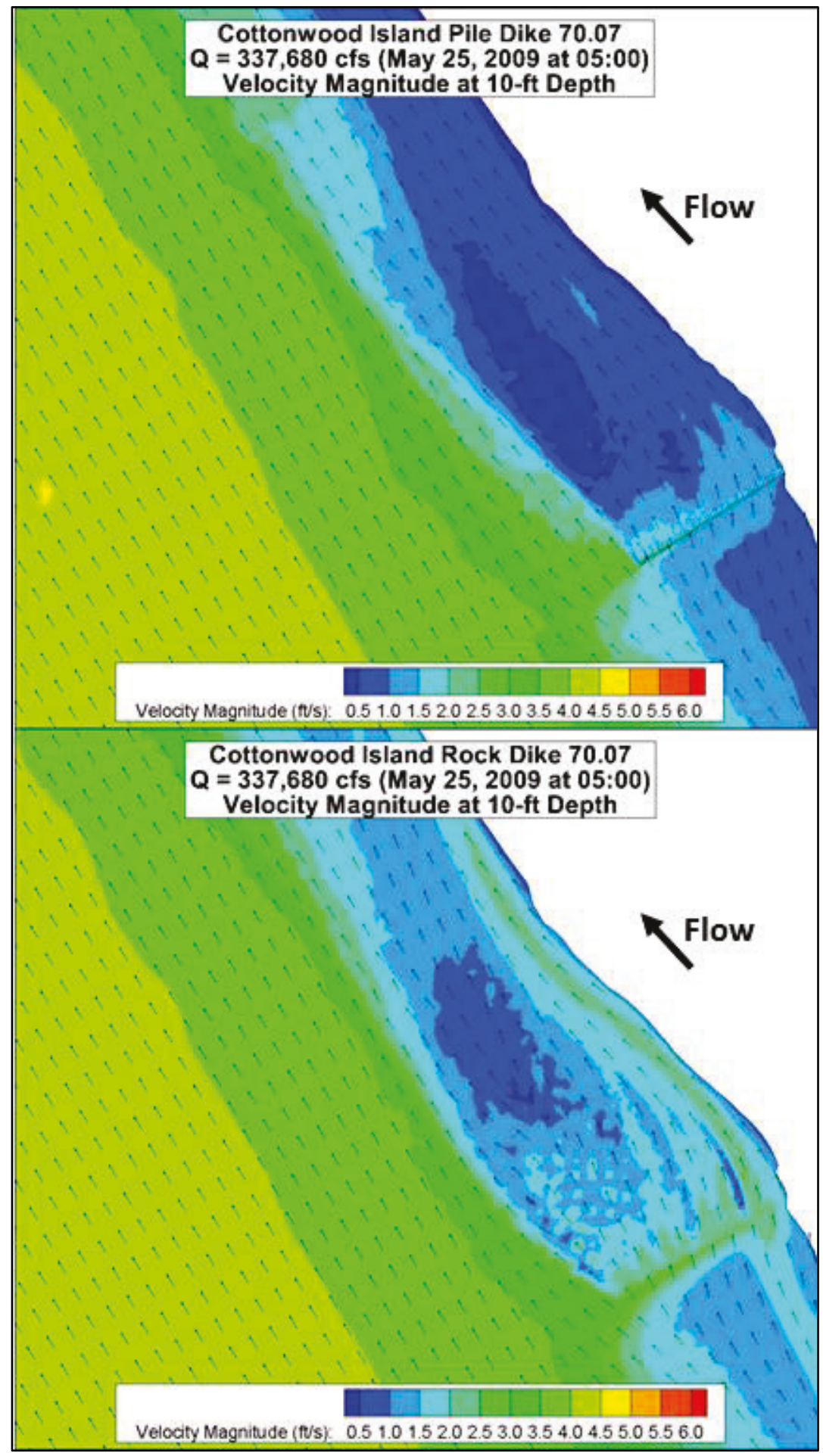


Figure 92. Eddies formed downstream of Dike 69.79 at $10 \mathrm{ft}$ depth for medium discharge.

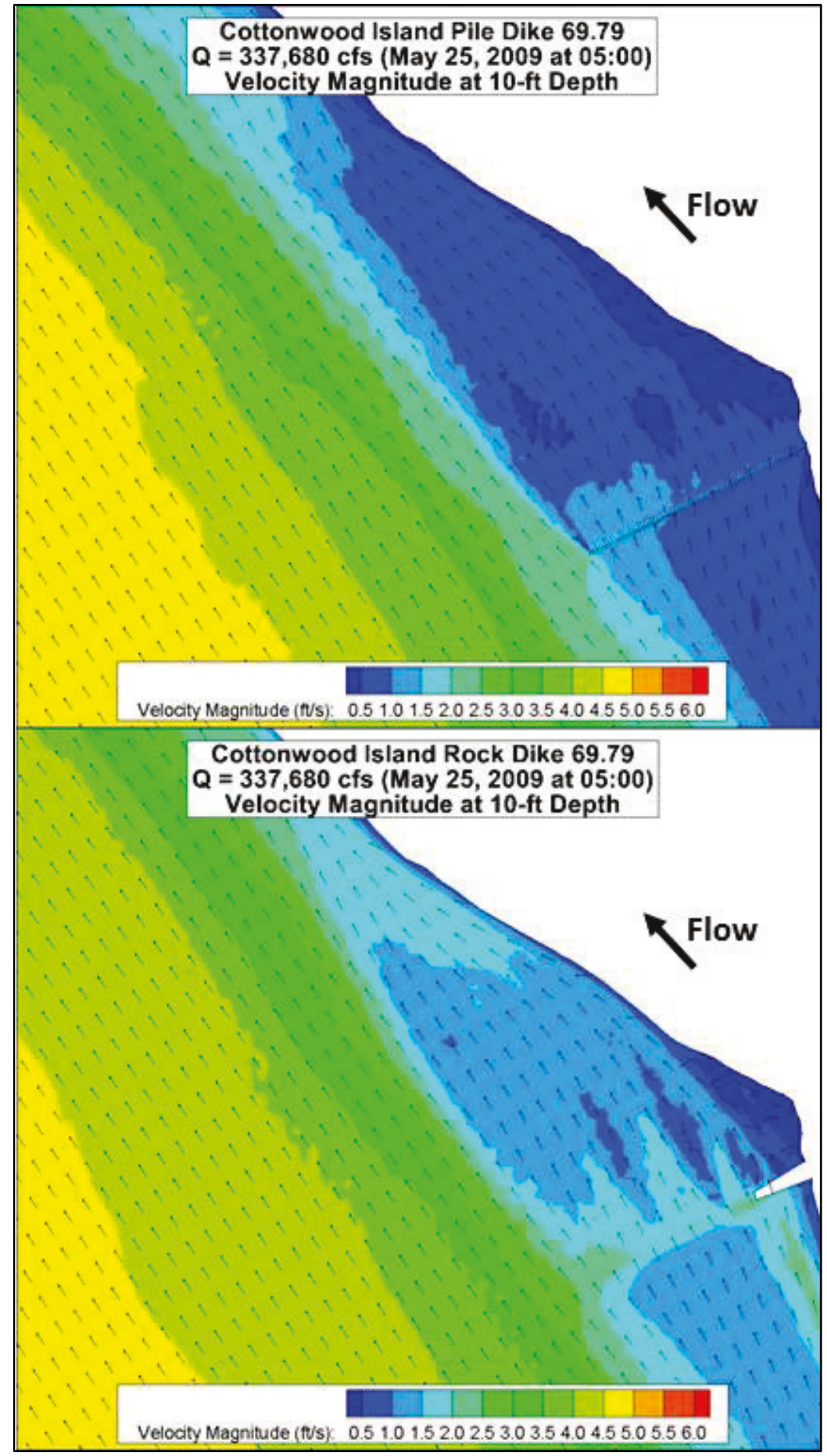


Figure 93. Medium discharge velocity magnitude difference comparison.

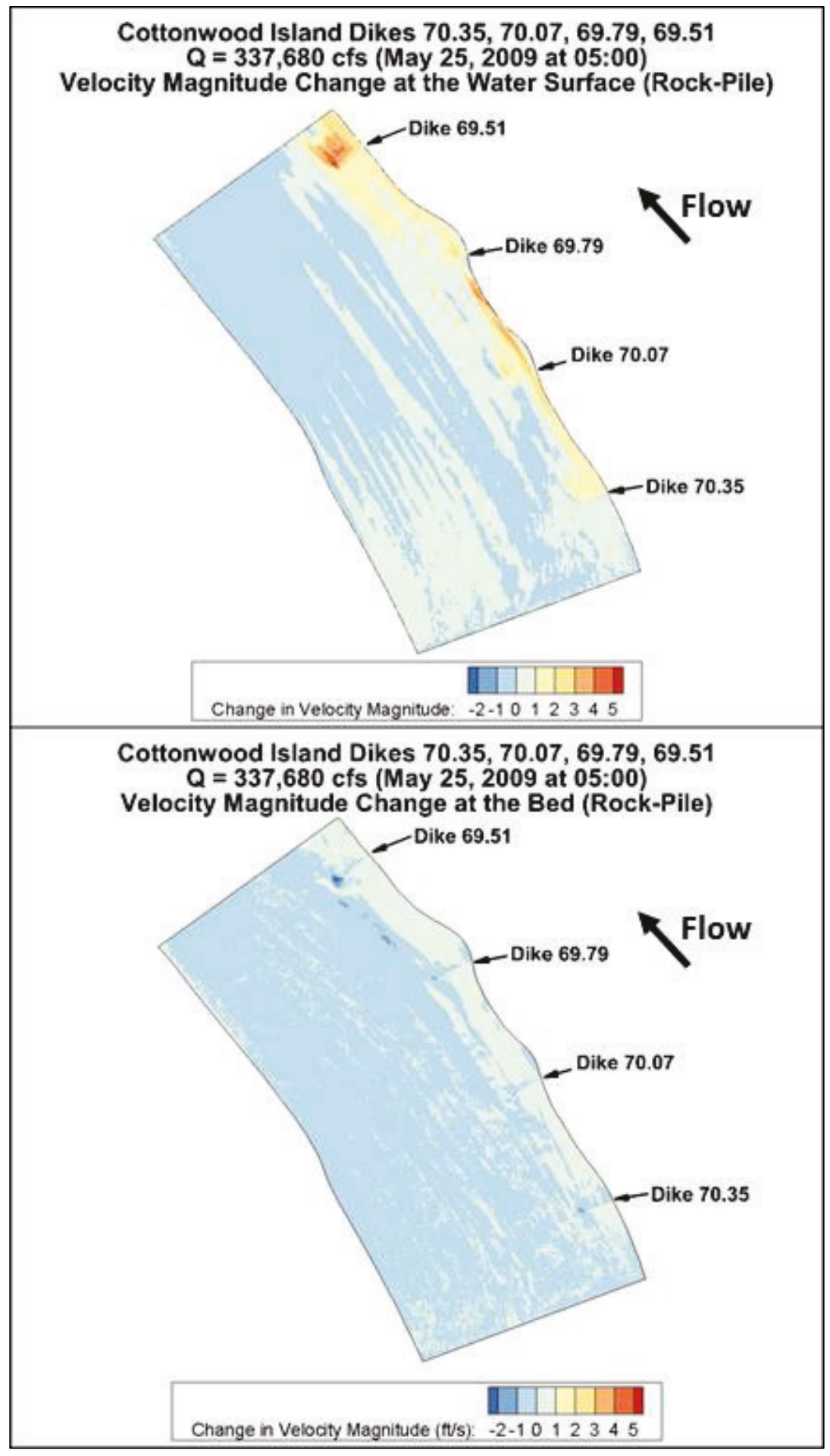


Figure 94. Medium discharge velocity magnitude difference comparison.

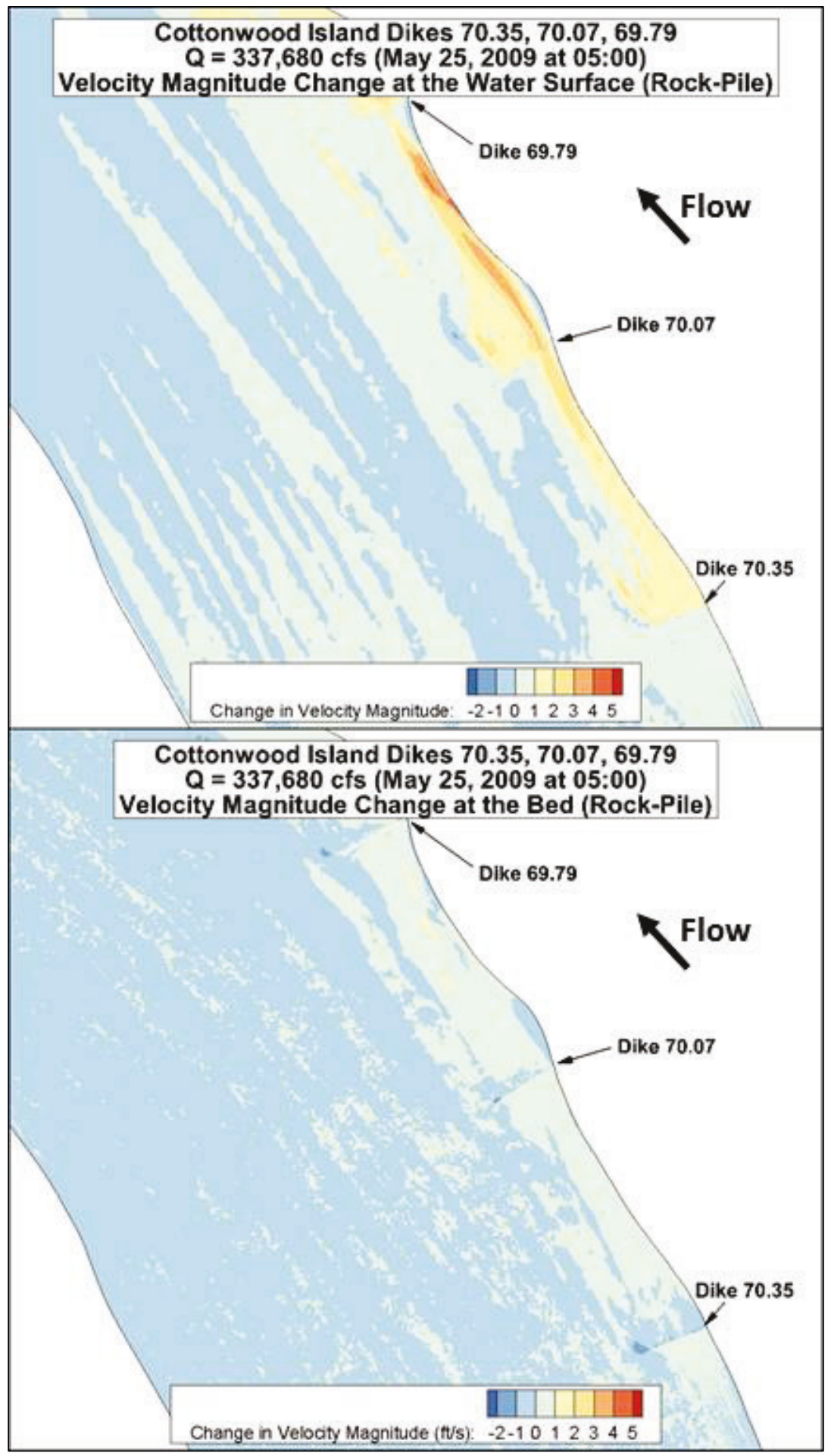




\section{Low discharge}

Figure 95. Low discharge full domain $5 \mathrm{ft}$ depth velocity magnitude comparison.

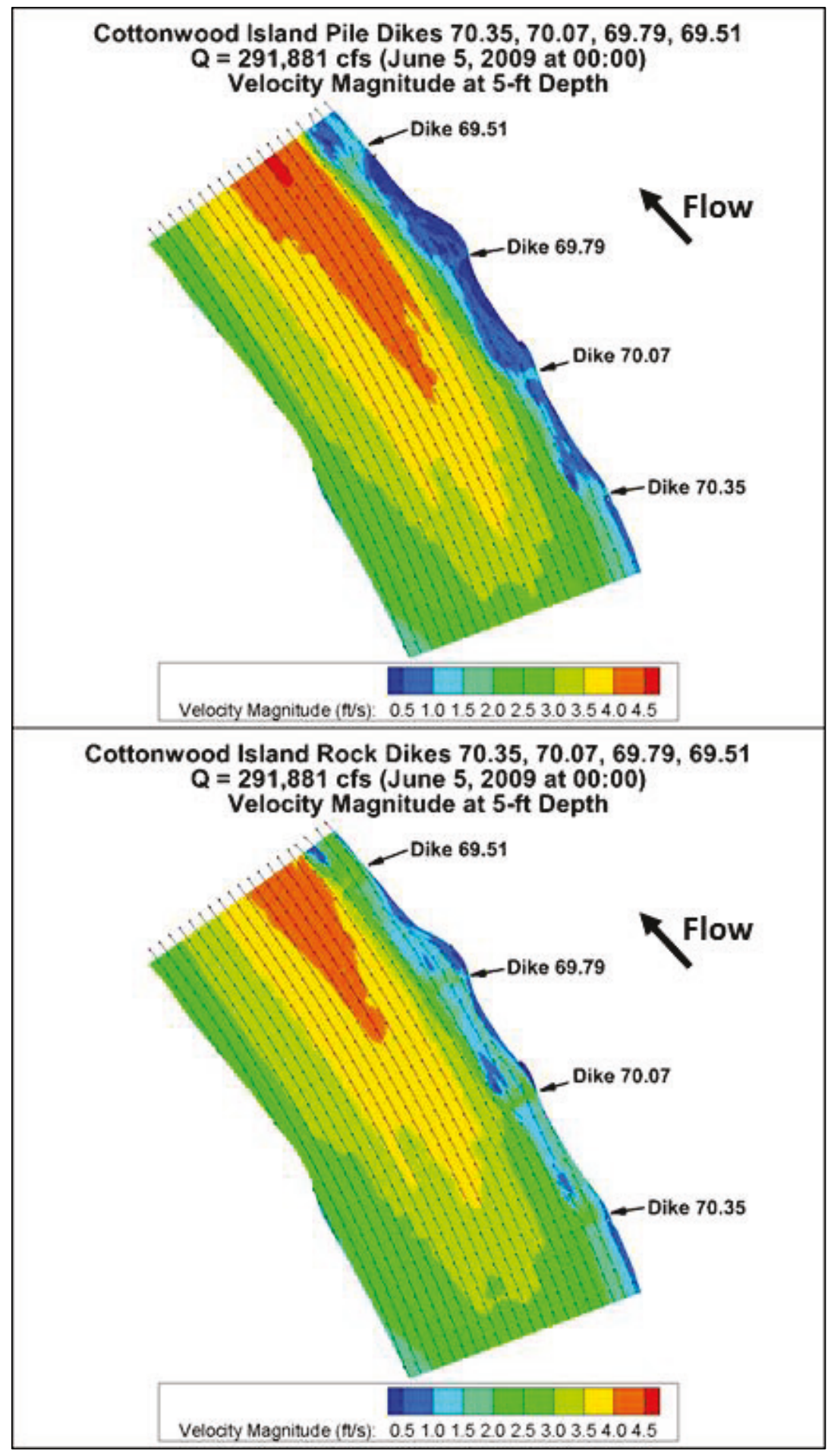


Figure 96. Low discharge full domain $5 \mathrm{ft}$ depth velocity magnitude comparison.

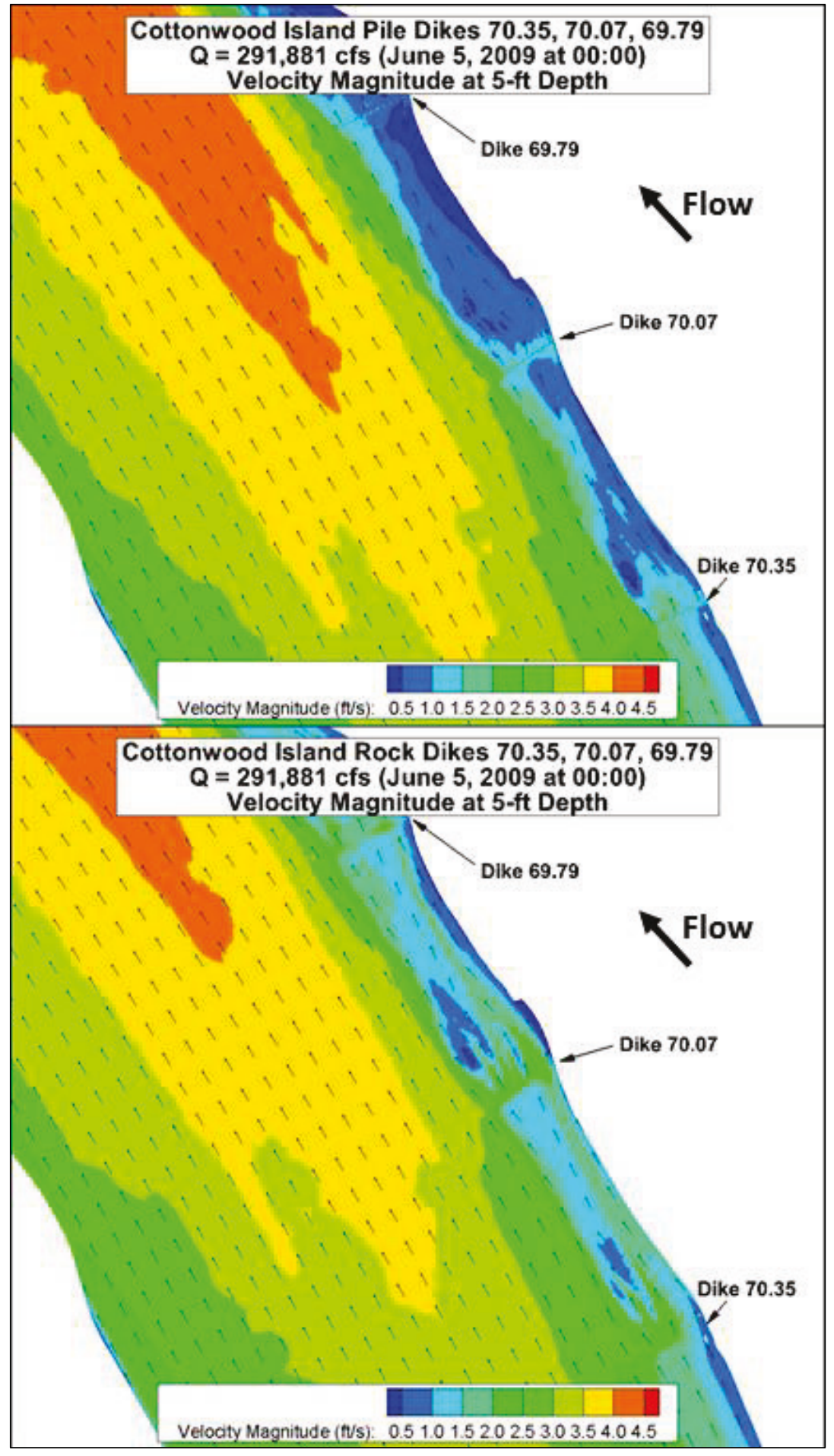


Figure 97. Low discharge full domain $5 \mathrm{ft}$ depth velocity magnitude comparison - isometric.

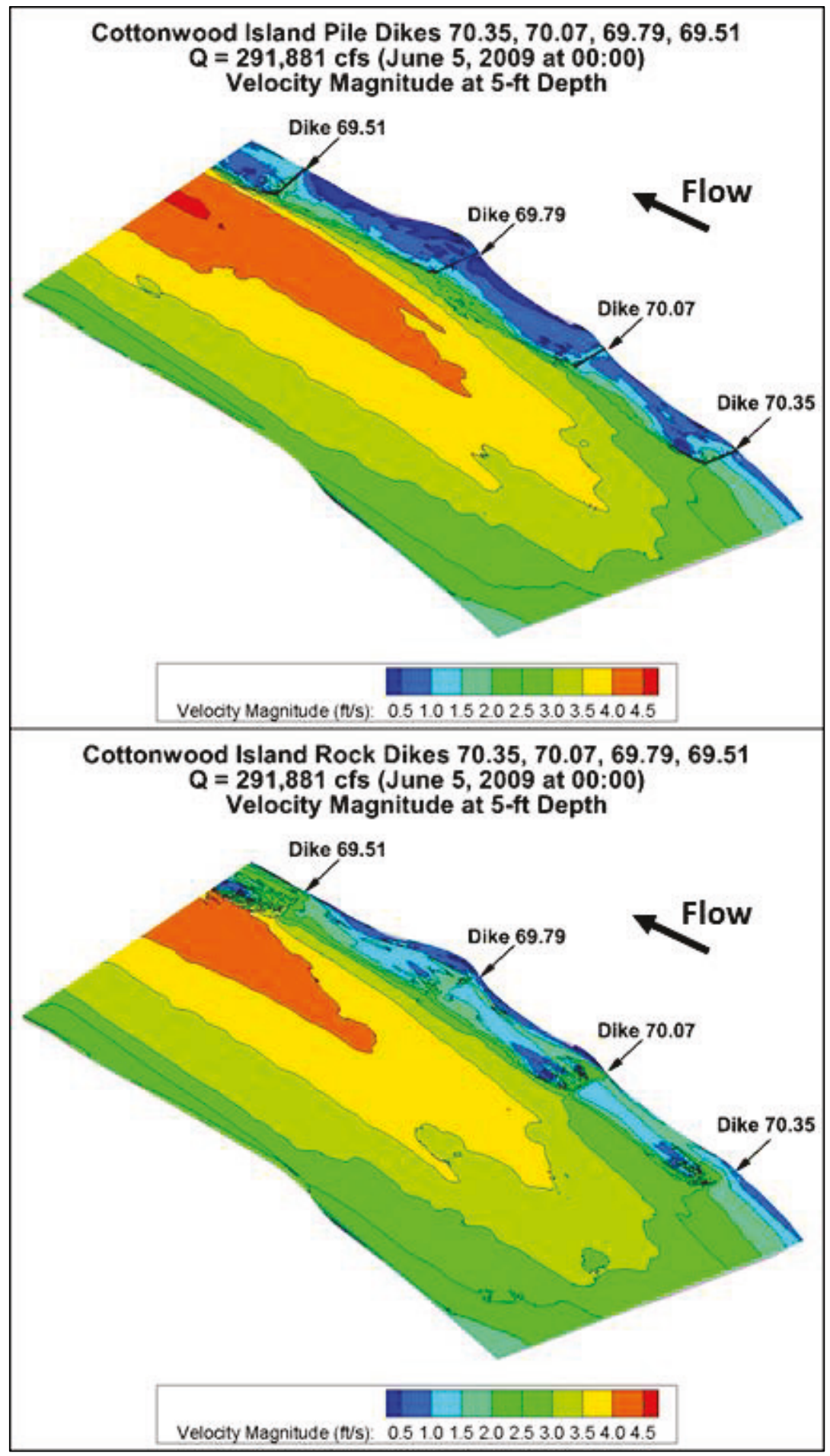


Figure 98. High discharge velocity contours at $5 \mathrm{ft}$ depth around Dike 69.79 - isometric.

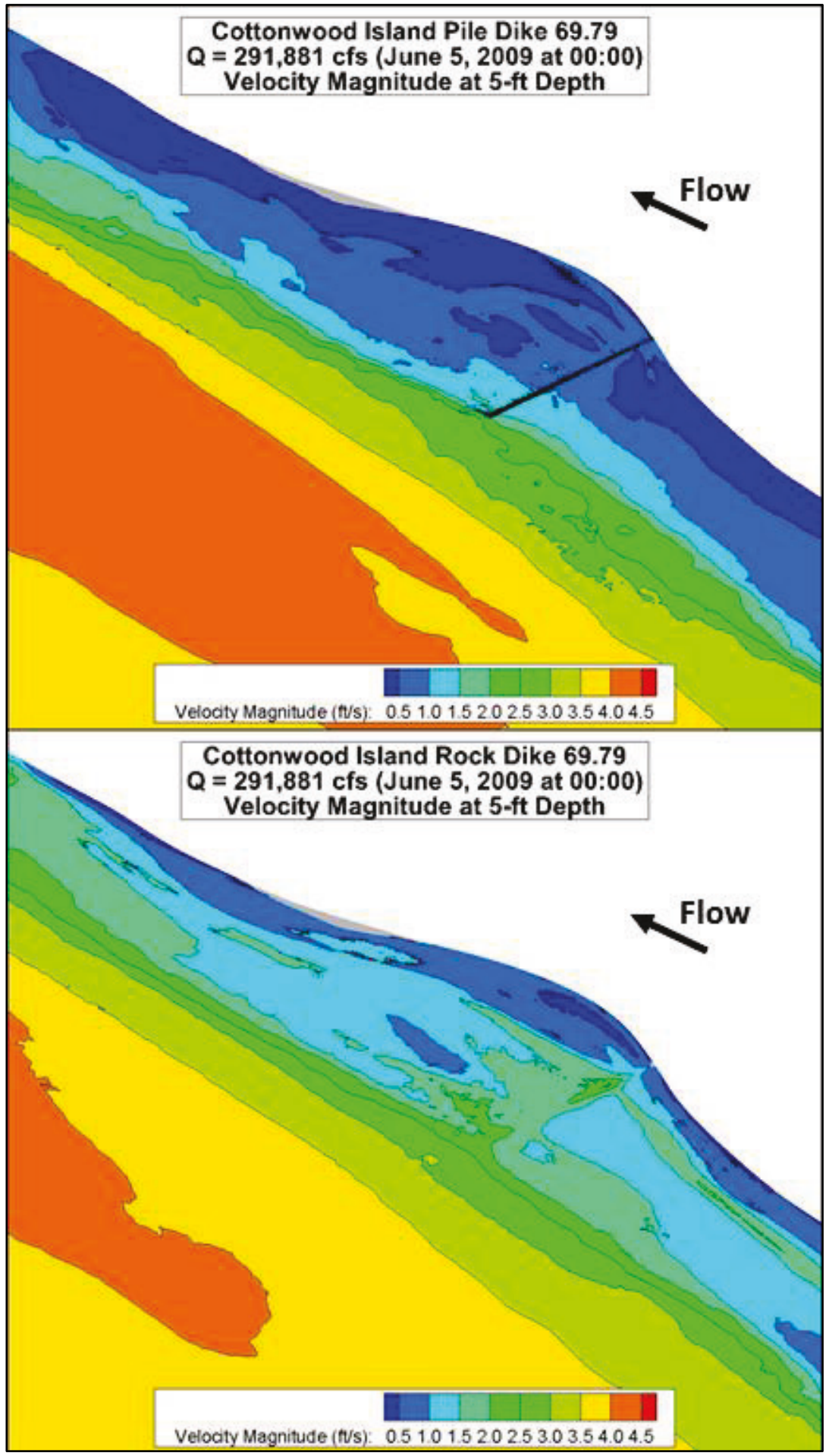


Figure 99. Eddies formed downstream of Dike 70.07 at $10 \mathrm{ft}$ depth for low discharge.

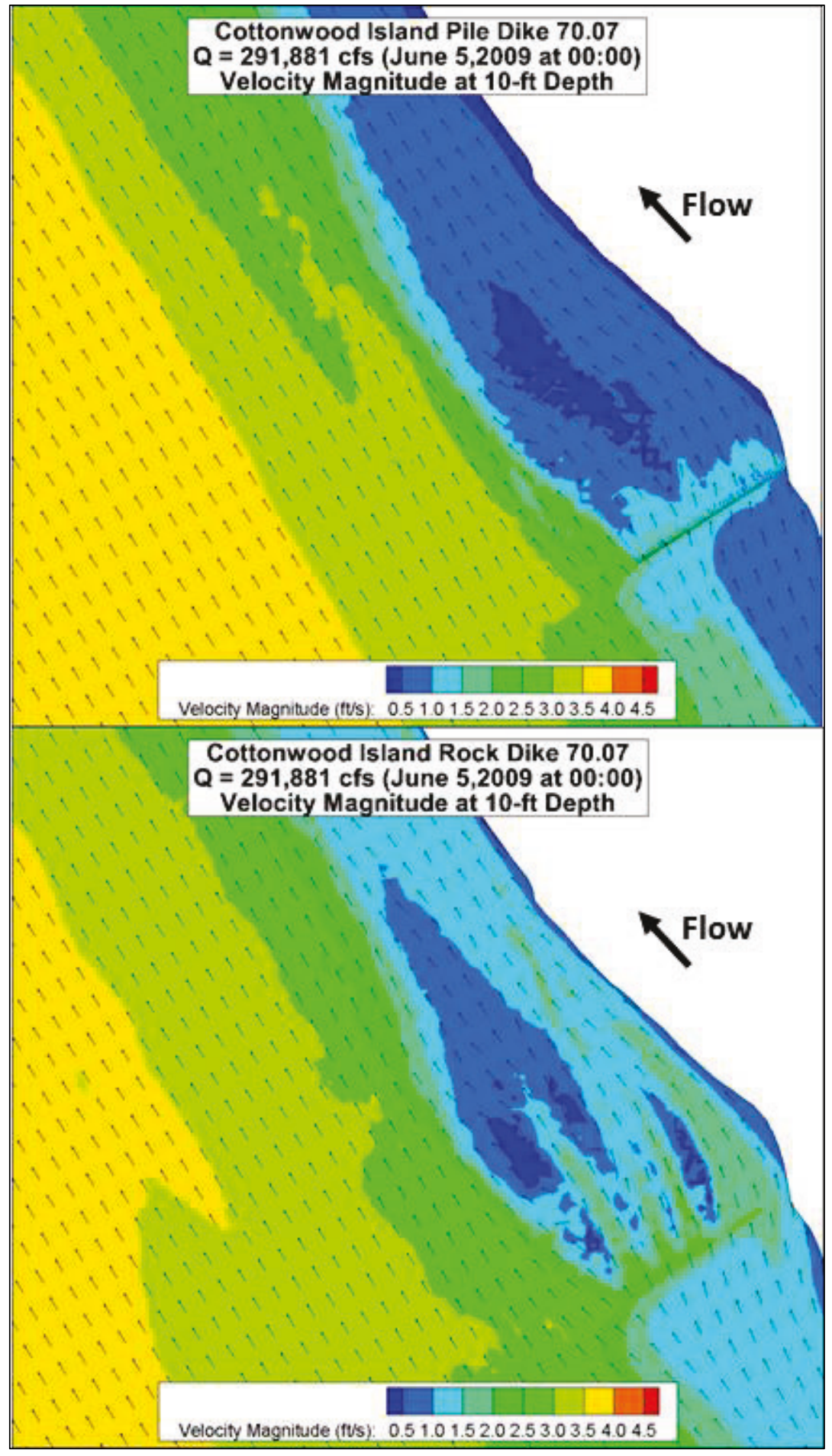


Figure 100. Eddies formed downstream of Dike 69.79 at $10 \mathrm{ft}$ depth for low discharge.

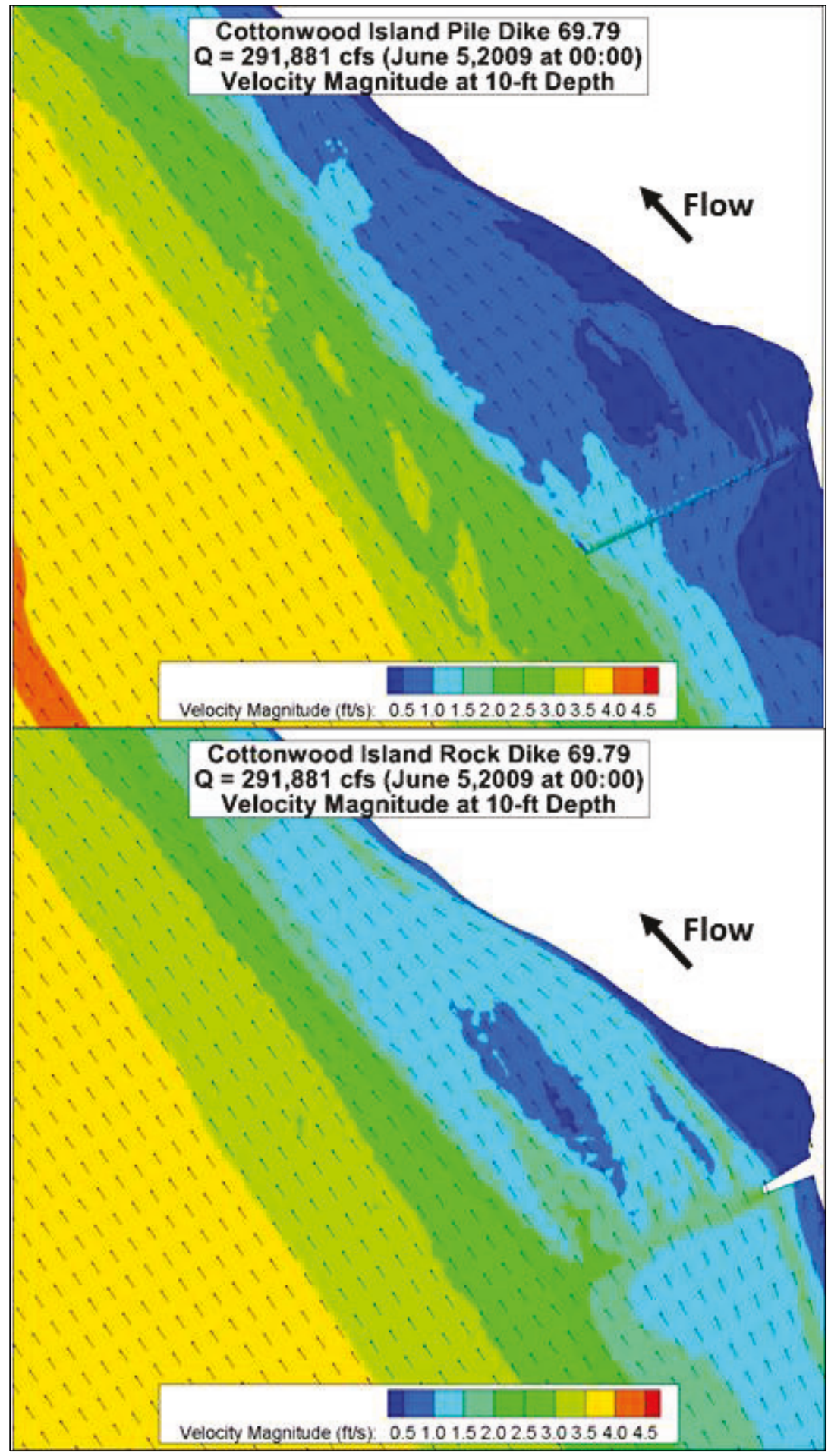


Figure 101. Low discharge velocity magnitude difference comparison.

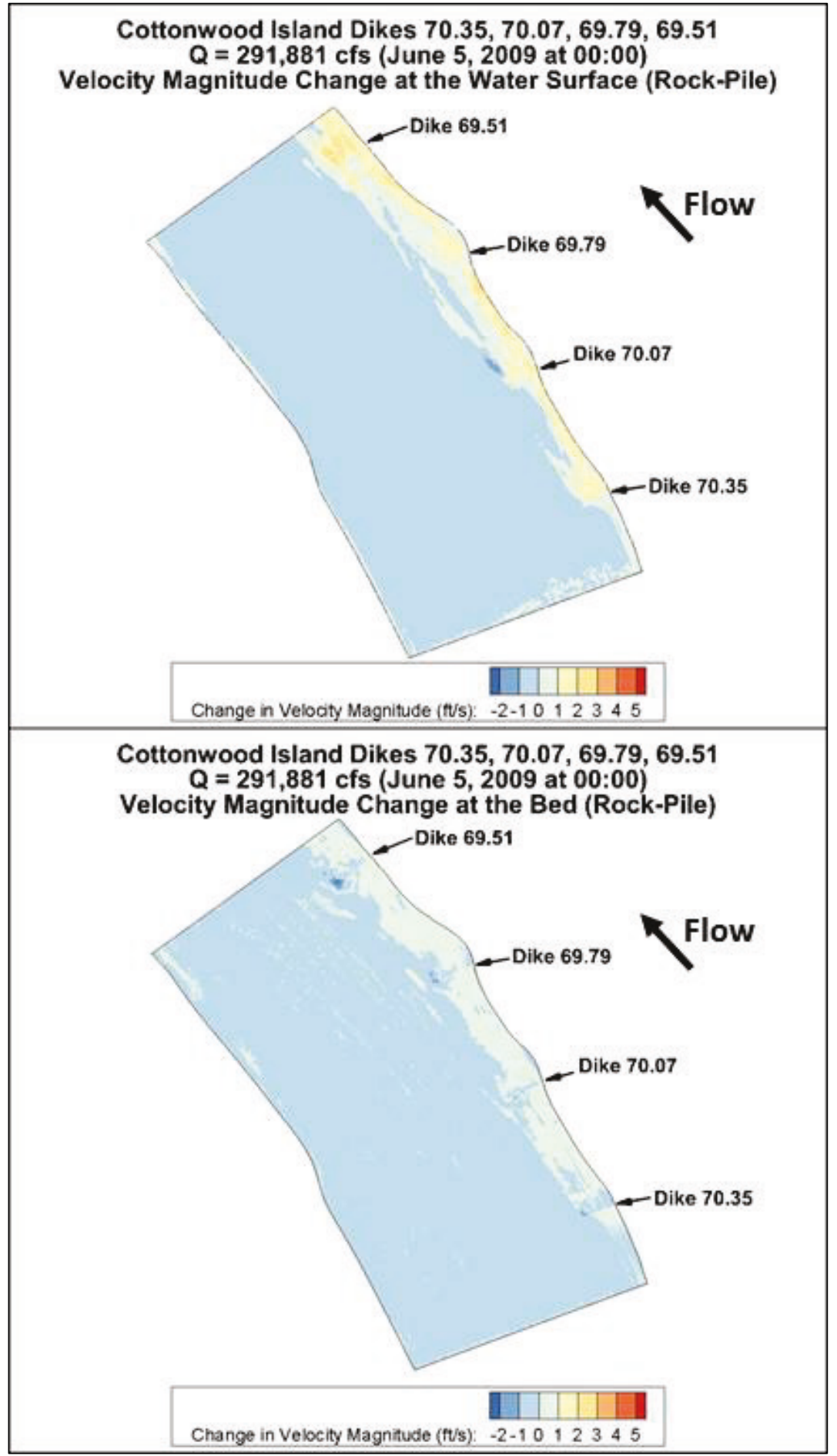


Figure 102. Low discharge velocity magnitude difference comparison.

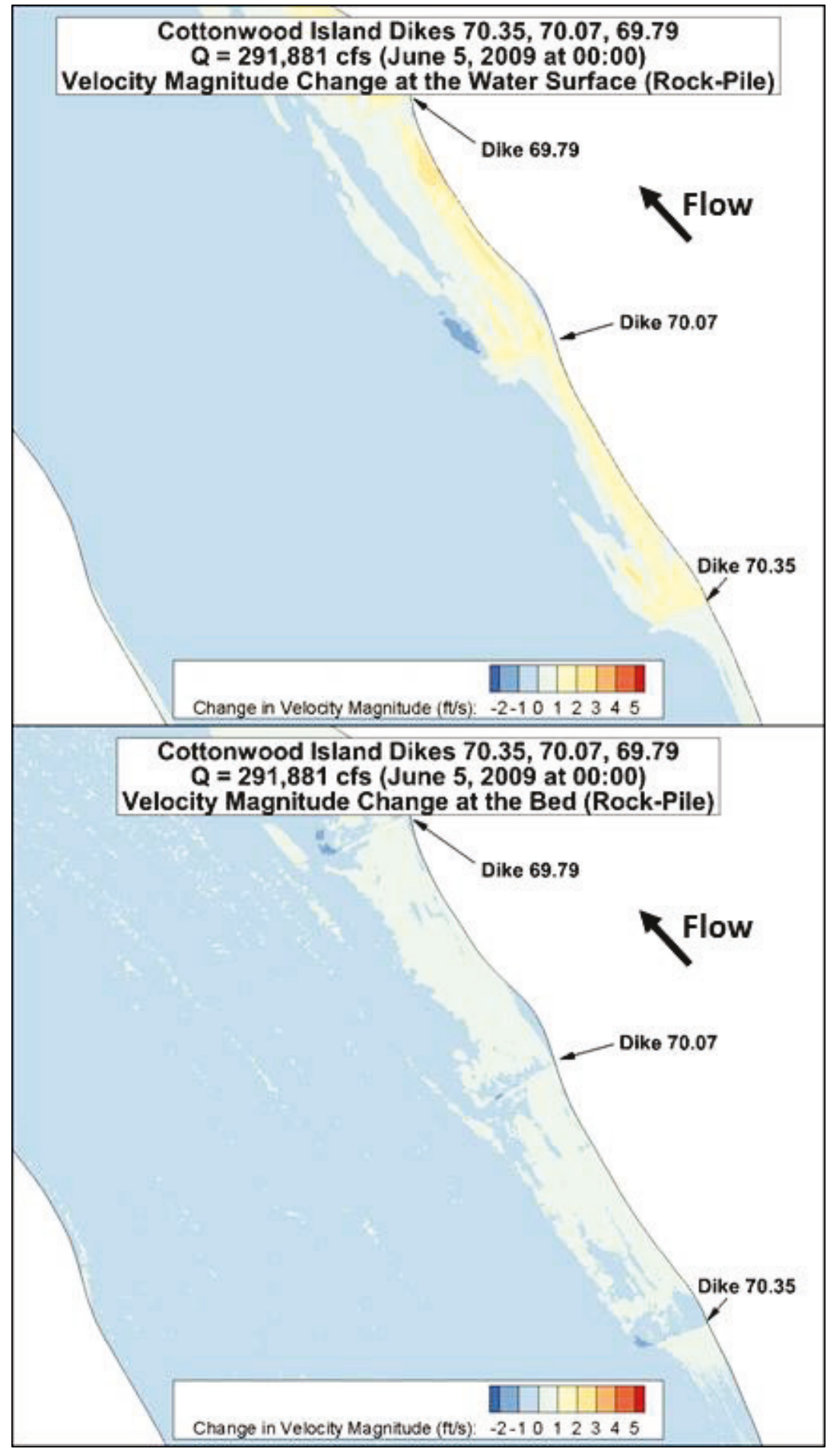


Vertical slices across Dike 70.07 and Dike 69.79

Figure 103. Vertical slice locations for Pile Dike 70.07.

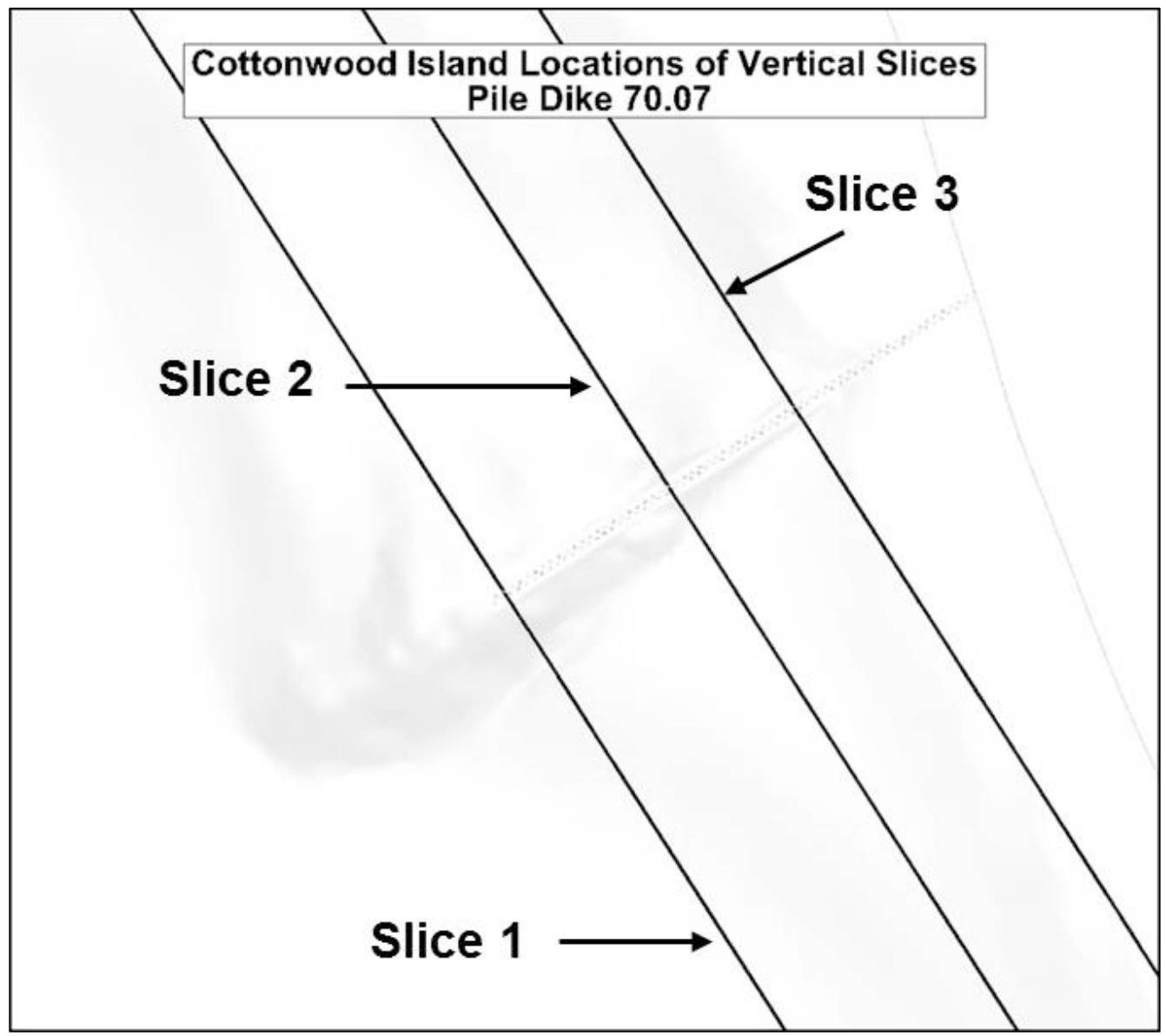


Figure 104. High discharge vertical velocity profile at slices across Pile Dike 70.07.

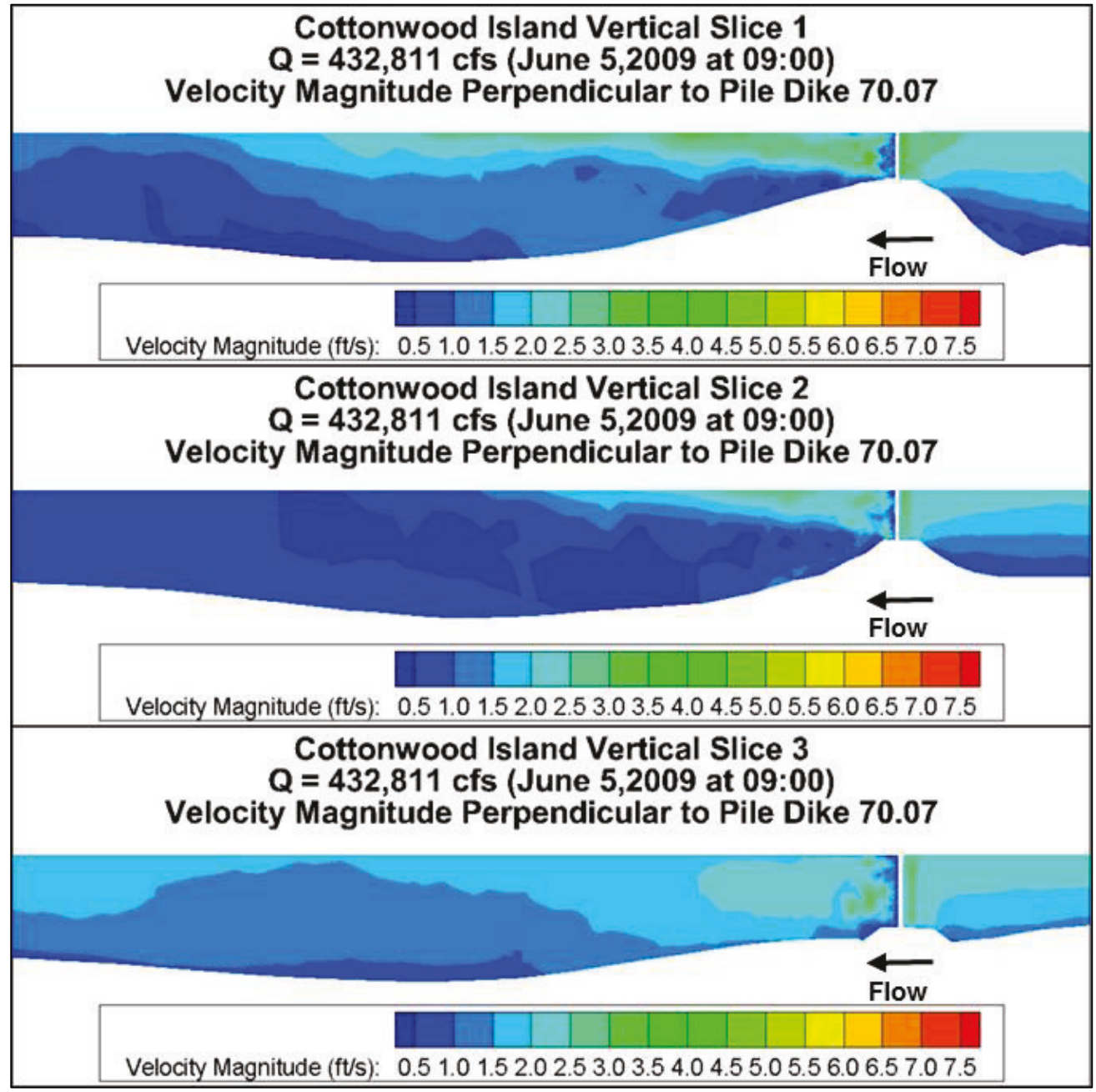


Figure 105. Medium discharge vertical velocity profile at slices across Pile Dike 70.07 .

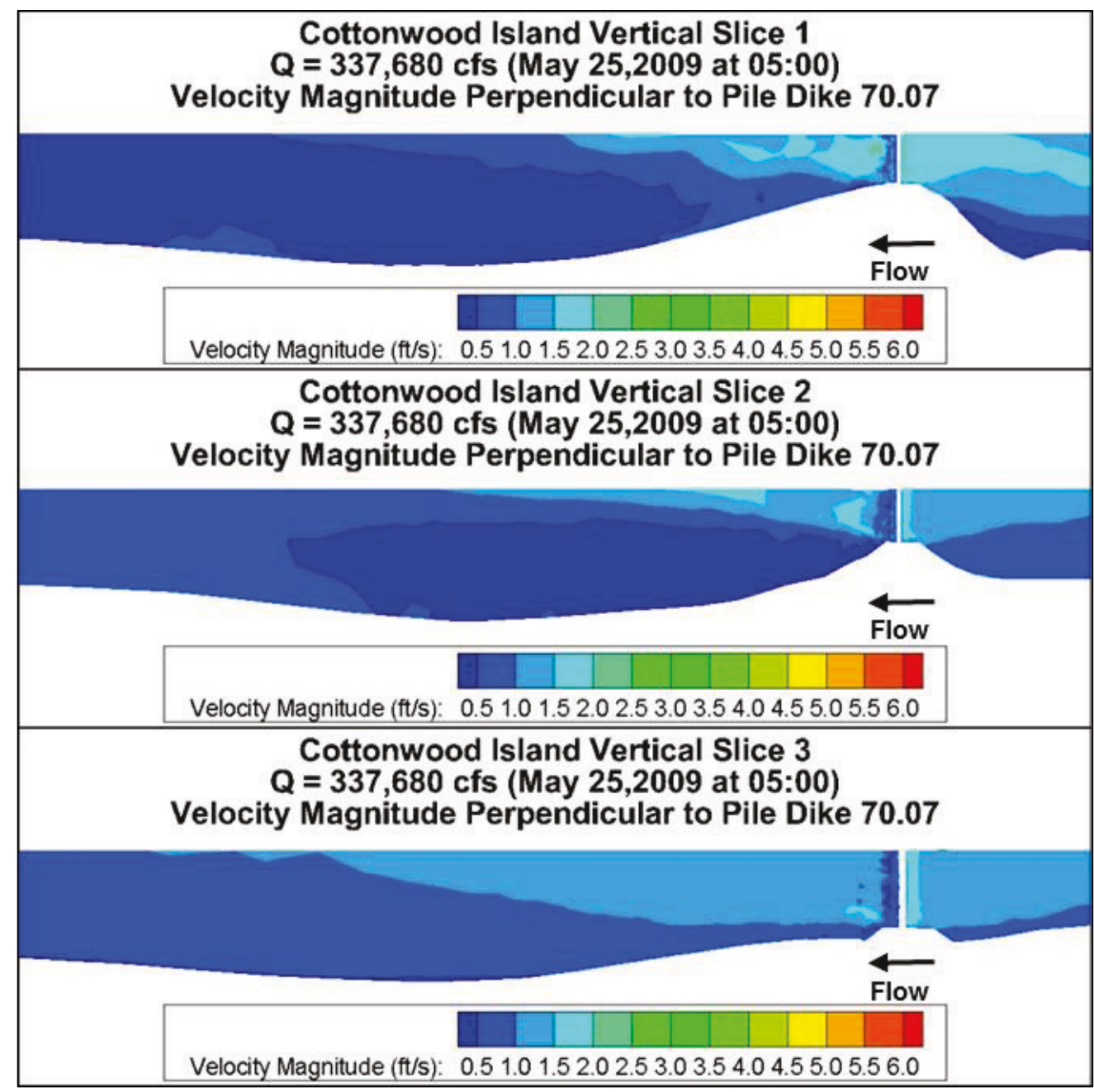


Figure 106. Low discharge vertical velocity profile at slices across Pile Dike 70.07.

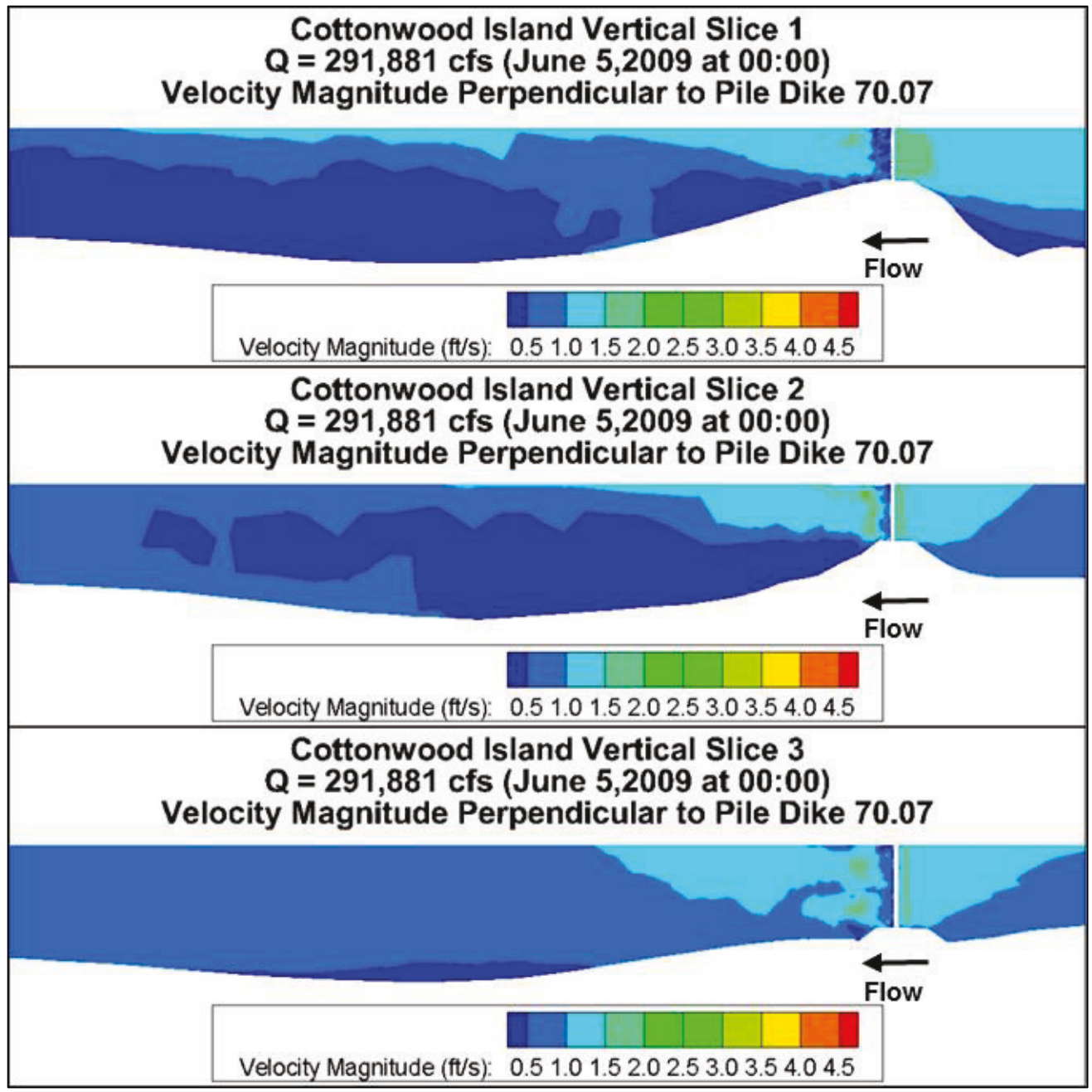


Figure 107. Vertical slice locations for Rock Dike 70.07.

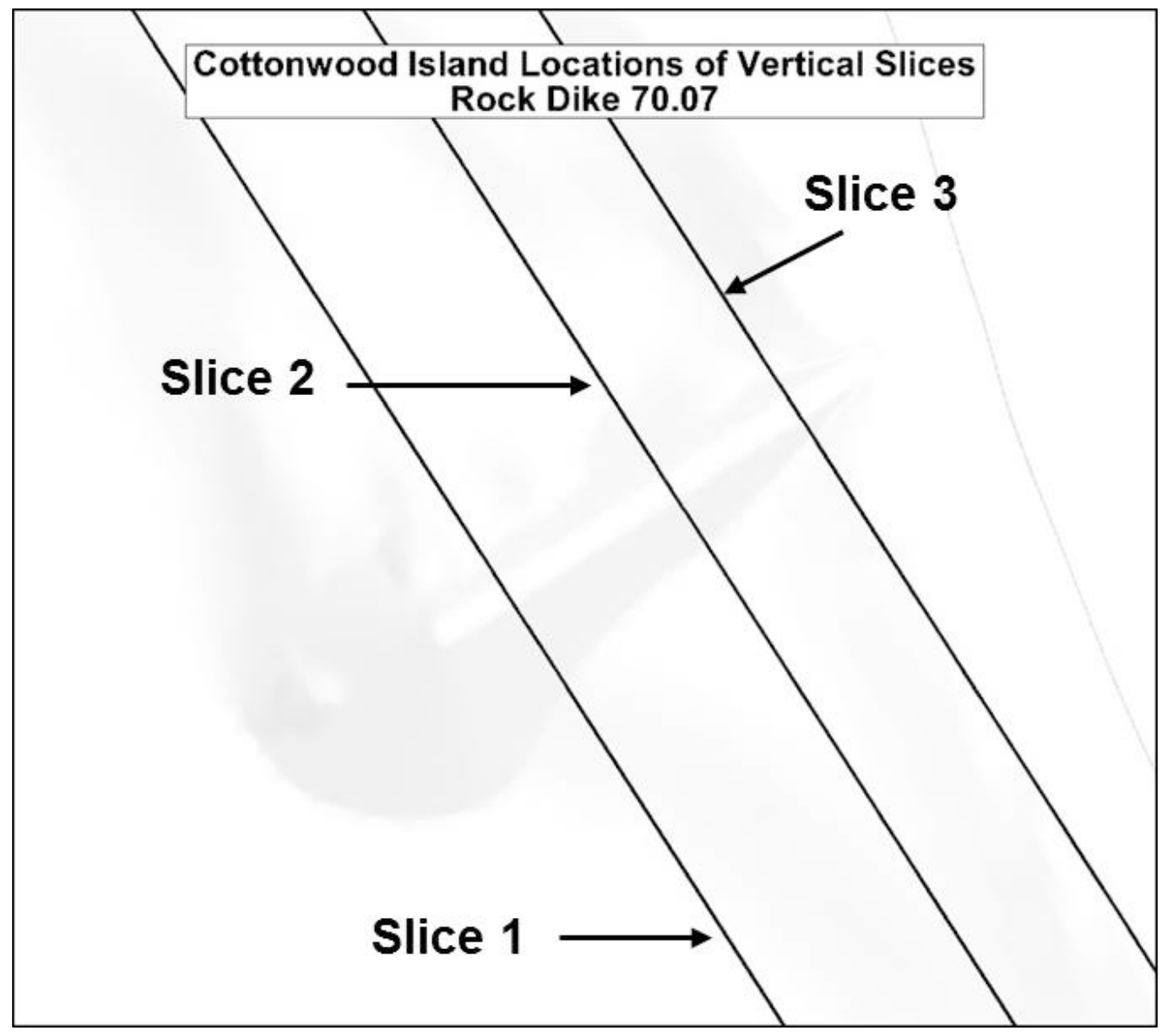


Figure 108. High discharge vertical velocity profile at slices across Rock Dike 70.07.

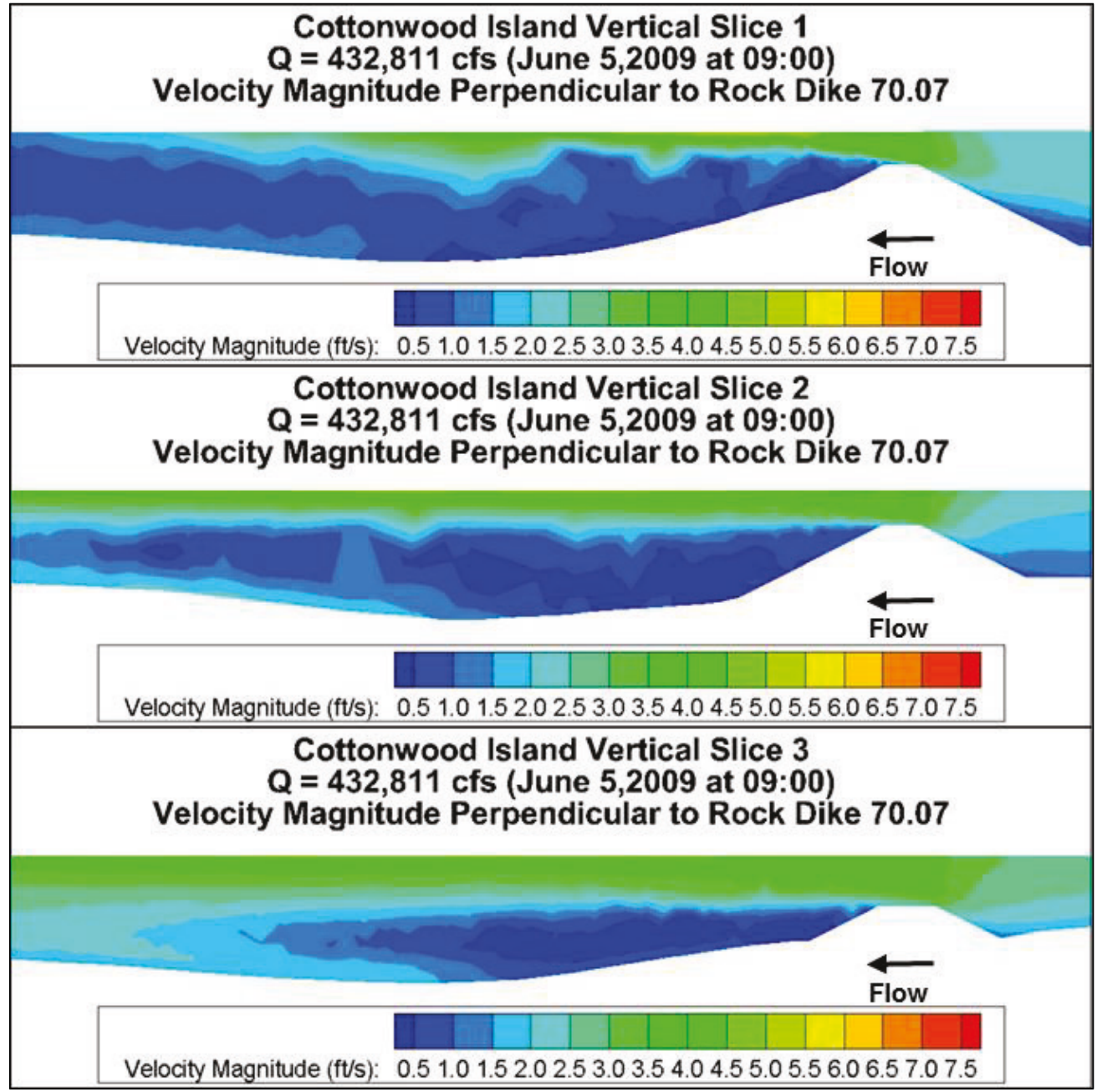


Figure 109. Medium discharge vertical velocity profile at slices across Rock Dike 70.07 .

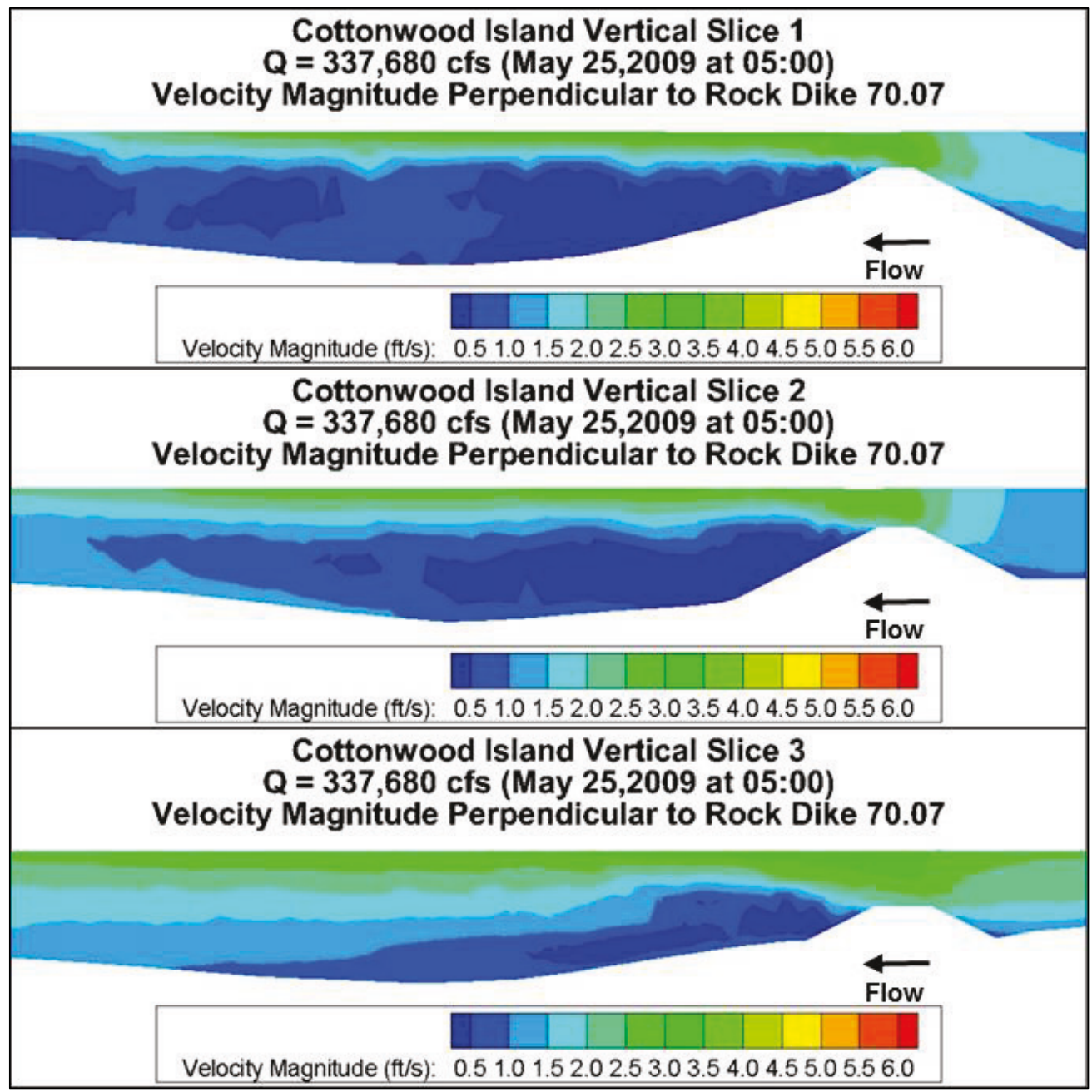


Figure 110. Low discharge vertical velocity profile at slices across Rock Dike 70.07.

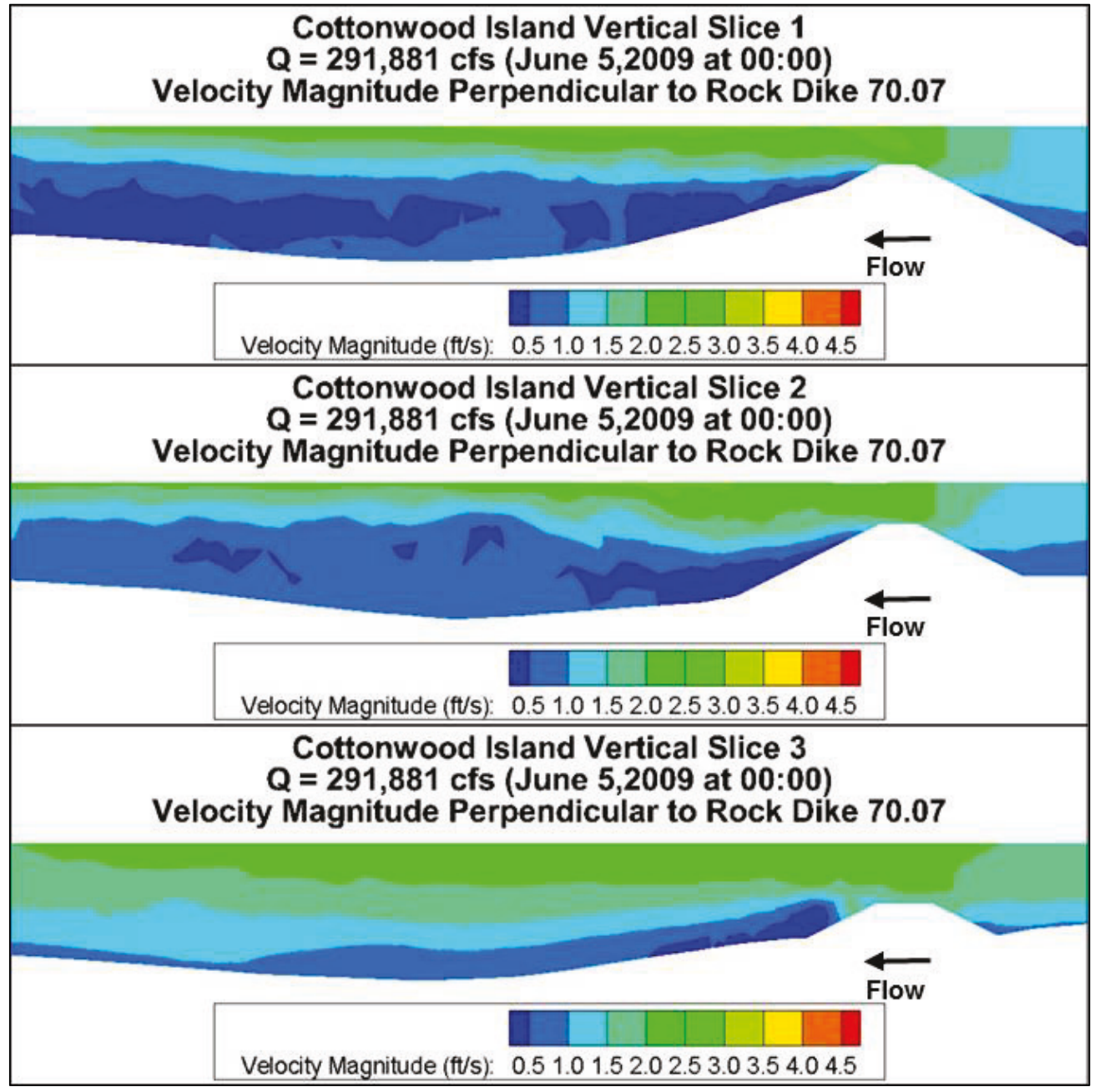


Figure 111. Vertical slice locations for Pile Dike 69.79.

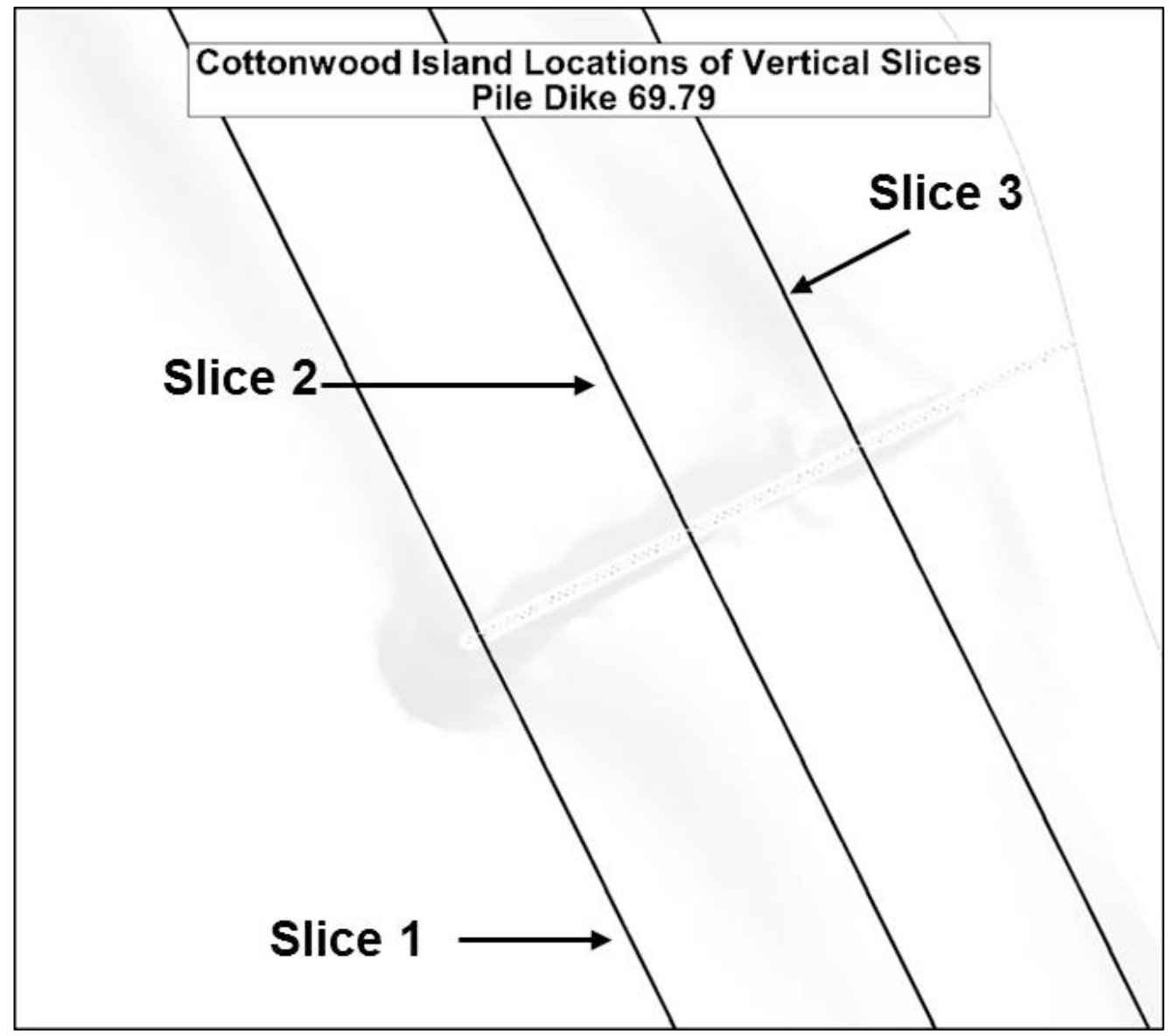


Figure 112. High discharge vertical velocity profile at slices across Pile Dike 69.79.

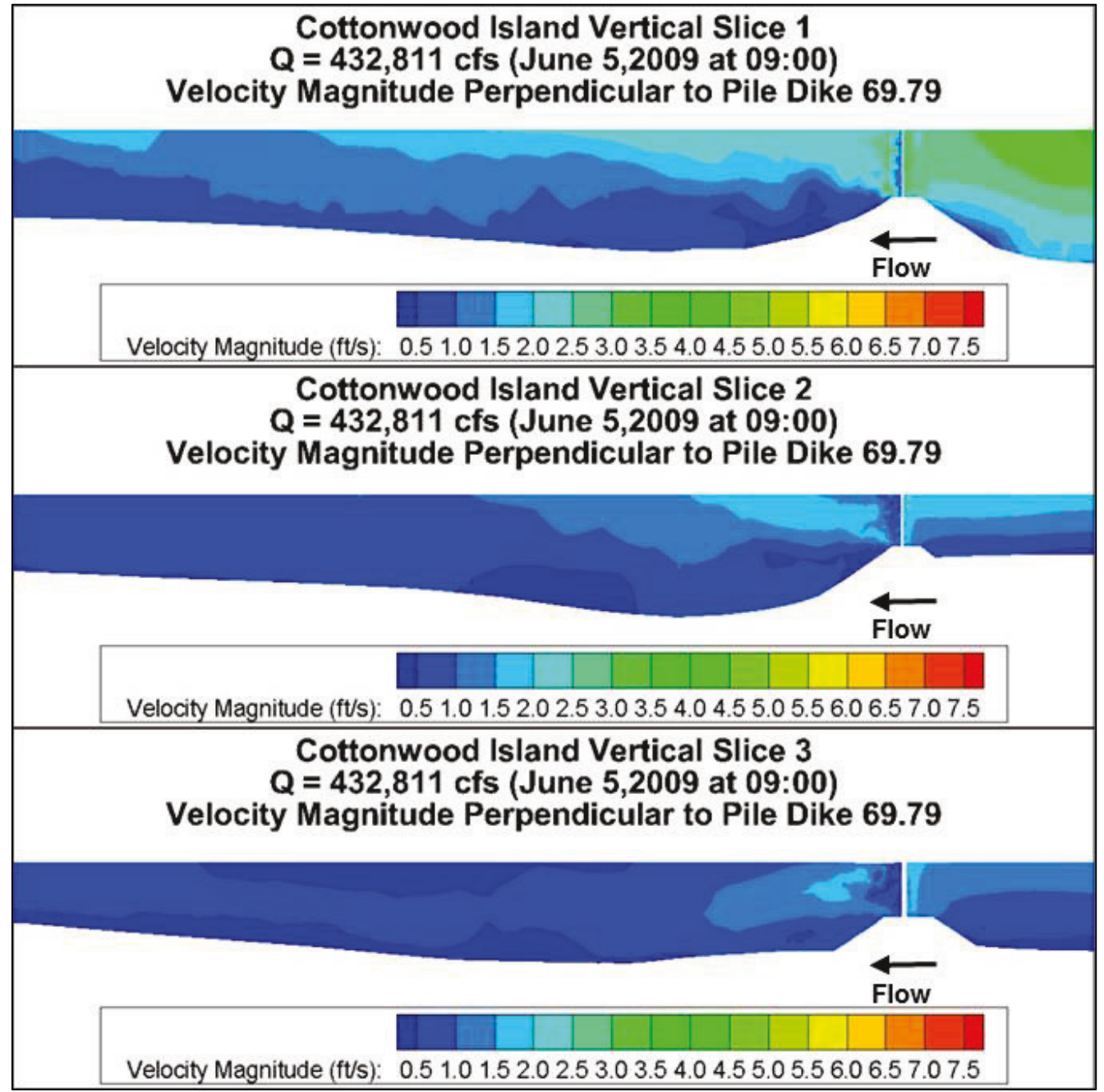


Figure 113. Medium discharge vertical velocity profile at slices across Pile Dike 69.79.

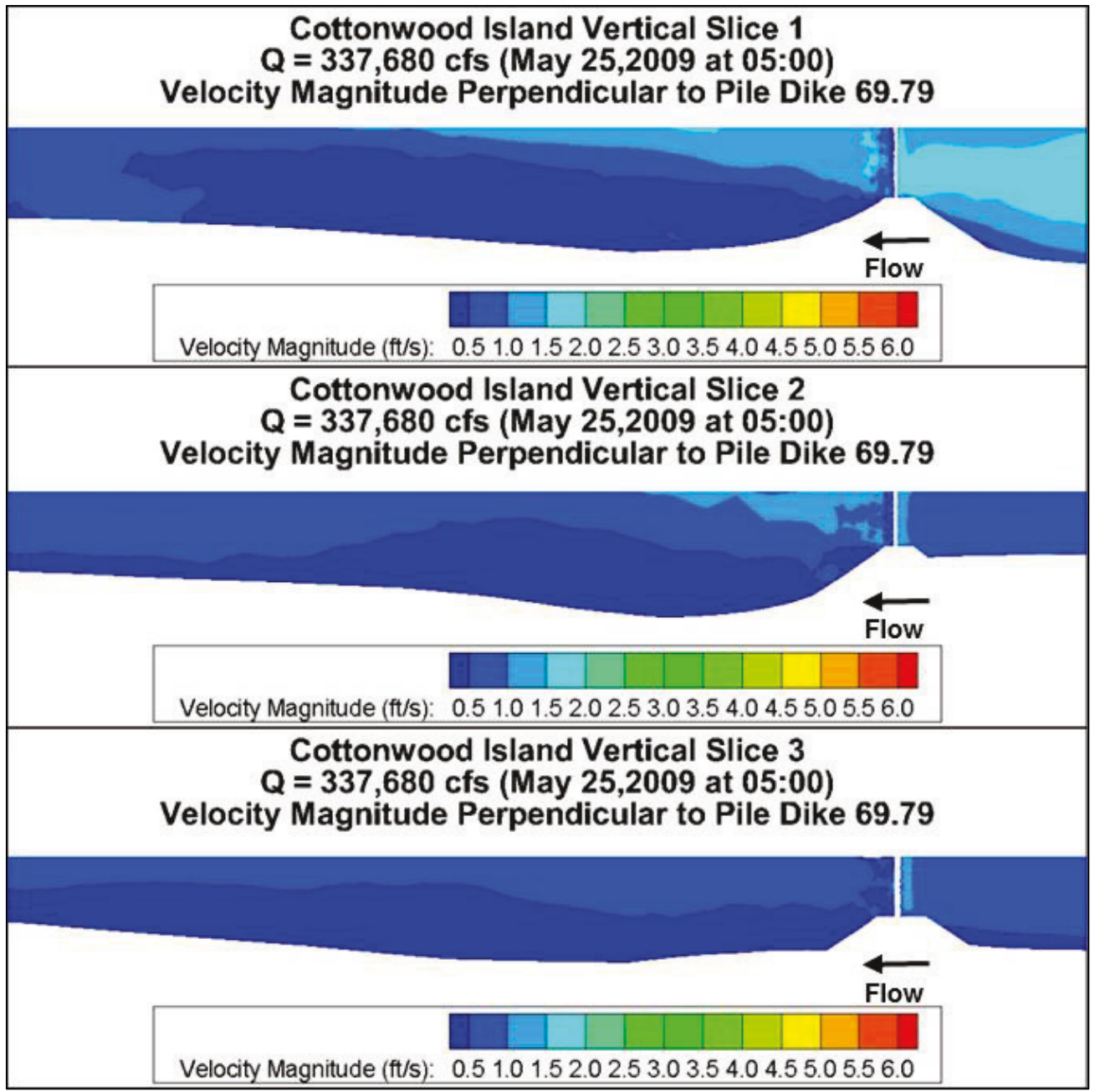


Figure 114. Low discharge vertical velocity profile at slices across Pile Dike 69.79.

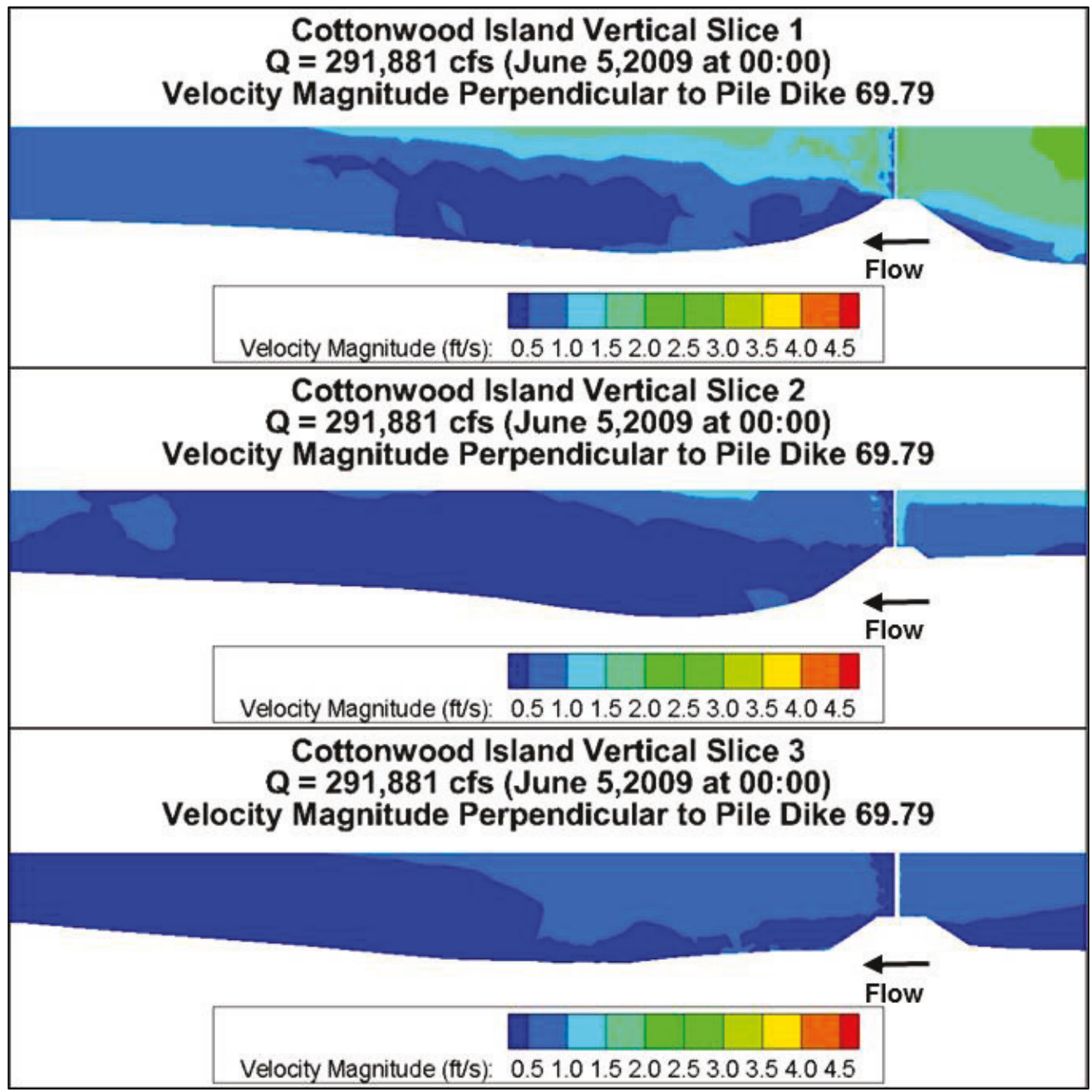


Figure 115. Vertical slice locations for Rock Dike 69.79.

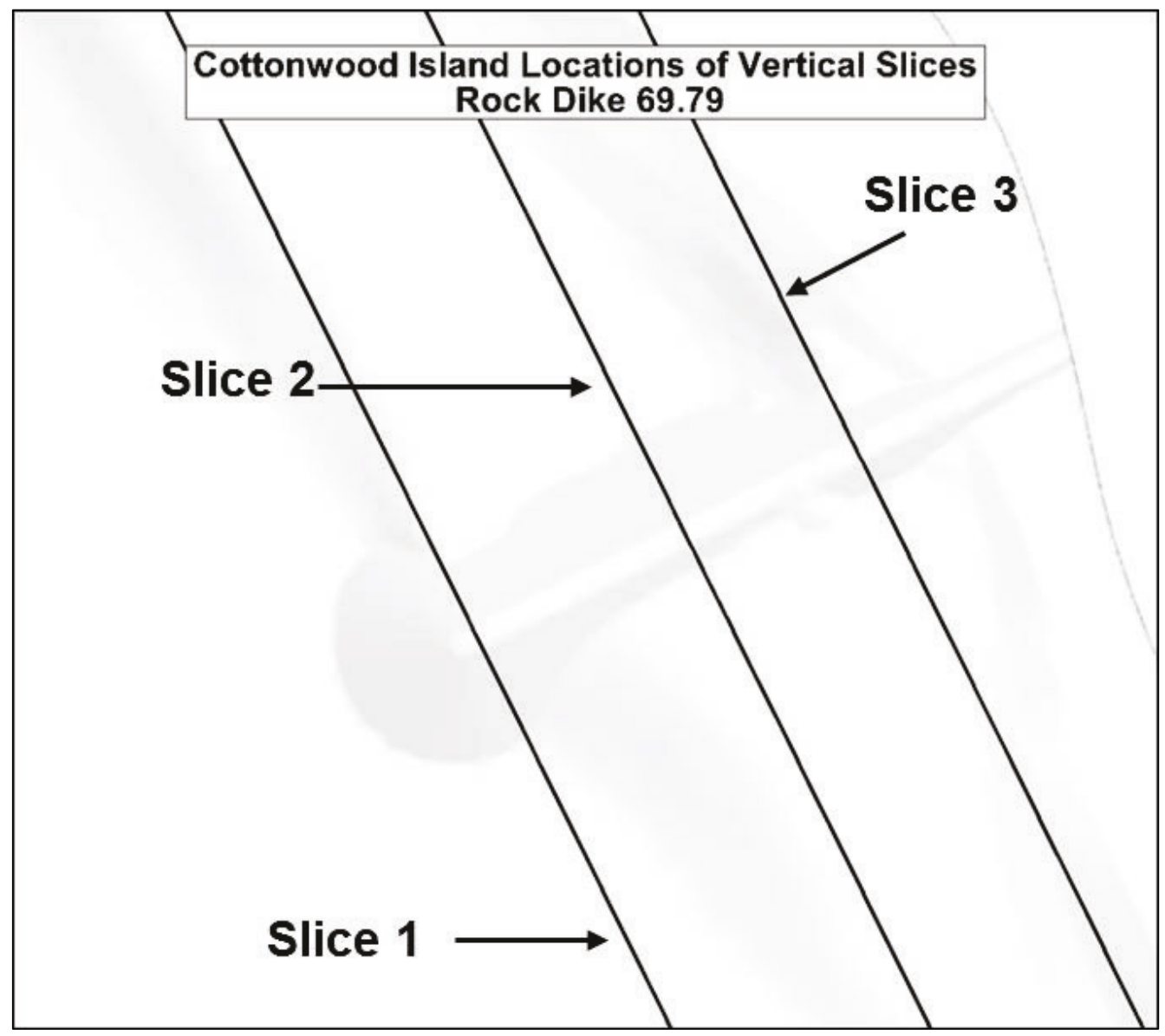


Figure 116. High discharge vertical velocity profile at slices across Rock Dike 69.79.

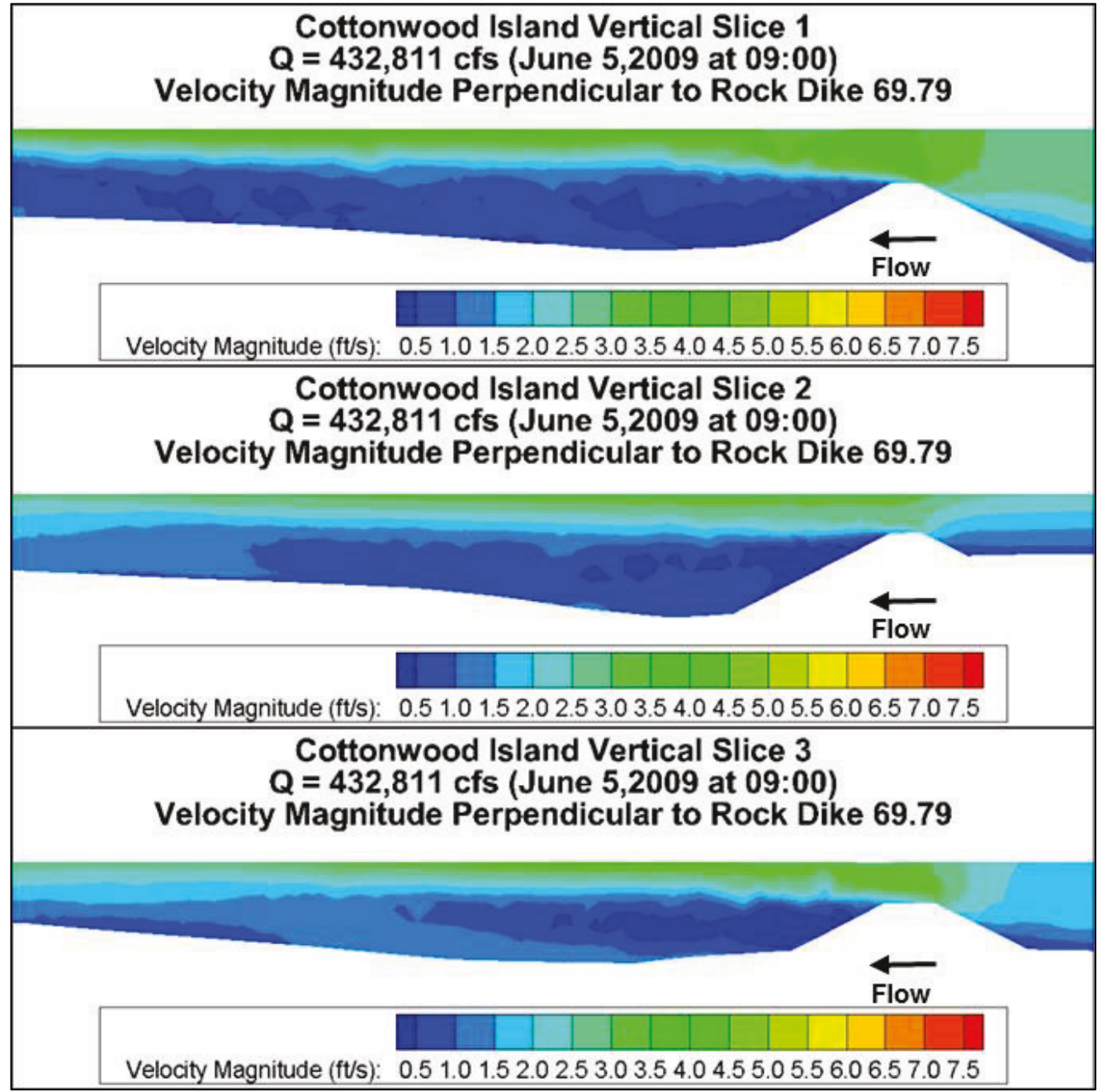


Figure 117. Medium discharge vertical velocity profile at slices across Rock Dike 69.79.

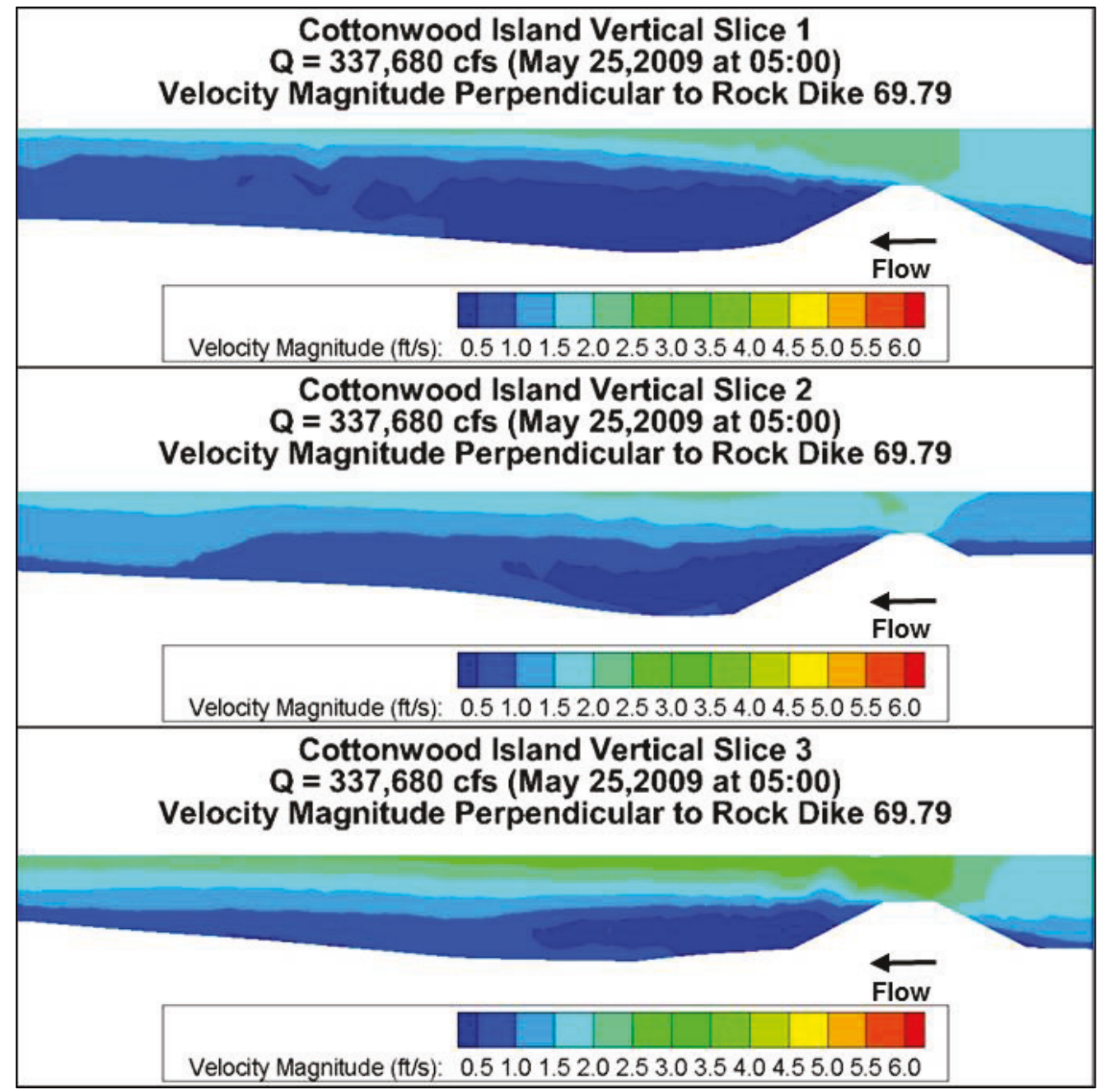


Figure 118. Low discharge vertical velocity profile at slices across Rock Dike 69.79.

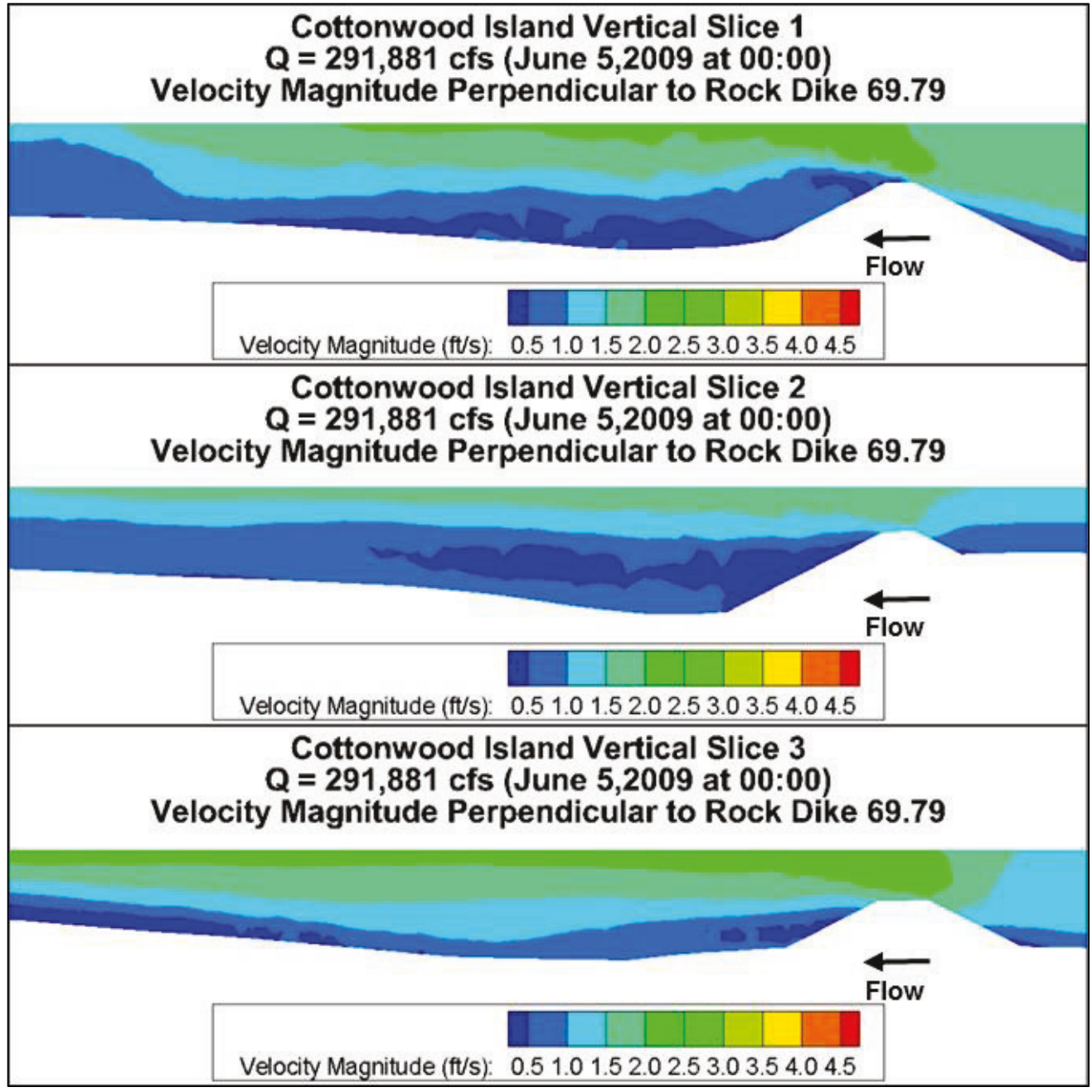




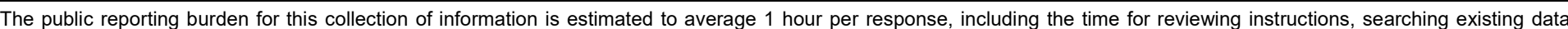

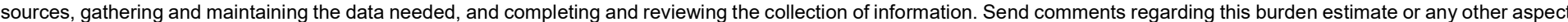

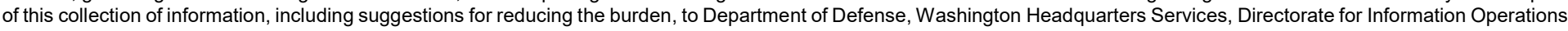

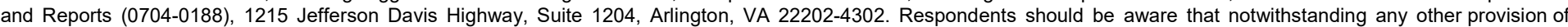
law, no person shall be subject to any penalty for failing to comply with a collection of information if it does not display a currently valid OMB control number. PLEASE DO NOT RETURN YOUR FORM TO THE ABOVE ADDRESS.
1. REPORT DATE
February 2019
2. REPORT TYPE
Final Report
3. DATES COVERED (From - To)

\section{TITLE AND SUBTITLE}

Numerical Model Study of the Flows around Pile Dikes and Conventional Rock Dikes in the Columbia River

5a. CONTRACT NUMBER

5b. GRANT NUMBER

5c. PROGRAM ELEMENT NUMBER

5d. PROJECT NUMBER

445535

5e. TASK NUMBER

5f. WORK UNIT NUMBER

8. PERFORMING ORGANIZATION REPORT NUMBER

Coastal and Hydraulics Laboratory

U.S. Army Engineer Research and Development Center

3909 Halls Ferry Road

Vicksburg, MS 39180-6199

\section{SPONSORING/MONITORING AGENCY NAME(S) AND ADDRESS(ES)}

U.S. Army Corps of Engineers, Portland District

RDC/CHL TR-19-3

333 SW 1st Ave.

Portland, OR 97204

12. DISTRIBUTION/AVAILABILITY STATEMENT

Approved for public release; distribution is unlimited.

\section{SUPPLEMENTARY NOTES}

\section{ABSTRACT}

Will be inserted prior to final review. Pile dikes in the Columbia River are approaching the end of their expected service life. Two replacement options have been suggested: similarly shaped pile dikes and conventional rock dikes. A three-dimensional numerical model study has been conducted to provide flow information to support a decision between the two replacement options. This study focuses on the Cottonwood Island site on the Columbia River. The primary interest is determining the potential navigation impacts of changing from the pile dikes to the conventional rock dikes. The results of this model will also be used to study the secondary interests of effects to fish habitat and the possible operation concerns of scour potential and sediment deposition between the dikes. This report contains a discussion of the geometry and computational mesh development and flow solver used. The flow solutions are presented as contour plots in multiple areas of the flow domain. General trends among the flow solutions between the two types of dikes are evaluated and discussed.

\section{SUBJECT TERMS}

Columbia River, Dikes (Engineering), Fishes_-Habitat, Hydraulic models, Hydraulic structures

\section{SECURITY CLASSIFICATION OF:}

\section{a. REPORT}

Unclassified

\begin{tabular}{|c|c|} 
b. ABSTRACT & c. THIS PAGE \\
Unclassified & Unclassified
\end{tabular}

17. LIMITATION OF ABSTRACT

SAR
18. NUMBER OF PAGES

171 19a. NAME OF RESPONSIBLE PERSON

Allen Hammack

19b. TELEPHONE NUMBER (Include area code) 601-634-3628 